\title{
Drilling, Completion, Stimulation, and Testing of Hardy HW\#1 Well, \\ Putnam County, West Virginia
}

Final Report

William K. Overbey, Jr.

Richard S. Carden

C. David Locke

S. Phillip Salamy

Work Performed Under Contract No.: DE-AC21-89MC25115

\author{
For \\ U.S. Department of Energy \\ Office of Fossil Energy \\ Morgantown Energy Technology Center \\ P.O. Box 880 \\ Morgantown, West Virginia 26507-0880 \\ By
BDM Engineering Services Company \\ 7915 Jones Branch Drive \\ McLean, Virginia 22102
}

March 1992 


\begin{abstract}
This report discusses the detailed field operations in drilling, logging, casing, completing, stimulating and testing the Hardy HW\#1 well located in Union District, Putnam County, West Virginia. The project was designed and managed by BDM in cooperation with Cabot Oil and Gas Corporation. The well was spudded on November 29, 1989 and was completed at a total measured depth of 6406 feet on December 29, 1989. The well was drilled on an average azimuth of 335 degrees with a total horizontal displacement of 2618 feet. Approximately 1035 feet of the well had an inclination higher than 86 degrees, while 2212 feet of the well had an inclination greater than 62 degrees. The well was partitioned into five zones for stimulation purposes. Four zones were stimulated during three stimulation operations (Zones 3 and 4 were stimulated together). Zone 1 stimulation was a successful foam frac while the stimulations on Zones 2, 3-4 were partially successful. Initial gas production rates were 4.5 times greater than the natural production rate. After 21 months, gas produced from the BDM/Cabot well has declined at a rate about one-half that of a conventional vertical well in the area. This horizontal well is projected to produce 475 million cubic feet of gas over a 30-year period.
\end{abstract}




\section{TABLE OF CONTENTS}

Page

1.0 EXECUTIVE SUMMARY 1

2.0 INTRCDUCTION 3

3.0 LEASE ACQUISITION AND LOCATION DEVELOPMENT 3

$\begin{array}{lll}4.0 & \text { DRILLING PLAN SUMMARY } & 4\end{array}$

$\begin{array}{lll}5.0 & \text { DRILLING OPERATIONS } & 7\end{array}$

$\begin{array}{lll}5.1 & \text { Introduction } & 7\end{array}$

5.2 Vertical Hole 9

5.3 Build Section 11

5.4 Horizontal Section 14

6.0 LOGGING OPERATIONS 21

6.1 Introduction $\quad 21$

6.2 Mud Logging 21

6.3 Shallow Hole and Free Fall Logging 21

6.4 Horizontal Section Logging 22

7.0 MOTOR PERFORMANCE AND BOTTOM HOLE ASSEMBLIES 23

7.1 Introduction 23

7.2 Motor Performance and BHA's for Angle Building 23

7.3 Rotary Directional Drilling Assemblies for 28 Horizontal Section 
8.0 DIRECTIONAL CONTROL OPERATIONS

8.1 Introduction

8.2 Steering Tool Operations

30

8.3 MWD Tool Operations

9.0 ANALYSIS OF DRILLING OPERATIONS 33

\begin{tabular}{ll}
10.0 & COMPLETION OPERATIONS \\
\hline 5
\end{tabular}

10.1 Introduction $\quad 35$

$\begin{array}{ll}10.2 \text { Casing Design } & 37\end{array}$

10.3 Inflation of Casing Packers 38

10.4 Cementing 39

$\begin{array}{ll}11.0 \text { STIMULATION OPERATIONS } & 40\end{array}$

$\begin{array}{ll}11.1 \text { Introduction } & 40\end{array}$

$\begin{array}{ll}11.2 \text { Treatment of Zone } 1 & 40\end{array}$

11.3 Treatment of Zone $2 \quad 43$

11.4 Analysis of Problems in Fracing Zone $2 \quad 48$

11.5 Stimulation of Zones 3 and $4 \quad 55$

11.6 Analysis of Problems in Fracing Zone 3-4 58

12.0 WELL TESTING OPERATIONS AND ANALYSIS 61

12.1 Pressure Build-up Testing 61

12.1.1 Pre-Stimulation Testing and Árálysis 62

12.1.2 Post-Stimulation Testing and Analysis 72

12.2 Drawdown Testing - Post-Stimulation 77

12.3 Well Test Results and Conclusions 83

13.0 ANALYSIS OF COMPLETION, STIMULATION, TESTING AND 87 PRODUCTION OPERATIONS

13.1 Completion Operations $\quad 87$

$\begin{array}{ll}13.2 \text { Stimulation Operations } & 88\end{array}$ 
13.3 Well Testing Operations

14.0 WELL COST ANALYSIS

15.0 SUMMARY AND CONCLUSIONS

16.0 REFERENCES 


\section{LIST OF ILLUSTRATIONS}

\section{Eiqure}

Page

Figure 3.1 Relationship to the Planned Wellbore Trajectory to Structure on the Base of the Huron Shale

Figure 3.2 Location and Trajectory of Planned Horizontal Well Across a 3-Lease Production Unit

Figure $5.1 \quad$ Depth vs Days

Figure $5.2 \quad$ Vertical View

Figure $5.3 \quad$ Plan View

Figure 6.1 True Vertical Depth Presentation of Well Logs of the Hardy HW\#1 Well With Gas Shows

Figure 10.1 Hardy \#1 Well Schematic

Figure $11.1 \quad$ Nitrogen Breakdown (Prepad) on Zone 1

Figure 11.2 Foam Fracturing Treatment on Zone 1, Hardy HW\#1

Figure 11.3 Nitrogen Breakdown (Prepad) of Zone 2 (First Time)

Figure 11.4 Second Nitrogen Breakdown (Prepad) for Zone 2

Figure 11.5 Pressure Response During Initial Foam Pad Injection 
Figure 11.6 Aborted Attempt to Frac Zone 2 After Replacing 50 Packer

Figure 11.7 Nitrogen Pad Injection Into Zone 2 After

Perforating

Figure $11.8 \quad$ Foam Frac on Zone 2

52

Figure 11.9 Foam Frac on Zone 2 Showing Screen Out

53

Figure 11.10 Difficulty Associated with Attempting to Inflate Closely-Spaced Natural Fractures from a Horizontal Wellbore

Figure 11.11 Initial Attempt to Frac Zone 3-4 Using

57 Sand-Laden Foam

Figure 11.12 Attempt at Injecting Foam After Screen-Out

59 in Zone 3-4

Figure 11.13 Nitrogen Frac of Zone 3-4 Following Sand-Foam Screen-Out

60

Figure 12.1.1 Analysis of Pre-Stimulation Data Using 63 RHM Technique

Figure 12.1.2 Well Type Curve with Wellbore Storage 66 and Skin Effect

Figure 12.1.3 Change in Adjusted Pressure vs Adjusted Effective Time, Pre-Stimulation

Figure 12.1.4 Pressure Build-up Analysis for Pre-Stimulation Data Using Horner's Technique

Figure 12.1.5 Type Curves for Horizontal Wells 
Figure 12.1.6 Pre-Stimulation Type Curve Match

Figure 12.1.7 Change in Adjusted Pressure vs Adjusted Effective Time, Post-Stimulation

Figure 12.1.8 Pressure Build-Up Analysis for Post-

Stimulation Data Using Horner's Technique

Figure 12.2.1 Initial Production Data

Figure 12.2.2 Two Rate Flow Test Analysis, PostStimulation

Figure 12.2.3 Drawdown Pressure Type Curve Match

Figure 13.1 Gas Shows vs Measured Depth

Figure 13.2 Wellbore Contiguration

Figure 13.3 Production Decline Analysis for Vertical and

Figure 13.4 Production Projection Using Gas Reservoir Simulation (G3DFR)

Figure 13.5 Average Daily Production Data

Figure 13.6 Cumulative Production Data

Figure 13.7 Hardy \#1 Post-Stimulation Production Rate Match of Actual Data With Average Decline Curve of Wells in the Same Area

Figure 13.8 Hardy \#1 Project Cumulative Production Based on Type Curve Match of Average Well Decline 


\section{LIST OF TABLES}

Page

Table 5.1 Multishot Survey at Total Depth

Table 7.1 Comparison of Rates of Penetration of Motors

During Angle Building Drilling

Table 11.1 Summary of Frac Treatments for Hardy HW\#1

Table 11.2 Flowback Summary for Frac Job on Zone 1

Table 12.1.1 Basic Reservoir and Well Data

64

Table 12.3.1 Pre-Stimulation Well Test Analysis Results

84

Table 12.3.2 Post-Stimulation Well Test Analysis Results 85

Table 12.3.3 Estimates of $K_{V}$ and $K_{H}$ Values Based on 86

Table 12.1 Cost Data BDM/Cabot Horizontal Well 98 


\subsection{EXECUTIVE SUMMARY}

The Cabot Oil \& Gas Hardy HW\#1 well was spudded on November 29, 1989 , and drilling was completed at a total measured depth of 6,399 feet on December 29, 1989 . The well was drilled on an average azimuth of $335^{\circ}$, with a total horizontal displacement of 2618 feet. Approximately 1035 feet of the well had an inclination higher than $86^{\circ}$ (horizontal), while 2212 feet of the well had an inclination greater than 62 degrees. The well was turned to a 90 degree inclination over a measured course length of 1346 feet which is a true vertical depth (radius) of 829 feet.

The inclined well encountered 59 shows of gas with a calculated volume of more than 2 mcipd. Twelve gas shows had calculated volumes greater than 50 mcfpd, the largest of which was 178 mcfpd.

After reaching the kick-off point at 3253 feet, it required only 35 hours of drilling time to turn the well to a 90 degree inclination (horizontal at an average penetration rate of 41.0 feet per hour). The horizontal section was drilled with conventional rotary tools with a 7 $7 / 8$ " bit and the rate of penetration was 46.5 feet per hour. During drilling of the shallow vertical section of the hole, the average rate of penetration was 26.6 feet per hour for drilling both the $171 / 2^{n}$ and 12 $1 / 4$ " hole down to the KOP. When a strong flow of water was encountered in the Big Injun Sand and the well was mudded up, penetration rate dropped to 12.2 feet per hour.

Steering tool operations were the most costly and time consuming during drilling. Seven steering tool failures were encountered which resulted in delays of four days in the drilling operations.

Logging operations were beset with operational problems which provided an incomplete video survey of the borehole (to a depth of only 4550 feet) and successful geophysical logs going into the hole only. The available logs along with the mud logs were used to select the locations of the five external casing packers and the four ported collars in the casing string. 
The improvements in downhole motors have increased penetration rates to the point where they are nearly equal to those of vertical airdrilling rates. The Hardy HW\#1 well was drilled in twenty-eight days less time than the first air-drilled horizontal well which was drilled in 1986 (RET\#1).

The well was completed with five (5) casing packers and five (5) port collars included in the string of J-55, $10.5 \mathrm{lb} / \mathrm{ft} 4.5$ inch casing. A section of the casing in the inclined portion of the wellbore was cemented with 130 sacks of class A cement between $4057^{\prime}$ and $3500^{\prime}$ as a permanent barrier to water. Thus the wellbore was configured into four separate zones for stimulation purposes.

During stimulation activities, the port collars did not function as advertised by the vendor, and their opening and closing tools had to be modified in the field to make them work. This made stimulation and cleanup operations much more difficult and costly than anticipated.

Zone one (1) was broken down with nitrogen and fraced with 80 Quality foam and sand. Although the actual volumes injected were somewhat less than planned, the first stimulation was accomplished without too many problems. Zone two (2) was a different story. Two attempts were made before the well was partially fraced with foam at a much lower injection rate than originally planned. Zones 3 and 4 could be pumped into with nitrogen, but they would not accept foam, even at very low injection rates and without sand. These two zones were finally stimulated by pumping straight nitrogen into the zones at the highest rate possible without exceeding the established pressure limit.

The well was cleaned-up after stimulation, and pressure build-up and drawdown tests were conducted to determine the success of stimulation operations. An improvement ratio of 4.5 times natural production rate was determined as a result of the well testing activities.

The well is expected to produce 475 million cubic feet of gas over the next 30 years. Ultimate production before abandonment could well be double that amount. Production records examined for the first 21 months 


\subsection{EXECUTIVE SUMMARY}

The Cabot Oil \& Gas Hardy HW\#1 well was spudded on Novernber 29, 1989 , and drilling was completed at a total measured depth of 6,399 feet on December 29, 1989 . The well was drilled on an average azimuth of $335^{\circ}$, with a total horizontal displacement of 2618 feet. Approximately 1035 feet of the well had an inclination higher than $86^{\circ}$ (horizontal), while 2212 feet of the well had an inclination greater than 62 degrees. The well was turned to a 90 degree inclination over a measured course length of 1346 feet which is a true vertical depth (radius) of 829 feet.

The inclined well encountered 59 shows of gas with a calculated volume of more thar 2 mcipd. Twelve gas shows had calculated volumes greater than 50 mcfpd, the largest of which was 178 mcfpd.

After reaching the kick-off point at 3253 feet, it required only 35 hours of drilling time to turn the well to a 90 degree inclination (horizontal at an average penetration rate of 41.0 feet per hour). The horizontal section was drilled with conventional rotary tools with a 7 $7 / 8$ " bit and the rate of penetration was 46.5 feet per hour. During drilling of the shallow vertical section of the hole, the average rate of penetration was 26.6 feet per hour for drilling both the $171 / 2^{\prime \prime}$ and 12 $1 / 4$ " hole down to the KOP. When a strong flow of waser was encountered in the Big Injun Sand and the well was mudded up, penetration rate dropped to 12.2 feet per hour.

Steering tool operations were the most costly and time consuming during drilling. Seven steering tool failures were encountered which resulted in delays of four days in the drilling operations.

Logging operations were beset with operational problems which provided an incomplete video survey of the borehole (to a depth of only 4550 feet) and successful geophysicai logs going into the hole only. The available logs along with the mud logs were used to select the locations of the five external casing packers and the four ported collars in the casing string. 
The improvements in downhole motors have increased penetration rates to the point where they are nearly equal to those of vertical airdrilling rates. The Hardy HW\#1 well was drilled in twenty-eight days less time than the first air-drilled horizontal well which was drilled in 1986 (RET\#1).

The well was completed with five (5) casing packers and five (5) port collars included in the string of J.55, $10.5 \mathrm{lb} / \mathrm{ft} 4.5$ inch casing. A section of the casing in the inclined portion of the wellbore was cemented with 130 sacks of class A cement between $4057^{\circ}$ and $3500^{\prime}$ as a permanent barrier to water. Thus the wellbore was configured into four separate zones for stimulation purposes.

During stimulation activities, the port collars did not function as advertised by the vendor, and their opening and closing tools had to be modified in the field to make them work. This made stimulation and cleanup operations much more difficult and costly than anticipated.

Zone one (1) was broken down with nitrogen and fraced with 80 Quality form and sand. Although the actual volumes injected were somewhat less than planned, the first stimulation was accomplished without too many problems. Zone two (2) was a different story. Two attempts were made before the well was partially fraced with foam at a much lower injection rate than originally planned. Zones 3 and 4 could be pumped into with nitrogen, but they would not accept foam, even at very low injection rates and without sand. These two zones were finally stimulated by pumping straight nitrogen into the zones at the highest rate possible without exceeding the established pressure limit.

The well was cleaned-up after stimu'ation, and pressure build-up and drawdown tests were conducted to determine the success of stimulation operations. An improvement ratio of 4.5 times natural production rate was determined as a result of the well testing activities.

The well is expected to produce 475 million cubic feet of gas over the next 30 years. Ultimate production before abandonment could well be double that amount. Production records examined for the first 21 months 
of production indicate the rate of production decline from the horizontal well is about half the rate exhibited by vertical wells in the area.

\subsection{INTRODUCTION}

As part of an ongoing Department of Energy Program to test emerging technology as methods of producing additional natural gas resources at economic rates, the Morgantown Energy Technology Center has for more than twenty years been exploring the concept of horizontal drilling as an advanced technology concept to improve gas and oil recovery efficiency.

The first successful air-drilled horizontal well was designed and drilled by BDM International for DOE in 1986 (Reference 1) in Wayne County, West Virginia, in conjunction with a small industry partner. BDM Engineering Services Company (BDMESC), a subsidiary of BDM International, was awarded a second competitive contract in 1989 to continue to explore the economics of drilling, completing and producing horizontal wells in tight, resource rich, Devonian shales of the Appalachian basin.

BDMESC proposed a cost sharing arrangement with Cabot Oil and Gas Corporation whereby they provide leases for drilling, share in the well costs, and serve as operator for drilling and production operations. BDMESC conducted geologic studies, selected the drill sites to be approved by Cabot and DOE, designed the well, and supervised drilling and completion operations.

\subsection{LEASE ACQUISITION AND LOCATION DEVELOPMENT}

The results of a detailed geologic study and reservoir analysis of three areas in Putnam County, West Virginia, where Cabot Oil and Gas had 40,000 acres under lease were reported in a topical report "Selection of Geographic Area and Specific Site for Drilling a Horizontal Well in Cooperation with Cabot Oil and Gas Company." Area 2 in Union District near the village of Extra was selected as the specific area. The specific site and orientation of the well with respect to structure on the base of 
the Huron Shale is shown in Figure 3.1. Location of postulated fracture zones is indicated by the dashed line on Figure 3.1.

The location was presented to Cabo: Oil and Gas who then proceeded to develop a production unit outline and to clear the titles for the leases included for drilling operations. The proposed production unit is shown in Figure 3.2 along with the location of a postulated 300 million cubic feet production fairway which would be crossed by the horizontal well.

Considerable problems were encountered by Cabot in obtaining a clear title for the included leases as a result of a survey problem which occurred thirty or more years ago. The lease was finally cleared after three months of legal examination and resurveying of the involved properties. The staked location was surveyed on the ground and a drilling permit obtained from the West Virginia Oil and Gas Division of the West Virginia Department of Mines and Mineral Resources.

\subsection{DRILLING PLAN SUMMARY}

The Hardy HW\#1 Well was to be drilled as a horizontal well in the Lower Huron Shale to improve productivity. The well was designed to be drilled vertically to a kick-off point 716 ' below the top of the Berea Formation (approximately 3236' below GL). A string of $133 / 8^{\prime \prime}$ surface casing was to be set at $655^{\prime}$ to isolate fresh water and coal. A $95 / 8^{\prime \prime}$ intermediate string was to be set through the Berea Formation to isolate potential water and hydrocarbon bearing intervals.

At the kick-off point, the inclination was to be built with a downhole motor and steering tool at a rate of $8 \% 1100^{\circ}$ to an inclination of $87^{\circ}$. Then, 2000 feet of wellbore would be drilled in the target interval with a rotary assembly. The assembly would be designed to drop angle at approximately $0.25 \% 100^{\prime}$ causing the wellbore to drop out of the target interval at the end of the 2000 feet.

The preferred azimuth of the wellbore was $340^{\circ}$ which is nearly orthogonal to the natural fractures in the area. Provided the well stayed within the pooled acreage, direction would not be a problem. In relation to 


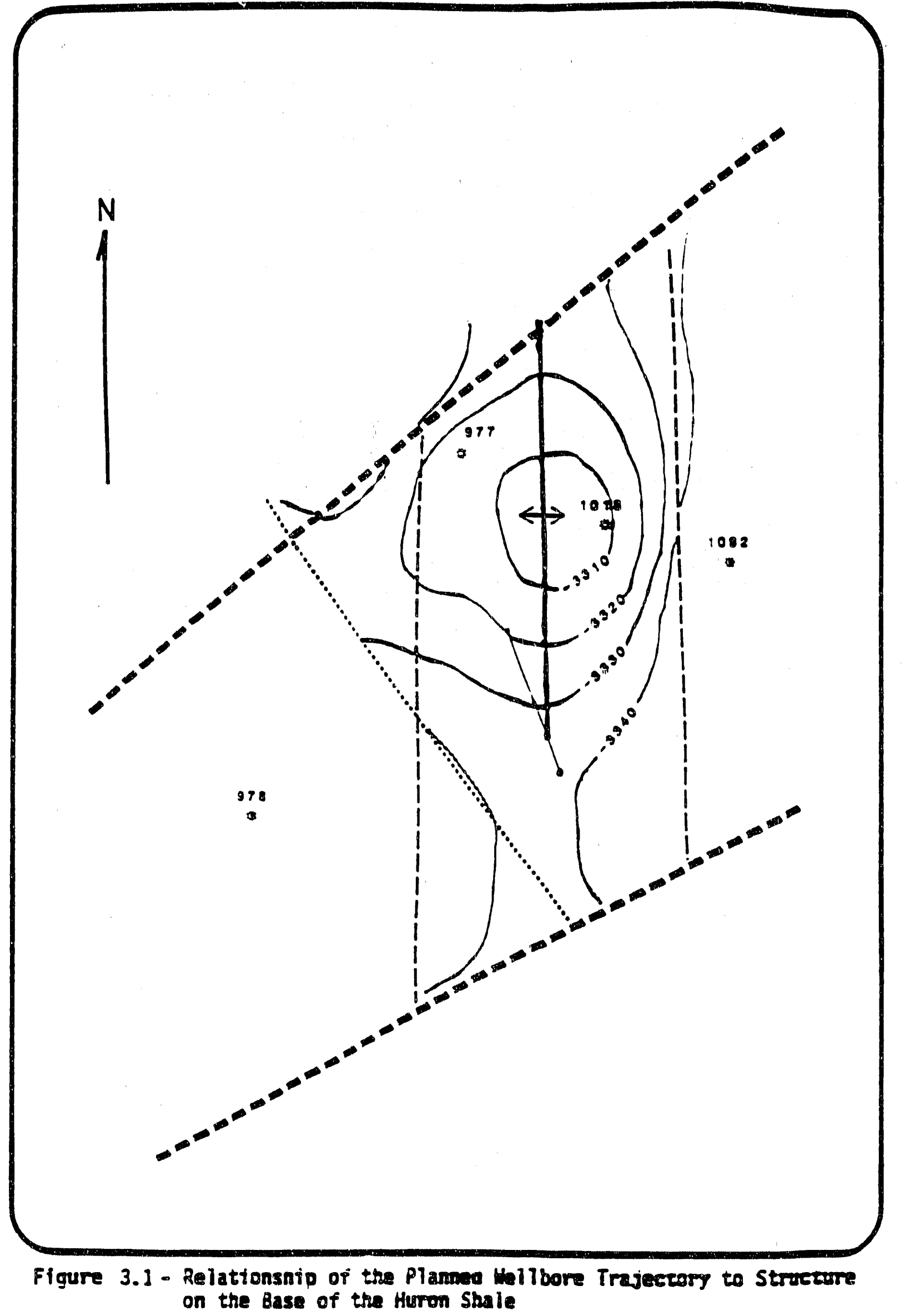



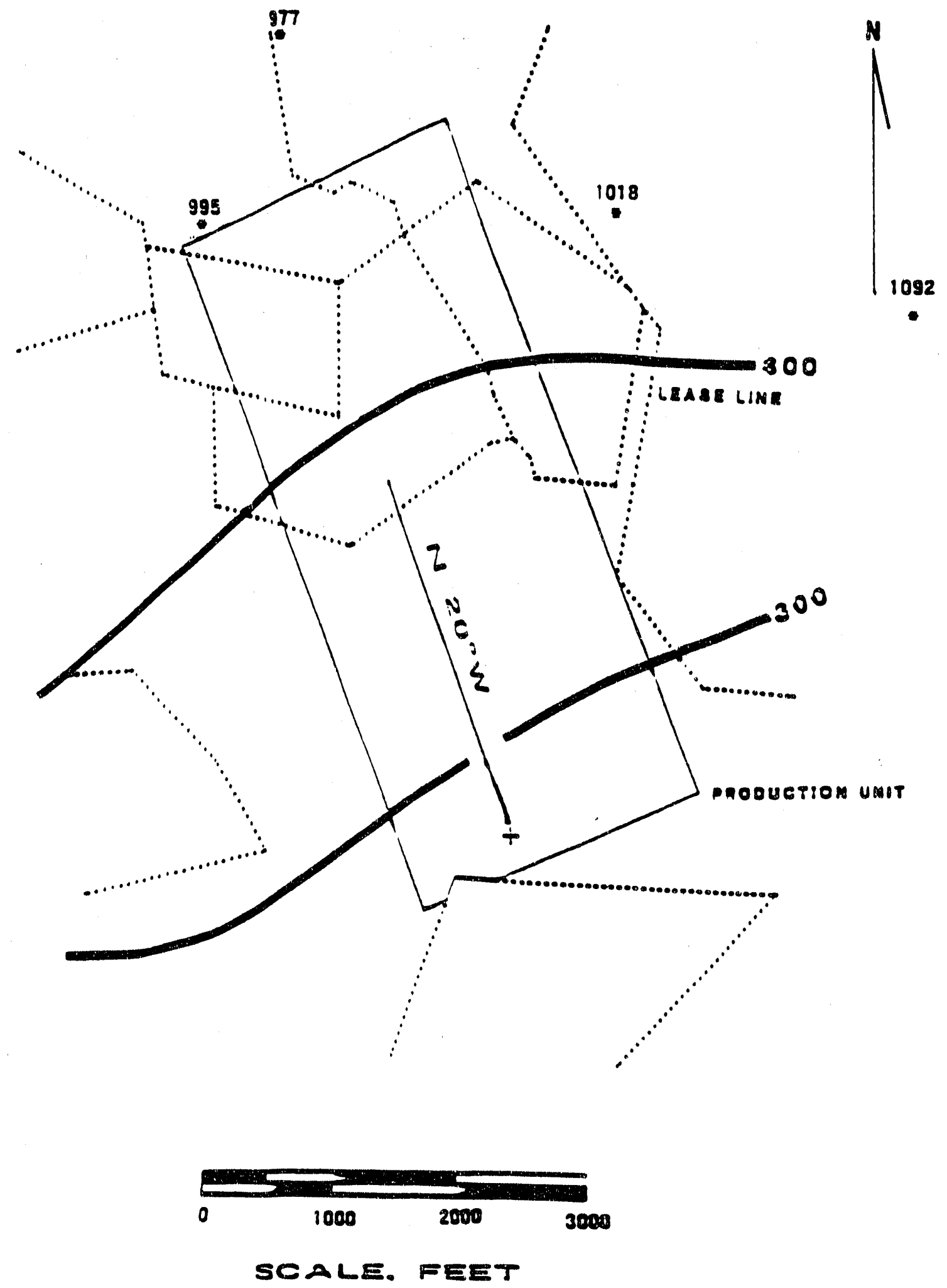

Figure 3.2- Locacton and Trajectory of Planned Horizoneal thll Across a 3-Lense Prowertion Unit 
TVD, the top of the target interval was 1431feet below the top of the Berea and the bottom was 1610 feet below the top of the Berea. Total target thickness was 179 feet.

After reaching total depth, the well would be logged with wireline free fall and drill pipe conveyed open hole logs and a video camera. Then 4 $1 / 2^{\text {n }}$ casing would be run using external casing packers to isolate individual producing intervals. The placement of the external casing packers and port collars would be determined using mud log data, open hole geophysical well logs, and the video camera.

\subsection{DRILLING OPERATIONS}

\subsection{Introduction}

Drilling operations were conducted at the site between November 29, 1989 and January 2, 1990. Total days on location were 30 compared to the anticipated 24 days (excluding the four day shut down over Christmas). A plot of depth versus time in days can be seen in Figure 5.1 with the plot comparing actual and projected times.

Drilling the vertical portion of the well to the kick-off point took four days longer than anticipated because of an excessive water flow and stuck drill pipe. The angle build section required eight days to drill compared to a planned seven days. Steering tool problems slowed drilling this section of the hole. The horizontal jection was planned to be drilled in five days which was the actual time required. Logging required four days of rig time compared to an estimated three days. Drilling from kickoff point to release of the rig took two days longer than had been anticipated.

The horizontal section of the wellbore started at a deeper TVD than had been planned because of problems associated with building inclination with the Eastman motor. The planned build rate was $8 \% 1100^{\prime}$ and the Eastman motor assembly averaged $6.7^{\circ} / 100^{\prime}$. The amount of wellbore within the target interval was still 2020'. 


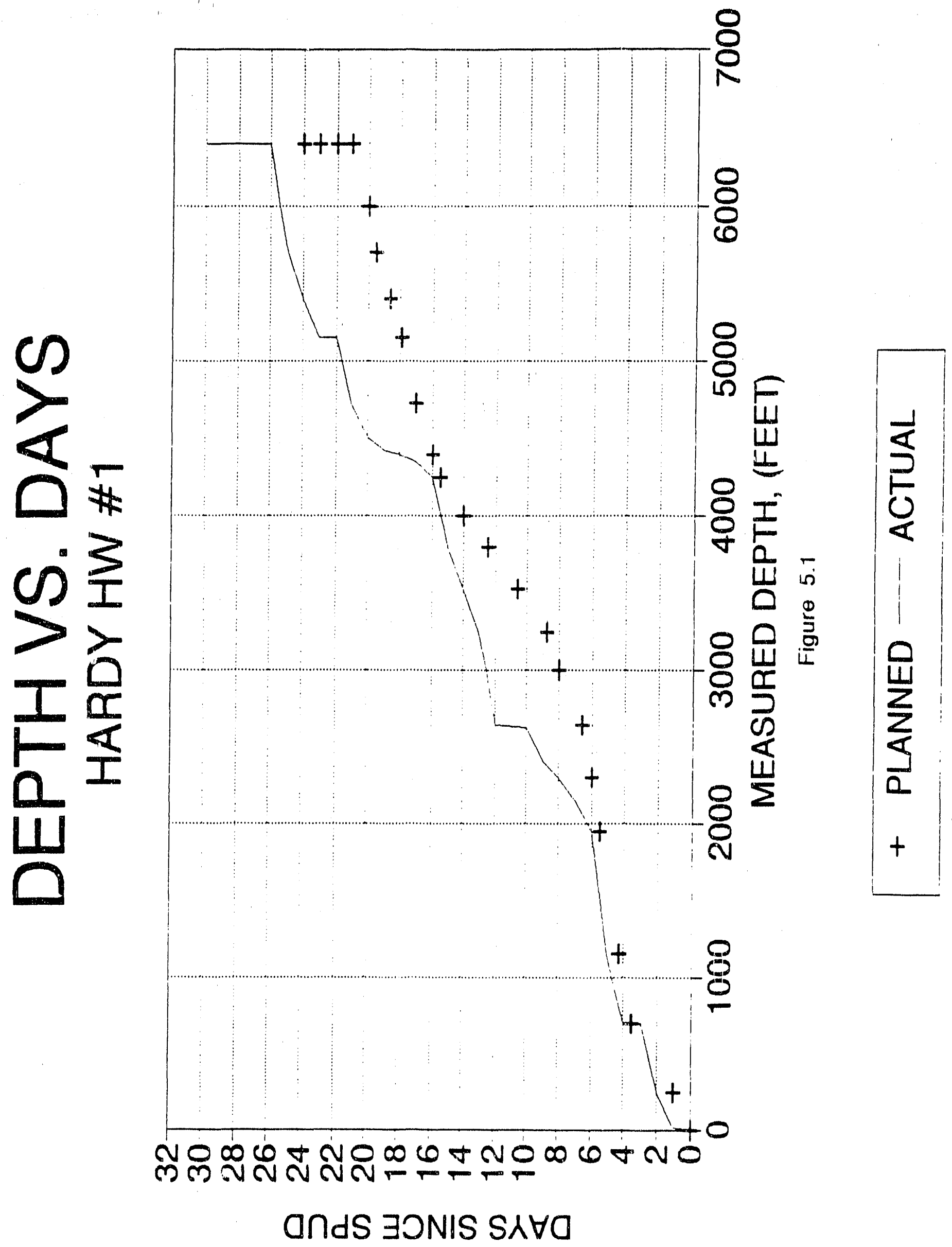




\subsection{Vertical Hole To 3253'}

The vertical portion of the well to the kick-off point was drilled on a footage basis by Great Western Drilling1. The well was spud at 11:00 pm on November 29, 1989. The conductor hole was drilled to 32 feet below ground level and a $20^{\prime \prime}$ conductor pipe was set. A $171 / 2^{n}$ surface hole was drilled to $696^{\prime} \mathrm{KB}$ through fresh water zones and coal.

Sixteen joints of $133 / 8^{\prime \prime}, 54.5 \# / \mathrm{ft}, \mathrm{J}-55, \mathrm{ST} \& \mathrm{C}$ casing were run and set at $668^{\prime} \mathrm{KB}\left(654^{\prime} \mathrm{GL}\right)$ to isolate fresh water zones and coal sections as required by the state of West Virginia. The casing tally can be found in Appendix A-1. The casing was cemented to surface with 460 sacks of Class " $A$ " cement containing 2 percent $\mathrm{CaCl}_{2}$. The cement was mixed at $15.6 \mathrm{ppg}$ with a yield of $1.18 \mathrm{ft} / \mathrm{sack}$.

The $121 / 4^{\prime \prime}$ intermediate hole was drilled to a depth of $1860^{\prime}$ when

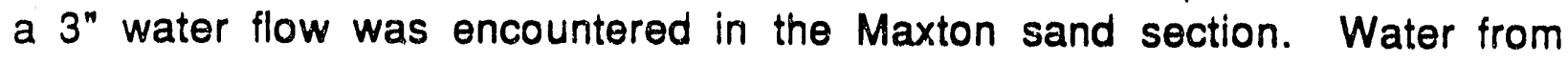
the Maxton had not been expected. The fresh water in the second reserve pit was drained to allow room for the formation water.

Drilling continued using mist until a large water flow was encountered in the Big Injun Formation (2105') where water had been anticipated. A third reserve pit had been constructed to accommodate the additional water. Air and mist drilling continued for less than one hour unil the third reserve pit was full. The well was making water in excess of 300 bbls per hour. Air drilling could not continue because there was no place to put the formation water.

At this point, the well was mudded up. A day's worth of rig time was used to rig up a mud pit, mud pump and shale shaker. Once circulation was established, drilling continued with partial returns. Initially, the well was losing around 40 bbls per hour and the loss slowly tapered off.

Drilling was stopped at 2301' feet while the rig crew worked on transferring more water into the mud pit (to make up for partial lost

1 Use of company names and/or trademarks are for identification only and do not imply endoresment of a service or product. 
circulation). When the crew came back to continue drilling, the drill pipe was differentially stuck. The drill pipe was worked for several hours but remained stuck.

To free the pipe, both aerating the mud and spotting oil were debated as possible solutions. It was assumed that aerating the mud might tear up the hole. So, 80 bbls of crude oil were spotted around the drill collars. Once the oil was spotted, the drill pipe came free in a short period of time.

Drilling then continued to 2657 feet which was the intermediate casing point. The drilling plan called for setting the $95 / 8^{\text {" }}$ casing fifty feet below the base of the Berea Formation. The mud logger showed the top of the Berea to be at 2579 feet.

A string of $95 / 8^{\prime \prime}, 36 \# / f t, J-55$, ST\&C casing was run and set at 2654' KB. The 9 5/8" pipe tally can be found in Appendix A-2. The casing was cemented as follows:

Pumped 15 bbls of fresh water, 330 sacks of Halliburton light cement followed by 100 sacks of Class " $A$ " cement containing 3 percent $\mathrm{CaCl}_{2}$ and $1 / 8 \mathrm{pps}$ flocele. The cement was displaced with 204 bbls fresh water and the plug was bumped with $1200 \mathrm{psi}$. The light cement was mixed at $13.6 \mathrm{ppg}$ with a yield of $1.54 \mathrm{ft} 3 / \mathrm{sack}$. The Class "A" cement was mixed at $15.6 \mathrm{ppg}$ with a yield of 1.18 $\mathrm{ft} 3 /$ sack.

While waiting on cement, a gamma ray correlation log was run showing the top of the Berea Formation to be at 2577 feet or about the same depth as picked by the mud logger. The kick- off point would then be 3295 feet; 716 feet below the top of the Berea.

After waiting on cement for 12 hours, the $133 / 8^{\prime \prime}$ casing was cut off and welded to the $95 / 8^{\prime \prime}$ casing for support. The mud system was rigged down and the air system rigged back up. The BOP's were nippled up and the casing drilled out with an $83 / 4^{n}$ bit. Drilling continued, dusting, to $3253^{\prime}$ when a survey was taken to determine inclination and well 
direction. The survey showed an inclination of $1^{\circ}$ and an azimuth of $279^{\circ}$ at a depth of 3191 feet.

\subsection{Build Section}

Based upon the Berea top, the kick-off point should have been 3295'; however, the kick- off point was changed to 3253' to provide some margin for failure to build angle at the planned rate. The Eastman motor was

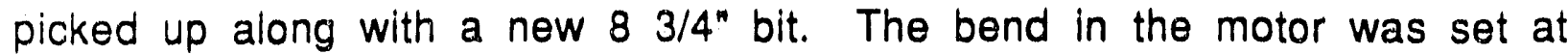
$1.1^{\circ}$ with an $83 / 8^{n}$ stabilizer below the bend. An $77 / 8^{n}$ integral blade stabilizer was placed above the motor. (See BHA data in Appendix B-1.)

The motor was tested at the surface and it operated normally. Three

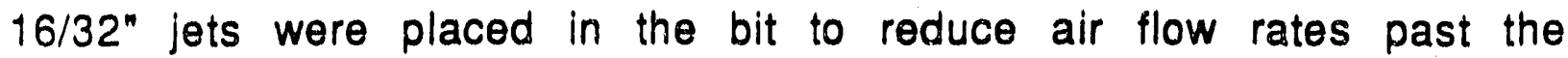
steering tool and increase steering tool life. The jets should have increased the pressure above the motor by 100 psi.

The motor was tripped to bottom and Smith's steering tool was run through a side entry sub to orient the motor. The first motor run drilled from $3253^{\prime}$ to $3487^{\prime}\left(234^{\prime}\right)$ at an average penetration rate of 47 feet per hour. Unfortunately, the build rate (not dogleg severity) experienced with the motor configuration was only $5.9 \% 100$. Build rates can be seen in the Build and Walk Rate Table in Appendix C. The motor was pulled from the hole to change the adjustable bend and lay down the top $77 / 8^{n}$ integral blade stabilizer.

The bend was set at the maximum angle of $1.3^{\circ}$ which according to Eastman's design program should yield a dogleg severity of $9.5 \% 100$ '. The motor was tripped back in the hole and drilling continued to 3603 feet. The build rate after changing the motor configuration was still 6.3\%/100'. It would not have been possible to hit the target at that build rate.

The motor was again pulled from the hole. This time a $1.5^{\circ}$ bent sub was placed on top of the motor. No experience was available to be able to project build rate for this BHA, so the anticipated build rate was unknown. The motor was tripped back to bottom and the well drilled to 3817 feet. The motor was now building inclination at an average rate of $6.6 \% 100$ which was still not fast enough to hit the target. Formation tendencies 
were assumed to be contributing to the lower build rates.

Prior to plugging back and sidetracking, one more attempt was made using the Eastman motor. The motor was tripped out of the hole and checked to make sure the bent sub and bent housing were still aligned. The bit size was reduced to $81 / 2^{n}$ and the jets were left out of the bit. The motor was then tripped back in the hole.

The build rate achieved in the smaller diameter hole was $8.4^{\circ} / 100^{\prime}$. At that rate, the well would be nearly horizontal at TVD of approximately $4100^{\prime}$ which was barely acceptable. Drilling continued to $4249^{\prime} \mathrm{MD}$ when the motor rotated $90^{\circ}$ to the right on a connection. The motor was worked back up to high side and the well was drilled to $4324^{\circ} \mathrm{MD}$. The survey data from the steering tool indicated that the well was turning to the left and not building much inclination. The geometry of the motor assembly in the hole had changed or the steering tool was no longer oriented properly.

The steering tool was pulled to check and make sure it was working properly. The orienting stinger (mule shoe stinger) had been pulled loose from the probe section when the tool was pulled from the monels. The stinger was left in the latch in. Since the steering tool had been pulled apart (took around 500 lbs of overpull, which is the same as the latch in should take), it was not possible to determine if the tool had still been oriented. The orientation of the probe in relation to the stinger should not have changed as long as the tool was still together.

Not knowing whether the problem was caused by the steering tool or the motor assembly, it was decided to also change out the motor assembly. The Eastman air drilling motor was laid down and a Baker motor with a $2^{\circ}$ bent housing was picked up. The Baker motor was run without any stabilizers.

The Baker motor was run in the hole with the same $81 / 2^{n}$ bit, but the bit was dressed with one 11/32nd and two 14/32nd inch jets. The motor drilled 98 feet but problems with the steering tool prevented drilling any further. However, the survey data indicated that the hole had turned to the left and not built any inclination. It was then obvious that the steering tool had caused the problem with the previous motor run. 
At a depth of 4422', the motor was pulled from the hole because of steering tool problems. No more steering tools were available on location so the Geoscience Electronics Electromagnetic MWD (EMWD) was picked up and run in the hole. The jets in the bit were changed to two 11/32nd and one $14 / 32$ nd inch to increase the pressure above the motor and reduce the vibration on the EMWD tool.

The motor tagged up ninety leet off bottom. The EMWD was having problems sending information to the surface and the operators felt that having the bit on bottom drilling would increase the signal strength. An effort was made to wash the bit to bottom without success. All indications were that the bit was beginning to drill a new hole. After washing (drilling with little resistance) five to ten feet, the motor was pulled from the hole. Drilling thead without tool face data was deemed too risky and drilling operations were halted until a steerilg tool was obtained.

Smith's three axis steering tool arrived on location and the motor vias run back in the hole. It was not possible to get the motor back in the clo hole and the well ended up sidetracked above 4338'. The motor drilled in 4502' and the steering tool failed again. The tool had come apart and the motor had to be pulled to retrieve the remainder of the steering tool.

The motor was run back in the hole and drilled to $4610^{\prime}$ at which point the inclination should have been $90^{\circ}$ with an azimuth of $340^{\circ}$. The motor was pulled and laid down. The rest of the well was drilled with rotary assemblies.

A multishot survey (See Appendix D) later showed that the well reached $90^{\circ}$ at a TVD of $4082^{\prime}$ which was 72 feet deeper than planned.

Hole cleaning was still a minor problem in the build section while running the motors. As in the previous well, cuttings would build up at an inclination of around $60^{\circ}$ and the hole would have to be circulated to remove the drill pipe. Although, without foam as a lubricating fluid, fewer joints had to be circulated out of the hole. When running rotary assemblies, no hole cleaning problems were experienced even at the same air flow rates. 


\subsection{Horizontal section}

The horizontal/slant section was drilled from 4610' MD to 6399' MD using rotary assemblies. The drilling plan had called for using the same rotary assembly that had been used in the Wayne County well. That assembly had dropped approximately $0.25 \% 100^{\prime}$ while drilling the horizontal section. Since the TVD was deeper than expected, the button cutters in the near bit reamer were replaced with flat cutters to reduce the amount of side cutting by the reamer while drilling. The effect should be to decrease the rate of drop or to increase inclination.

Bottom hole assembly number 6 was run in the hole at 4610'. (See Appendix B-2). The hole size was reduced to $7-7 / 8^{n}$ so that the build section would not have to be reamed and so that the external casing packers would have a better chance of sealing in a washed out area. The 7. $7 / 8^{\prime \prime}$ bit was dressed with three $16 / 32^{\prime \prime}$ jets.

The area of the hole that had been sidetracked at approximately 4338 ' stopped the rotary assembly; but with a little work, the assembly passed without a problem. The assembly drilled to a depth of 5126' MD.

The wellbore needed to drop back through the target interval so the building assembly was pulled and a dropping assembly run. The dropping assembly is assembly number 7 in Appendix B-2. The assembly should have dropped inclination at a rate of 1 to $1.5 \% 100$. Unfortunately, the assembly would not go into the right hole. At the sidetrack, the assembly kept going into the short hole. Apparently, the assembly was too stiff to make the corner. A more limber dropping assembly was run hoping it would go into the correct hole. Assembly number 8 (Appendix B-3) with a $10^{\prime}$ pony collar in front of the lead reamer was run. Drop rates would probably be higher than that desired but other refinement could not be made in the wellbore. The $10^{\prime}$ pendulum assembly had no problem getting into the correct hole.

Drilling operations were shut down over Christmas from 8:00 am on $12 / 22 / 89$ to $8: 00$ am on $12 / 26 / 89$. 
When drilling operations continued, the $10^{\prime}$ pendulum assembly was run to drill the remainder of the well. Only one more problem was experienced with the sidetracked hole. While trying to take a survey at $5422^{\prime} \mathrm{MD}$, the assembly went into the wrong hole several times. After retrieving the survey tool, the assembly went into the correct hole. From then on, the bit was not pulled above the sidetrack point in order to survey.

After reaching a depth of 5670', the pipe would no longer fall into the hole because of excessive down drag. The air rate was increased from 2000 to $2900 \mathrm{scfm}$ for two connections but the hole drag remained constant. Hole cleaning was not a problem. The drill pipe had to be rotated with the slips to get it into the hole. Drill pipe connections were taking 30 to 45 minutes each.

Hole drag also prevented taking additional surveys. Surveys were taken by pulling the bit out of the hole to a depth of $4390^{\prime}$. The singleshot was run into the hole on Smith's releasing overshot. The releasing overshot used a monel sensor to operate. Whenever the tool sensed it was in a nonmagnetic collar, the sensor would activate a motor that would release the survey tool. The slick line and sensor were removed from the hole and the survey tool tripped to bottom. After waiting for the time to take the survey, the bit was again tripped to 4390'. A standard overshot was run on the slick line and the survey tool retrieved. The BHA was tripped back to bottom to continue drilling.

The maximum time that could be set on the survey tool time was 99 minutes. Having to rotate the pipe to bottom, tripping consumed too much time, and the timer would activate before the survey tool ever reached bottom. Therefore, no singleshot surveys were taken below 5372'.

At this depth, it appeared the 10' pendulum was dropping at a rate of 2 to 2.5\%/100'. Without good survey data and having limited options available with respect to BHA's, the well was drilled to total depth. Total depth was determined by two factors: when predominantly grey shale was being drilled and no more shows were seen by the mud logging unit. The cuttings showed mostly grey shale below 6220' and the last mud log show was seen at 6168'. Drilling was terminated at a measured depth of 6406'. 
The pipe was strapped out of the hole and the measured depth was found to be 6391.47' KB. (See drill pipe tally 12/29/89 in Appendix E). To be certain of the depth, the pipe would be carefully strapped again during the multishot survey.

After reaching total depth, the well was logged. Free fall logs were run first with the video camera falling to $4100^{\prime}$ where the inclination was $\left(60^{\circ}\right)$. The open hole logs fell to $4325^{\prime}$ where the inclination was $\left(74^{\circ}\right)$. The drill pipe conveyed video log was run to 4550'. Logging was terminated because no signal was being received from the tool. The drill pipe conveyed, open hole logs were run to $6360^{\circ}$ depth. For more information on the logs, see Section 6.0 Logging.

After the logging, a multishot survey was run. Surveys were taken every stand (61-62') from 3200' to total depth. Without the reamer, the pipe went in the hole easier. It did not have to be rotated in the hole but still had to be worked down.

The multishot survey showed that the wellbore entered the target interval at a measured depth of $4178^{\circ}\left(4010^{\circ}\right.$ TVD) and dropped out of the target at a measured depth of 6198' (4178' TVD). These depths corresponded with mud log shows and samples. The drill pipe measurement showed a total depth of $6399.40^{\circ} \mathrm{KB}$ and the total depth was corrected to that depth. (See multishot pipe strap 1/1/90 in Appendix F.

The azimuth of the survevs between 5000 and 5500 foet showed magnetic interference. The azimuth was almost 180 degrees off. Therefore, the azimuth was left at 339 degrees for calculation purposes. Table 5.1 shows the multishot data. The singleshot data can be found in Appendix G.

Plots of the planned versus actual wellbore path are exhibited in Figures 5.2 and 5.3.

After laying down the drill pipe, 140 joints of $41 / 2^{n}, 10.5 \# / f t, K$ 55. ST\&C casing (including four pup joints) were run in the hole. The casing contained five external casing packers and four port collars. The 
Hardy \#1 BDM/DOE/CABOT Horizontal well Multishot Survey pace 1

\begin{tabular}{|c|c|c|c|c|c|c|c|c|c|}
\hline $\begin{array}{l}\text { MASUED } \\
\text { OLPTK } \\
\text { FEET }\end{array}$ & $\begin{array}{l}\text { DRIT } \\
\text { Mare } \\
\text { OEmeses }\end{array}$ & $\begin{array}{l}\text { DRIT } \\
\text { AZIATK } \\
\text { DEFIES }\end{array}$ & $\begin{array}{l}\text { CORSE } \\
\text { LEMGTK } \\
\text { PEET }\end{array}$ & $\begin{array}{l}\text { Trate } \\
\text { VERTICAL } \\
\text { OEPTH }\end{array}$ & $\begin{array}{l}\text { REE E P A } \\
\text { F O O R R O } \\
\text { MOATH }\end{array}$ & $\begin{array}{c}\text { A GULA } \\
\text { INATES } \\
\text { EAST }\end{array}$ & $\begin{array}{l}\text { Cosune } \\
\text { DISTAMCE } \\
\text { PaET }\end{array}$ & $\begin{array}{l}\text { Aovine } \\
\text { Azimink } \\
\text { DEmess }\end{array}$ & 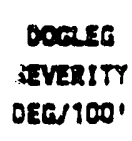 \\
\hline 0.00 & 0.00 & 232.00 & 0.00 & 0.00 & 0.00 & 0.00 & 0.00 & 0.00 & 0.00 \\
\hline $31 \% .00$ & 0.75 & 222.00 & 3996.00 & 3194.00 & 0.00 & 0.00 & 0.00 & 0.00 & 0.00 \\
\hline 3256.00 & 1.50 & 288.60 & 62.00 & 3255.90 & 0.00 & -1.20 & 1.20 & 270.00 & 1.61 \\
\hline 3318.00 & 6.75 & 322.20 & 62.00 & 317.39 & 1.91 & -3.93 & 6.37 & 295.95 & 5.89 \\
\hline 3579.00 & 8.75 & 328.80 & 61.00 & $\$ 578.65$ & 7.78 & -8.03 & 19.98 & $31: 07$ & 6.65 \\
\hline 34691.00 & 12.50 & 328.00 & 62.00 & 3439.33 & 17.47 & -16.09 & 22.45 & $329.9:$ & 6.05 \\
\hline 3503.00 & 16.25 & 326.00 & 62.00 & 3499.63 & 30.38 & -22.47 & 37.79 & 323.59 & 6.10 \\
\hline 3565.00 & 20.50 & 325.00 & 62.00 & 3558.25 & 46.48 & .33 .54 & 57.32 & 326.19 & 6.87 \\
\hline 3627.00 & 26.25 & 327.50 & 62.00 & 3615.57 & 66.06 & -46.76 & 80.91 & $326 . \pi 2$ & 6.17 \\
\hline 3689.00 & 28.25 & 530.00 & 61.00 & 3670.27 & 89.04 & .60 .83 & 107.83 & 325.36 & 6.91 \\
\hline 3750.00 & 32.25 & 530.00 & 62.00 & 3723.32 & 116.08 & -76.66 & 138.98 & 326.6 & 6.65 \\
\hline 3812.00 & 36.50 & 530.60 & 62.00 & 5776.58 & 146.39 & .93 .96 & 173.96 & 327.91 & 6.85 \\
\hline 3876.00 & 41.75 & 330.00 & 62.00 & 3023.06 & 180.26 & -113.40 & 283.02 & 327.89 & 8.67 \\
\hline 3936.00 & 46.50 & 389.00 & 62.00 & 3867.55 & 297.65 & .135 .40 & 256.15 & 328.09 & 7.76 \\
\hline 3997.00 & 59.75 & 328.00 & 61.00 & 3907.66 & 256.76 & -159.49 & 302.26 & 328.15 & 8.70 \\
\hline 4059.00 & $57 . C D$ & 328.60 & 62.00 & 3963.56 & 299.48 & .186 .18 & 352.64 & 328.12 & 8.67 \\
\hline 6129.00 & 62.00 & 330.60 & 62.00 & 3975.02 & 345.26 & .213 .69 & 406.06 & 328.25 & 8.53 \\
\hline 6183.00 & 66.75 & 532.20 & 62.00 & 4009.32 & 396.13 & .260 .78 & 461.86 & 328.59 & 8.19 \\
\hline 6266.00 & 70.25 & 530.00 & 69.00 & 6026.18 & 445.76 & .288 .29 & 518.56 & 328.84 & 6.50 \\
\hline 6306.00 & 72.73 & 326.60 & 62.00 & 4063.35 & 493.05 & .300 .30 & 577.30 & 328.66 & 10.02 \\
\hline 4368.00 & 77.50 & 323.50 & 62.00 & 6059.76 & 569.20 & .335 .93 & 636.98 & 328.17 & 7.82 \\
\hline 4630.00 & 3.25 & 326.00 & 62.00 & 4070.12 & 590.96 & .379 .49 & 697.96 & 327.85 & 10.63 \\
\hline 4609.00 & 86.25 & 503.20 & 61.00 & 4076.76 & 663.15 & .602 .16 & 758.54 & 327.98 & 19.52 \\
\hline 4553.00 & 87.25 & $537 .: 2$ & 62.00 & 4089.35 & 699.17 & -628.28 & 819.92 & 328.59 & 8.05 \\
\hline 4615.00 & 90.50 & 538.60 & 62.00 & 4082.57 & 756.63 & .652 .00 & 881.19 & 329.14 & 5.48 \\
\hline $46 \pi 7.00$ & $99 . \pi$ & 539.00 & 62.00 & 4089.35 & 816.11 & -676.72 & 962.61 & 329.75 & 2.58 \\
\hline 4739.00 & 92.25 & 338.00 & 62.00 & 6079.99 & 879.76 & .697 .43 & 1003.69 & 330.29 & 1.80 \\
\hline 4800.00 & 93.00 & 538.60 & 61.00 & 4076.40 & 928.25 & .520 .26 & 1004.19 & 330.73 & 1.23 \\
\hline 4862.00 & 93.28 & 339.20 & 62.00 & .073 .22 & 985.85 & .542 .95 & 1925.68 & $331 .: 6$ & 1.66 \\
\hline 4926.00 & $93 . \pi$ & 538.02 & 62.00 & .069 .23 & 1043.43 & .565 .63 & 1986.88 & 339.54 & 1.80 \\
\hline 4986.00 & 96.00 & 527.00 & 62.50 & .065 .06 & 1900.98 & -588.30 & 1268.30 & 539.88 & 1.66 \\
\hline 5067.00 & 96.25 & 339.00 & 61.00 & .060 .65 & i157.79 & .610 .10 & 1308.70 & $532.2 ?$ & 0.69 \\
\hline 5109.00 & $96, \pi$ & 339.00 & 62.00 & .055 .79 & 1215.49 & .632 .25 & 1370.09 & 332.52 & 0.89 \\
\hline 5979.00 & 96.00 & 539.00 & 62.00 & .059 .06 & 1273.20 & .656 .40 & 1631.53 & 352.80 & $1.2:$ \\
\hline 5233.00 & 92.75 & 339.00 & 62.00 & 2067.49 & 1330.98 & .676 .58 & 1693.08 & 533.05 & 2.82 \\
\hline 5296.00 & 99.75 & 339.00 & 61.00 & 4065.02 & 1387.89 & .698 .63 & 1553.79 & 353.29 & 1.66 \\
\hline 5356.00 & 90.25 & 359.00 & 62.00 & 4043.93 & 1445.76 & $\cdot 720.66$ & 1615.61 & 555.59 & 2.62 \\
\hline 5618.00 & 89.00 & 339.00 & 62.00 & 6066.36 & 1505.54 & .762 .86 & 1677.13 & 533.79 & 2.02 \\
\hline 5480.00 & 87.25 & 339.00 & 62.00 & 1066.37 & 1561.49 & $\cdot 765.07$ & 1738.84 & 333.90 & 2.82 \\
\hline$\$ 542.00$ & 85.50 & 339.00 & 62.60 & $: 050.29$ & 1619.25 & $\cdot 787.26$ & 1800.48 & 336.07 & 2.82 \\
\hline
\end{tabular}




\begin{tabular}{|c|c|c|c|c|c|c|c|c|c|}
\hline $\begin{array}{l}\text { BOASUED } \\
\text { DEPTH } \\
\text { PEET }\end{array}$ & $\begin{array}{l}\text { DAIFT } \\
\text { AMaL } \\
\text { DEmes }\end{array}$ & $\begin{array}{l}\text { DRIFT } \\
\text { AzInTH } \\
\text { DECeEES }\end{array}$ & $\begin{array}{l}\text { COUSE } \\
\text { LEMETH } \\
\text { PEET }\end{array}$ & $\begin{array}{l}\text { TEUE } \\
\text { VERTICAL } \\
\text { OEPTH }\end{array}$ & 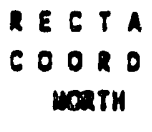 & $\begin{array}{l}\text { MULAR } \\
\text { INATES } \\
\text { EAST }\end{array}$ & $\begin{array}{l}\text { Closure } \\
\text { olstakas } \\
\text { pert }\end{array}$ & 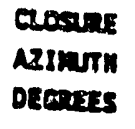 & $\begin{array}{l}\text { Dotel } \\
\text { suarit' } \\
\text { ose/100' }\end{array}$ \\
\hline 5603.00 & 03.75 & 360.20 & 61.00 & 6056.00 & 1676.13 & .808 .51 & 1860.86 & 36.25 & 3.30 \\
\hline 5645.00 & 22.75 & 340.00 & 62.00 & 6063.29 & 1733.99 & .829 .56 & 1922.21 & 536.63 & 1.61 \\
\hline 5727.00 & 89.00 & 539.00 & 62.00 & 6072.05 & 1791.68 & -851.06 & 1903.35 & 256.59 & 3.26 \\
\hline 5789.00 & 79.25 & 358.00 & 62.00 & 4082.68 & 1848.31 & -873.46 & 2046.29 & 336.71 & 3.26 \\
\hline 5850.00 & 78.75 & 357.60 & 61.00 & 4096.32 & 19003.63 & -89.36 & 2104.10 & 334.79 & 1.89 \\
\hline 5912.00 & 77.00 & 336.00 & 62.00 & 6107.35 & 1959.29 & -920.53 & 2164.69 & 536.83 & 3.23 \\
\hline 5974.00 & 75.50 & 585.00 & 62.00 & 6122.08 & 2016.01 & .045 .50 & 2226.91 & 336.85 & 2.88 \\
\hline 6036.00 & 73.25 & 533.00 & 62.00 & 6138.78 & 2067.67 & .971 .67 & 2284.60 & 334.80 & 4.78 \\
\hline 6097.00 & 79.25 & 332.00 & 61.00 & 6157.38 & 2919.20 & .998 .50 & 2342.65 & 334.77 & 3.63 \\
\hline 6159.00 & 69.75 & 330.00 & 62.00 & 6970.07 & 2170.31 & .1026 .83 & 2600.96 & 334.68 & 3.89 \\
\hline 6221.00 & 67.75 & 329.00 & 62.00 & 4200.56 & 2220.10 & -1056.15 & 2658.52 & 334.56 & 3.56 \\
\hline 6283.00 & 65.50 & 328.00 & 62.00 & 4225.16 & 2268.62 & -1085.89 & 2515.19 & 336.62 & 3.92 \\
\hline 6365.00 & 66.00 & 327.00 & 62.00 & 4251.58 & 2315.91 & .1116 .02 & 2570.79 & 336.27 & 2.83 \\
\hline 6389.00 & 62.65 & 326.00 & 56.00 & 4275.83 & 2356.15 & .1162 .65 & 2618.60 & 336.13 & 3.00 \\
\hline
\end{tabular}




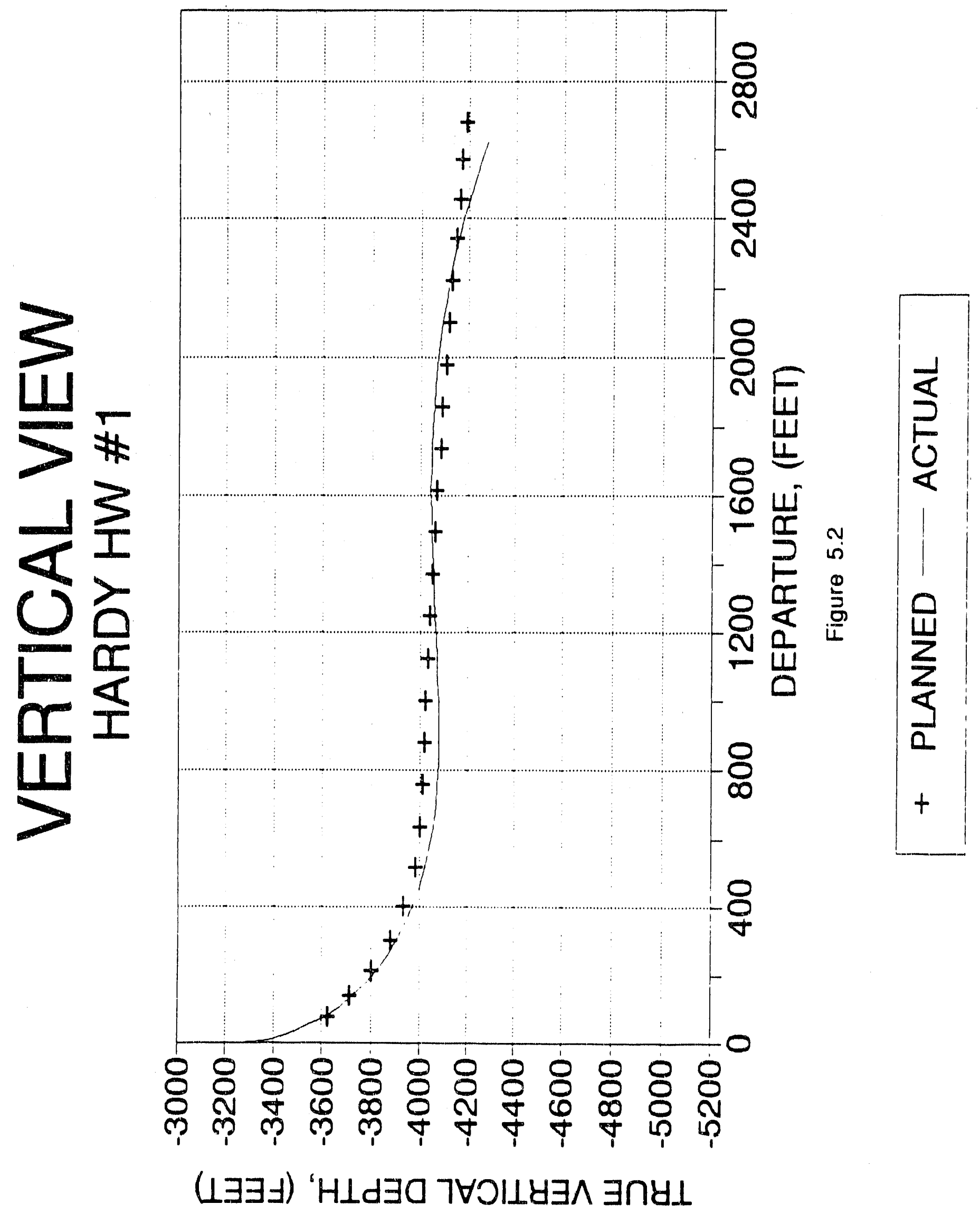




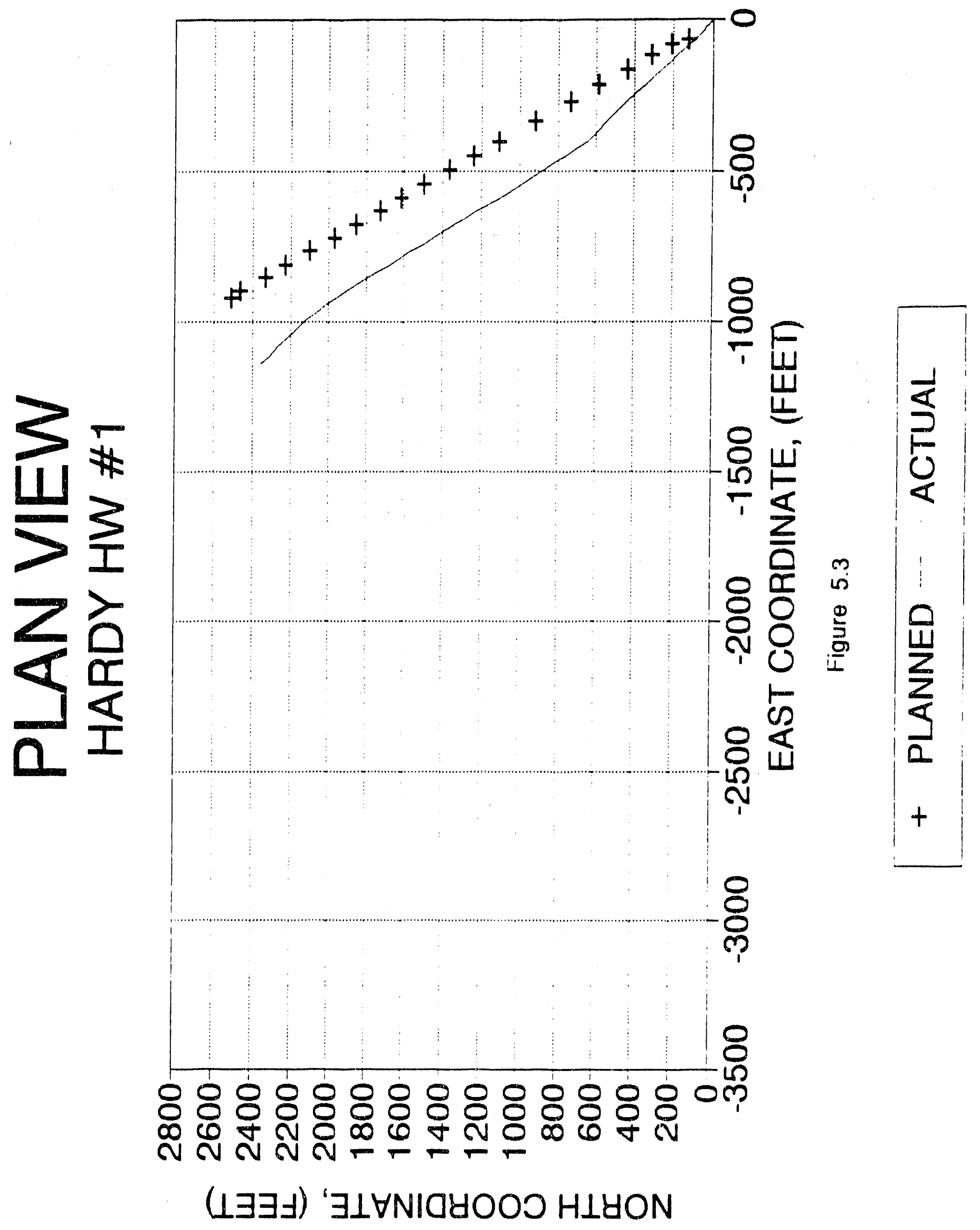


casing tally and setting depth of the packers and port collars can be found in Appendix A-3.

The casing was landed in the wellhead slips and the rig released.

\subsection{LOGGING OPERATIONS}

\subsection{Introduction}

Logging of this well was planned to identify key stratigraphic units used in the location of the kick-off point, and in the determination of hydrocarbon gasses present in the target formation. Logging was also used to determine the points where external casing packers were to be placed in the casing string. The location of points where significant gas shows were encountered was determined to aid in the selection of zones where the well is to be stimulated (if required). Conventional geophysical logs were obtained as well as hydrocarbon mud logs.

\subsection{Mud Logging}

Mud logging of the well was initiated at a depth of 800 feet. A fairly complete record of shallow and deep sandstones, limestones, coals and shales was obtained. A record of all hydrocarbon gasses encountered was also made. This data was plotted on the $\log$ as units of hydrocarbon gasses per foot of depth drilled. This data was used in locating the intervals where external casing packers were located in the casing string. Mud logging was accomplished by capturing a portion of the return air stream and sending it through a gas chromatograph to determine the various components. The system was calibrated at the beginning of logging operations so that calculations could be made to estimate the volume of gas encountered by the drill bit. Appendix $H$ lists the depths and the calculated volumes of gas encountered during drilling operations.

\subsection{Shallow Hole and Free Fall Logging}

Original plans were to run a correlation gamma ray log from the surface to the bottom of the $121 / 4^{\prime \prime}$ hole, however, in an effort to reduce 
costs, the well was not logged until all drilling operations had been completed. The purpose in running the correlation logs was to accurately locate the Berea sandstone top for measurement to the planned kick-off point. The free fall logs were run to make sure that the entire wellbore would be logged since the side-door sub could not be moved downhole beyond the bottom of the $95 / 8^{\prime \prime}$ casing. This meant that only 2600 feet of inclined and horizontal hole could be logged by pushing the logging tools when attached to the drill string since the $95 / 8^{\prime \prime}$ casing was set at 2650 feet.

Free fall logs were obtained down to a depth of 4327 feet. The logging suite consisted of gamma ray, compensated density, temperature and differential temperature, and caliper logs. The logs revealed that the Berea sandstone was found at a depth of 2667 feet below ground level. The top of the Huron Shale was found at a measured depth of 3767 feet below ground level or 2944 feet below sea level.

\subsection{Horizontal Section Logging}

The inclined and horizontal sections of the well were logged by attaching the logging sonde to the front end of the drill string and pushing the tools through the open wellbore. Logging operations started at a depth of 3850 feet on the way in (labeled down log) and continued in to a total depth reach of 6360 feet. The down log was recorded in 60 foot sections which is the length of two joints of drill pipe which can be stacked on the rig floor. Depths were correlated by comparison with the strapping of each joint of drill pipe as it was run in the hole. When the up logs were run, a little slack left in the wireline cable which looped around the drill pipe and could not be pulled out. As a result the up logs were not scaled properly and were not usable. Strapping the pipe out of the hole and correlating the depth of each joint will prevent the accumulation of slack in the cable.

By using multishot survey data of the inclination of the borehole, the logging company was able to reconstruct a True Vertical Depth (TVD) presentation of the log. This TVD $\log$ is for correlation with nearby vertical wells to determine the various stratigraphic layers that were 
penetrated by the horizontal well. Figure 6.1 is a presentation of the TVD log of the well and the target interval of the well.

\subsection{MOTOR PERFORMANCE AND BOTTOM HOLE ASSEMBLIES}

\subsection{Introduction}

Motor performance during drilling of the inclined section of the well is extremely important and can have considerable effect on the overall economics of the drilling operation. BDMESC has attempted to determine the optimum motor to be used in the Appalachian area which is traditionally an air drilling country. Two motors were tested in this well to determine which motor would provide the best economics of operation. Eastman Christensen recently introduced a high torque air motor designed to build angle at a rate of $9.5 \% 100$. A Baker Hughes Drilling Systems adjustable bent housing motor was also used during the angle building phase of drilling operations. Initial plans were to test the motors under a high pressure system (600 psi) but those were changed to test the economics of lower pressure systems (200 - 300 psi) which are less costly and more readily available in the Appalachian area.

\subsection{Motor Performance and BHA's of the Angle Building Section}

The first motor to be run at kickoff point was the Eastman Mach IAD which is an air drilling motor. The motor drilled from 3253' to 4324' (1071') in four separate runs. The first run was from 3253' to $3487^{\prime}$ (234') in five hours. The motor was pulled to change the configuration because if was not building fast enough. The average rate of penetration was $46.8 \mathrm{ft} / \mathrm{hr}$.

The motor was run with an air rate of $2000 \mathrm{scfm}$. The bit contained three 16/32nd inch jets in hopes that the lower air velocity around the steering tool would prolong the life of the steering tool. The standpipe pressure was $290 \mathrm{psi}$ and the average calculated flow rate through the motor was $810 \mathrm{ppm}$. Oil was injected at an average rate of 10 gallons per hour. 


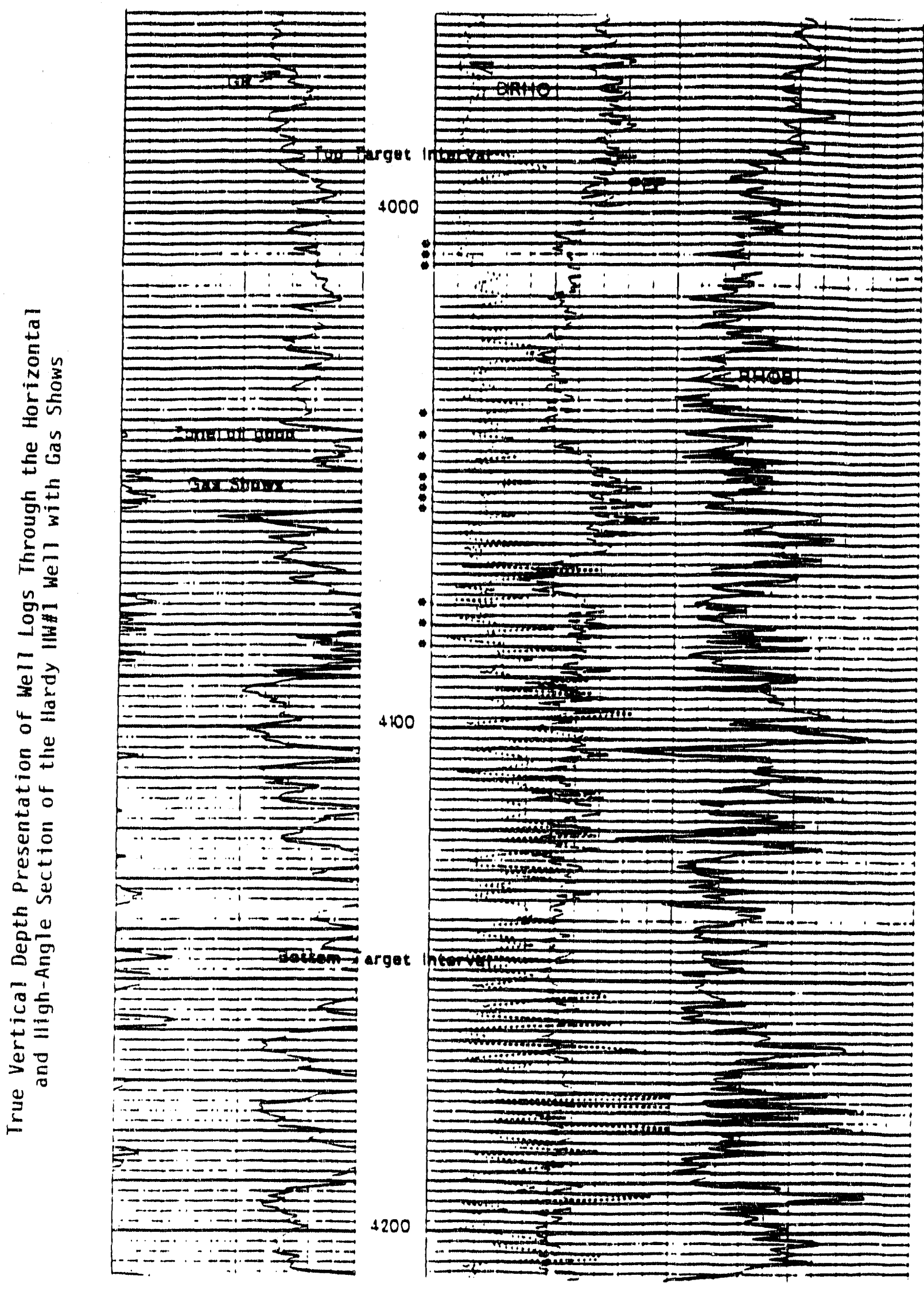

TVO LOG

Figure 6.1 
Initially, SAE 30 motor oll was used. Eastman indicated that a much higher viscosity motor sil would probably be better. The oil was changed to hammer oil which increased the standpipe pressure and slowed the motor penetration rate slightly. Changing back to the motor oll reduced standplpe pressure and increased penetration rate.

The bend in the motor had been set at $1.1^{\circ}$ with $83 / 8^{n}$ stabilizer near the bit and a 7-7/8" Integral blade stabilizer above the motor. The motor generated an average dogleg severity of 5.9\%/100'. According to Eastman, the motor should have built at $8 \% 100$.

Run number two was from $3487^{\prime}$ to $3603^{\prime}$ (116') in 2.75 hours. The motor was pulled because it was not building fast enough. The average penetration rate was $42 \mathrm{ft} / \mathrm{hr}$.

The bend in the motor had been set at $1.3^{\circ}$ (maximum) and the top stabilizer was left off. Eastman predicted the motor would build at $9.5^{\circ} / 100^{\prime}$. The operating parameters were the same as the first run.

The motor generated an average dogleg severity of $5.6^{\circ} / 100^{\prime}$ as calculated from the multishot data. The build rate still was not fast enough. The motor was pulled from the hole to make another adjustment.

On the third motor run, a $1.5^{\circ}$ bent sub was placed on top of the motor leaving the bend in the motor set at $1.3^{\circ}$. Eastman could not predict the build rate with their computer program. The third motor run drilled from $3603^{\prime}$ to $3817^{\prime}\left(214^{\prime}\right)$ in 6.75 hours. The average penetration rate was $31.7 \mathrm{ft} / \mathrm{hr}$. The average dogleg severity was $7 \circ / 100^{\prime}$ which still was not enough.

The motor was pulled and the hole size was reduced to $81 / 2^{\mathrm{N}}$. No jets were put in the $81 / 2^{n}$ bit in order to increase the penetration rate. The bent sub and housing were not changed. This fourth motor run drilled from $3817^{\prime}$ to $4324^{\prime}$ (507') in 10.75 hours. The average penetration rate was $47.2 \mathrm{ft} / \mathrm{hr}$. The average dogleg severity was $8.4 \% 1100^{\prime}$ which was not enough to hit the target TVD of 4010' but would allow the well to be horizontal at a TVD near $4100^{\prime}$. 
The equivalent flow rate throughout the motor was $1563 \mathrm{ppm}$ with a surface pressure of $185 \mathrm{psi}$. The oil rate was gradually reduced from 5 gallons per hour to no oil injection at all. However, there was still plenty of residual oil in the drill string.

The motor was pulled because the steering tool falled. At the time, its was not known whether the steering tool or the motor configuration caused the problem, so the Eastman motor was not rerun. The average rate of penetration of the Eastman motor was 42.0 feet per hour.

The Baker Hughes Drilling Systems Adjustable Bent Housing Motor was run slick (no stabilizers) with the bend set at the maximum of 2 degrees. Four separate runs were also made with the Baker motor. The motor drilled from 4324' to 4610'; a total of $370^{\prime}$. The total length drilled is more than the measured depth along the wellbore because the hole was sidetracked. Approximately 103 feet of side track was drilled which could not be used.

The first run with the Baker motor (motor run \#5) drilled from 4324' to $4374^{\prime}\left(50^{\prime}\right)$ in 1.25 hours. The average penetration rate was $40.0 \mathrm{ft} / \mathrm{hr}$. The motor was pulled because of a problem with the steering tool.

The second run (motor run \#6) drilled from $4374^{\prime}$ to $4422^{\prime}$ (48') in 1 hour. The average penetration rate was $48 \mathrm{ft} / \mathrm{hr}$ and the motor was again pulled because of steering tool problems.

The third run (motor run \#7) with the Baker motor sidetracked the well at 4338' and drilled to $4502^{\prime}$ when the steering tool failed. The motor drilled $164^{\prime}$ in 4.25 hours with an average penetration rate of 38.6 $\mathrm{ft} / \mathrm{hr}$.

The remainder of the build section was drilled with the fourth run (motor run \#8). The motor drilled from $4502^{\prime}$ to $4610^{\prime}$ (108') in 3.25 hours. The average penetration rate was $33.2 \mathrm{ft} / \mathrm{hr}$.

The only change made with the motor was to change the bit jets between runs number two and three. The jet nozzles were changed from one $11 / 32$ nd and two $14 / 32$ nds to two $11 / 32$ nds and one 14/32nds. For 
the first two motor runs, the equivalent flow rate through the motor was $622 \mathrm{gpm}$. For the last two motor runs, the equivalent flow rate through the motor was $549 \mathrm{gpm}$. Both flow rates exceed the manufacturers recornmended maximum, but no problems were experienced with the motor.

The flow rate at the surface was 1600 scfm. The surface pressure for all four motor runs ranged from 280 to 320 psi with the lower pressure corresponding to the larger jet sizes. The 300 psi pressure was selected to find out if the motors could be run without a high pressure air package. The high pressure package is not readily available in the area and is expensive to rent. Being able to drill with lower pressures would reduce the overall cost of the well.

Also, it was noted that taking the jets out of the bit with the Eastman motor increased the penetration rate. Using the larger jets in the Baker motor also increased the penetration rate. Larger jets increase the equivalent flow rate through the motor and therefore, the rpm. The Baker motor averaged $38.3 \mathrm{ft} / \mathrm{hr}$ in this well compared to $20 \mathrm{ft} / \mathrm{hr}$ in the DOESterling Drilling Roane County well. There was considerably more siltstone drilled in Roane County than Putnam County. No significant change in maximum bit weight was observed.

An air-mist drilling fluid system was not used with the Baker motor. For lubrication, SAE 30 motor oil was injected into the drill string at a rate of 5 to 10 gallons per hour. The motor operated the same as it had on the Roane County well which was drilled with an air-mist systern under 600 psi pressure. It seems likely that the high pressure reducing flow rate through the motor produced a lower penetration rate for the same motor.

The average dogleg severity generated by the Baker motor was $9.5 \% 100$. The dogleg severity in the Roane County well was also $9.5^{\circ} / 100^{\prime}$.

The Eastman motor had 25.25 drilling hours and 0.75 circulating hours (total 26 hours). The Baker motor had 9.75 drilling hours and 11.25 circulating hours (total 21 hours). The Baker motor had more circulating hours, because the pipe had to be pumped part way out of the hole each 
time the motor was tripped out. The Eastman motor had a faster rate of penetration by 3.6 feet but could not build angle at the well design rate of $8 \%$ feet of penetration. Table 7.1 compares the two motors during their eight motor runs.

\subsection{Rotary Directional Drilling Assemblies for Horizontal Section}

Two rotary, directional drilling assemblies were used to drill the horizontal/slant section of the well from $4610^{\prime}$ to total depth. The first assembly consisted of a $77 / 8^{\prime \prime}$ bit, float sub, 3-pt reamer, x-0 sub, and two monels. The assembly is the same as that used in the BDM/DOE Wayne County well except the button cutters in the 3-pt reamer had been replaced with flat cutters. Since the TVD was already deeper than desired, dropping much more inclination would not have been desirable. It was assumed that the flat cutters would reduce the dropping tendency or even cause a slight building tendency.

The building assembly is BHA \#6 in Appendix B. The assembly drilled from $4610^{\prime}$ to $5126^{\prime}\left(516^{\prime}\right)$ and built inclination at a rate of $0.7 \% 100^{\prime}$. No consistent walk tendency was established. The inclination at $5126^{\prime}$ was projected to be $95^{\circ}$, and the wellbore needed to drop through the rest of the target interval. Without running a dropping assembly, it would not have been possible.

Botttomhole assembly \#7 (Appendix B) was run to drop inclination at about 1 to $1.5 \% 100$. Unfortunately, it would not go into the sidetracked hole. Each time it was tried, the assembly would go into the hole that ended at 4422 '.

Bottomhole assembly \#8 was run as an alternative assembly. The assembly consisted of a $77 / 8^{\prime \prime}$ bit, bit sub, short drill collar $\left(10.75^{\prime}\right), 3$ pt reamer, $x-0$, float sub, and two monel drill collars and is considered a short pendulum assembly. The pendulum would probably drop faster than necessary, but the options were limited by the sidetrack at $4338^{\prime}$.

BHA \#8 drilled from 5126' to 5763'. One slight modification was made in the assembly at a depth of 5763'. To help reduce drag going into 
Table 7.1 Comparison of Rates of Penetration of Motors During Angle Bullding Drtlling

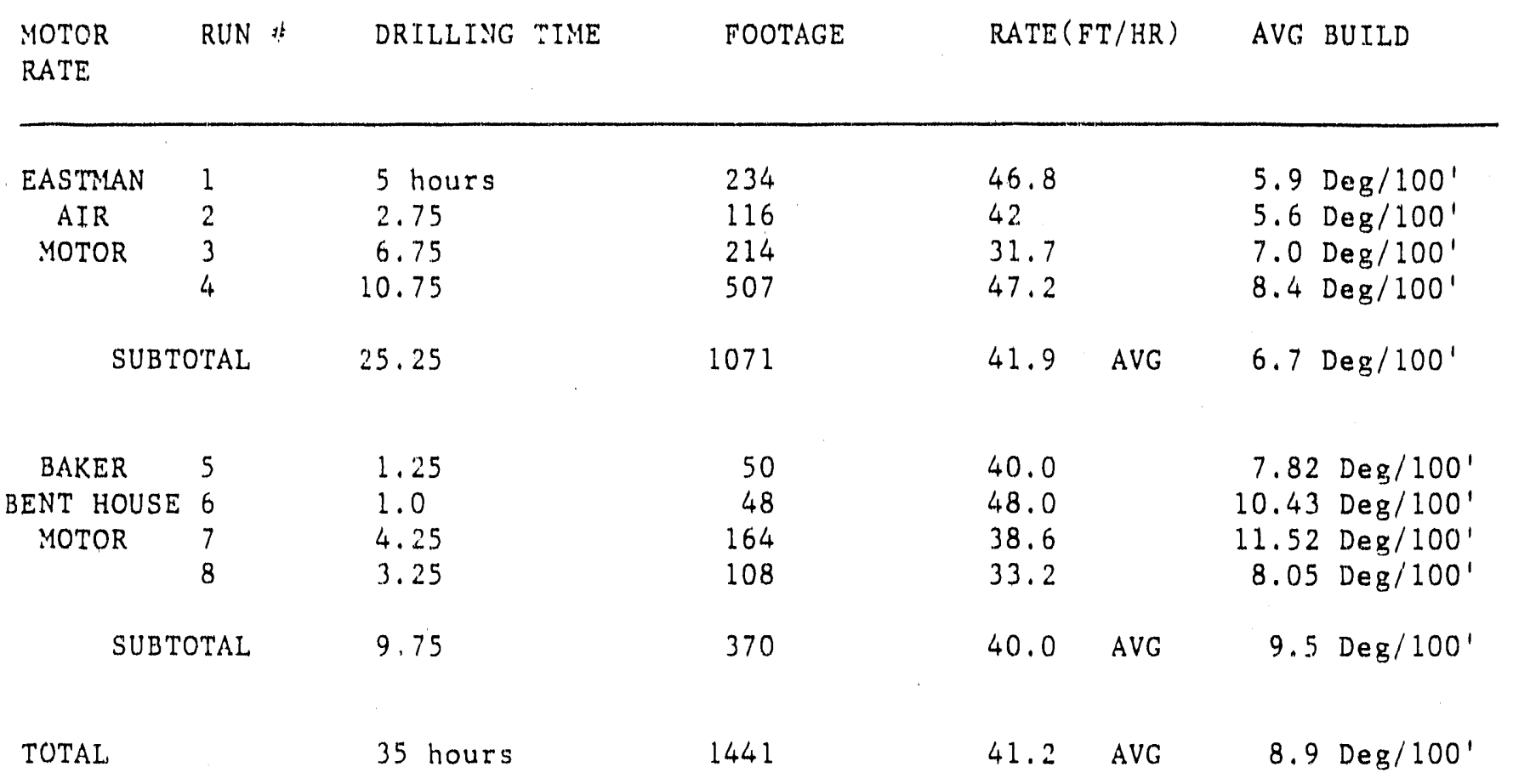


the hole, one of the two monels were laid down and is shown as BHA \#9 in Appendix B.

The average drop rates for BHA \#8 and BHA \#9 were 2.34\% 100 and $2.75^{\circ} / 100^{\circ}$, respectively. Because of the problems with the multishot surveys, the walk tendency of BHA \#8 can not be determined. BHA \#9 walked $1.94^{\circ} / 100^{\prime}$ to the left.

All the rotary assemblies were run with a bit weight of 20,000 to 25,000 pounds and rotary table speed of $60 \mathrm{rpm}$. The lower bit weight was to keep the drill pipe from bucking in the horizontal and build sections. Drill collars were placed at the top of the build section to provide the weight necessary to keep the drill pipe from buckling in the vertical section of the hole. The collars were also used to help push the pipe into the hole on trips and connections. The placement of the collars can be seen in Appendix B for each of the rotary assemblies when they were run in the hole. Drilling continued until the collars reached a maximum inclination of $45^{\circ}$. Then the pipe was tripped and the collars moved up the hole.

\subsection{DIRECTIONAL CONTROL OPERATIONS}

\subsection{Introduction}

in drilling a horizontal or slant well, one of the most important aspects of the drilling operation is obtaining data relative to the azimuth and inclination of the drill bit. In areas where mud is the preferred circulation medium, tools have been developed, which provide this data reliably and consistently, however, in the Appalachian area where air is used as the circulating medium, tools have not yet been hardened to provide reliable operations expected from mud drilling in other parts of the country.

\subsection{Steering Tool Operations}

Problems with the steering tool were the most costly and time consuming problems encountered during the drilling of the well. The steering tool had been pulled from the hole seven times because it was not 
performing properly. In addition, almost two days of rig time were spent waiting on steering tools.

Smith International had initially brought four, two axis probes to the location. The first probe operated without any problem from the kickoff point to around 3900' whe it failed. The probe apparently shorted out after the driller's panel was sfrayed with water on the rig floor.

The second probe was run and drilled 1.5 hours before it was pulled (at approximately $3960^{\circ}$ ). The tool face had been bouncing around and it became difficult to tell which way the motor was pointed. Even though the tool had not failed, a third probe was run inside a fiberglass case (instead of steel). The fiberglass case was supposed to reduce the vibration on the tool.

The tool face still bounced significantly while drilling and became progressively worse as the inclination increased. The air rate was lowered to as much as $1400 \mathrm{scfm}$ but it made no difference. Surveys had to be taken after connections because it took over ten minutes for the probe to settle down. As soon as the air was turned back on, the probe would again vibrate.

At a depth of 4249', the probe had turned $90^{\circ}$ to the right with respect to the motor tool face. Initially, it was thought that the motor had actually turned $90^{\circ}$. Drilling continued to $4324^{\circ}$ when the surveys indicated the well was turning left. In reality, the steering tool barrel had rotated with respect to the mule shoe stinger. A nut holding the mule shoe stinger fixed in place had vibrated loose allowing the barrel to turn while making a connection. The tool was pulled out and the motor tripped out to retrieve the stinger.

The third probe was run back in after repairing the barrel. Drilling continued for one half hour but the tool was bouncing around too much to get any good information out of it. The fourth and last probe was run and drilling continued for three quarters of an hour before it was pulled for the same reason. 
The probes would not give accurate tool face information above an inclination of $70^{\circ}$. A three axis probe was required. Eastman's steering tool which has a three axis probe was ordered out.

The Eastman tool was run in the hole. While tripping to bottom, the generator quit and had to be restarted. When power was returned to the tool, it was no longer working. Eastman felt that a power surge probably shorted out the tool.

The first tool was pulled and a second Eastman steering tool run. As soon as the air was placed on the well, the tool began to bounce around. A total of 48 feet was drilled, but the tool face was so erraic that it was not possible to tell which way the motor was oriented. The second Eastman probe was pulled from the hole and the drill pipe tripped out.

An attempt was made to orient the motor using Geoscience's Electromagnetic Measurement While Drilling Unit (EMWD) but the tool could not get a signal to the surface. No drilling was done with the EMWD while waiting for additional steering tools to arrive on location.

Smith arrived with two, three axis probes shortly after tripping out of the hole. The three axis probe was run and performed much better than the two axis probes. The tool face still bounced around but not enough to halt drilling.

On a connection at 4502', the steering tool again failed. The tool was pulled from the hole and the barrel was found to have parted above the probe. The pipe was tripped out of the hole to recover the remainder of the steering tool. The barrel was repaired and drilling continued to $4610^{\prime}$ when the desired inclination and direction were obtained.

Judging from the difference between the performance of the two and three axis probes, Smith's two axis probe was not capable of giving a reliable tool face above $70^{\circ}$. Smith had thought there would be no problem obtaining tool face; however, surveys would have had to be run to get inclination and direction. 


\subsection{MWD Tool Operations}

Geoscience Electronics has modified MWD tools which were used successfully in fluid systems for drilling river crossings for application in the harsh air drilling environment of the Appalachian Basin. The early system failures were related to extreme buffeting by the 2,000 to 3,000 cfm air flow volumes. These problems have been reduced by continued work with DOE so that they do not loom as a major factor in the potential application.

The tool was placed in the drill string for testing and use when the wireline steering tools had failed and while waiting on replacement probes. The system was tested on the surface when going in the hole, and again every 500 feet going down 3200 feet, but when the tool was in position at the bottom of the hole at 4222' (inclination of $83^{\circ}$ ) a signal with tool face orientation data could not be received back at the surface. Apparently the problem was a mixture of lack of signal strength caused by a mismatch in formation impedance. It would seem that impedance matching at the location based on offset well resistivity log data is a flexibility that will be required to make this unit function in any future horizontal well applications. A mid-drill string signal, repeater may be required to boost signal strength while maintaining battery life of the primary unit.

\subsection{ANALYSIS OF DRILLING OPERATIONS}

This drilling project was planned to be drilled in the most economic manner to obtain data for analyzing the economics of slant/horizontal drilling in the Devonian Shales. This report was prepared to discuss the results of new drilling techniques that were tested and the performance of current "off the shelf" technologies utilized during the drilling operations.

The major success during this drilling operation was the increase in the rate of penetration during the angle building phase of the operation. This is due to the use of high torque, low speed downhole motors which were operated at pressures of 250 to 350 psi with air flow rates ranging 
from 1700 to 2000 cubic feet per minute (cfm) of air. Another innovation was the use of oil which was injected at slow rates (5 gallons per hour) to lubricate the downhole motors. This method prevented damage to the formation from water in the normal foam-air mist system used and saved several thousand dollars in chemical costs for the air-mist mixture.

The biggest problem which continued to plague the air-drilling aspect of directional drilling was the steering tools which need to be hardened for air-drilling operations. This resulted in four or five additional days of daywork repair costs. Steering tool service companies are lagging behind in this aspect of directional drilling operations.

Another test was made of the electromagnetic measurement while drilling system (EMWD) which failed because the equipment could not put enough power into the signal so that it could be detected at the surface. There seemed to be a problem of impedance matching of the transmitted signal to the formation being penetrated. This system seems to have promise when the problem can be solved and the signal can be received back at the surface.

Mud logging operations have been very successful and useful on the air-drilled directional wells. Continuous monitoring of the air strearn has shown where gas was being produced from the target horizons and helped in the placement of external casing packers for completion operations. It would be difficult to know the formations penetrated without the use of a mud logging unit and sample examination.

Conventional geophysical logging operations continue to be difficult and fraught with numerous problems which can impact the quality of logs obtained. A good set of logs were obtained when the tools were being pushed into the hole on the drill string, but failure to keep proper tension of the line resulted in unusable logs on the return trip and the destruction of about 3,000 feet of logging cable.

The video $\log$, which is considered a key log in a horizontal well because of the information that can be obtained about the spacing and of natural fracture orientation, was a failure during this operation. Video cameras require special cables and, therefore, accommodating the cable in 
side-door subs and power connect operations seemed to be the major source of problems which produced the failure in the Hardy HW\#1 well operations. The tool worked to a point where the hole had reached ninety degree inclination when the "hot connect" which provided power for the lights and camera failed ostensibly because of the lack of slack in the line below the side-door sub.

\subsection{COMPLETION OPERATIONS}

\subsection{Introduction}

The completion design of the Hardy HW\#1 well was based largely on the results of the successful completion of the previous DOE-sponsored horizontal well in Wayne County, West Virginia (BDM/RET\#1). The BDM/RET\#1 well had been successfully completed with a 4-1/2" casing liner with 7 different zones being isolated from each other by inflatable casing packers. Access to each zone was provided by two port collars which could be open and closed using special tools. This system allowed testing, production, and stimulation of individual zones or group of zones as necessary.

The BDM/RET\#1 well was an experimental well and more zones were isolated for completion than would normally be done in a well completed for purely commercial purposes. One of the purposes for the Hardy HW\#1 well was to replicate the previous BDM/RET\#1 test, but to do so using drilling and completion technology more representative of that which would be more likely to be used by industry in a purely commercial well. Therefore, the completion design was limited to the identification of four zones for appropriate stimulations. Figure 10.1 shows each of the four zones on the welibore schematic and Figure 10.2 shows where the zones occur with respect to the true-vertical-depth (TVD) $\log$ of the well.

As can be seen from Figure 10.2, the best gas "shows" were in intervals at 4004-4010 feet TVD and 4050-4058 feet TVD. Both Zone 1 and Zone 2 penetrated the lower interval of good shows. Zone 4 penetrated both intervals of good shows. Zone 3 did not penetrate either of the two 


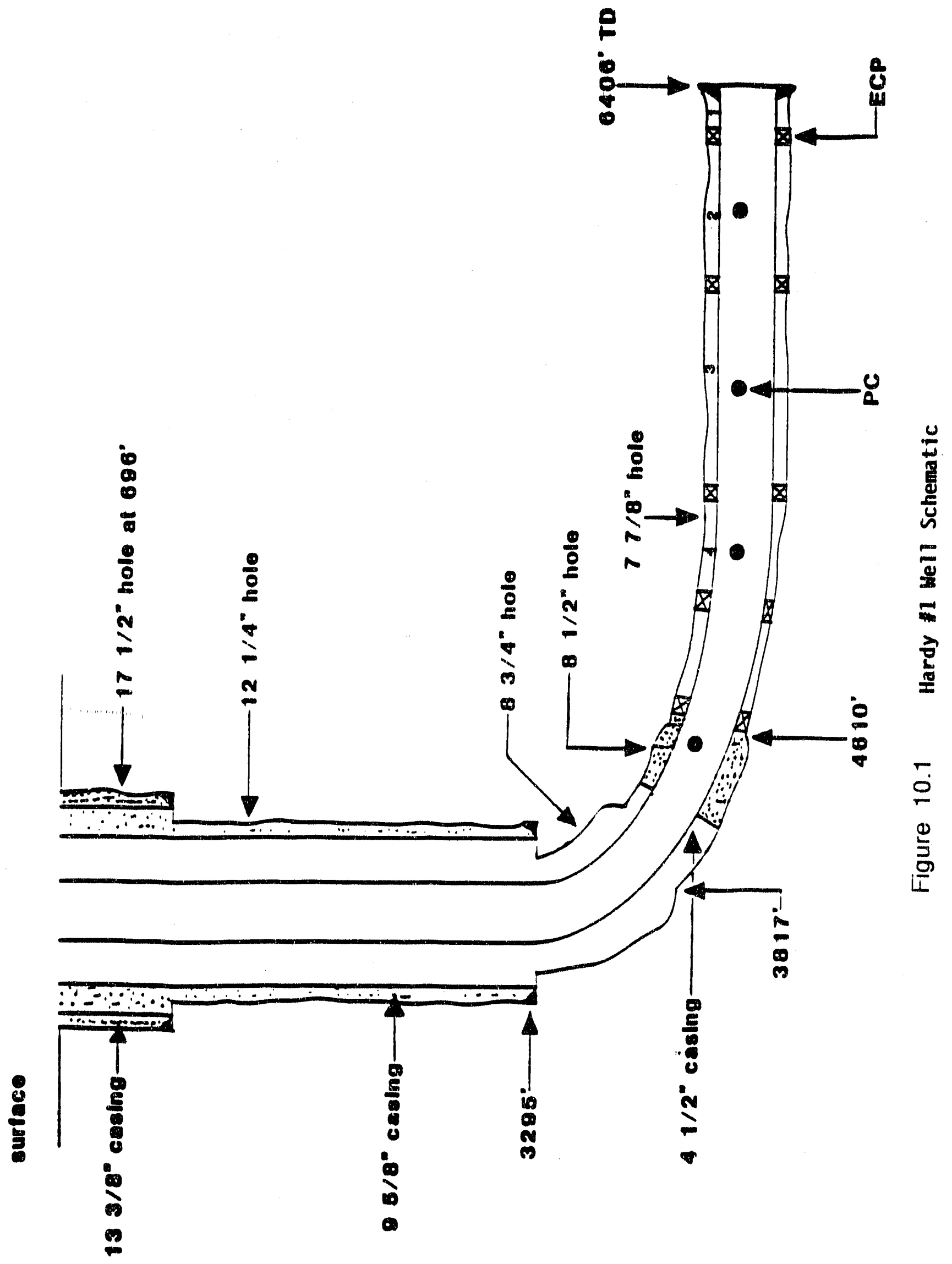


best intervals but did penetrate an interval which had gas shows at 4075 4081 feet TVD.

\subsection{Casing design}

In order to isolate the four zones for individual stimulation, the well was cased with 4-1/2 inch, 10.5\#/ft, J-55, ST\&C casing. Options considered for isolating the individual zones included conventional cementing of the casing with perforations to access the individual zones, use of inflatable casing packers in the casing string with port collars to access the zones as was done in the BDM/RET\#1 (Reference 1) well, a combination of these two techniques.

Because of the relatively successful completion of the BDM/RET\#1 well, the casing packer - port collar option was selected for completing the Hardy HW\#1. Five TAM International, Inc. casing packers were placed in the casing string at measured depths of $6014,5515,4765,4390$, and 4106 feet. The original completion plan called for 5 TAM International, Inc. port collars to be placed in the casing string with one of the port collars fitted with a "bull plug" for opening with applied pressure and another fitted with a "baffle" for opening by dropping a ball and applying pressure. This design should have allowed the farthest two zones to be accessed and stimulated with a conventional ball-and-baffle technique and without having to use an "opening tool" to open the port collars. The final design, however, utilized only three of the five avallable port collars because the two specially-fitted port collars could not be run. This was because of a decision not to complete the lower-most section of the wellbore and to isolate the section with a casing packer. The casing packer would have been impossible to inflate and set with the bull-plugged port collar above it. The three remaining port collars were placed in Zones 1,2, and 3. (The lower zone numbers indicate zones farthest from the wellhead.) Zone 4 was left without a port collar because it was in a position where it could be conventionally perforated using wireline equipment. A fourth "spare" port collar was placed above the shallowest casing packer for use in cemeriting the casing in that part of the hole. 
The size, weight, and grade of the casing, 4-1/2 inch OD, 10.5\#/ft, J55; respectively were designed to meet stimulation requirements. Based on hydraulic fracture treatments on nearby vertical wells, bottomhole treating pressures were expected to be approximately $1200 \mathrm{psi}$. Using the bottomhole treating pressure and service company friction factors for the injection of foam, tophole treating pressure for injecting 60 barrels per minute of 80 -quality foam down 4-1/2 inch casing was estimated to be less than $3500 \mathrm{psi}$. After derating the pipe to account for bending stresses in the inclined hole, it was determined that $10.5 \# / \mathrm{ft}, \mathrm{J}-55$ grade pipe would meet all design requirements.

\subsection{Inflation of Casing Packers}

The procedure selected for inflating the Tam International casing packers was to first inflate and then test the uppermost packer, (Packer \#5) which would be supporting the cement to be injected above the producing zone as a permanent water barrier. Upon the successful inflation of packer \#5 and cementing the casing above it, the remaining packers would be individually inflated and tested. If packer \#5 could not have been successfully inflated, then packer \#4, the next uppermost packer, would have been used to support the cement column. The fluid of choice for inflating the packers was nitrogen, a non-damaging fluid in the event of a packer element failure. After the inflation of a packer, the remaining nitrogen would then be used to inject into one of the zones adjacent to the packer while observing flow from the zone on the other side of the packer to verify the packer's integrity.

Packer \#5 was successfully inflated after two attempts. The close spacing (approximately two feet) of the inner cups on the TAM Combo Tool required precise positioning of the tool to inflate the packers. Normally, the tool is used to inject through port collars and the tool is automatically in position upon using the tool to open the port. To position the tool for inflating the packers, it was necessary to locate the nearest port collar, and then move the tool the measured distance to the packer. On the first attempt to inflate packer \#5, the tool apparently was located a few inches too low. The second attempt was successful after one of the inner cups on the Combo tool was removed to expand the working length of the tool to 2.9 feet. It was later learned that the Combo tool did not 
always provide positive identification of the port collars and that tubing drag could cause the port collars to be mislocated. The tool was later modified in the field to give it an even longer working length and to better centralize its opening dogs to provide positive engagement of the port collar shifting ring.

The procedure described above was used to individually inflate the remaining packers. With the modified tool, minimal problems were encountered in inflating the rest of the packers. Rig time to inflate the first packer, packer \#5, was approximately sixteen hours. Rig time to inflate the next packer using the longer tool (12-foot cup separation) was about 6.5 hours.

\subsection{Cementing}

Although the basic completion method for this well was essentially open-hole with a liner, one section of the casing was cemented in place. The casing immediately above the uppermost casing packer was cemented from approximately 4057 feet to 3500 feet measured depth with 130 sacks of Class A cement. The purpose of this cement was to establish a permanent barrier against any water that might enter the wellbore above the productive interval.

The cementing operation was conducted by pumping the cement through a port collar immediately above the upper most casing packer using TAM International's "Combo" tool. The Combo Tool is a speciallybuilt tool for selectively opening or closing ports while simultaneously providing the capability of injecting or producing fluids (e.g. cement slurries) via the tubing through an opened port between opposing cups on the tool. The cement was displaced from the tubing with water and a rubber plug. The cement was "overflushed" with approximately half a barrel of water, the plug was "bumped" with 800 psi, and the tubing head valve was closed. The port was left open and the combo tool left in place while the cemient set overnight because differential pressure on the combo tool cups prevented movement of the tool. Even though the cement had been flushed from the tubing with a half-barrel of excess water, the combo tool was difficult to move the next day. After it was recovered from the well, the tool was found to have several pleces of cement in it. 


\subsection{STIMULATION}

\subsection{Introduction}

The Hardy HW\#1 was stimulated with 80-quality foam and 20-40 sand as the proppant in Zones 1 and 2 . Zones 3 and 4 were stimulated as a single zone using nitrogen only as the working fluid. Only Zone 1 was stimulated as originally planned. The stimulation treatments for Zones 2,3 , and 4 had to be modified in the field in order to obtain at least partial success.

The initial stimulation designs for the Hardy HW\#1 well were based primarily on the favorable results of the stimulations conducted on the BDM/Eneger/DOE well in Wayne County, WV. Because of the ease with which the Wayne County stimulations were executed, the stimulations for the Hardy HW\#1 were very similar except that much higher rates were planned for the Hardy well. The high rates were used to assure adequate treatment volumes and rates for treating multiple fractures with sandladen fluid. Table 11.1 summarizes the stimulations originally planned and those which were actually performed on each zone. As is illustrated in the table, the original intent was to size the treatment volumes approximately proportionate to the length of the respective zones.

\subsection{Treatment of Zone 1}

As can be seen in Table 11.1, Zone 1 was expected to have the highest treating pressure of all zones. The zone was farthest from the wellhead and would be expected to have the highest frictional pressure loss. In fact, however, Zone 1 was found to have the lowest treating pressure, and was the only zone for which design rates and volumes were achieved.

The closure pressure for Zone 1 was estimated at approximately 1600 psig (bottomhole) based on stimulations of nearby vertical wells. The actual closure pressure based on the breakdown of the formation with nitrogen was about $1200 \mathrm{psig}$ (see Figure 11.1). Total frictional pressure losses were estimated to be 2800 psi based on service company correlations. Adding the friction pressure to the estimated closure 
Tabie 11.1

Suramary of Frac Treacments for the Hardy HW $\# 1$

Planned
Fluid Type
Voluwe (bbl)
Ame Sand (Ibs)
Rate (bpm)
Max. Pressure
(psi surrace)

Actual for eacin zone

Fluid Type

Volume (bbl)

Ame Sand (lbs)

Rate (bpm)

Treakng Pressure
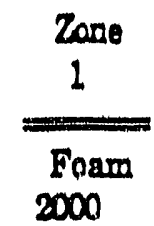

170,000

60

3800

1

Foam
1800
140.000
60
2000

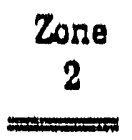

Foam

2800

250.000

60

3550

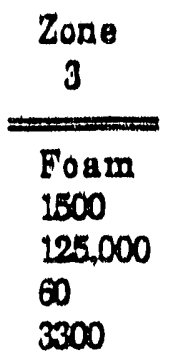

$2 \quad 3-4$ (Cominined)

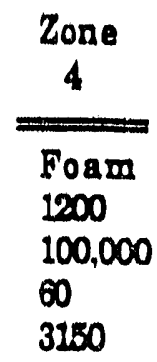

\begin{tabular}{ll}
\hline Foam & Nitrogen \\
450 & 420 (foam).1.8 mmei N2 \\
5000 & 8000 \\
20 & 60 bpm. 50.000 serion \\
$3200-4000$ & $3200-4000$
\end{tabular}

Table 11.2

Flow-dacx Summary ior Frac job on Zone-1

\begin{tabular}{|c|c|c|c|c|c|c|}
\hline \multirow{2}{*}{$\begin{array}{l}\text { ivater } \\
\text { Date }\end{array}$} & \multicolumn{2}{|c|}{ Gas Flow } & & \multicolumn{3}{|c|}{ Cnoke } \\
\hline & Tine & $\begin{array}{l}\text { Diameter } \\
\text { (incies) }\end{array}$ & $\begin{array}{l}\text { Pressure } \\
\text { psig) }\end{array}$ & $\begin{array}{l}\text { Recovery } \\
\text {. bbisis }\end{array}$ & $\begin{array}{l}\text { Recovery } \\
\text { (pew) }\end{array}$ & $\begin{array}{l}\text { Measurement } \\
\text { (mseriday) }\end{array}$ \\
\hline $02 / 1490$ & 1025 & 0.250 & 1200 & 0 & 0 & - \\
\hline $02 / 15 / 90$ & 0800 & 0.250 & 720 & 6 & 1.7 & - \\
\hline $02 / 15 / 90$ & 1100 & 0.375 & - & - & - & - \\
\hline $02 / 15 / 90$ & 1545 & 0.375 & $\ldots$ & 9 & 24 & - \\
\hline $02 / 1590$ & 1610 & 0.438 & 36 & - & - & - \\
\hline $02 / 15 / 90$ & 2330 & 0.563 & $\ddot{0}$ & - & - & - \\
\hline $02 / 1690$ & 00000 & 0.563 & 10 & 45 & 125 & - \\
\hline $02 / 1690$ & 0800 & 2.000 & 40 & 47 & 12.9 & 557 \\
\hline $02 / 1690$ & 1230 & 2.000 & - & - & - & 163 (mist) \\
\hline $02 / 16 / 90$ & 1530 & 2000 & - & 47 & 13.1 & 323 \\
\hline $02 / 17 / 90$ & 0800 & 0.375 & \pm 72 & - & - & - \\
\hline $02 / 17 / 30$ & 1100 & 0.563 &. & 56 & 15.5 & - \\
\hline $02 / 1790$ & 1700 & 0.563 & - & 60 & 16.6 & 267 \\
\hline $02 / 1890$ & $\infty 600$ & 0.563 & 493 & 60 & 16.6 & - \\
\hline $02 / 1890$ & 1600 & 2000 & - & 64 & 17.7 & 292 \\
\hline
\end{tabular}




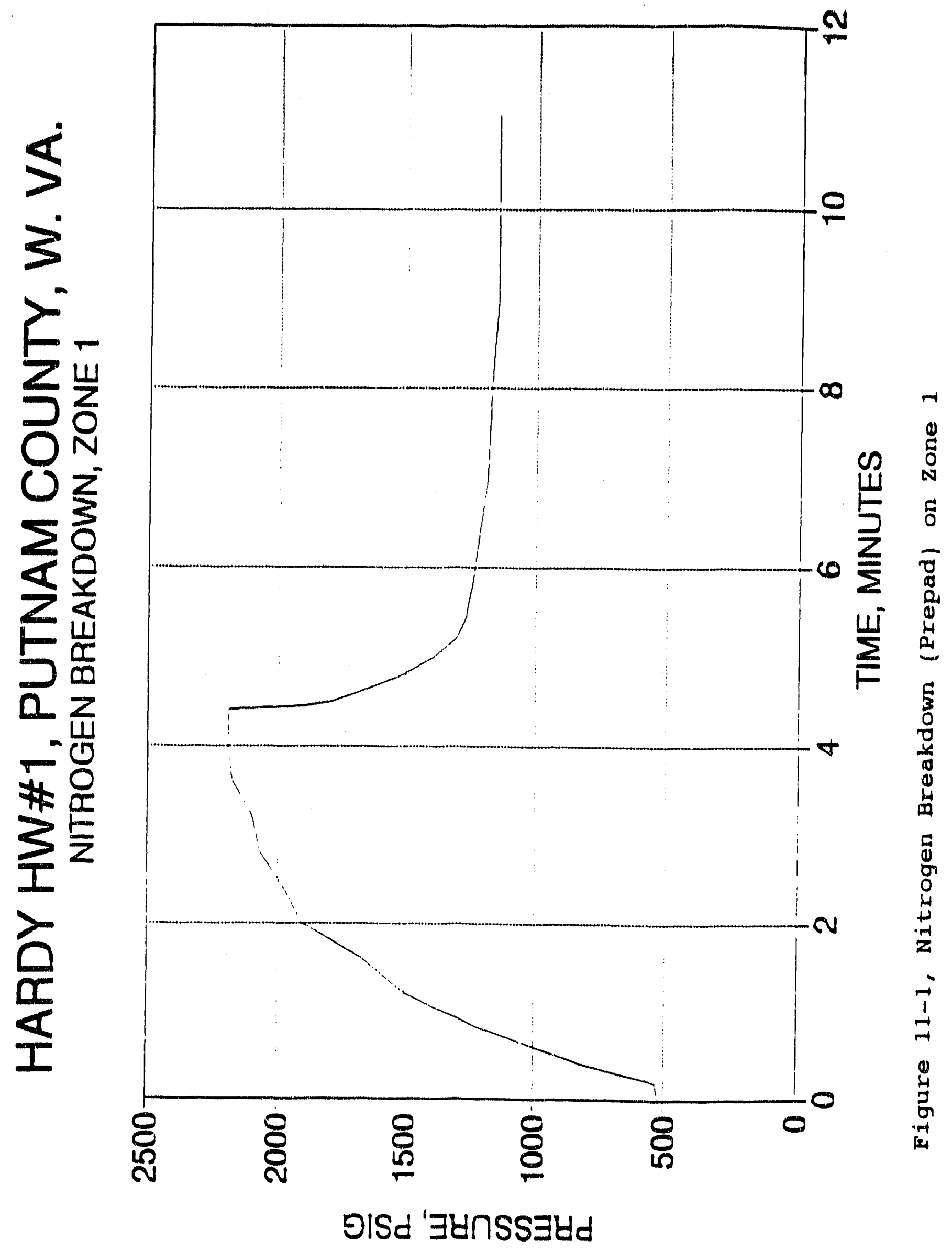


pressure of $1600 \mathrm{psi}$ and then subtracting the hydrostatic pressure of the foam column (approximately $600 \mathrm{psi}$ ) resulted in the estimated treating pressure of $3800 \mathrm{psig}$. The actual treating pressure never exceeded 3000 psig, however, suggesting either lower frictional losses, a lower closure stress, or both.

Most, if not all, of the difference in estimated versus actual treating pressure was due to lower-than-predicted frictional losses. Although the nitrogen breakdown indicated a closure stress of $1200 \mathrm{psi}$ or about 400 psi less than predicted, analysis of the shut-in period after stimulation indicated that closure stress had increased to approximately 1650 psi (see Figure 11.2). Therefore, the lower-than-expected treating pressure was due mainly to less total friction than predicted.

The stimulation of Zone 1 was executed with very few problems. The only major problem in execution resulted from malfunctioning service company monitoring equipment and a miscommunicaton of remaining sand volume. As a result, only 140,000 of the planned 170,000 pounds of sand was actually used in the job.

Following the treatment, the well was flowed back on a 0.25 -inch chake overnight. Choke sizes were then increased stepwise during the next two days of flow back to a full 2-inch opening. Table 11.2 shows the flow back summary for Zone 1 . Only 64 barrels or about $1 / 6$ of the treatment water was recovered during the flow back period. The gas open flow rate after being open eight hours on the fourth day of flow back was measured at $292 \mathrm{mct} / \mathrm{day}$.

\subsection{Treatment of Zone 2}

The overall plan for Zone 2 was to close the port collar to Zone 1, open the port collar to Zone 2, and then to stimulate Zone 2 with a foam frac treatment similar to, but proportionately larger than, Zone 1. Because of difficulty in being able to positively engage, open, and close the port collars with TAM International's "Combo Tool," an excessive amount of time was spent attempting to position the port collars for the stimulation of Zone 2. Over eighty hours of service rig time was utilized in attempting to position port collars and in placing a retrievable plug 


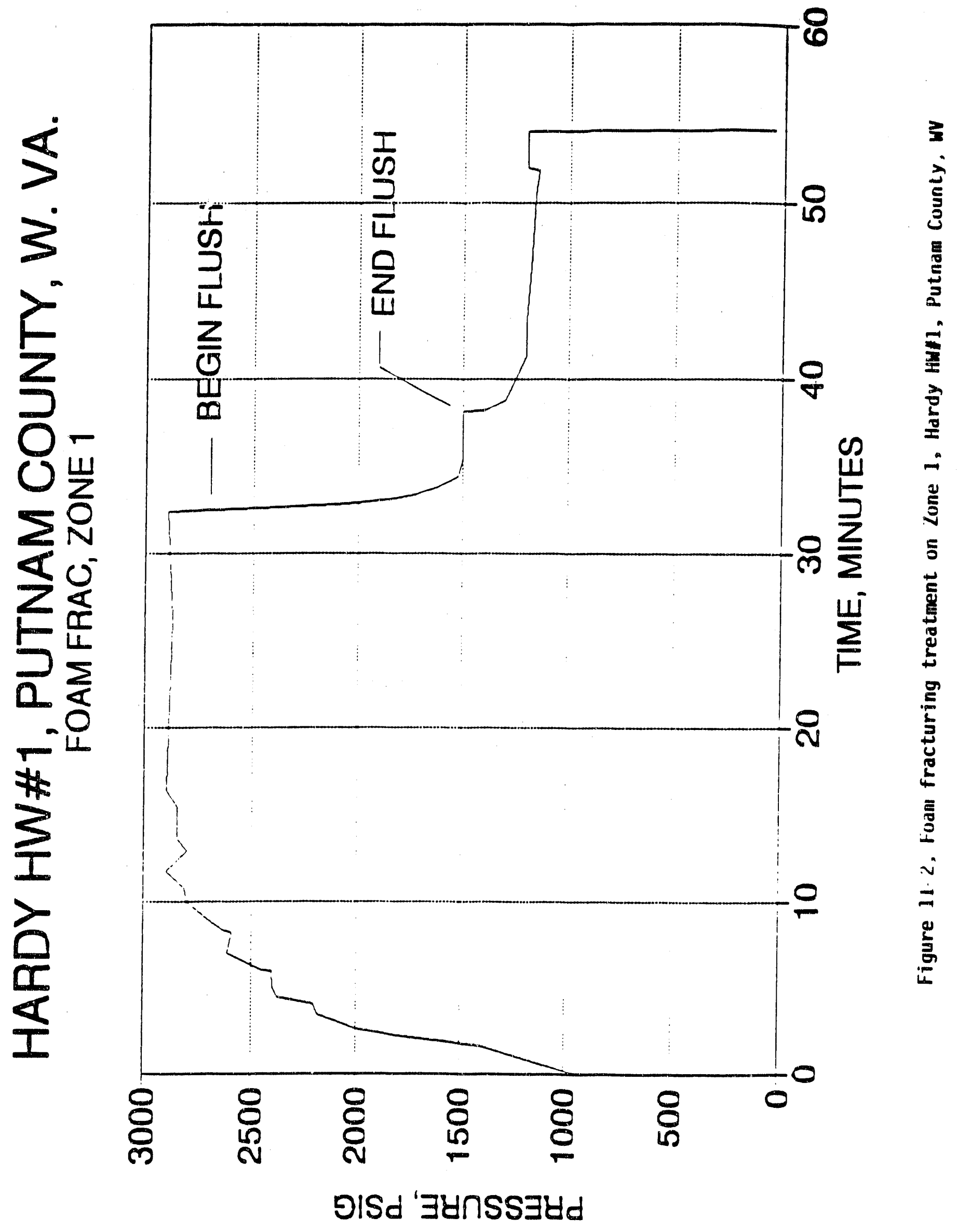


below the port collar serving Zone 2 prior to the first attempt to stimulate Zone 2.

After a series of unsuccessful attempts to close the port collar to Zone 1, an inflatable packer (plug) was placed in the casing between Zone 1 and 2. Initial attempts to set the packer by inflating it with nitrogen failed, and the packer was then set by inflating it with water. The port collar to Zone 2 was then opened so that the zone could be accessed for stimulation.

The first attempt to stimulate Zone 2 failed. Figure 11.3 shows the nitrogen breakdown chart for Zone 2. The similarities and differences between Figures 11.1 (Zone 1) and 11.3 (Zone 2) are worthy of note. Both curves flattened at about 1900 psig, but the pressure began to rise again on Zone 2 before flattening again at about 2300 psi. The falloff curves for the two zones are also quite different in that Zone 1 fell off rapidly dropping 800 psi within the first minute, then leveling off at about 1000 psi. Zone 2, on the other hand, took twice as long to drop 800 psi and never really leveled off at all except for a brief time at about 1300 psi. The distinct change in the rate of pressure decline at 1300 psi indicated a bottomhole closure pressure of approximately 1500 psig or about 300 psi more than was estimated from the nitrogen breakdown of Zone 1. The fact that the pressure continued to decline at a relatively rapid rate after fracture closure indicated that one or more natural fractures were continuing to accept nitrogen at a relatively high rate (2 to $3 \mathrm{mmscf} / \mathrm{day}$ ) even though pumping had ceased. As shown in Figure 11.3, the pressure declined to 800 psi within 13 minutes, after which pressure was no longer monitored.

During the initial nitrogen breakdown, a nitrogen pump truck malfunctioned causing an overnight delay in executing the frac treatment. On the day following the initial breakdown, a second breakdown or nitrogen "pre-pad" was injected into the formation. Injection rates were similar to the initial breakdown, but the pressure response was somewhat different (see Figure 11.4). The pressure climbed to nearly 3100 psig before leveling off compared to 2300 psig the previous day. It should be noted, however, that the final injection rate during the initial breakdown was only 24,000 scim compared to more than 30,000 scfm during the 


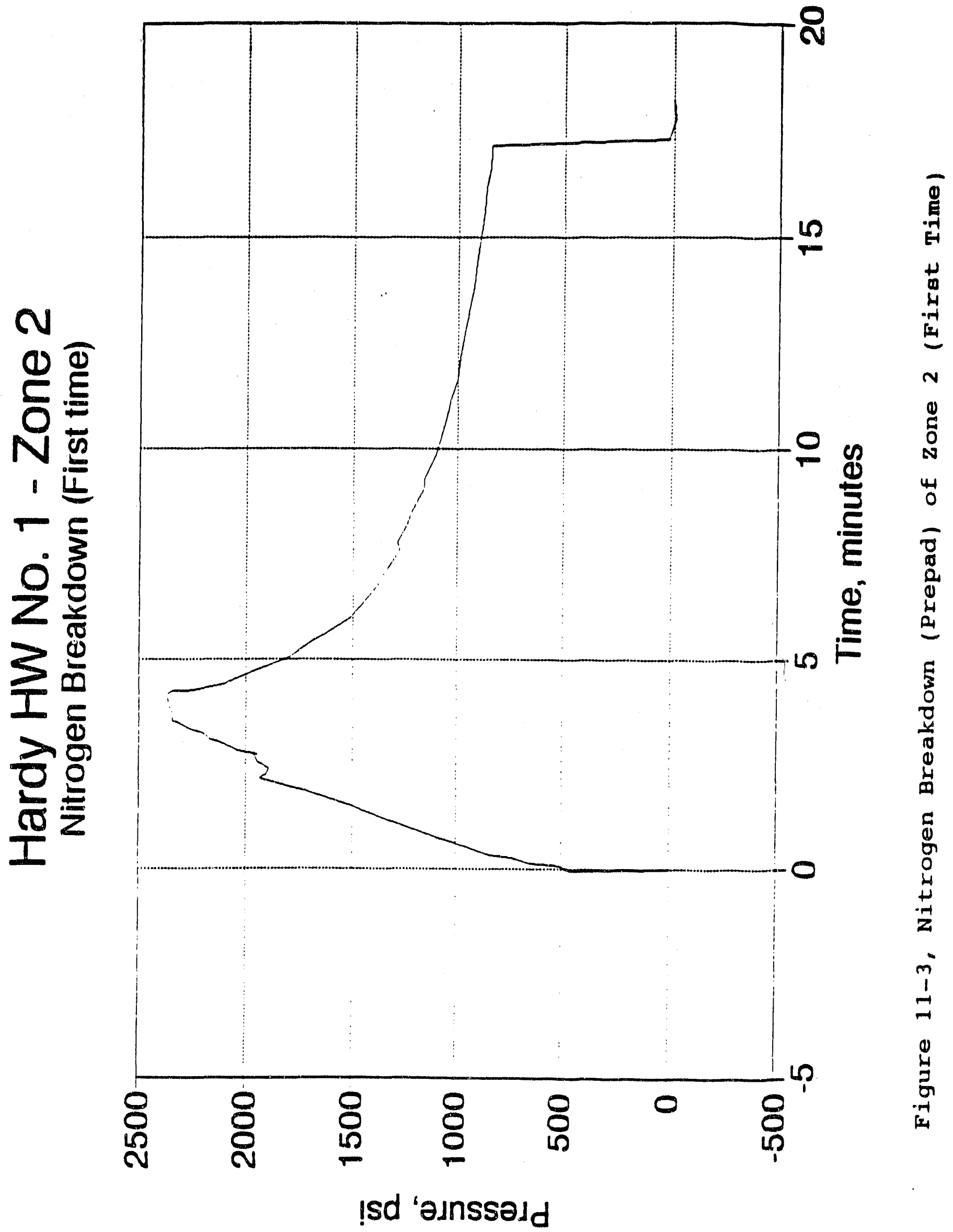




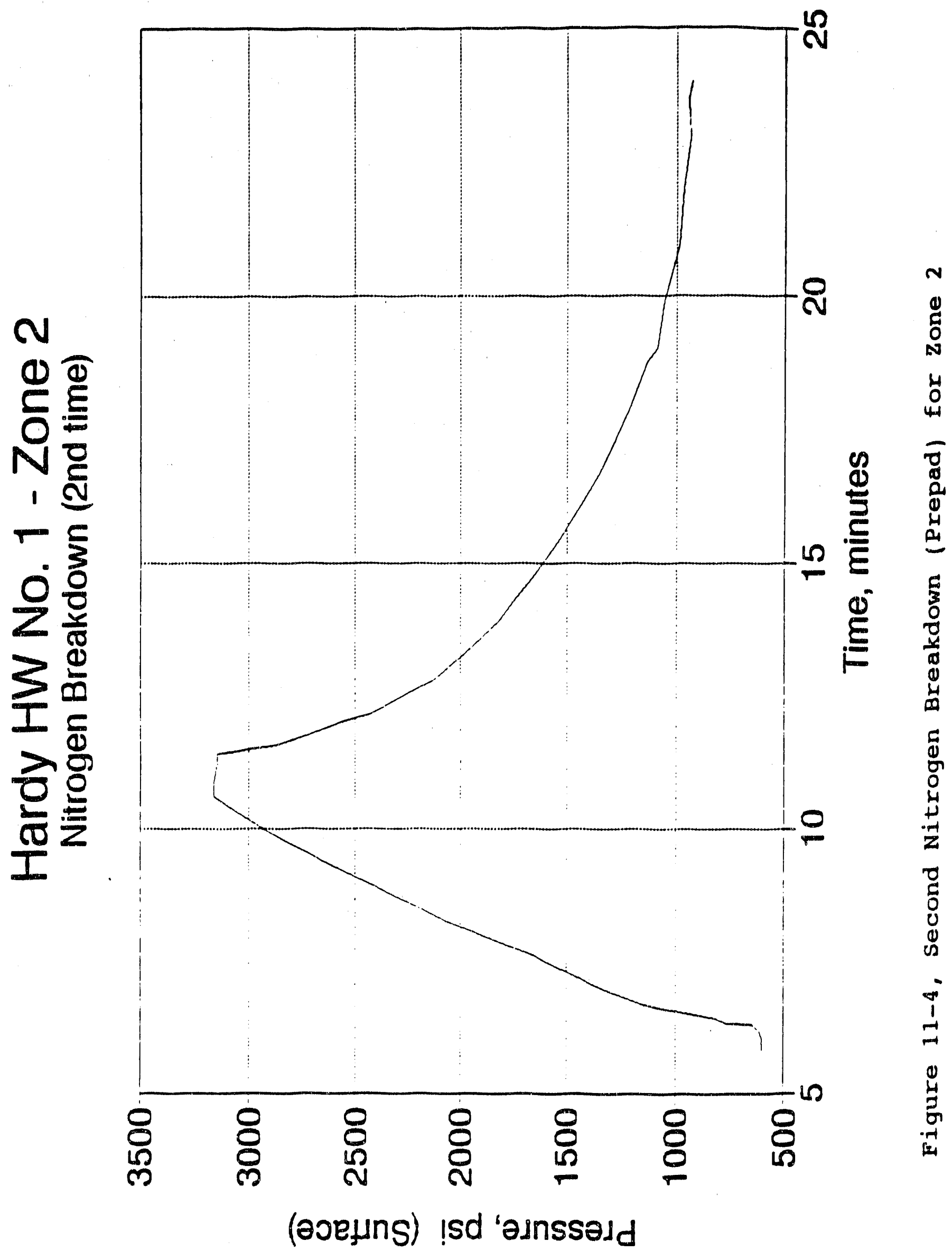


second injection period. Therefore, the increase in injection pressure was most likely due to the higher frictional losses associated with the higher rate.

After the nitrogen prepad was injected, a 50-barrel foam pad was injected at three rates increasing stepwise from $20 \mathrm{bpm}$ to $40 \mathrm{bpm}$ and 60 bpm. Figure 11.5 shows the pressure response that resulted from the foam pad injection. As shown in Figure 11.5, the injection pressure quickly grew to over 4000 psig, which was above the design safety pressure thus shutting down the frac job before any sand-laden foam could be injected.

Because of the apparent increase in frictional losses associated with this zone compared to Zone 1, it was believed possible that the retrievable packer had shifted after the initial breakdown and had partially blocked the port collar. After a series of attempts, the packer was finally retrieved and replaced by a new packer and another attempt was made to frac the well. Figure 11.6 illustrates that aborted attempt. On the possibility that the port collar accessing Zone 2 might be partially closed, the casing adjacent to Zone 2 was perforated with thirty 0.47 -inch holes to assure access to the formation and to minimize friction loss within the casing system.

After the 30 perforations had been placed in the casing adjacent to the zone, a final attempt was made at fracing Zone 2. Pressures associated with the nitrogen prepad injection are shown in Figure 11.7. The pressure response was typical of previous attempts, with the maximum pressure reaching over $3250 \mathrm{psig}$ at an injection rate of approximately $33,000 \mathrm{scfm}$. Figure 11.8 illustrates the predictable results at injection rates of 60 and $40 \mathrm{bpm}$ of 80 -quality foam. The job "sanded off" at approximately 17 minutes into the job while injecting a foam slurry with $1.5 \mathrm{lb} /$ gallon of $20 / 40$ sand. (See Figure 11.9).

\subsection{Analysis of Problems in Fracing Zone 2}

During the several attempts to frac Zone 2, various hypotheses were proposed to explain the peculiar behavior of the zone. These hypotheses ranged from downhole equipment problems to pre-stressing of the 


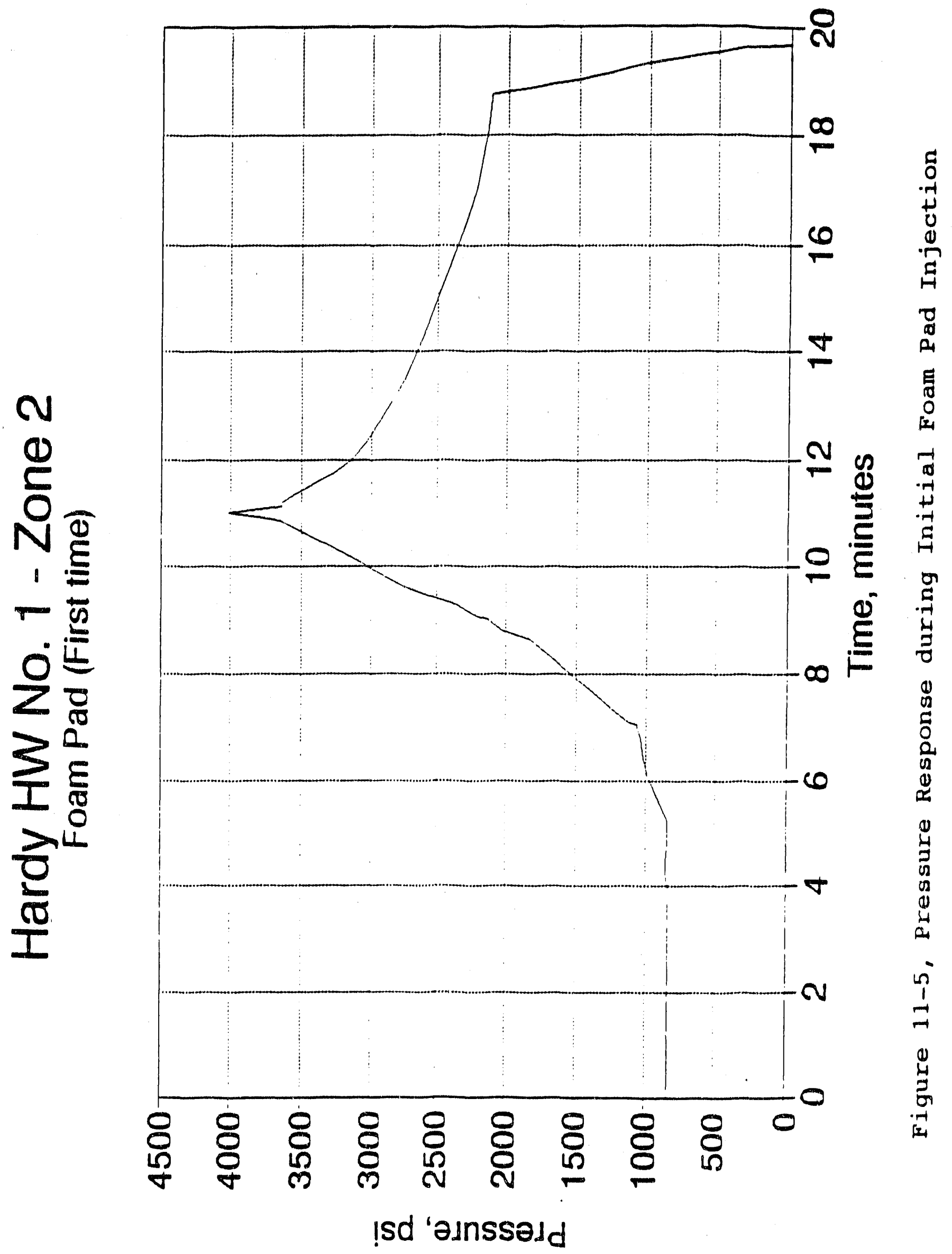




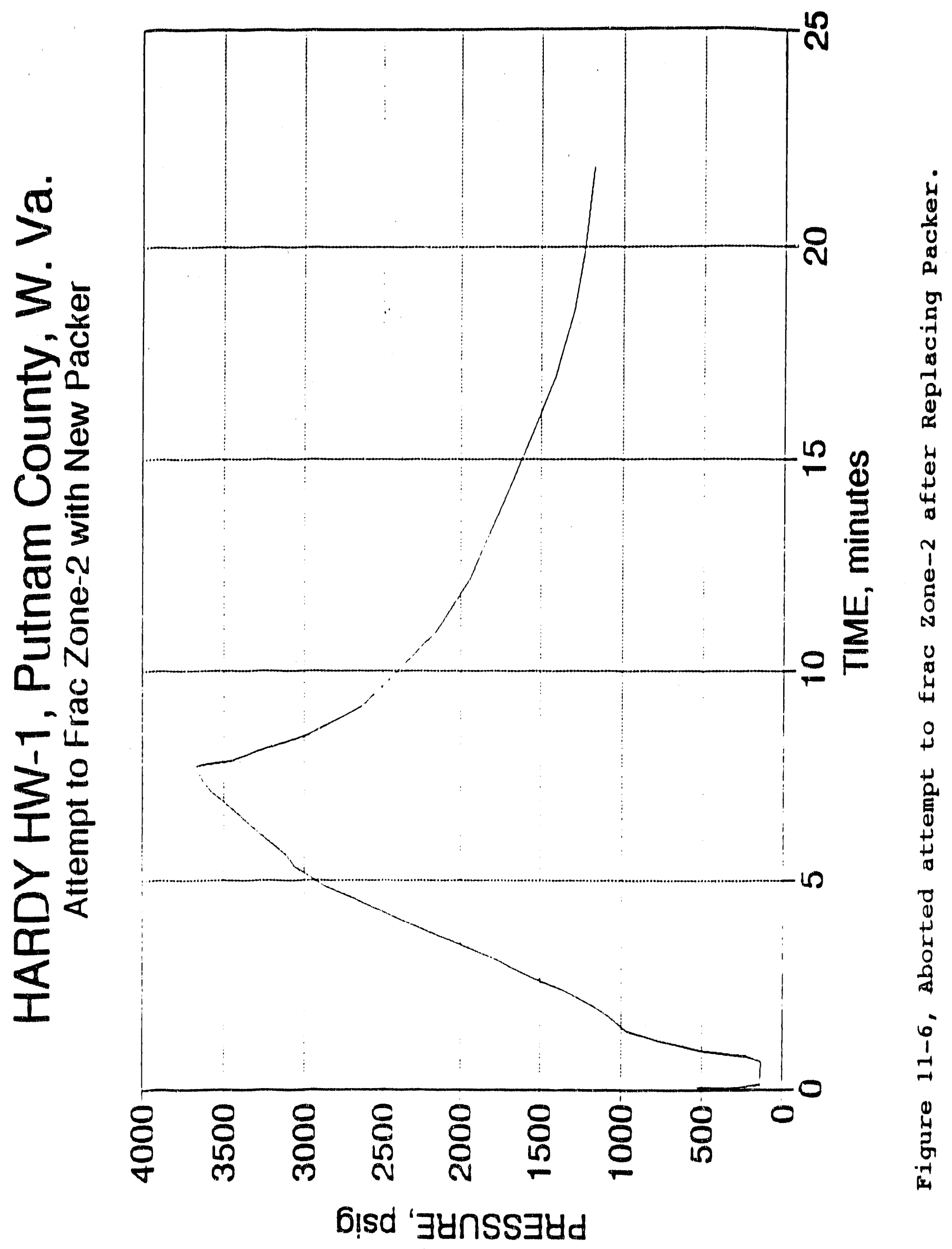




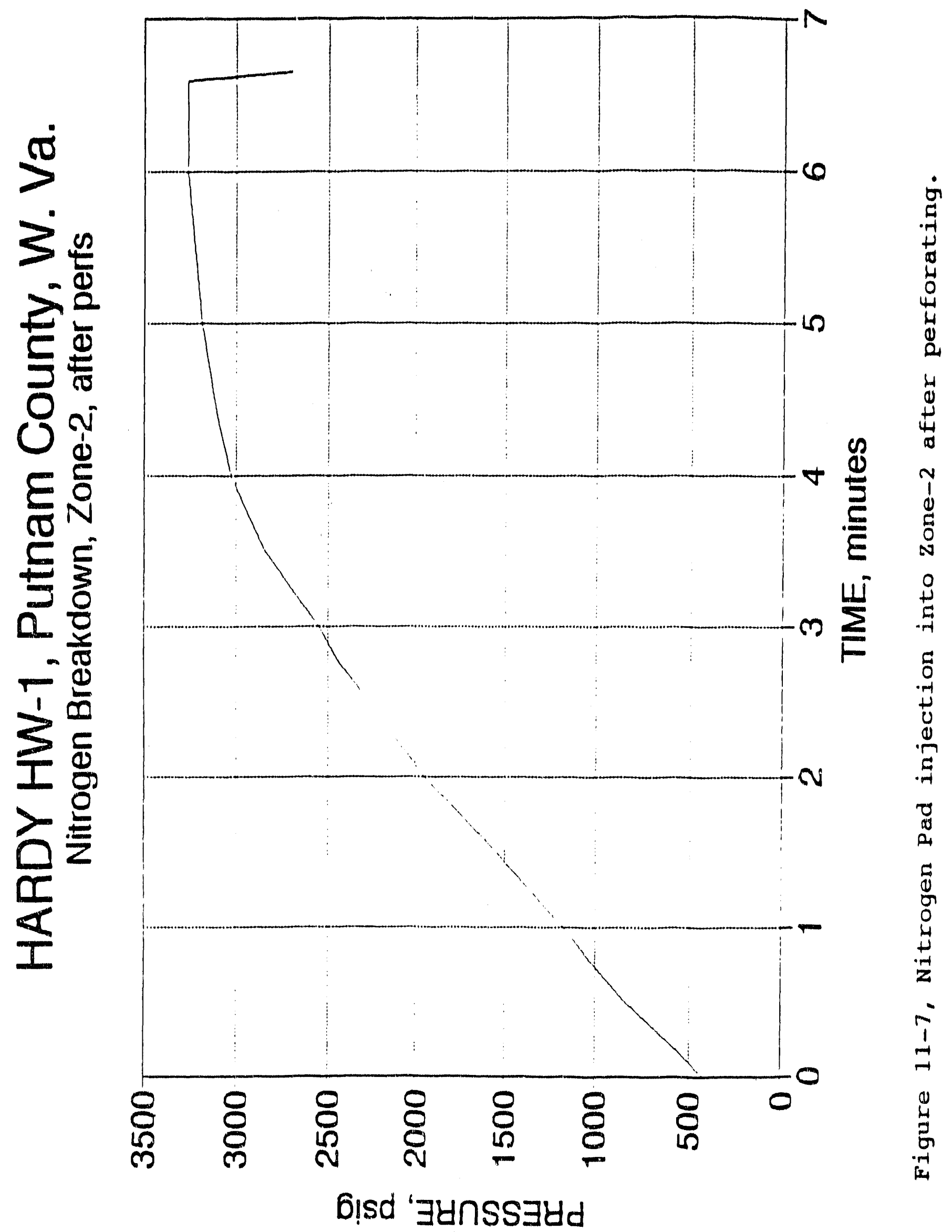



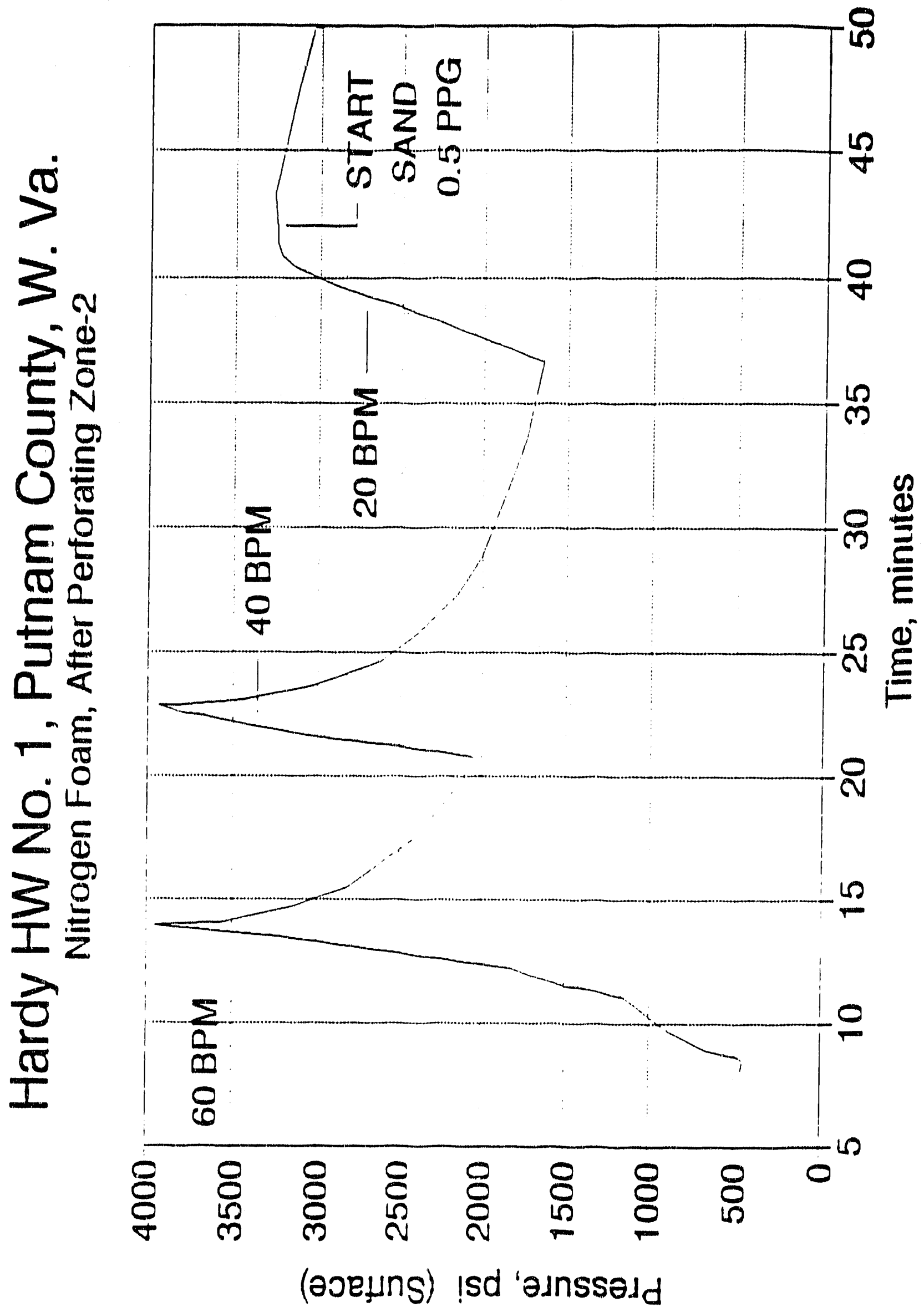

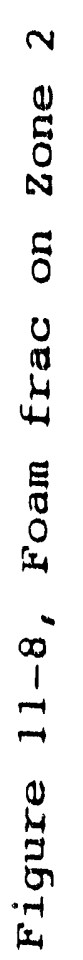




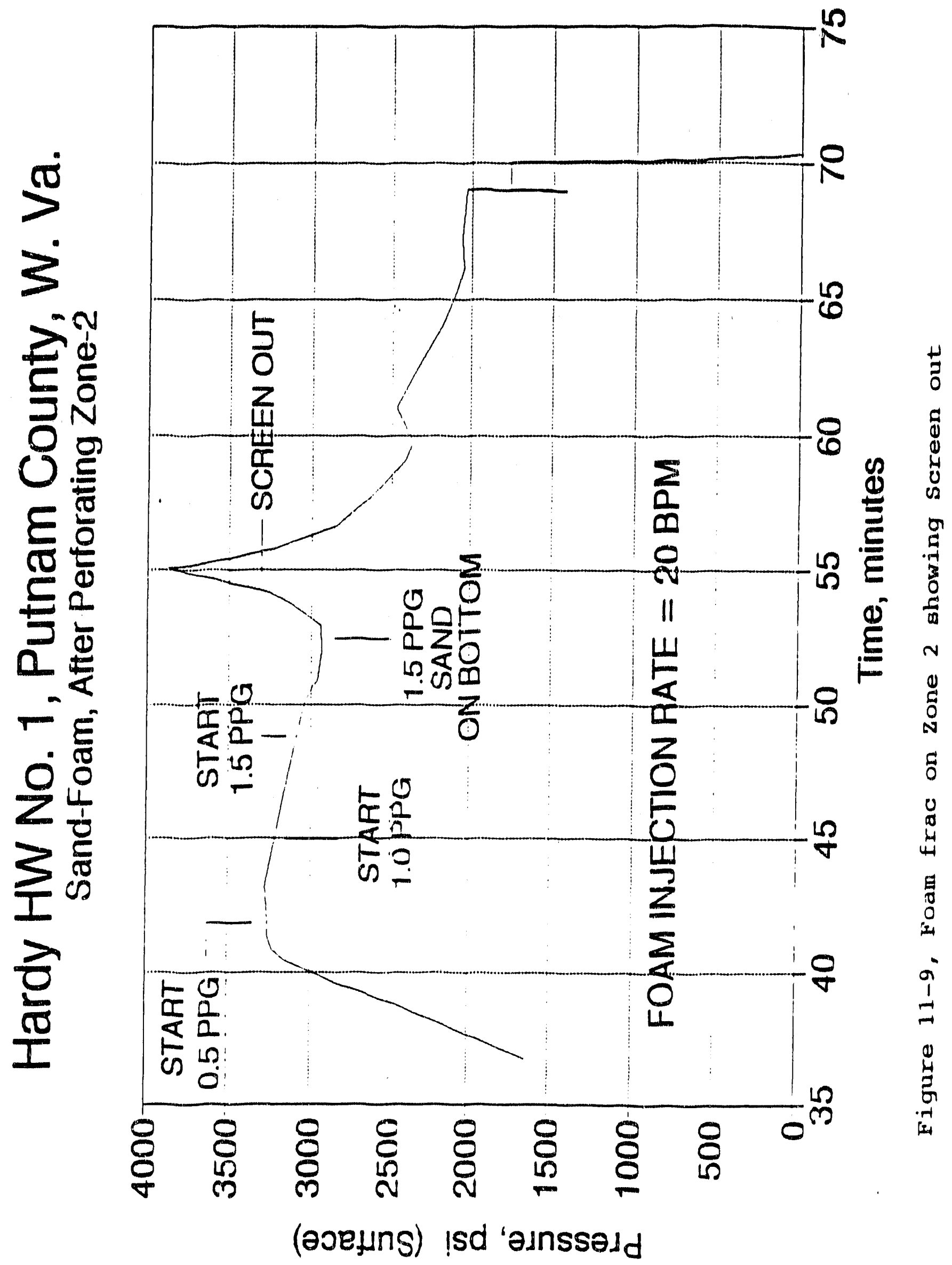


formation by the preceding frac treatment on Zone 1. Suggested explanations included the following:

1. Blockage of port collar by retrievable packer

2. Closed or partially closed port collar

3. Mud, sand, or rubble behind the casing

4. Zone 2 fractures filled by sand when Zone 1 was fraced.

5. Stress bulld-up in formation by prior frac in Zone 1.

6. Too many natural fractures to inflate for the avallable rate.

7. Interval too long for effective stimulation.

Initially, the first three suggested explanations appeared to have the most merit; however, after careful examination of the data, the latter two appear to be closer to the answer. The first two suggestions, both of which imply restricted exit from the casing, were essentially ruled out when additional perforations failed to correct the problem. Although explanation number three cannot be completely ruled out, it would seem - likely that loose material subject to cyclic fluid movement in the annular space behind the casing would cause more erratic pressure behavior than was observed. Likewise, explanation number four cannot be completely ruled out, but it does not seem likely to have occurred, especially at the pressures observed during the Zone 1 frac treatment. While frac fluids probably "leaked off" from Zone 1 into Zone 2, the movement of sand into Zone 2 fractures would have to have involved a fracture parallel to the wellbore, not a likely occurrence at the observed frac pressures.

Explanations six and seven are essentially the same in that a longer zone implies more fractures, and this is close to the most logical explanation. To initiate a fracture in shale in a horizontal wellbore in a plane other than one containing the wellbore itself, there must be preexisting natural fractures. Otherwise, the shale is so uniformly impermeable that it would be impossible for fluids to break out of the wellbore without first initiating a longltudinal fracture along the wellbore. The same problem exists with a uniformly permeable formation where the frac fluid enters the formation on a uniform front along the length of the horizontal wellbore. Since no differential stresses are created parallel to the wellbore except at the very ends of the injection 
zone, it is nearly impossible to create a fracture that is perpendicular to the wellbore, regardless of the minimum stress orientation. A situation similar to this very well may have existed in Zone 2.

Zone 2 had a number of fractures recorded on the mud log. Based on the abllity to inject nitrogen into the zone at relatively high rates (2-3 mmcfd) while at relatively low pressures (less than $1100 \mathrm{psig}$ ), it would appear that several fractures were capable of accepting fluld. If these fractures are in clusters of relatively closely-spaced fractures, then it may have been almost impossible to drive one or more fractures perpendicular to the wellbore and of a width sufficient to accept a highdensity sand-laden fluid. Figure 11.10 illustrates the difficulty of inflating closely-spaced fractures from the horizontal wellbore. At the final rate of $20 \mathrm{bpm}$ with foam and $1.5 \mathrm{ppg}$ sand, the estimated bottomhole treating pressure was over 4000 psig, far above the calculated minimum horizontal stress value of approximately $1500 \mathrm{psig}$.

\subsection{Stimulation of Zones 3 and 4}

After the extreme difficulty encountered in fracing Zone 2, plans for the stimulation of Zones 3 and 4 were modified. A shrinking budget necessitated reducing the cost of the remaining stimulation work. Therefore, Zones 3 and 4 were combined and stimulated as a single zone (Zone 3-4). Because a large amount of sand remained on location after the failure to execute the large treatment on Zone 2, another high volume, high rate foam frac was attempted on Zone 3-4.

Zone 3-4 was perforated with 42 holes between measured depths of 4207 and 4476 feet. Ten of the holes were in Zone 3 between 4430 and 4476, measured depth, and 32 holes were in Zone 4 between 4207 and 4370 feet, measured depth. The "select-fire" perforating gun on rollers fell freely to 4420 feet ( $81^{\circ}$ of inclination from vertical) and was pumped to 4476 ( $85^{\circ}$ using nitrogen (8000 scfm).

Zone 3.4 was then stimulated with an 80-quality sand-laden foam. Figure 11.11 shows the pressure response during the stimulation of Zone 34. Sand concentration reached a maximum of $1.5 \mathrm{lbs} / \mathrm{gal}$ into the fracture(s) before "screening out." This screen-out was similar to the 


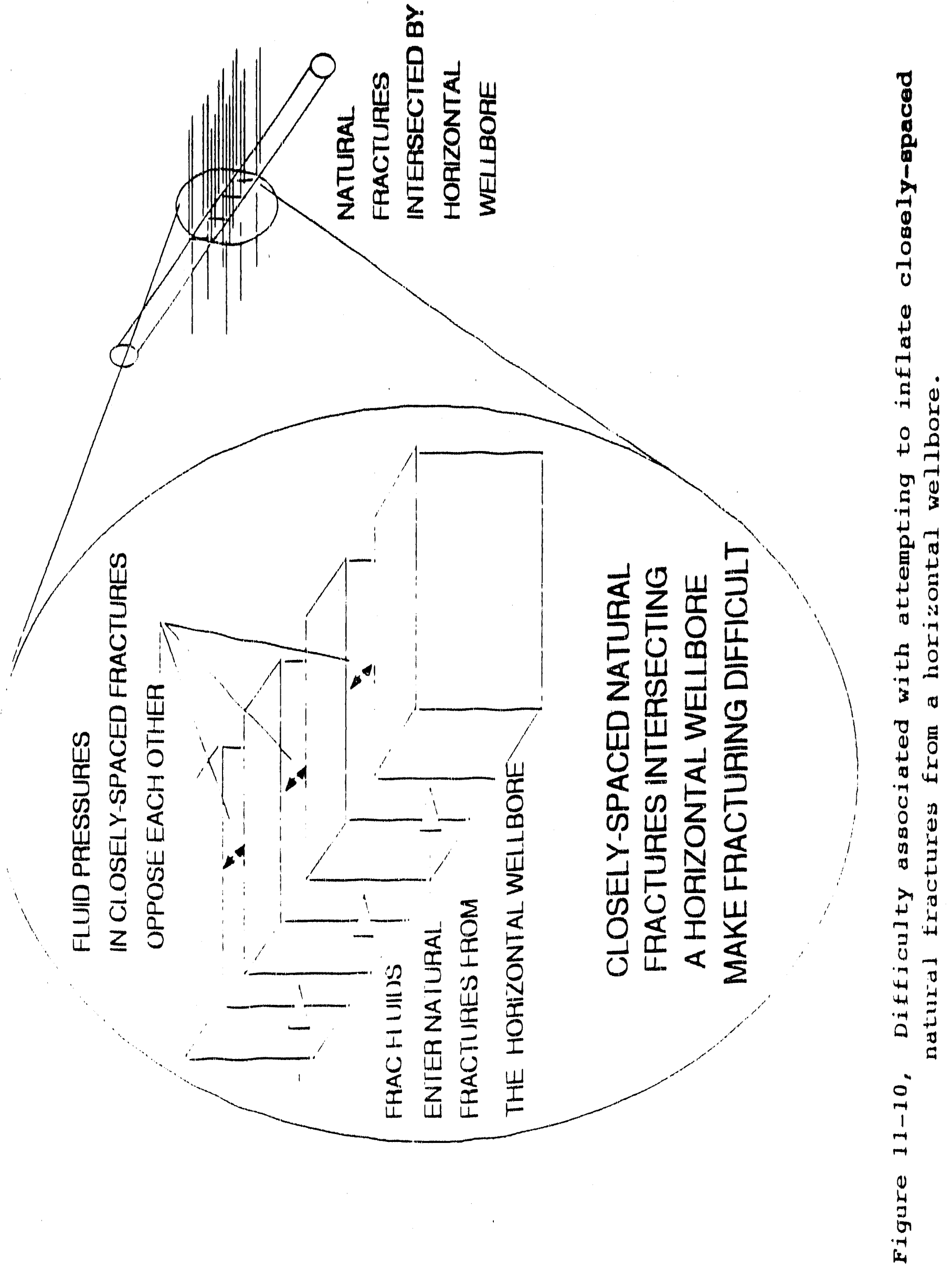




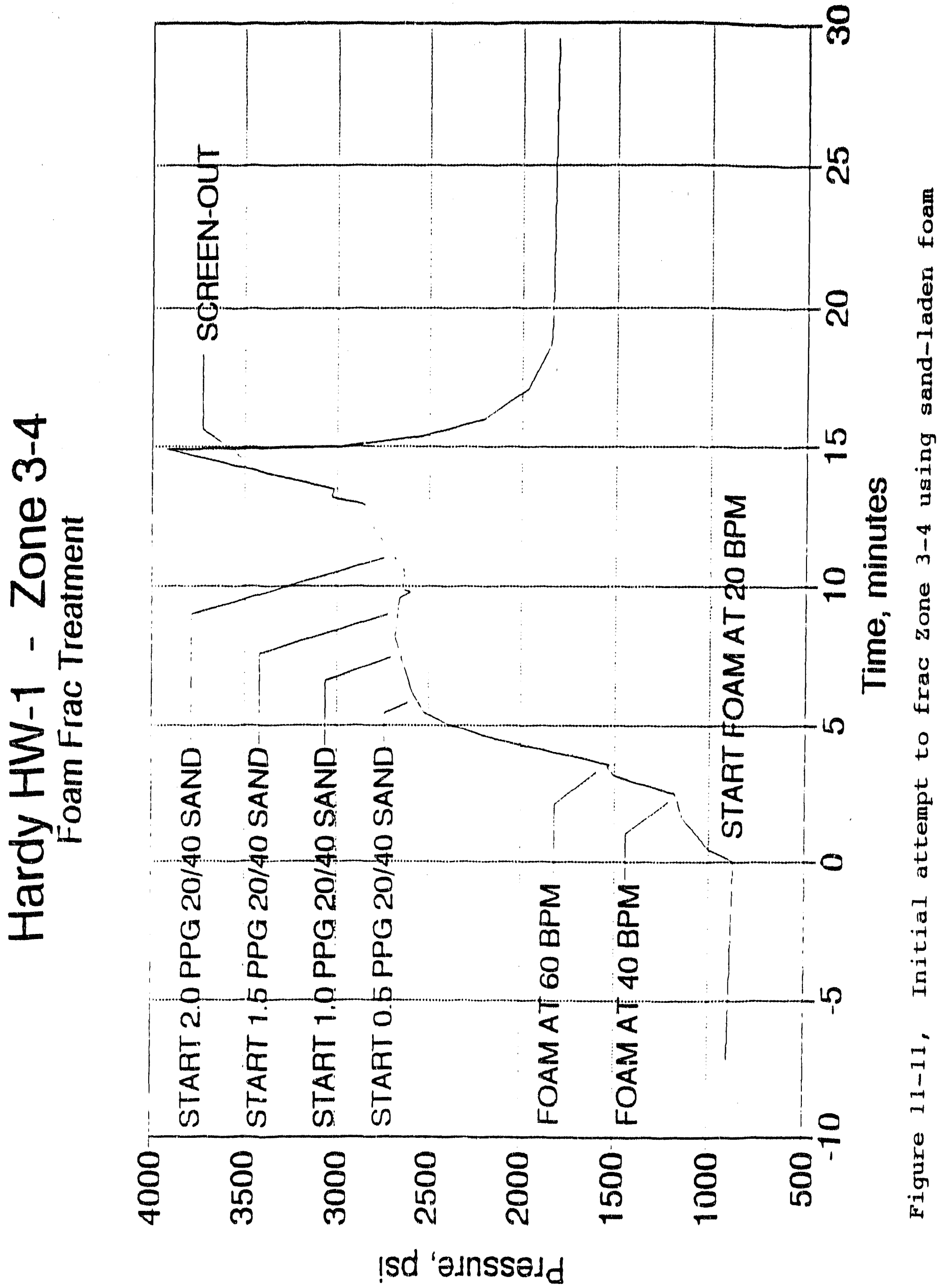


screen-out in Zone 2 in that the maximum sand concentration reached was $1.5 \mathrm{lbs} / \mathrm{gal}$; however, the Zone 3-4 screen-out occurred while foam was being pumped at $60 \mathrm{bpm}$ compared to $20 \mathrm{bpm}$ that had been pumped into Zone 2. In both cases, however, the screen-outs occurred almost simultaneously with the arrival of the $1.5 \mathrm{lbs} / \mathrm{gal}$ sand concentration at the formation face. Prior to the screen-out in Zone 3-4, nitrogen breakdown and pre-pads of $134 \mathrm{mcf}$ and $135 \mathrm{mcf}$ had been injected at $35,000 \mathrm{scfm}$ and $1900 \mathrm{psi}$ (surface). Just prior to the screen-out, the surface injection pressure was approximately 2700 psi (estimated BHP was 1600 psi. based on service company correlations). Total sand-laden fluid injected into the formation was only 1000 gallons.

After partial clean-up of fluids from the first attempt to foam frac Zone $3-4$, a second attempt was made. During this attempt, no sand was injected. Very quickly, after the arrival of the 80 -quality foam at the formation face, the injection pressure rose to $3700 \mathrm{psi}$ (surface) and the treatment was halted (Figure 11.12). The foam was allowed to flow back from the well and the treatment was continued using only nitrogen. The final stimulation of Zone 3-4 consisted of 2,867,000 scf of nitrogen injected at an average rate of $50,000 \mathrm{scfm}$. The treating pressure ranged from 2850 to 3400 psi (surface) with the highest pressure being recorded within the first four minutes after restart of the treatment with nitrogen (Figure 11.13).

\subsection{Analysis of Problems in Fracing Zone 3-4}

Unlike the problems associated with fracing Zone 2, the problem of fracing Zone 3-4 appeared to be a more conventional screen-out. Zone 2 treated at $20 \mathrm{bpm}$ with a bottomhole pressure of about $4000 \mathrm{psi}$, but Zone 3-4 treated at $60 \mathrm{bpm}$ with a bottomhole pressure of approximately 1600 psi immediately prior to the screen-out.

Zone 3-4 was also a candidate for injection into multiple fractures simultaneously. This would also help explain the screen-out in that the multiple fractures would cause the equivalent of high fluid loss, limiting the achievable bottomhole pressure and, hence, the average fracture width. Once a number of these fractures became filled with sand near the 


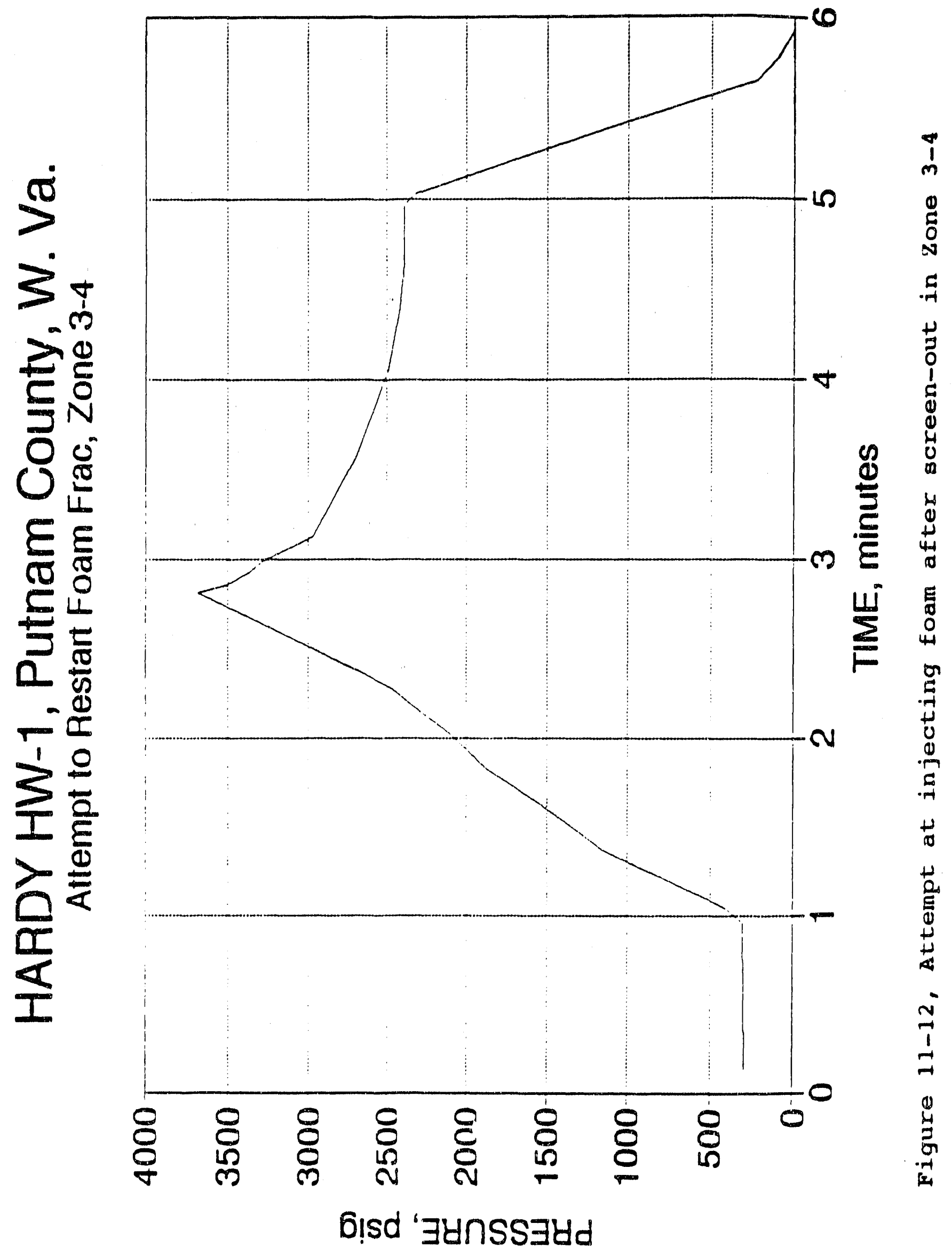




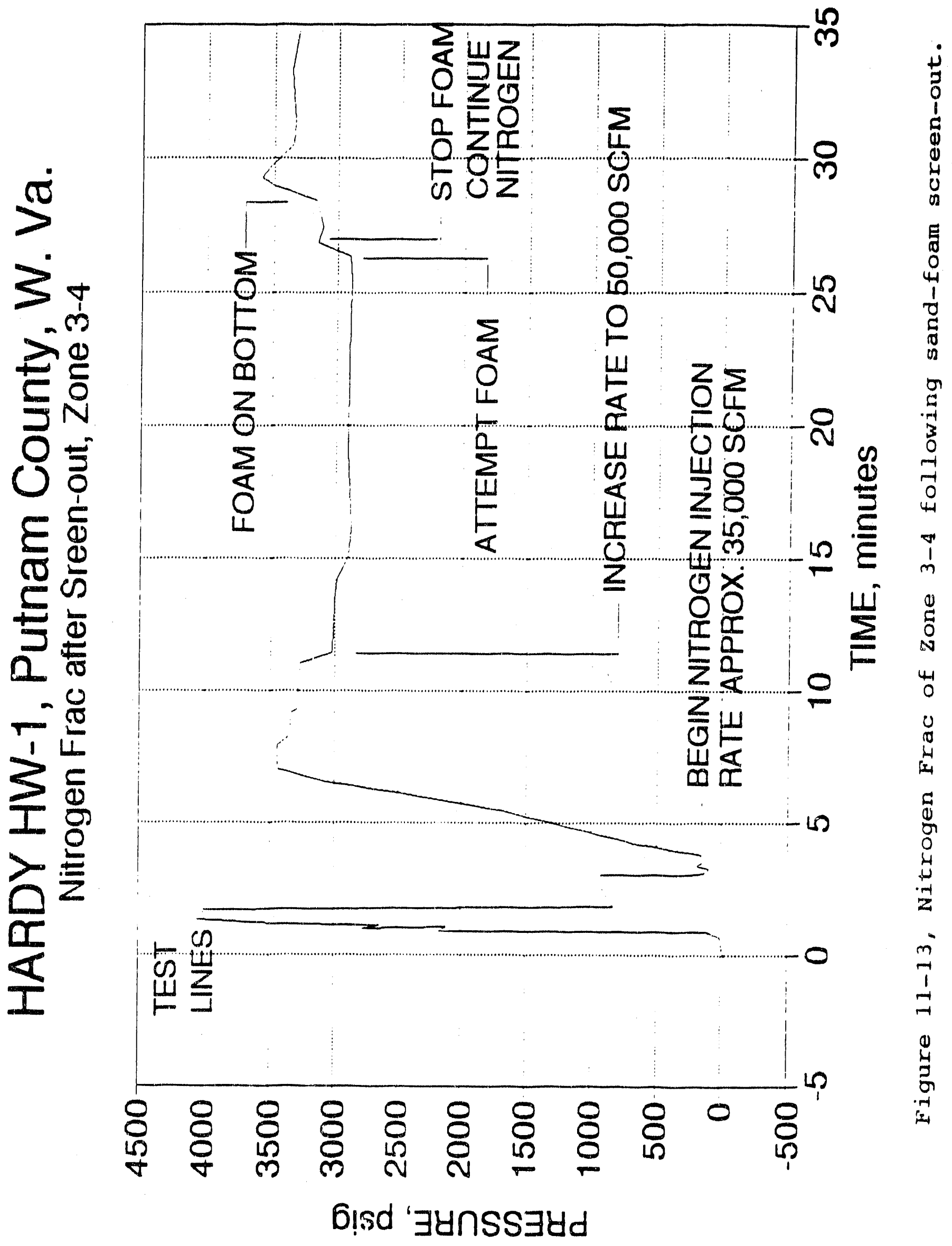


wellbore, it would be difficult to continue injecting at the relatively high rates being used.

\subsection{WELL TESTING OPERATIONS AND ANALYSIS}

Pre- and post-stimulation well testing were conducted on BDM/Hardy \#1. On January 26, 1990 an 11-day pre-stimulation pressure build-up test was conducted.

Following the stimulation of the four zones, a 14-day post-stimulation pressure build-up test was conducted. Pressure measurements were recorded at the surface using pressure charts. In addition to the pressure build-up tests, the well was produced at a fixed rate which allowed BDMESC engineers to monitor the pressure decline, and therefore, analyze the drawdown data. The results of the pressure buildup and drawdown analyses contributed to the basic understanding of the various reservoir parameters which control the production of BDM/Hardy $\# 1$.

\subsection{Pressure Build-up Testing}

Reservoir paremeters which control the productivity of horizontal wells could be estimated/calculated as a result of the analysis of pressure build-up test data. Pre- and post stimulation results when compared, reflect the effectiveness of the stimulation techniques applied on the wells. In particular, pressure build-up test results are of importance in cases where the productive horizontal section is divided into several zones where each zone could be tested and produced separately. Pre-stimulation and post-stimulation pressure build-up testing was performed on the entire horizontal section for BDM/Hardy $\# 1$. Individual zone testing (four zones) was not attempted.

Early time pressure build-up testing data can reveal important information/values of vertical permeability. Vertical permeability data when combined with estimated horizontal permeability values using late pressure-time data, will help verify permeability control along the horizontal wellbore. 
12.1.1 Pre-Stimulation Testing and Analysis

An 11-day pressure build-up test was conducted on BDM/Hardy \#1 using downhole electronic pressure measuring devices. In addition, surface pressures were recorded using pressure chart recorders. The pressure values were recorded every one minute for a period of eleven days. Table L-1 (Appendix $L$ summarizes the recorded pressure values). Due to time constraints and the cost associated with testing each zone separately, BDMESC and DOE/METC elected to test BDM/Hardy \#1 when all the zones were in communication in order to arrive at general reservoir parameter values for BDM/Hardy \#1.

To account for gas properties such as viscosity, and compressibility, pressure and time values were converted to equivalent adjusted pressures and adjusted effective times (Table L-1). The procedure for converting actual recorded pressure and time values to equivalent adjusted values is documented in a GRI report (Reference 2).

As a first step in estimating the pre-stimulation reservoir properties such as the stabilized reservoir pressure, average formation capacity $\left(K_{\theta} h\right)$, and formation damage, the Rectangular Hyperbolic Method, RHM (Reference 3), was implemented to determine/estimate an average initial reservoir pressure value. A plot of pressure as a function of inverse time (Figure 12.1.1) was generated and a simple linear regression model of the best fit for pressure versus inverse time was determined. Table 12.1.1 lists input values used in the pre-stimulation data analysis.

The following equations were used to determine the various reservoir properties using the RHM technique:

$$
\mathrm{Bg}, \mathrm{av}=\text { Formation volume factor }=5.04(\mathrm{Zav} / \mathrm{T} \quad(\mathrm{RB} / \mathrm{MCF})
$$

(Pav)

where $\quad$ Zav $=$ average gas deviation factor, dimensionless $\mathrm{T}=$ reservoir tomperature, $\left({ }^{\circ} \mathrm{R}\right)$

$\mathrm{Pav}=$ average reservoir pressure, (psia)

Therefore,

$$
\mathrm{Bg}, \mathrm{av}=\frac{(5.04)(0.219)(571)}{389}=6.80 \mathrm{RB} / \mathrm{MCF}
$$




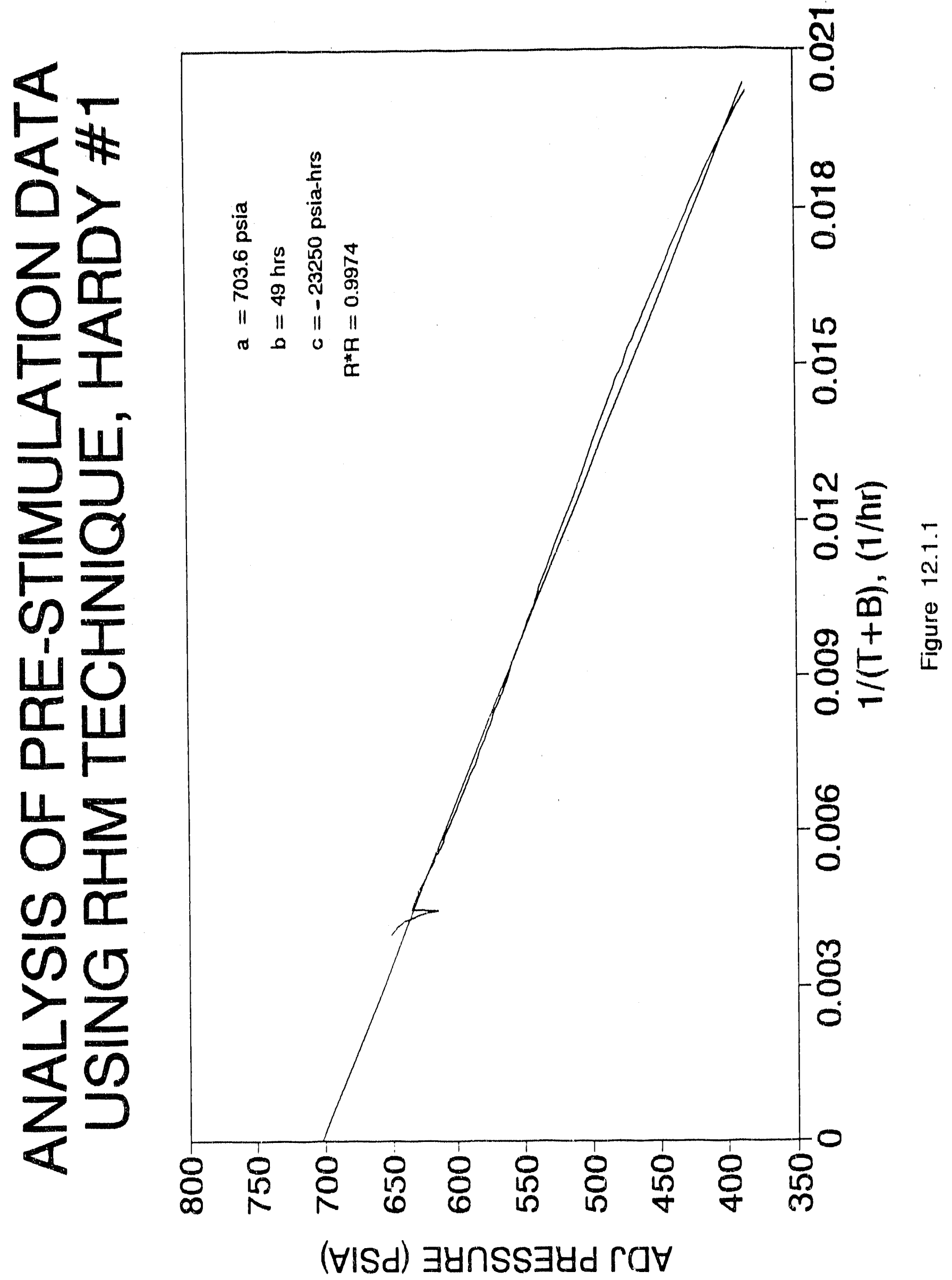




\section{Table 12.1.1 BASIC RESERVOIR AND WELL DATA \\ HARDY \#1}

Input Values:

Well length $(L)$ :

Well radius $\left(r_{w}\right)$ :

Reservoir gross thickness:

Productive thickness:

Porosity:

rWD:

Lo:

Reservoir pressure:

Gas viscosity:

Gas compressibility:

Gas deviation factor:

Gas formation volume factor:

Reservior temperature:

Flow rate pre-stimulation

Flow rate after-stimulation

$\begin{array}{cl}2020 & \mathrm{ft} \\ 0.328 & \mathrm{ft} \\ 180 & \mathrm{ft} \\ 50 & \mathrm{ft} \\ 0.01 & \\ 0.0003 & \\ 20 & \\ 700 & \mathrm{psi} \\ 0.010216 & \mathrm{Cp} \\ 0.00180 & \mathrm{psia}-1 \\ 0.9197 & \\ 6.8 & \mathrm{RB} / \mathrm{mv} \bar{T} \\ 571 & { }^{\circ} \mathrm{R} \\ 18 & \mathrm{mcfpd} \\ 100 & \mathrm{mcfpd}\end{array}$


From Figure 12.1.1 the $y$ intercept $=a=$ Initial reservoir pressure $(p s i a)=704$ psia

$c=$ value of the slope $=-23250 \mathrm{psia}-\mathrm{hr}$

$b=$ constant for the linear regression model at a regression coefficient, $R^{2}$, equal to unity, in this case $b=49$ hours at $R^{2}=0.9974$.

Therefore,

$\mathrm{m}=\frac{23008(-0)}{4(b)}$

$\mathrm{m}=$ equivalent to Horner's slope $=273.19 \mathrm{psia} / \mathrm{cycle}$

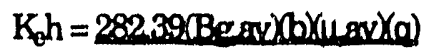

$-(-23250)$

where $q=$ gas flow rate, mcfpd.

Therefore $K_{0} h=1 \mathrm{md} \mathrm{ft}$

This technique is valid and accurate in estimating the initial reservoir pressure independent of other reservoir parameters.

In addition, to the RHM technique, type curves were implemented for the pre-stimulation data analysis. A Flopetrol Johnston/Schlumberger type curve for vertically fractured wells and pseudo steady state interporosity flow, Figure 12.1.2, was used.

A plot of change in adjusted pressure versus adjusted effective time, Figure 12.1.3, was best-fit in the aforementioned type curve. The match point values are used to estimate the average formation capacity, $\mathrm{K}_{\theta} \mathrm{h}$, and the apparent skin, $\mathrm{S}^{\prime}$, value. Therefore:

$$
K h=(1412)(\mathrm{Bgeav})(\mathrm{urv})(\mathrm{BD})
$$

where $\mathrm{PD}=$ dimensionless pressure value from type curve, (match point)

$$
\begin{aligned}
\Delta \mathrm{Pa} & =\text { change in adjusted pressure value, (match point) } \\
\mathrm{K}_{\mathrm{e}} \mathrm{h} & =\frac{(141.2)(18)(6.80)(0.012159812)(7.0)}{(1000)}=1.47 \mathrm{md}-\mathrm{ft}
\end{aligned}
$$




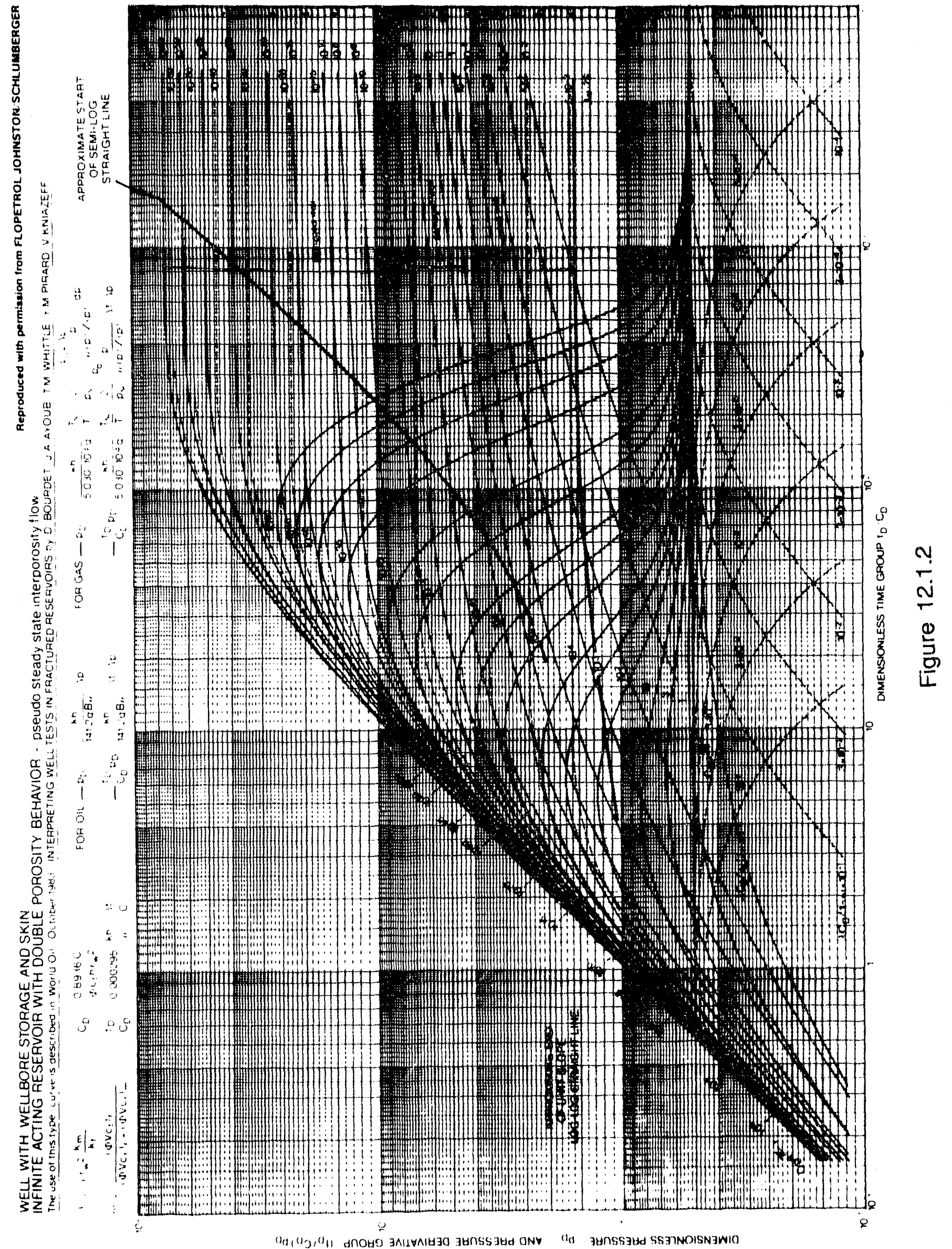




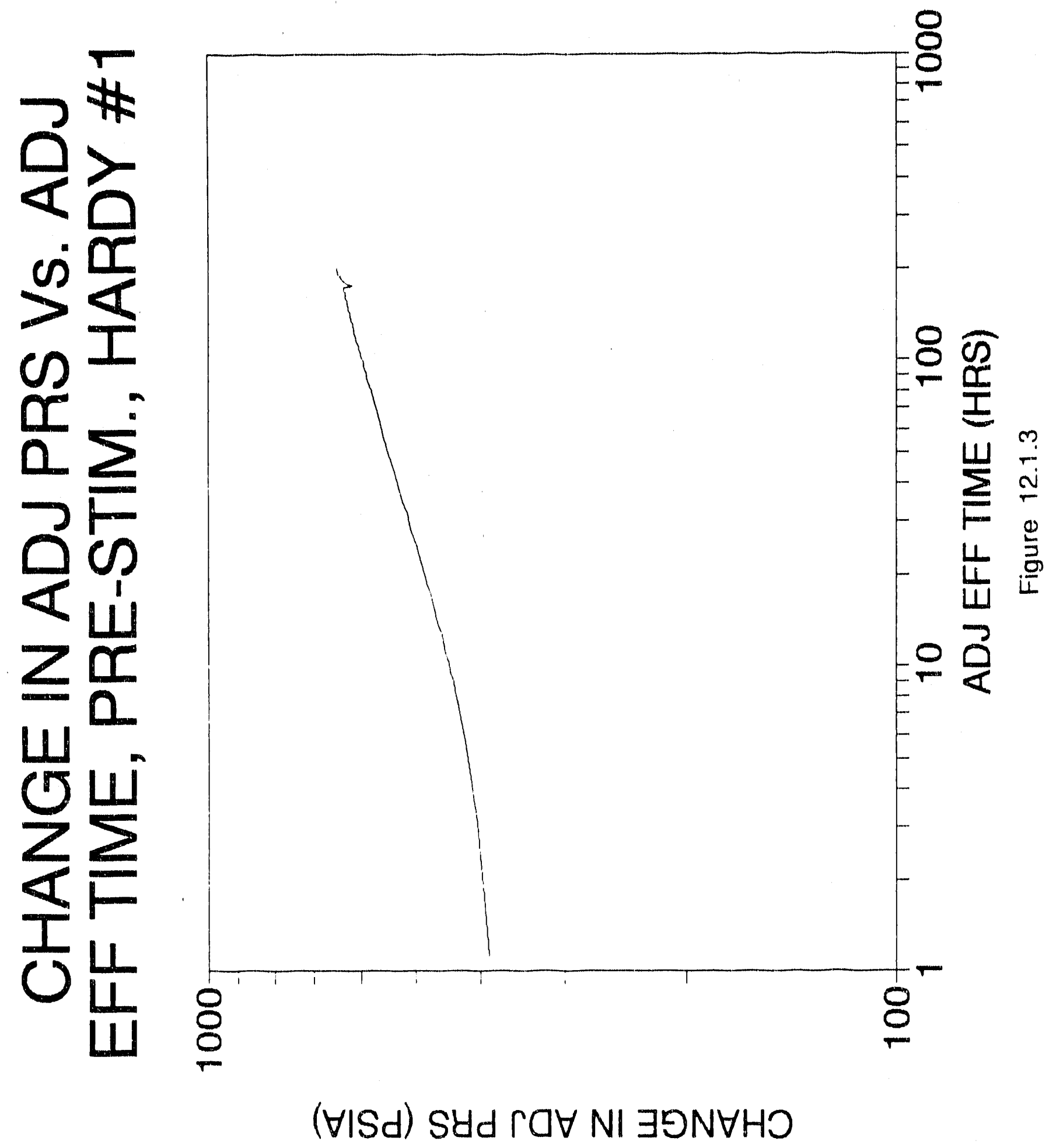


Assuming a productive formation thickness of 50 feet, average formation permeability is estimated at $0.029 \mathrm{md}$.

In order to compute the apparent skin factor, a value of dimensionless wellbore storage constant, $C_{D}$, needs to be calculated as such:

$$
C_{D}=\frac{(0,000263720 k) * \Delta t_{000}-}{(0, a v)\left(C_{t}\right)\left(r_{w}^{2}\right)(\mu, a v)\left(t_{D} / C_{D}\right)}
$$

where $\quad \emptyset_{\text {av }}=$ average formation porosity, (fraction)

$\mathrm{C}_{\mathrm{t}}=$ total formation compressibility, (psia-1)

$\mathrm{rw}=$ wellbore radius, $(\mathrm{ft})$

$t_{D} / C_{\mathfrak{D}}=$ match point from type curve

$\Delta t a e=$ change in adjusted effective time, (match point)

$C_{D}=\frac{(0.00026370 .029) \quad * \quad 10}{(0.01)(0.0018044)(0.16625)^{2}(0.012159812)\left(2.6 \times 10^{2}\right)}$

$C_{D}=48.5$

Using the dimensionless wellbure storage constant, $C_{D}$, equation 12.1.6 can be used to compute the apparent skin factor, $S^{\prime}$. Therefore:

$$
S=0.5 \ln \frac{\left(C_{D P^{2}}\right)}{\left(C_{D}\right)}
$$

where $\mathrm{C}_{\mathrm{D}} \mathrm{e}^{2 \mathrm{~s}}=$ match point value from type curve

$$
S^{\prime}=0.5 \ln \left(\frac{1}{(48.2)}\right)=-2.0
$$

Horner's technique was implemented in order to validate the estimates/values of the reservoir parameters using the other techniques. A plot of adjusted pressure versus adjusted Horner time was generated (Figure 12.1.4). The $y$-intercept at Horner time equal zero is equivalent to the estimated reservoir pressure. Therefore:

$$
\begin{gathered}
P_{\mathrm{i}}, \mathrm{av}=767 \text { psia } \\
\mathrm{m}=\text { slope of Horner's line }=-190 \mathrm{psia} / \text { cycle } \\
\mathrm{K}_{\mathrm{e}} \mathrm{h}=\frac{(1626) \text { (a)(uav)(Beav })}{(\mathrm{m})}
\end{gathered}
$$




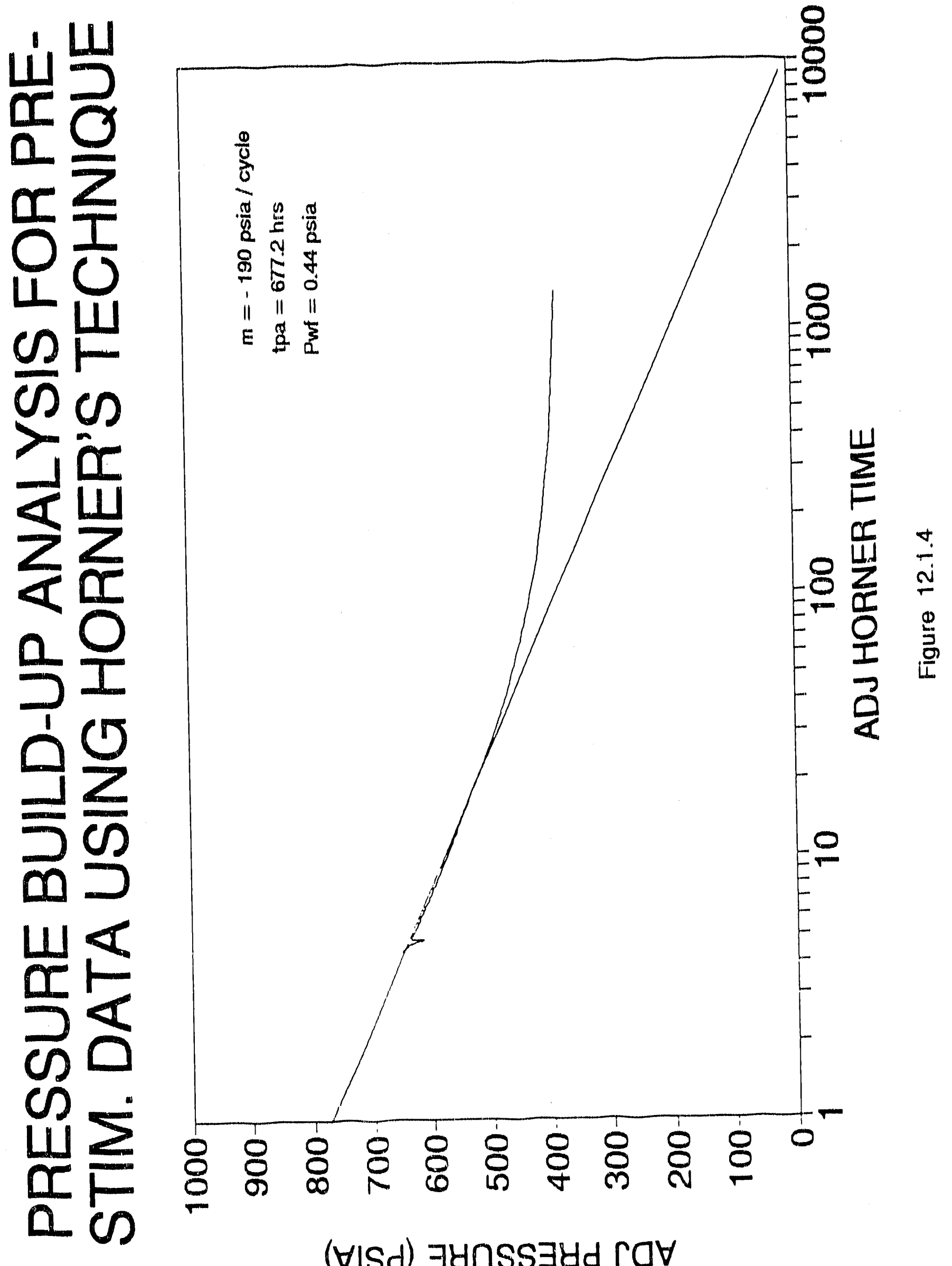


$K_{0} h=(162.6)(18)(0.012159812)(6.80)=1.25 \mathrm{md}-\mathrm{ft}$

(190)

In order to determine the skin factor/value using Horner's technique, the adjusted pressure at adjusted time equivalent to one hour needs to be determined. Using the Horner's straight line equation, $\mathrm{Pa}, 1 \mathrm{hr}$ is determined as follows:

$$
\begin{aligned}
& y=m x+h \\
& y=m \log \left(\frac{t a+\Delta t a)+b}{\Delta t a}\right. \\
& y=(-190) \log \frac{(t p a+\Delta t a)+767}{\Delta t a}
\end{aligned}
$$

where tpa $=$ adjusted production time, $\mathrm{hrs}=677.2$

$\Delta \mathrm{ta}=$ adjusted shut-in time, $\mathrm{hrs}=1 \mathrm{hr}$

Therefore

$$
\mathrm{Pa}, \mathrm{hhr}=(-190) \log \frac{(677.2+1)}{1}+767=229 \mathrm{psia}
$$

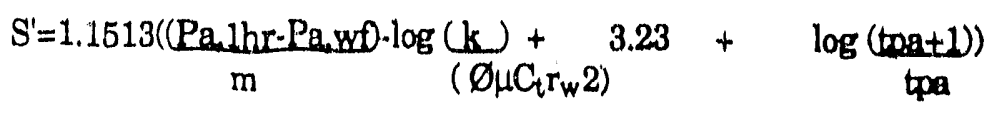

$S^{\prime}=-5.0$

Finally, type curves which were generated for horizontal wells (Reference 4) were used for analyzing the BDM/Hardy \#1 pre-stimulation data. Earlier these type curves were used in the analysis of the BDM/RET\#1 horizontal well pressure data. A dimensionless pressure versus dimensionless time type curve for horizontal wells with wellbore storage effects was used for the analysis (Figure 12.4.5).

Based on the available geologic and engineering data, several assumptions were made in order to compute the necessary variables needed for the analysis. In order to determine the dimensionless values of $L_{D}$ and $r w_{D}$, where:

$$
\mathrm{L}_{\mathrm{D}}=\text { Dimensionless well length }=\underset{2 h}{\mathrm{~L}_{4}} \operatorname{SQRT} \underset{(\mathrm{Kh} h)}{(\mathrm{KW})}
$$

and $r_{W D}=$ Dimensionless wellibore radius $=2 a w$ 

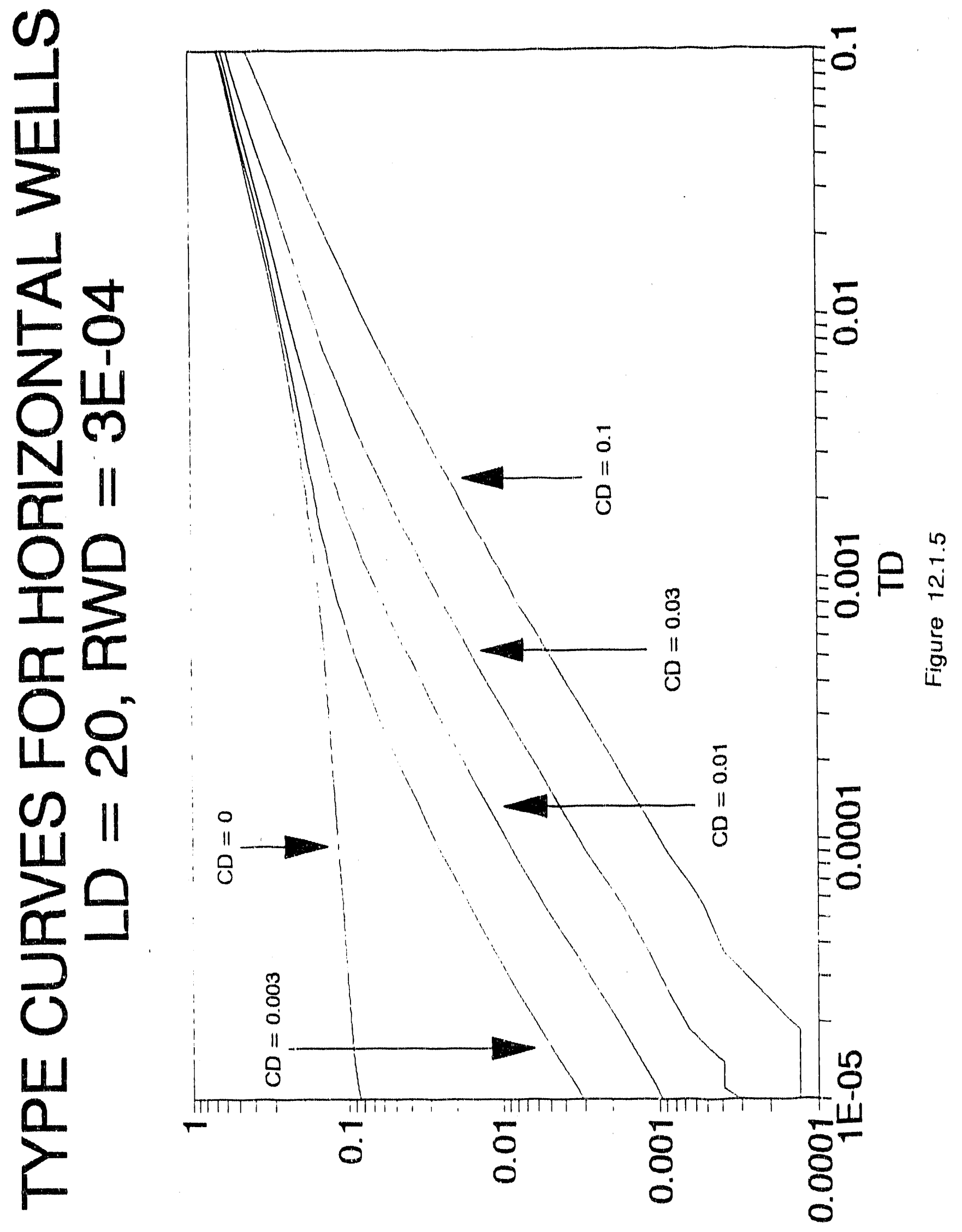

ad 
a value of productive formation thickness of 50 feet was assumed based on geophysical well logs.

Using the appropriate type curve and matching the pressure buildup data as exhibited in Figure 12.1.6, the following match points were obtained with $L_{D}=20$ type curve.

$\begin{array}{lll}P_{D}=0.215 & \Delta P a=1000 & C_{D}=0.0 \\ t_{D}=100 & \Delta t_{B e}=0.0005 & \end{array}$

Therefore, using equation 12.1 .12 , an average formation capacity value was computed as follows:

$K_{\mathrm{e}} \mathrm{h}=(141.2)(q)(\mathrm{Bg}, \mathrm{av})(\mu, \mathrm{av})(\mathrm{BD})$

$(\triangle \mathrm{Pa})$

$K_{e} h=(141.2)(18)(6.8)(0.012159812) Q 215$

1000

$K_{e} h=0.045 \mathrm{md}-\mathrm{ft}$

Using Equations 12.1 .10 and 12.1.13, the results of the pre-stimulation analysis indicate an offective length of 900 feet and a $K_{V} / K_{h}$ of 4 which represents an anisotropy ratio of $4: 1$.

$$
L e=\frac{0.001055-\mathrm{Ke}}{\sigma_{\mu \mathrm{C}_{\mathrm{t}}}} \frac{\left(\Delta \mathrm{t}_{\mathrm{tee}}\right)}{\left(\mathrm{t}_{\mathrm{D}}\right) \mathrm{MP}}
$$

\subsubsection{Post Stimulation Testing and Analysis}

Following the stimulation of BDM/Hardy \#1, where Zones 1,2, and 4 were stimulated and attempts were made to stimulate Zone 2, a 14-day pressure build-up test was conducted where surface pressure values were measured. Surface pressure values were then converted to bottomhole conditions. The data collection and analysis is exhibited in Table L-2 (Appendix L). It is important to note that the pressure build-up test was performed when all the zones were in communication rather than on a zoneby-zone basis. A zone-by zone testing would have helperi determine the effect of the stimulation techniques. An overall testing when all the zones are in communication will generate a basic understanding of the effect of the stimulation techniques on the well's productivity. 

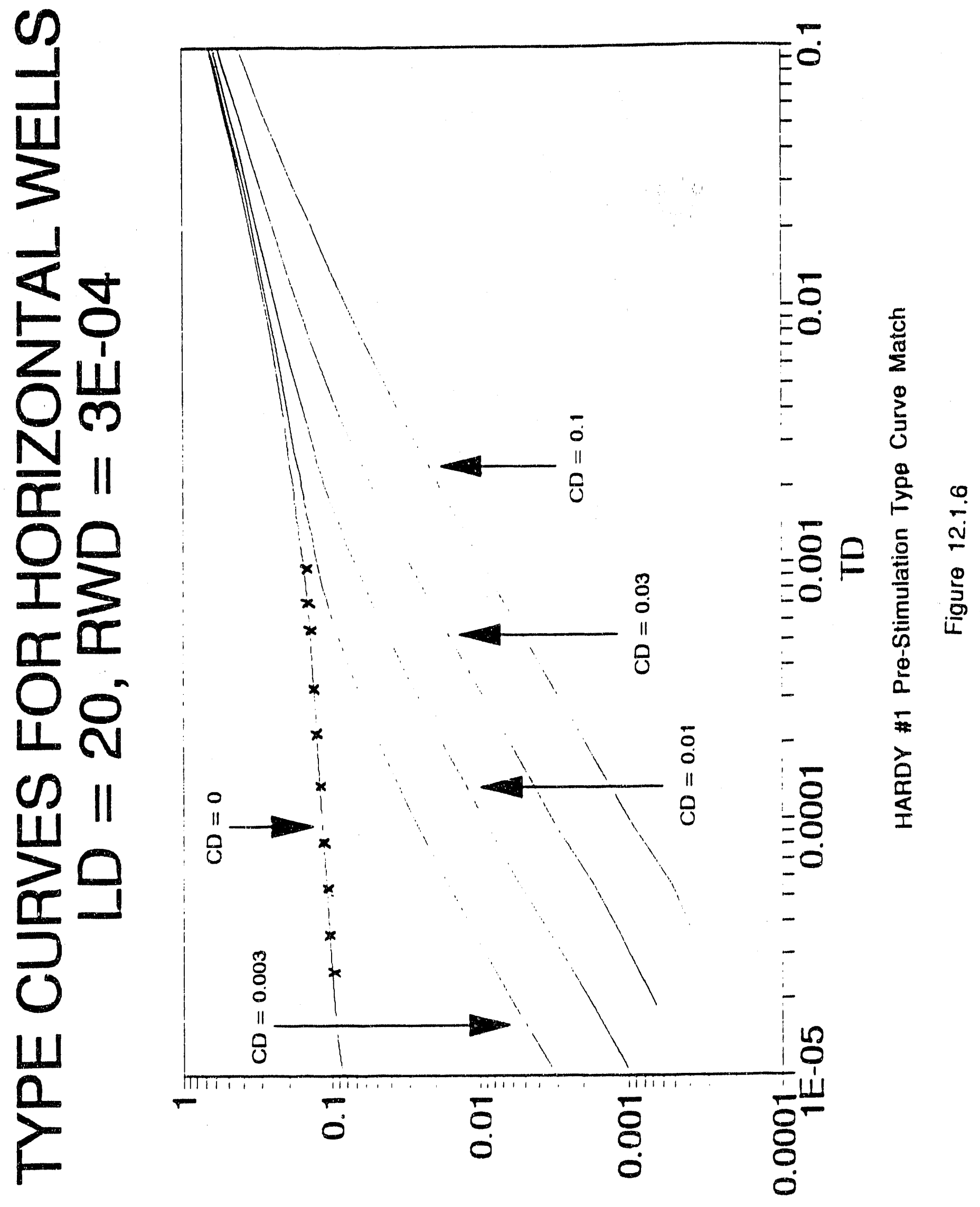

ad 
As mentioned in Section 12.1.1, values of adjusted pressures and adjusted effective time were used for analyzing the post-stimulation pressure data (see Table 1-2). Input values for post-stimulation data analysis are summarized in Table 12.1.1.

In a first attempt, type curves were used to determine the end of the wellbore storage effects. The following are the match point values obtained from the type curves for vertically fractured wells as a result of matching Figure 12.1.7.

$$
\begin{array}{ll}
\Delta \mathrm{t}_{\mathrm{Re}}=100 & \mathrm{t}_{\mathrm{D}} / \mathrm{C}_{\mathrm{D}}=370 \\
\Delta \mathrm{Pa}=1000 & \mathrm{PD}_{\mathrm{D}}=5.2 \\
\mathrm{C}_{\mathrm{D}} \mathrm{e}^{2 \mathrm{~s}}=0.3 &
\end{array}
$$

Therefore, in order to compute values of formation capacity and effective skin, equations 12.1.1, 12.1.4, 12.1.5, and 12.1.6 were used for the analysis as follows:

$$
\mathrm{Bg}, \mathrm{av}=5.04 \frac{(0.919)(571)}{418}=6.32 \mathrm{RB} / \mathrm{MCF}
$$

Where $P, a v=$ average reservoir pressure $=418$ psia

$$
Z=\text { gas deviation factor }=0.919
$$

Using equation 12.1.4, the average reservoir formation capacity value was computed at $K_{\theta} h=\mathbf{5 . 6 4} \mathrm{md}-\mathrm{ft}$ at an average flow rate equivalent to 400 mctpd.

Values of $C_{D}$ and $S^{\prime}$ were determined at 1326.3 and -5.0 respectively.

From the type curve analysis, the data falling within the semi-log region were analyzed using Horner's technique. Figure 12.1.8 which exhibits a plot of adjusted pressure versus adjusted Horner's time revealed a straight line with a slope $m=-230.55 \mathrm{psia} /$ cycle.

Using equation 12.1.7, 12.1.8, and 12.1 .9 values of formation capacity and apparent skin were estimated at $5.42 \mathrm{md}-\mathrm{ft}$ and -6.0 respectively. 


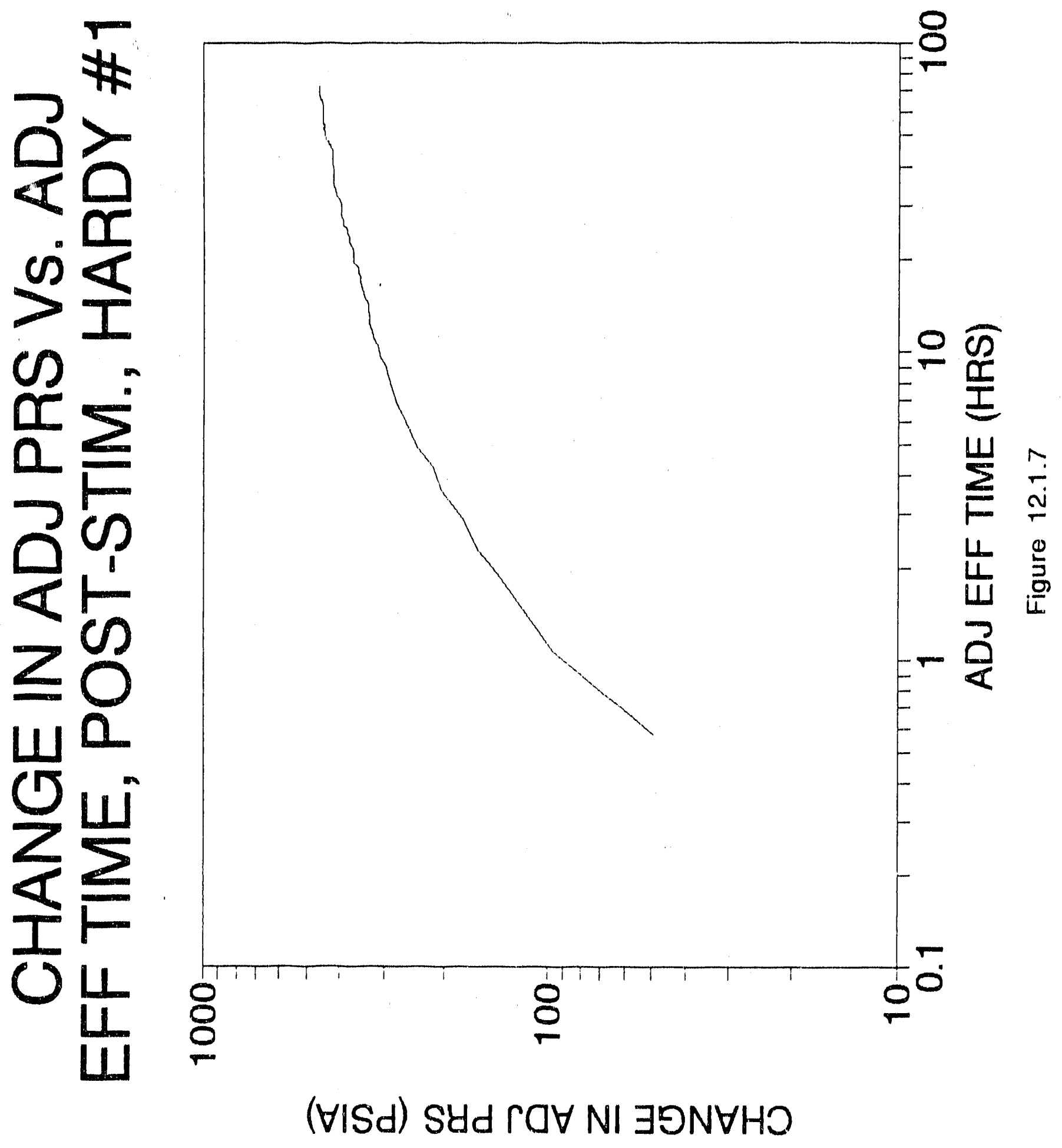




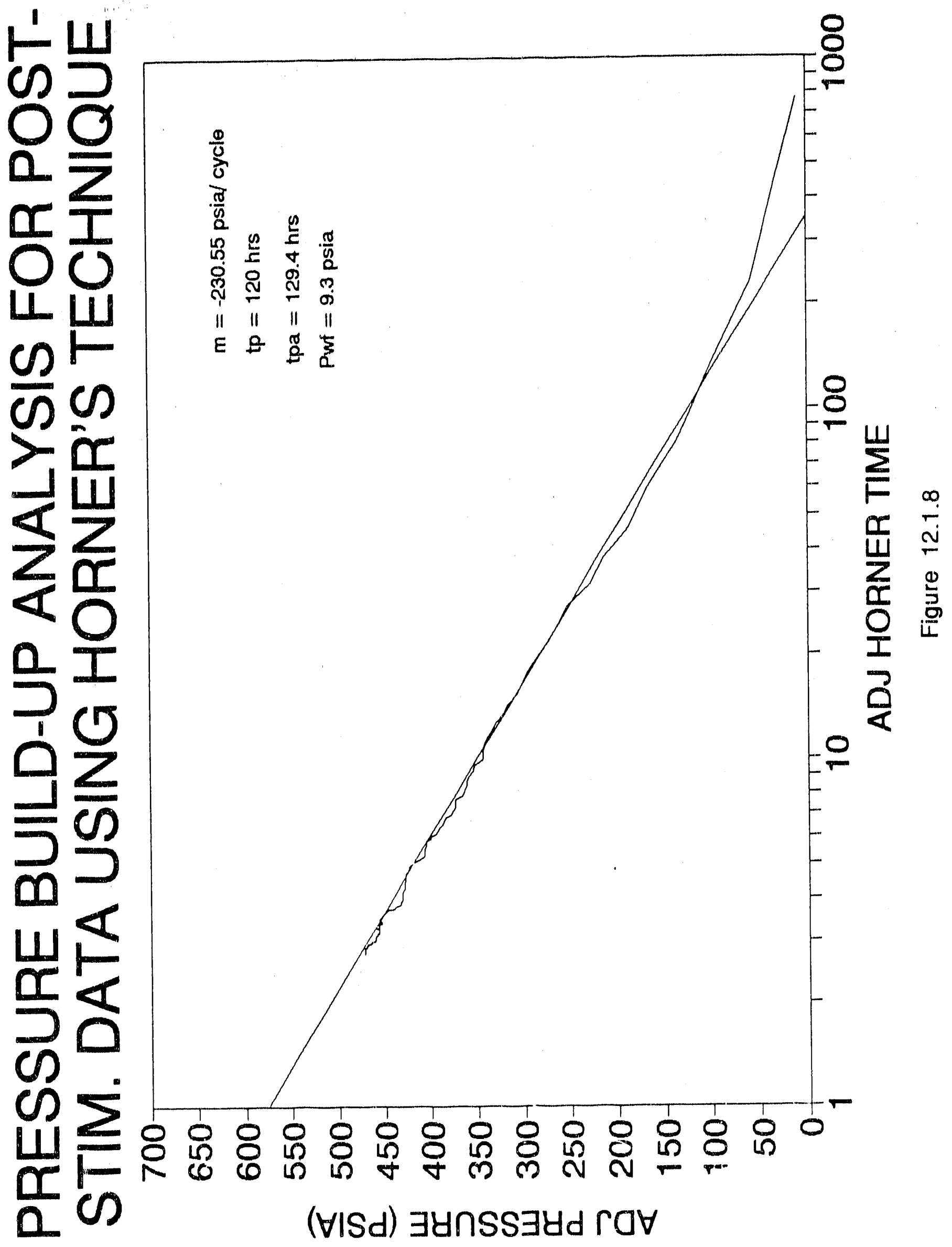


Finally type curves generated for horizontal wells were implemented for the analysis of the post-stimulation data. Figure 12.1.6 was used to determine the curve match. The following is a list of the match points as a result of the matching procedure:

$$
\begin{array}{ll}
\Delta \mathrm{t}_{\mathrm{d}, \mathrm{w}} 0.10 & \Delta \mathrm{Pa}=1000 \\
\mathrm{t}_{\mathrm{D}}=0.00 / 32 & \mathrm{P}_{\mathrm{D}}=0.3 \\
\mathrm{C}_{\mathrm{D}}=0.1 &
\end{array}
$$

Therefore, using equation 12.1.12 an average formation cäpacity value was determined as follows:

$$
\begin{aligned}
& \mathrm{K}_{\mathrm{e}} \mathrm{h}=\frac{(141.2)(100)(6.32)(0.0121598)(0.3)}{1000} \\
& \mathrm{~K}_{\mathrm{e}} \mathrm{h}=0.325 \mathrm{md}-\mathrm{ft}
\end{aligned}
$$

\subsection{Drawdown Testing -Post Stimulation}

Following the post-stimulation pressure build-up test, the well was placed line against a line pressure equivalent to 70 psia. A constant well flow rate of 100 mcfpd was attempted while the well's pressure was monitored at that rate. At early times, approximately the first six days, there was a fluctuation in production rate due to freezing at the wellhead. The average production rate for the first six days was approximately 61 mcfpd. This value was determined by computing the cumulative production at $364 \mathrm{mcf}$ and determining the average daily rate.

Therefore:

$$
\mathrm{q}_{1}=\frac{364}{6}=61 \mathrm{mcfpd}
$$

After the first six days the production rate was successfully maintained at 100 mcfpd. Figure 12.2.1 illustrates the relationship between the flow rates, well pressures, and cumulative production with time.

For the accuracy of this analysis a two-rate production test was implemented in order to provide information about the formation capacity and apparent skin. Wellbore storage effects are often thought to be minimized or eliminated by two-rate tests. In fact, wellbore storage effects last just about the same amount of time in a two-rate test as in a normal build-up, drawdown, or falloff test. However, a two-rate test 
JอW $\exists \Lambda I \perp \forall 7 \cap W \cap 0$

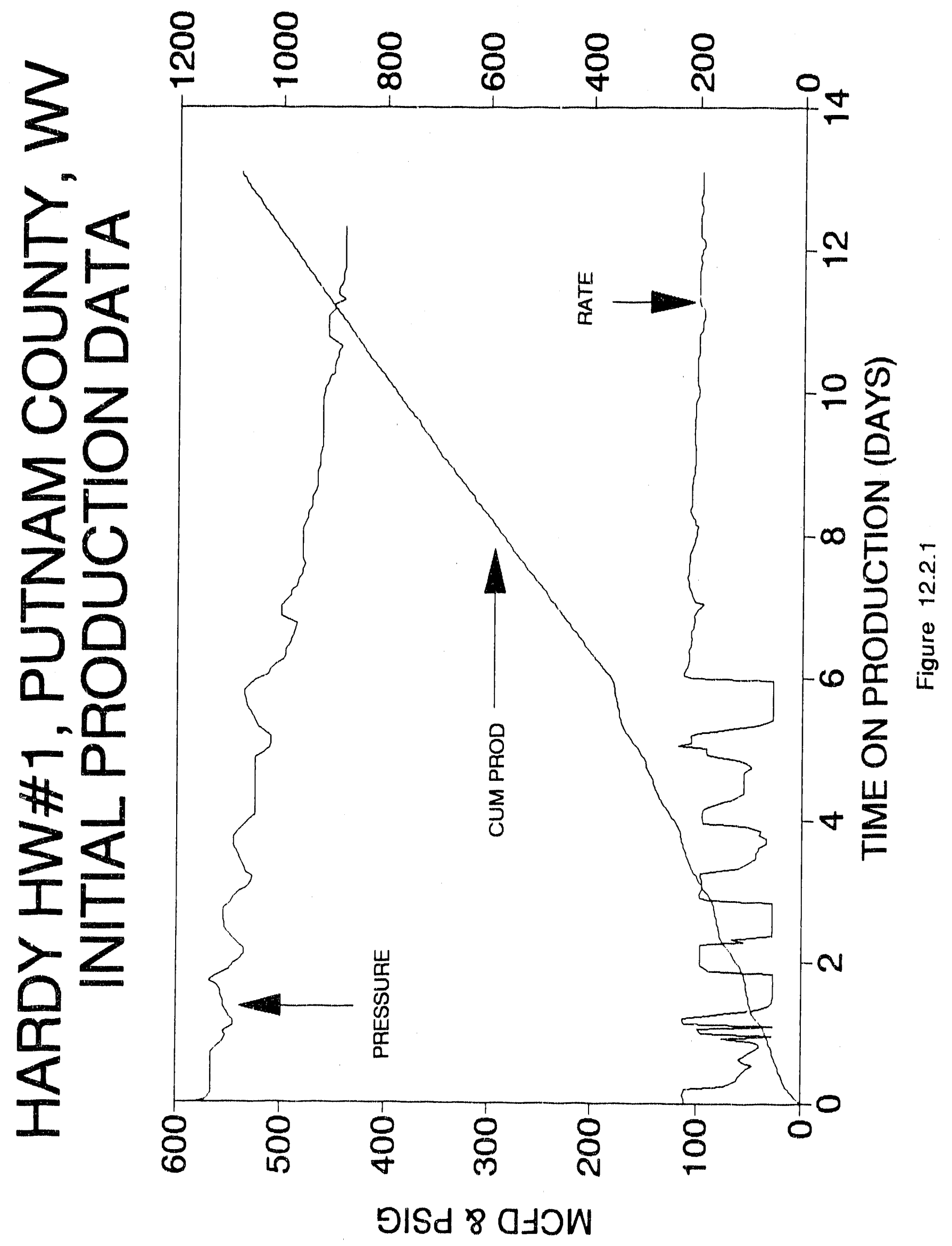


often can be used to prevent a wellbore storage increase, thus providing analyzable test when one otherwise might not be possible.

The collected data were analyzed as shown in Table L-3. Pressure and time data were converted to adjusted pressure and time values. In order to determine the respective values of permeability and apparent skin the analysis technique suggested in Chapter four 4 was used. The general equation for two-rate flow test analysis (equation 4.6, Reference 5) was used and a plot of adjusted pressure versus log of flow time and flow rates was generated (Figure 12.2.2). A best fit using simple linear regression was used to generate a straight line with slope $m_{1}{ }^{\prime}$.

Therefore:

$$
\begin{aligned}
\mathrm{k}_{\mathrm{e}} \mathrm{h} & =\frac{162.6(\mathrm{Bg} \text {.av)})(\mathrm{mav})(\mathrm{al})}{\mathrm{m}_{1}} \\
\mathrm{k}_{\mathrm{e}} \mathrm{h} & =\frac{(162.6)(6.3)(0.02159812)(61)}{(104)} \\
& =7.31 \mathrm{md}-\mathrm{ft} @ \mathrm{~h}=50^{\prime} \quad \mathrm{K}=0.1462 \mathrm{md}
\end{aligned}
$$

The value of skin is calculated using equation 4.11 (Reference 5).

Therefore:

$$
\begin{aligned}
& S^{\prime}=1.1513(Q 1)\left(\left(P a, w_{f}(\Delta t=0)-P a, 1 h r\right)-\log (\mathbb{k})+3.2275\right) \\
& \left(q_{1}-q_{2}\right) \\
& \left(\varnothing \mu \mathrm{C}_{\mathrm{t}} \mathrm{r}_{\mathrm{w}}{ }^{2}\right) \\
& P a, 1 h r=-104.2\left(\log (t 1+\Delta t)+a_{2} \log \Delta t\right)+651 \\
& \Delta \mathbf{t} \quad \mathbf{q}_{1}
\end{aligned}
$$

where $\mathrm{Pa}$, int $=651$ psia

$\mathrm{Pa}, \mathrm{hr}=-104.2\left(\log \frac{(144+1)}{1}+\frac{100}{61} \log (1)\right)+651$

Therefore using equation 12.2.2 $S^{\prime}=-4.44$

To evaluate ine $P^{*}$, reservoir false pressure, which is used to estimate the initial average reservoir pressure the following equation was used.

$$
P a^{*}=P a, \text { int } \underset{q_{1}-q_{2}}{\left.-\frac{q_{2}}{(P a, w f(}(\Delta t=0)-P a, 1 h r\right)}
$$




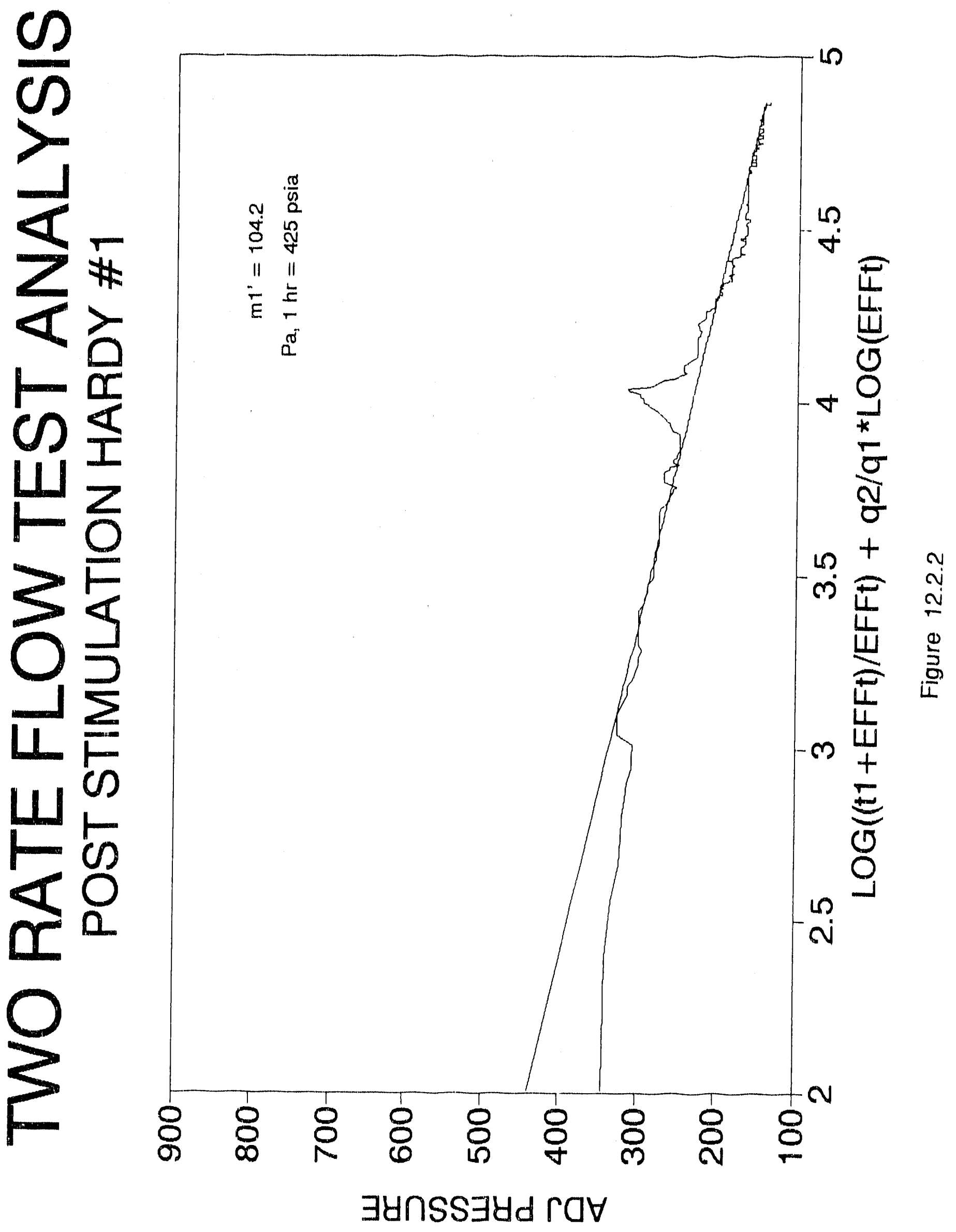




$$
\begin{aligned}
& \mathrm{Pa}^{*}=651-\frac{100}{61-100}(445-425) \\
& =702 \text { psia }
\end{aligned}
$$

To estimate the drainage volume average pressure by the $\mathrm{MBH}$ method (Chapter 6, Reference) first we obtain the false pressure value $P^{*}$. Then the average pressure is estimated from

$$
\begin{aligned}
& \mathrm{P}=\mathrm{P}^{*}-\frac{\mathrm{mPDMBH}}{2.3025}(\mathrm{tpDA}) \\
& \operatorname{tpDA}=0.0002637(\mathrm{k})(\mathrm{to}) \\
& \text { OuCA } \\
& =\frac{(.0002637)(146)(144)}{(.01)(.0121598)(.0018044)(\pi)(1490)^{2}}=0.004
\end{aligned}
$$

Using Figure 6.24 the value of $\mathrm{PDMBH}=0$

Therefore $P=P^{*}=702$ psia

Type curves for horizontal wells were used to estimate the effective formation capacity, effective horizontal wellbore length, and $K_{V} / K_{H}$ values. Using the pressure-time matches at $C_{D}=0.1, L_{D}=20$, and $r_{W D}=3 \times 10.4$ (Figure 12.2.3), values of $K_{\theta} h, L_{\theta}$, and $K_{V} / K_{H}$ were estimated using equations 12.1.10, 12.1.12, and 12.1.13.

The match points were:

$$
\begin{array}{ll}
\Delta \mathrm{Pa}=100 & \Delta t=100 \\
\mathrm{P}_{\mathrm{D}}=0.048 & \mathrm{t}_{\mathrm{D}}=.0053
\end{array}
$$

$K_{\mathrm{e}} \mathrm{h}=(141.2)(\mathrm{q})(\mathrm{Bg}, \mathrm{av})(\mu, \mathrm{av})\left(\mathrm{P}_{\mathrm{D}} \mathrm{L}\right.$

$\mathrm{K}_{\mathrm{e}} \mathrm{h}=(141.2)(100)(6.32)(0.012159812) 0.048$

$\mathrm{K}_{\mathrm{e}} \mathrm{h}=0.52 \mathrm{md}-\mathrm{ft}$

Values of $L_{\theta}$ and $K_{v} / K_{h}$ were computed at 1000 feet and 4 respectively. 

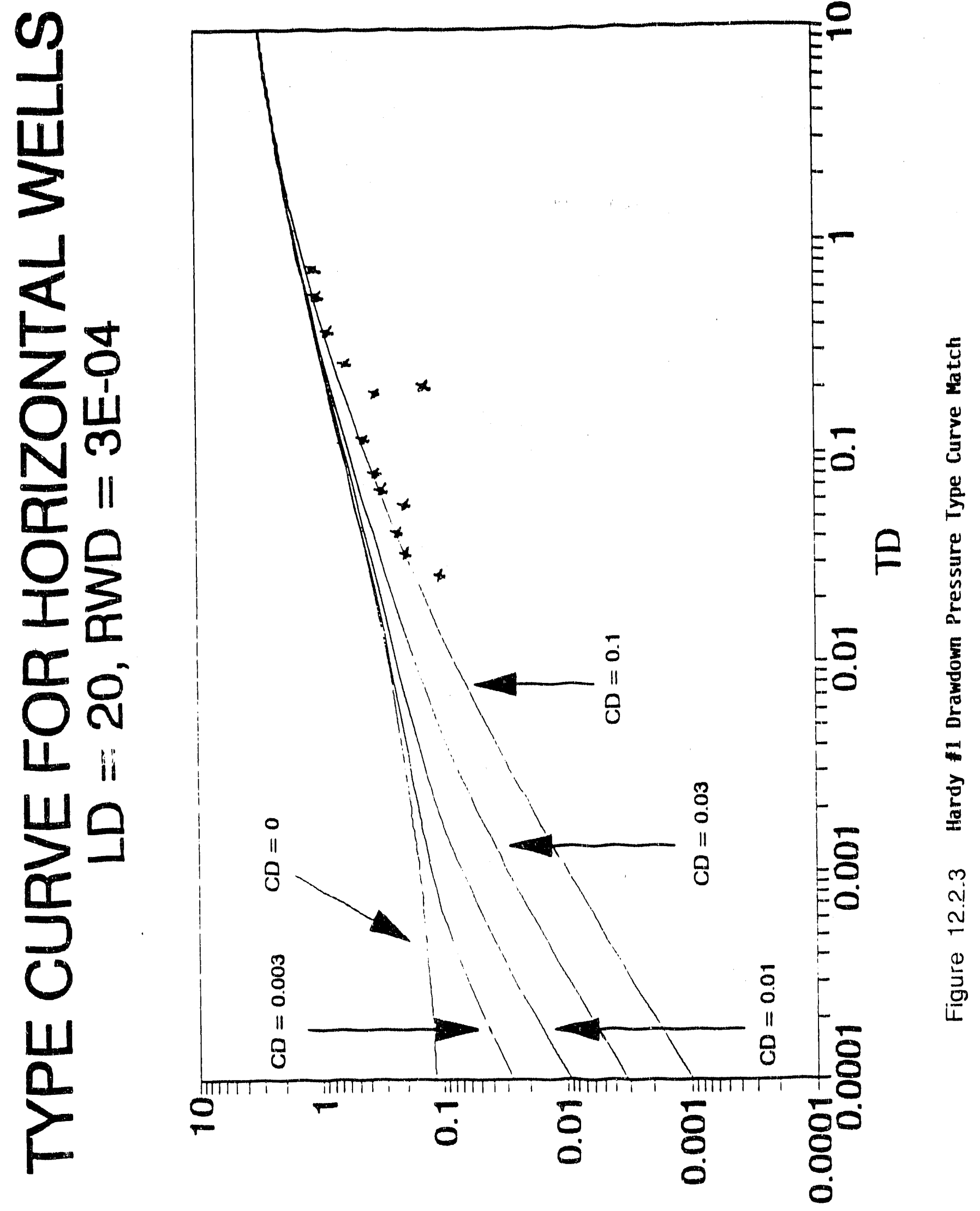

ad 


\subsection{Well Test Results and Conclusions}

Tables 12.3.1 and 12.3.2 summarize the results of the various preand post-stimulation well tests conducted on BDM/Hardy \#1. The RHM technique estimated a pre-stimulation initial reservoir pressure of 704 psla. This technique is valid and accurate in estimating the initial reservoir pressure independent of other reservolr parameters since the basis for this technique is solely statistical in nature.

The computed values of $K_{y} / K_{H}$ for both wells based on horizontal well type curve analysis indicates a 4 to 1 ratio. Assuming $K_{\theta}=\left(K_{V} / K_{H}\right) .5$ and using the computed $K_{V} / K_{H}$ ratios, values of $K_{V}$ and $K_{H}$ were estimated for the different tests results as exhibited in Table 12.3.3. The $K_{V}$ and $K_{H}$ values do not reflect the exact permeability values but rather establish the ranges of permeability based on computed $L_{\theta}$ values and the assumption of a productive thickness based on geologic data and geophysical well logs.

The Horner technique, applied to the post-stimulation data indicated an improvement ratio in the $K_{\theta} h$ value of 4.5 as a result of stimulation compared to an improvement ratio of 7.0 using horizontal well type curves. Post-stimulation flow rate testing has shown an increase in average production rate for BDM/Hardy \#1 from $18 \mathrm{mcfpd}\left(510 \mathrm{~m}^{3 / d a y}\right)$ (open flow) to 100 moipd (2831 $\mathrm{m}^{3} / \mathrm{day}$ ) at a producing pressure of 130 psig $\left(896 \times 10^{3} \mathrm{~Pa}\right)$ indicating an improvement ratio of at least 5.5 .

The low formation capacity values computed using horizontal well type curves, compared to the higher values using conventional techniques applicable for vertical well test analysis, indicate that conventional techniques applied to horizontal wells may yield composite value of $K_{\theta} h$ which incorporates the horizontal well length and formation capacity. When horizontal well type curves are applied to the same data, the true effective formation capacity can be derived.

From horizontal well type curves, $L_{\theta}$ values were computed for BDM/Hardy \#1 based on pre- and post-stimulation test results. $L_{\theta}$ value of 1000 feet $(305 \mathrm{~m})$ was determined for BDM/Hardy \#1. The actual drilled horizontal wellbore length for BDM/Hardy \#1 is approximately 2000 feet $(610 \mathrm{~m})$. The difference between actılal and effective horizontal wellbore lengths is due to the fact that horizontal well type curves assume a single- 

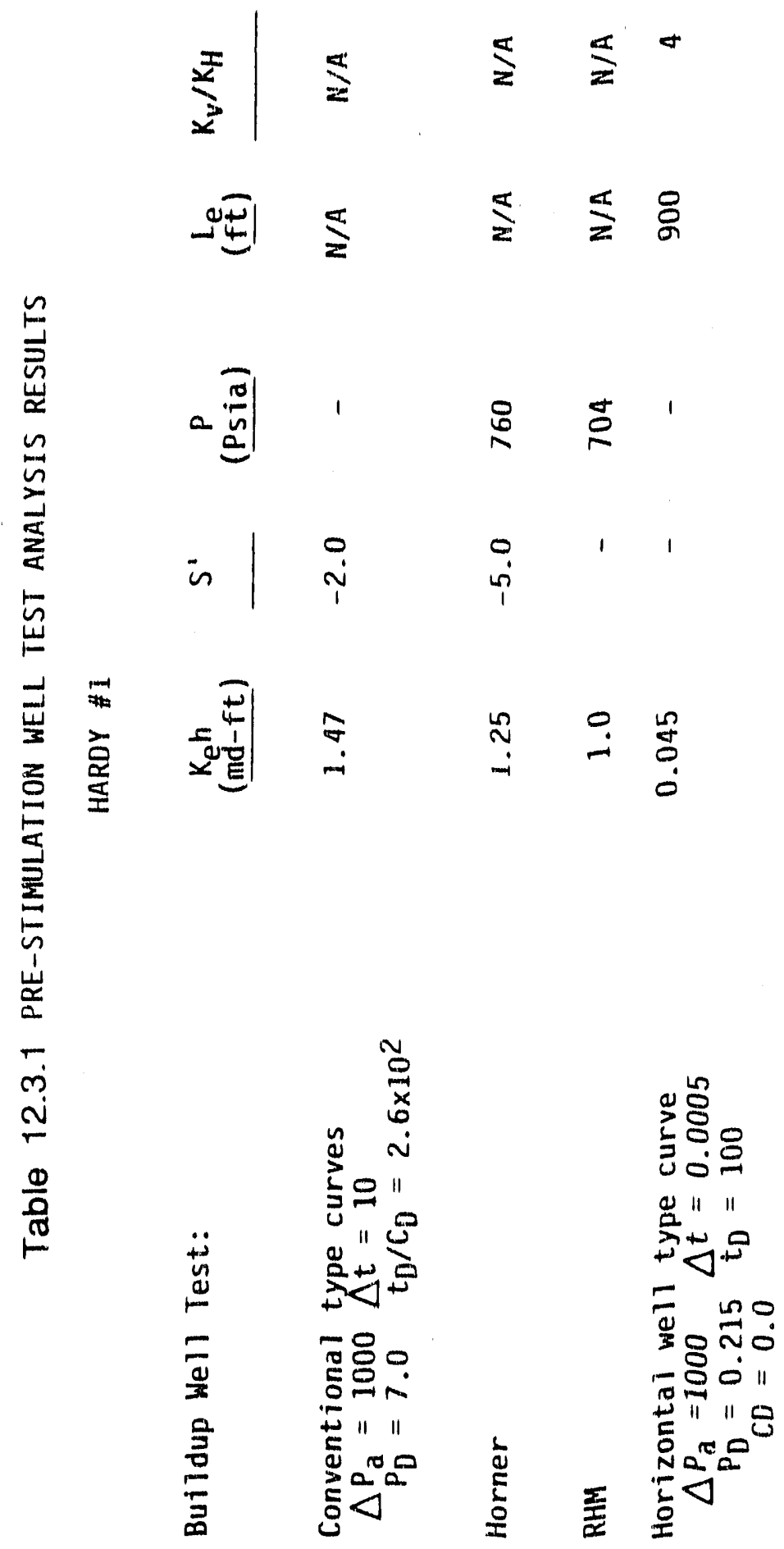


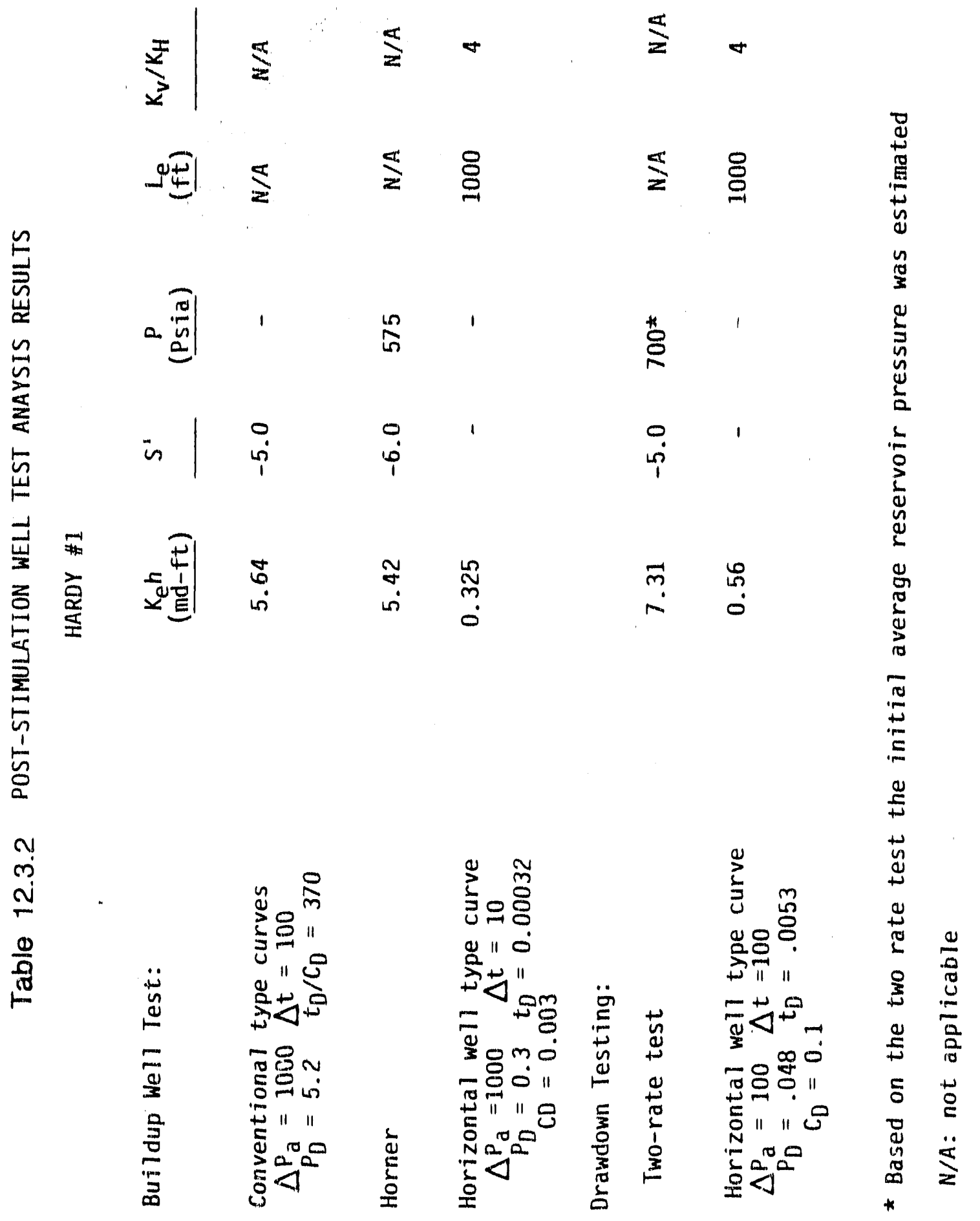



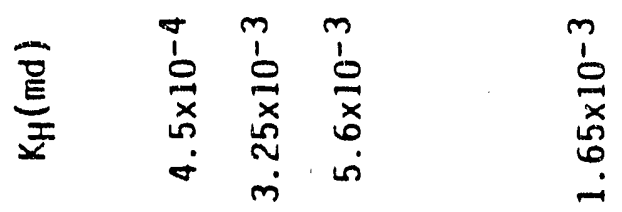

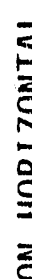

퐁

$\lesssim \simeq$

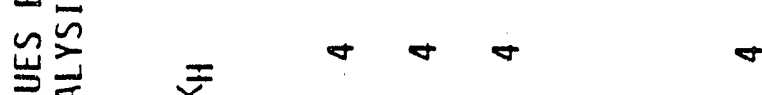

焉

牙紧

믈

$>$

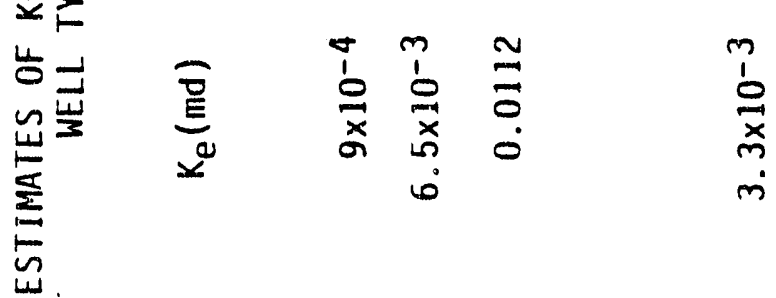

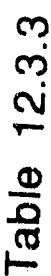

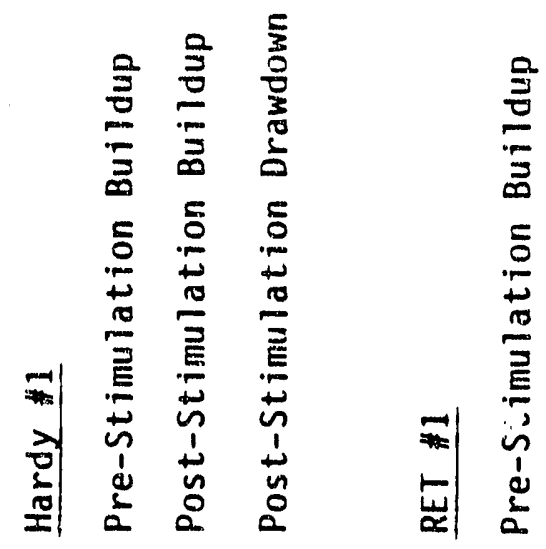


porosity homogeneous reservoir; whereas, the actual reservoirs are very heterogenous, with considerable variation in permeability along the length of the wellbore.

The application of horizontal well type curves resulted in lower than expected formation capacity values for the Devonian Shale strata in the test wells. This may help explain the need to stimulate horizontal wells in order to achieve the desired production rates. As a result of the stimulations, certain reservoir parameters appeared to be enhanced such as the formation capacity and effective horizontal wellbore length. These improvements were also reflected in the pre- and post-stimulation production flow rate tests.

This study illustrates some of the problems that may be encountered in applying conventional techniques to horizontal wells and the value of horizontal well type curves for better estimates of reservoir parameters. Conventional techniques when applied to horizontal well tests may yield only composite or relative values. With the horizontal well type curves used in this study, estimates of vertical and horizontal permeability values are possible only if productive thickness is known.

\subsection{ANALYSIS OF COMPLETION, STIMULATION, TESTING, AND PRODUCTION OPERATIONS}

\subsection{Completion Operations}

The completion planned for this well was designed to test open hole, cased, and cemented completions in the same formation and wellbore. The purpose being to gain data and insight into the differences in stimulation efficiency between the two types of completions.

The original completion plan was to separate the horizontal interval into four (4) five hundred (500') foot long open hole sections with a liner incorporating external casing packers to insure isolation, and to cement the angle build section of the wellbore.

After the drilling operations were completed, examination of the mud $\log$ and geophysical logs provided information and data which led to a modification of the completion plan. The wellbore exited the target 
formation interval before the planned horizontal length had been drilled and the operator and others decided to eliminate this interval from consideration for stimulation. Approximately 116 feet of the wellbore was below the target interval, and another 278 feet which had few gas shows (see figure 13.1) was also eliminated from further consideration for stimulation.

The remaining wellbore was segregated into four zones as shown in figure 13.2. Zone one (1) was 492 feet long and contains the largest number of gas shows in the well. The second zone (2) was 750 feet long and contained six (6) gas shows along the wellbore. Zone number three (3) was 368 feet long, and zone number four (4) was 276 feet long. It is believed that modifying the completion plan in this manner was fully justified based on the data and information available at the time. Evaluation of the final openflow production rates after stimulation from three other horizontal or slant wells indicated that fracture efficiency was reduced when open hole sections longer than 350 feet were stimulated. The area of the wellbore shallower than zone four (4) was cemented. This section contained several small gas shows and minor oil shows. Consideration was originally given to conducting at least one stimulation in this section, however, problems encountered in stimulating the openhole sections resulted in excessive costs being incurred and this idea was abandoned.

In future horizontal well open hole type completions, careful consideration should be given to the length of open hole sections to be stimulated. Some combination of cased and cemented borehole and openhole completion should be considered. Depending upon the situation, perhaps no more than four zones should be stimulated, and these probably should not be longer than 350 feet.

\subsection{Stimulation Operations}

An attempt was made to improve the efficiency of stimulation operatione by using sliding sleeve ported collars for access to the wellbore behind the casing. The units were originally designed so that the first port collar which would be placed in zone 1 would open just by pressuring up on the casing. This could be done during the frac job itself, and a second stage could be initiated by dropping a ball which would 


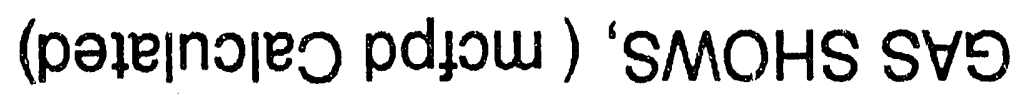

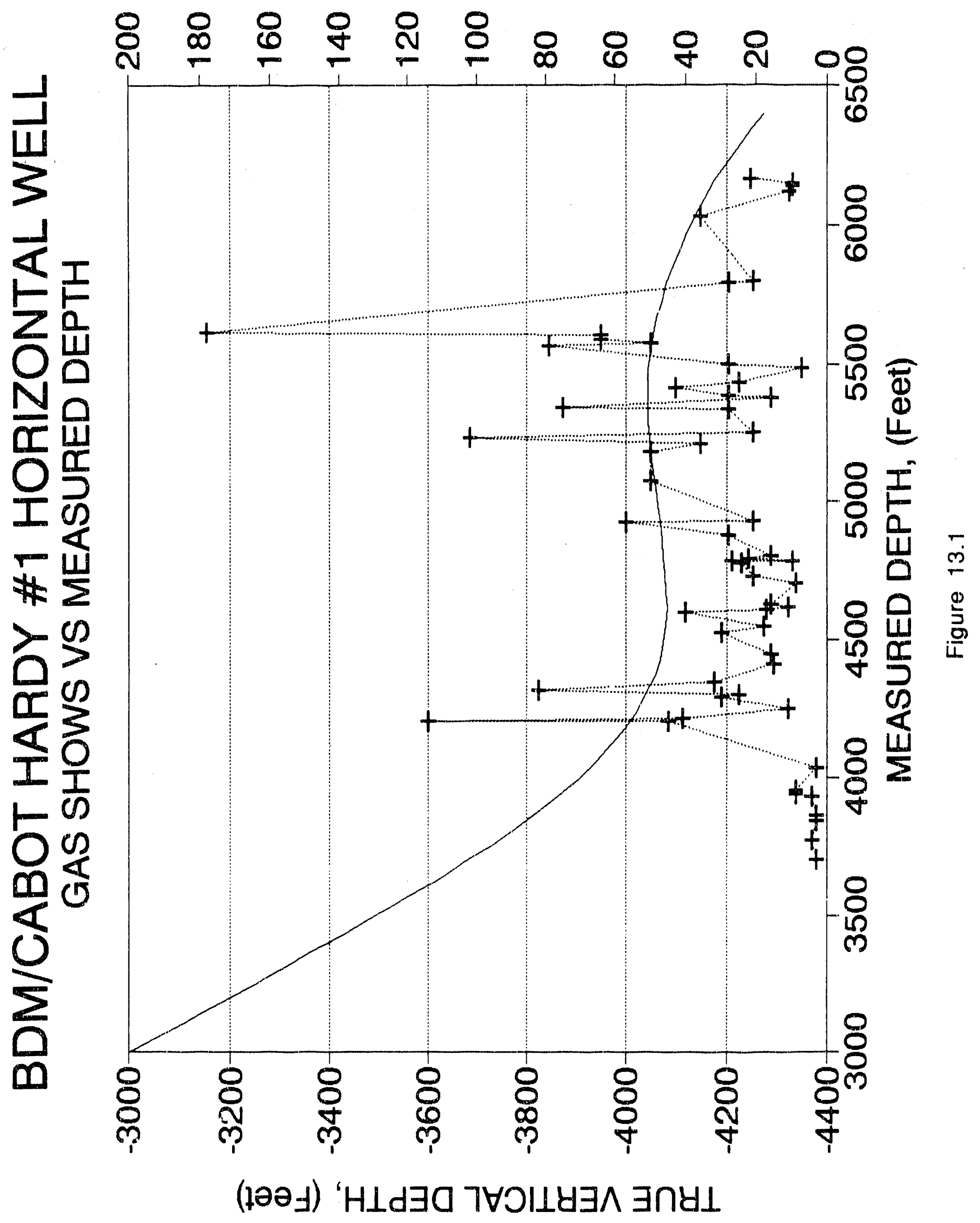




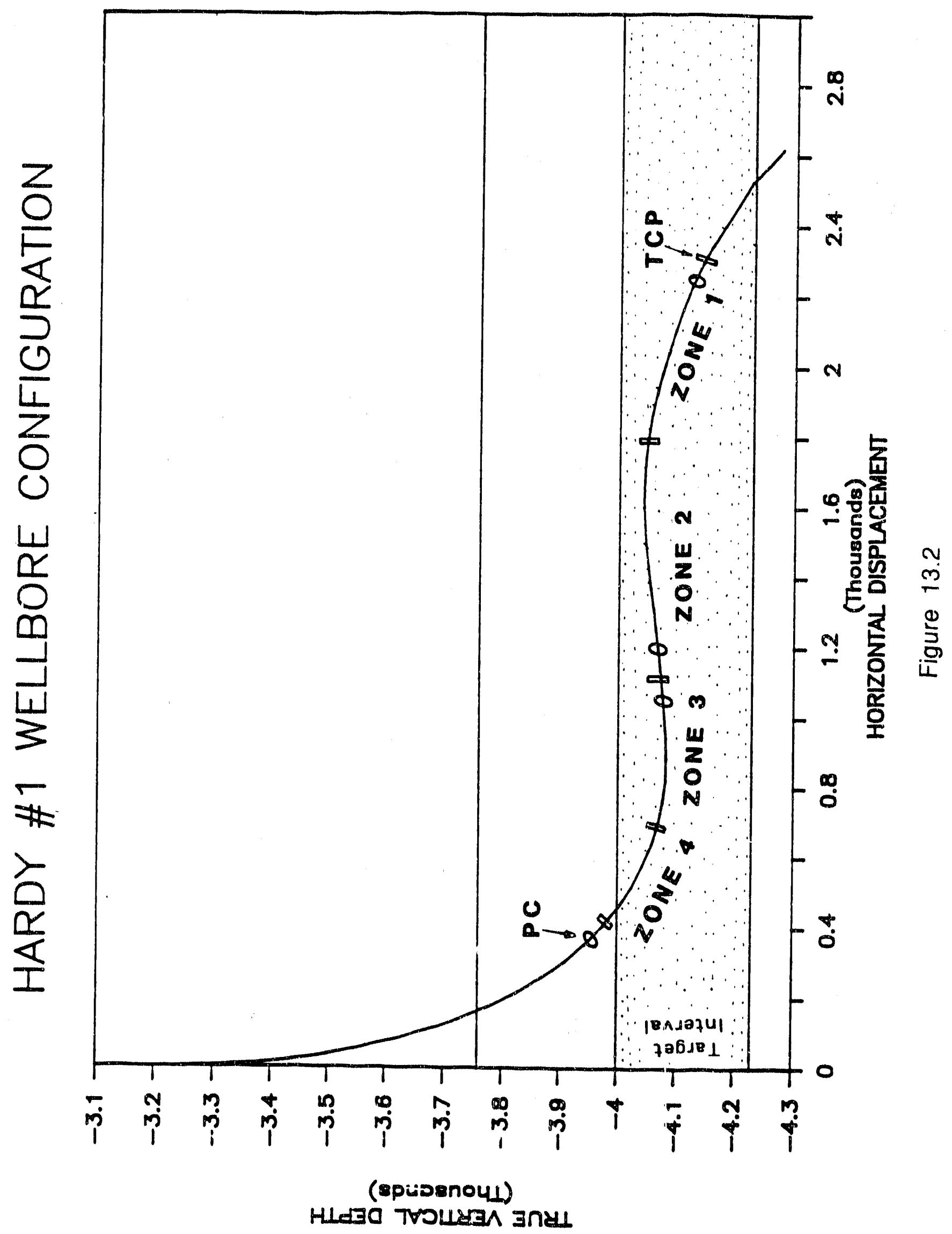


lodge in a baffle inside the second port collar, therefore opening the second port collar, and thus allowing two stages of stimulation to be conducted back to back. The pressure required to open the first port collar had to be set higher than the setting pressure of the external casing packers. However, the selection of an option to leave the first zone as a zone not to be stimulated prevented the use of the tool in the second zone and this ball and baffle technique was not tested. This would certainly be an option that should be given consideration in future horizontal holes and particularly in slant holes.

Cost effective options to consider for access to the formation for stimulation should include one or two joints of slotted casing. Isolation of one zone from other zones would be achieved with retrievable bridge plugs.

Zone one stimulation was conducted as expected except for a lower closure pressure (1200 psi) than projected. Failure to pump all of the sand available was unfortunate but not catastrophic. The zone cleaned up well and the open flow rate of 292 mcfpd after 8 hours on the fourth day after stimulation was encouraging. There was a curious phenomena which was observed but not explained. Breakdowns on both days for the stimulation was with nitrogen, with the first breakdown pressure being at 1900 psi while twenty-four hours later it was 2200 psi or 300 psi higher. Apparently during the overnight shut-in, the nitrogen gas which was injected moved through the fracture system increasing pressure and apparent stress as a result of the previous operation. The gas left in the wellbore most likely added 300 psi to the combination of horizontal earth stress and reservoir pressure that had to be overcome to open and propagate fractures.

As the stimulation process continued in Zone 2, a similar phenomena occurred with breakdown pressure increasing from 2300 psi to 3100 psi after an overnight delay. Increased friction pressure can account for part of this 800 psi increase but not all.

This phenomena suggests that further studies with stress models may be required to consider methods of optimizing stimulation procedures in horizontal wells when four stimulations are planned. Such modeling could exanine the potential beneficial effects of completely 
modeling could examine the potential beneficial effects of completely flowing a stimulated zone back until it returns to ambient reservoir conditions prior to stimulation.

\subsection{Well Testing Operations}

Well testing operations on horizontal wells is a very important aspect of the total operation. Well test results could aid in projecting well production and evaluating economics of drilling, completion stimulation, and production operations. Since the technology is new and still in the development stage, this analysis was helpful in determining the economics of the well as drilled and completed.

During the site selection process, BDMESC obtained complete records on all of the Cabot wells that were drilled in the area plus records from a few other companies which had production in the area. Analysis of this data showed that the average production rate for wells in the area started at about $60 \mathrm{mcfpd}$ and declined to $40 \mathrm{mcfpd}$ in 50 months. Based on a projected gas value of $\$ 2.00$ per mcf, a commercial horizontal well in the Devonian Shale would need to have an IOF rate close to 200 mcfpd as shown in Figure 13.3. The results of BDMESC's well testing and analysis indicated that the Hardy \#1 needed reduced cost or improved production rates are to make horizontal drilling more attractive. Economic analyses of this well is contained in the final project report prepared for DOE.

The type curve analysis methodology used by BDMESC is believed to be an adequate method of projecting reserves for horizontal wells. Review and analysis of the production data from this well at 5, 10, and 15 year intervals will confirm the predictive ability of the methodologies used in the study.

\subsection{Production Operations}

The results of well test analyses were used to simulate the post-stimulation productivity of Hardy \#1 using a three-dimensional reservoir simulator. The post-stimulation well test analysis indicated a formation capacity value of $7.31 \mathrm{md}-\mathrm{ft}(\mathrm{Kh})$ and an effective wellbore length of $900^{\prime}$. Using this data, the projected cumulative gas production after 30 years is $475 \mathrm{mmcf}$ (Figure 13.4). 


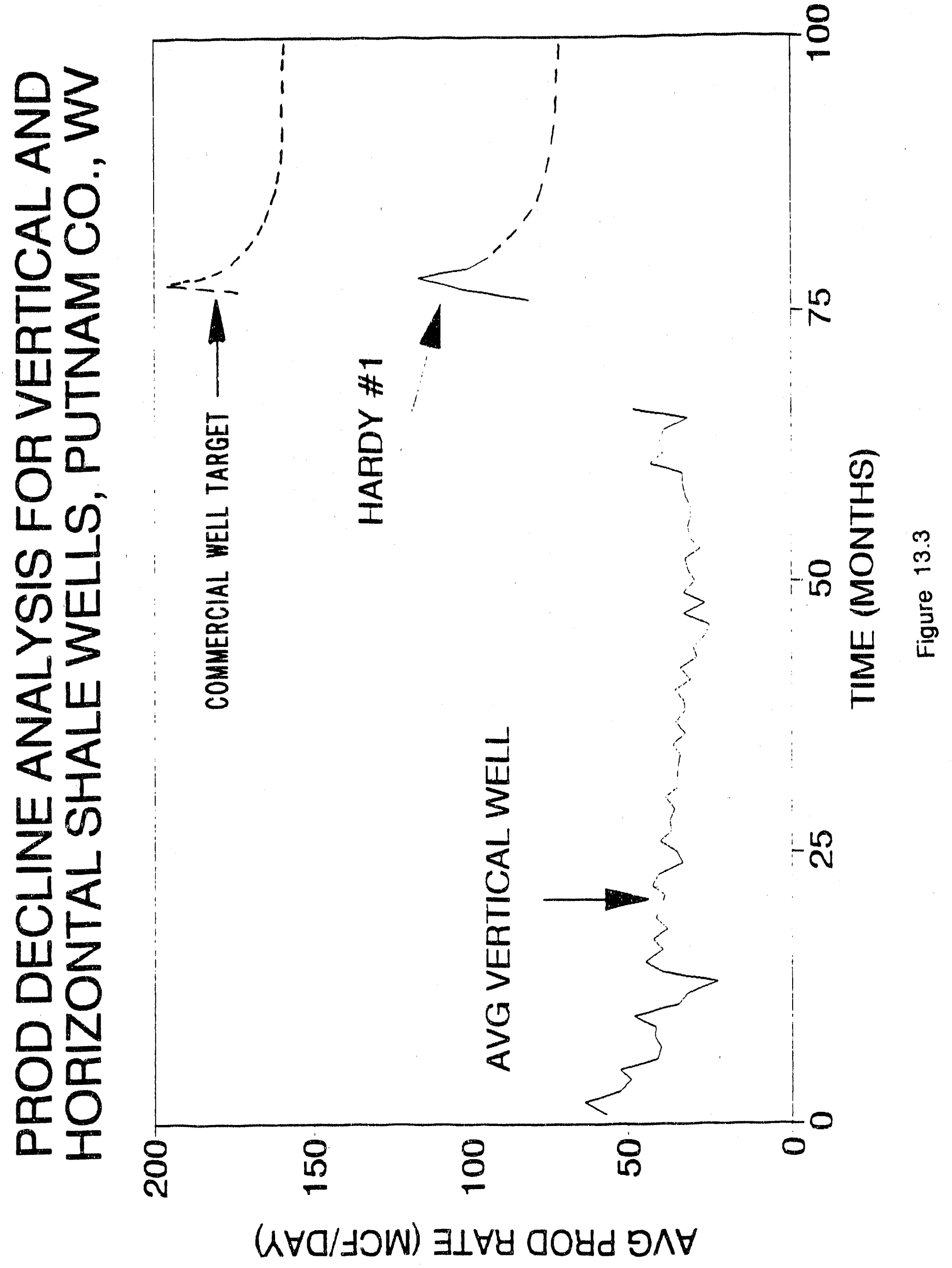




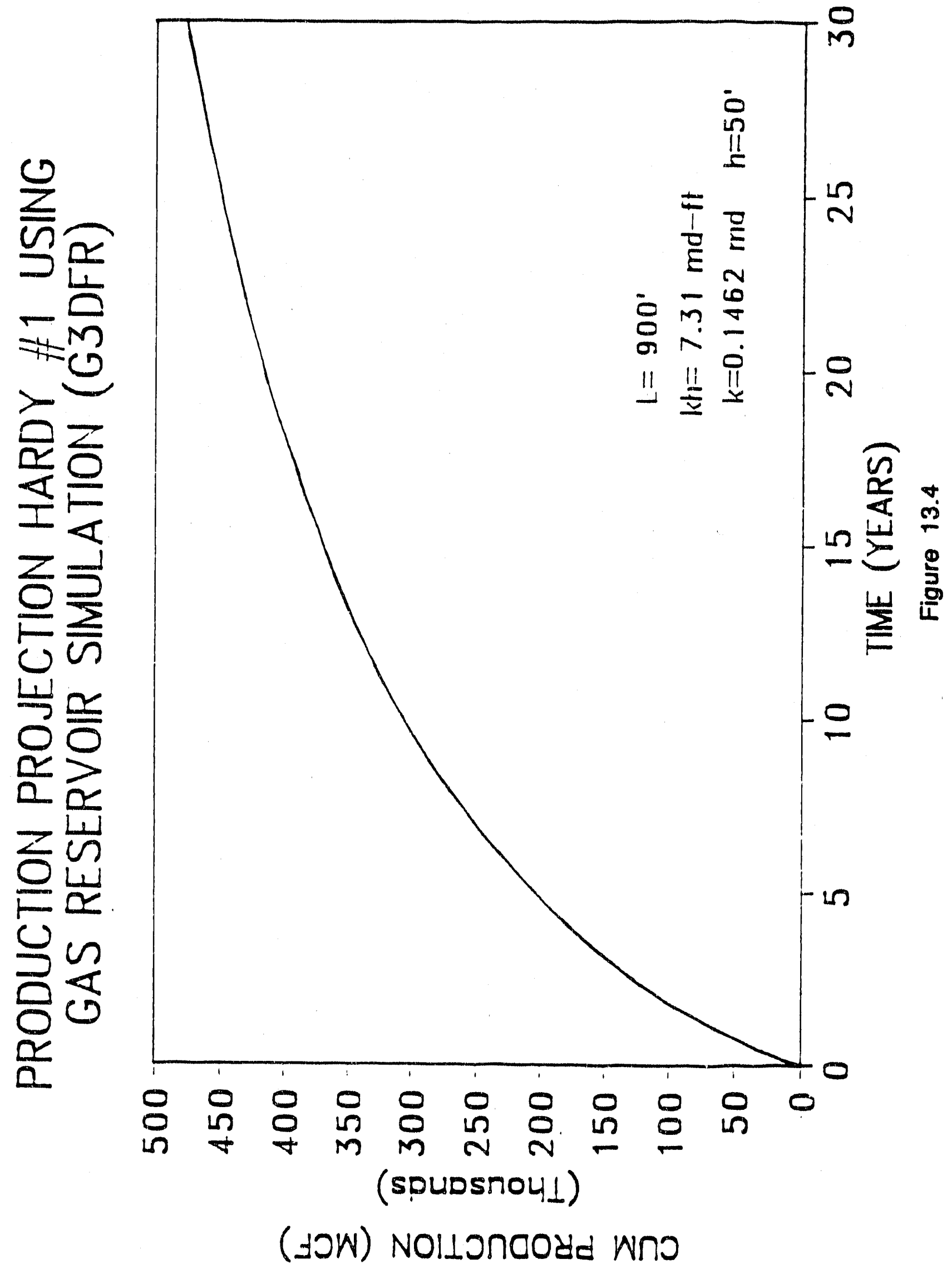


Hardy \#1 was turned into the gas sales line on May 16, 1990. Figures 13.5 and 13.6 present the actual daily production rate and the cumulative production respectively for the period of May 1990 to March, 1992, a period of twenty months.

As indicated in Figure 13.5, Hardy \#1 produced at an average rate of 70 mcfd for most of the first two years. It is believed that if Zones 2 and 3-4 were stimulated successfully, the production from Hardy \#1 would have been double the current rate.

The production decline rate for the horizontal well is about half the decline rate of a typical vertical well in the area. This is believed to be a function of the much larger drainage area defined by the horizontal well as compared to the vertical wells.

Fiure 13.7 is a match of the actual production data and the production decline type-curve based on actual well data from the area. Using the decline curve match, the projected cumulative gas production after 30 years is 415 mmcf (Figure 13.8).

\subsection{WELL COST ANALYSIS}

Well cost was reduced significantly for Hardy\#1, when compared to the well cost of RET\#1, the first air-drilled horizontal well. This cost reduction is attributed to improvements in drilling and completion technologies over a period of four years. The major reduction in cost was in the drilling phase where drilling time was reduced from 58 to 30 days.

Table 14.1 exhibits the cost involved in drilling, completing, and stimulating Hardy\#1. The high stimulation cost is mainly attributed to problems and associated delays encountered when attempting to maripulate the port collars, and perforate the casing to stimulate zone 2 and combined zone 3-4., which would not accept sand-laden foam at concentrations greater than $1 \mathrm{lb} / \mathrm{gal}$.

A single vertical well drilled and completed in the Putnam County area, costs approximately $\$ 180,000.00$. The total cost for the Hard'y \#1 well was $\$ 921,211.00$, which is 5.1 times the cost of a vertical well. The average vertical well in the area of the Hardy\#1 well had projected 


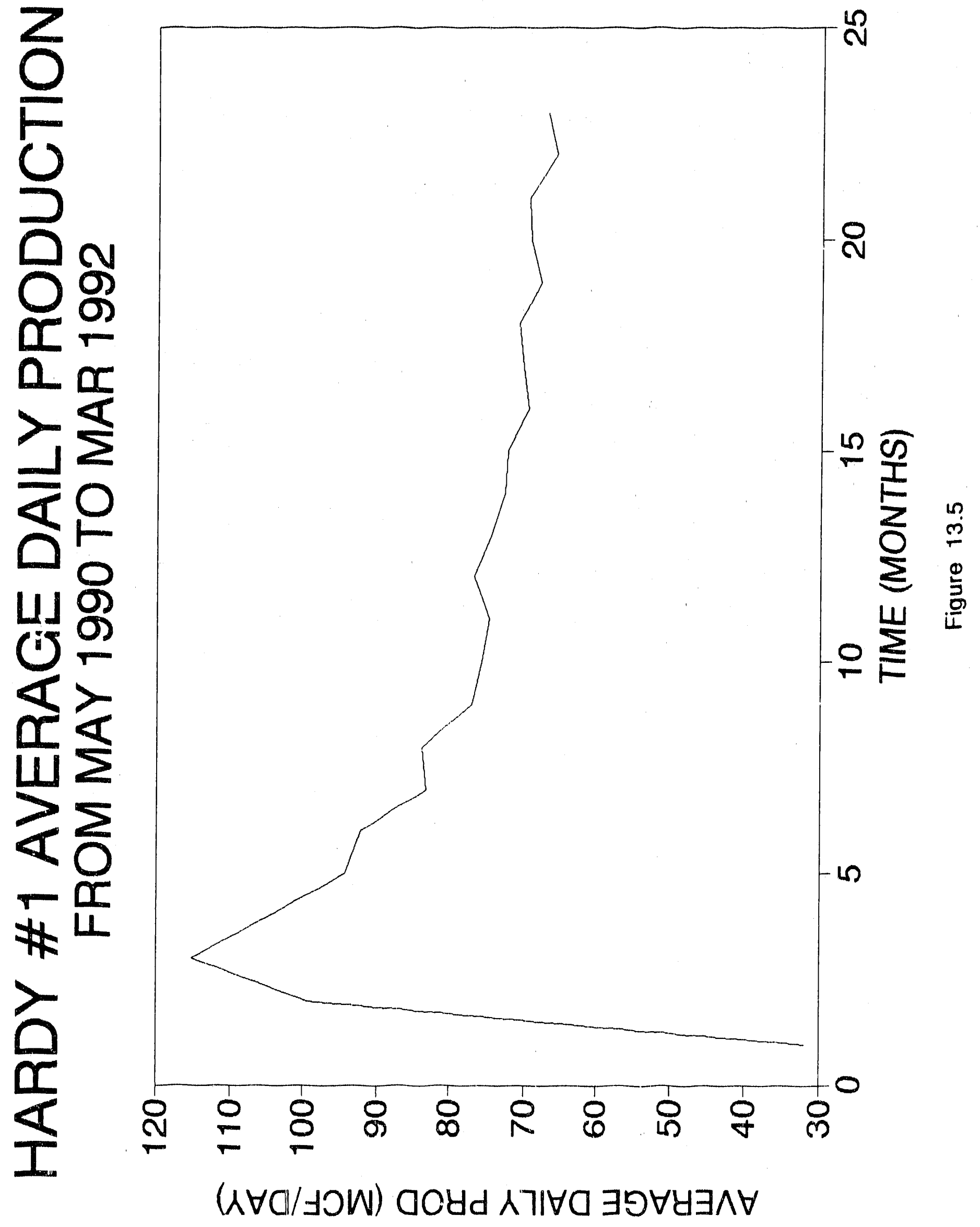




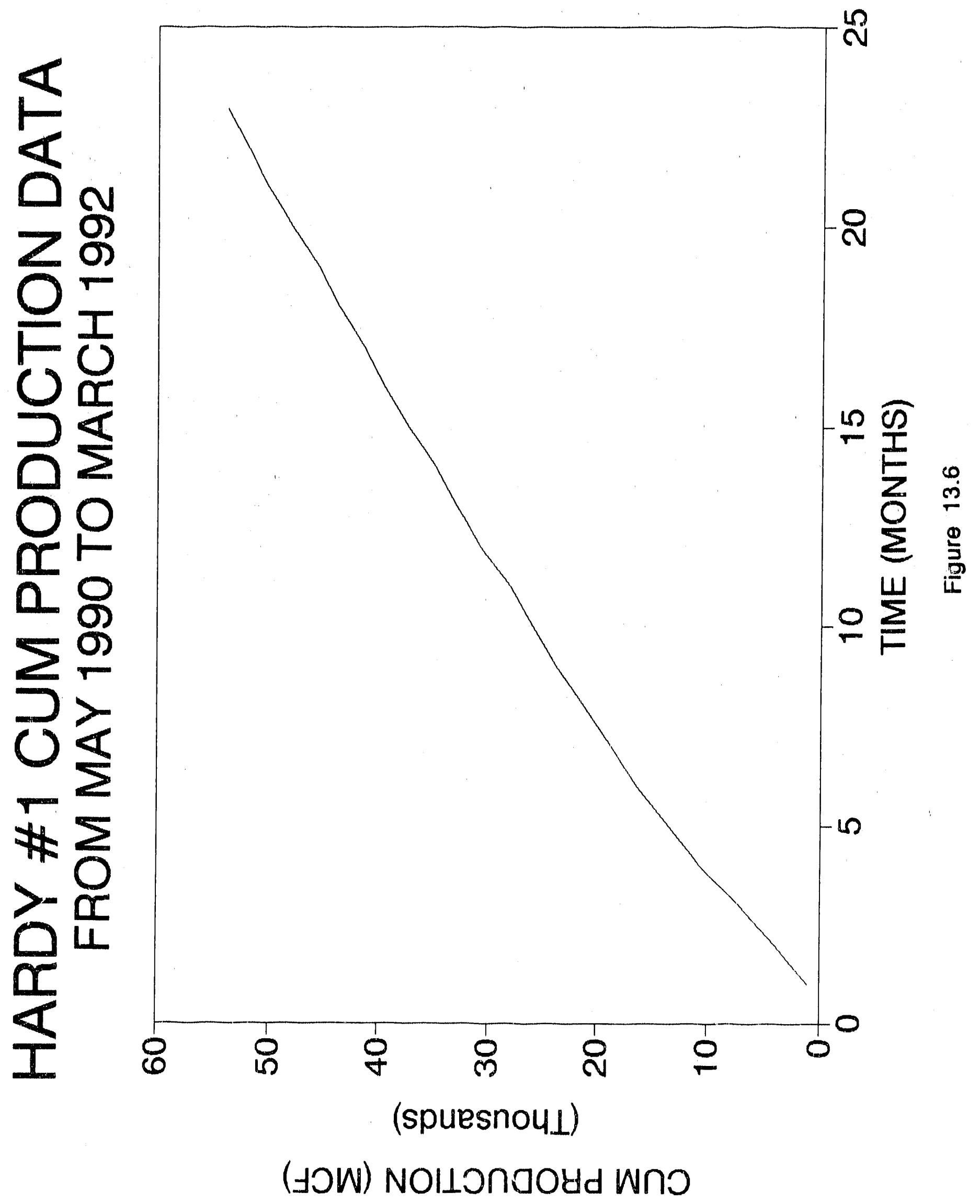


Table 14.1 - Cost Data BDM/Cabot Horizontal Well

DRILLNG ACTIVITIES

TTEM DESCRIPTION

BDM/CABOT/DOE

Drilling \& Services

205,575

Directional Driller Services

33,757

Steering Tool \& Directional Tool Rental

28,907

Directional Consultant Engineer - GSM

7,085

Rentals (Reamers, Stabilizers, Other)

3,558

Drilling Fluid Additives

9,300

Tubulars

89,680

Cementing

13,681

External Casing Packers \& Port Collars

19,277

Build Location, Reclamation \& Dozer

57,172

Mud Logging

11,133

Field Engineer (Vertical Hole)

7,448

Drill Pipe Inspection

Pciver Tongs

5,303

630

Permit \& Survey

7,525

Neter Setup \& Testing

2,438

Miscellaneous (Trucking \& Field Services)

3,370

DRILLNG SUBTOTAL

505,888

CORING AND LOGGING ACTIVTIIES

Coring

Shallow Logging

23,212

Deep Logging

40,933

CORINGLOGGING SUBTOTAL

64,145

STIMULATION ACTIVTTIES

Setup \& Testing ECP's \& PC's

6,074

Dozer \& Road Work

4,890

Production Tubing, Tank Rental \& Water Hauling

19,382

Video Camera Runs

2,810

Operate ECP's \& PC's Services

27,936

Fishing Equipment

10,789

Frac Fluids \& Stimulation Equipment

150,943

Perforations

13,977

24,910

Field Engineer

18,464

Tool Rental \& Testing

4,904

Pip Disposal/Reclamation

59,183

Trucking \& Miscellaneous

6,918

STIMULATION SUBTOTAL

351,178

GRAND TOTAL HORIZONTAL WELL COST

921,211 


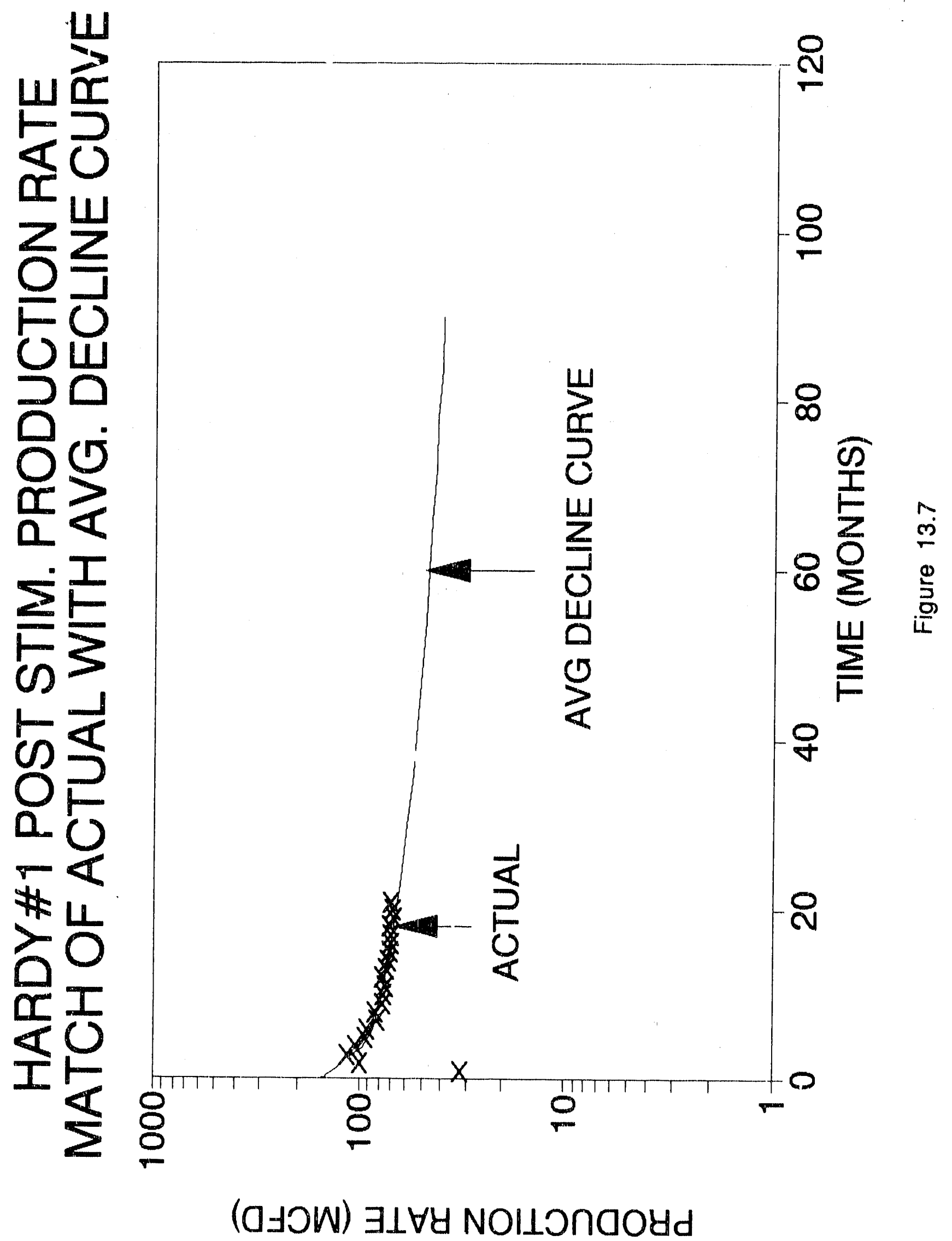




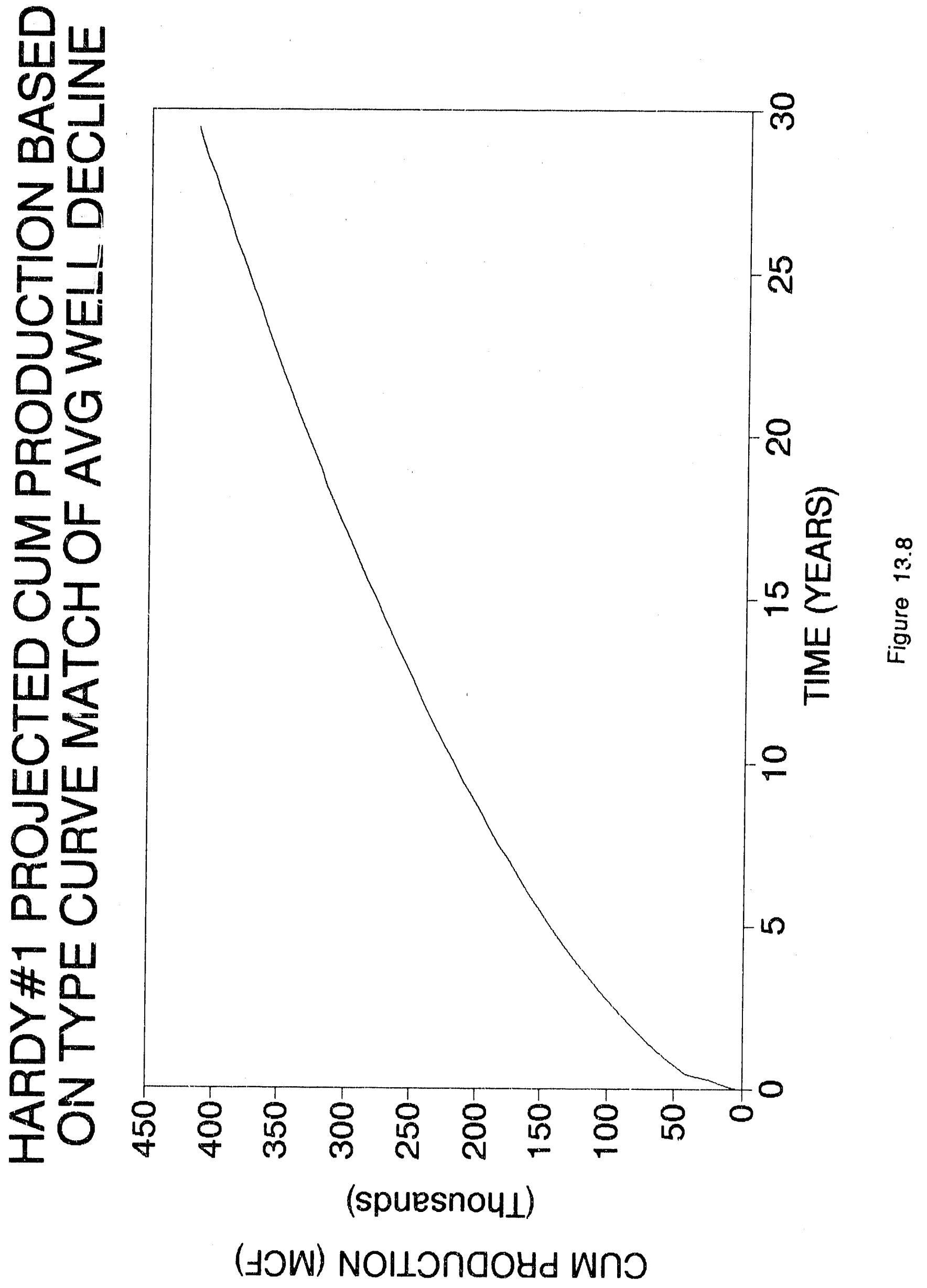


ultimate recoveries of $231 \mathrm{mmcf}$ of gas compared to a projected 475 mmcf of recovery over 30 years for the Hardy \#1 well.

The economics of the BDM/Cabot well are documented in the Final report to the DOE ("Site Selection, Drilling, and Completion of Two Horizontal Wells in the Devonian Shales of West Virginia"). Gas production achieved by the BDM/Cabot well as compared to the average vertical well drilled in the area is not sufficient to overcome the learning curve costs associated with this first well. The well is considered to be marginally eccnomic based on present conditions of cost and gas sales price.

\subsection{SUMMARY AND CONCLUSIONS}

The Hardy HW\#1 was drilled without any major problems during the inclined angle building phase except for steering tool operations. Reliable tool face data acquisition equipment needs to be developed and tested to further reduce drilling costs.

Geophysical logging operations are far too costly for the data provided. Operators may choose to rely on mud logging data as the primary source of data for completion operation decisions. Video logging can be very useful but low cost reliable high resolution systems must be developed to make them attractive to Appalachian area operators.

Actual drilling operations were reduced from fifty-eight days in 1986 (RET\#1 well) to thirty days on the Hardy HW\#1 well although the length of footage drilled was only twenty feet less than the RET\#1 well. The increased rate of angle building saves more than twenty days in drilling time.

One of the most important aspects of drilling a successful slant/horizontal well is the site selection process. Selection of an area that has high probability of providing enough reserves for payout of the drilling operation is a key goal.

Drilling with air as the circulation medium and oil as a lubricant for downhole motors operated at 250 to 300 psi pressure is a viable alternative to drilling at higher pressures (600 psi) even if there is no 
improved hardening of the steering tools to reduce vibration at lower pressures and higher volume through-puts.

Port collars which operate by rotation rather than reciprocation are very difficult to operate in a horizontal hole and are not an efficient design for this type of operation.

In an open hole type of completion where access to open natural fractures are provided, the length of treatment zones should probably be limited to 350 to 400 feet. This suggest that a 1400 to 1600 foot horizontal wellbore length providing four zones for stimulation may be more suitable for fractured Devonian Shale reservoirs than a longer wellbore length considering costs and efficiencies of operation. 


\subsection{REFERENCES}

1. Overbey, W.K. Jr., Salarny, S.P., Locke, C.D., "Recovery Efficiency Test Final Report," U.S. Department of Energy, Contract \#DEAC21-85MC22002, Morgantown, West Virginia, February, 1989.

2. GRI: "Eastern Devonian Gas Shales Workshop Presentations and Short Course," Charleston, WV, Sept. 7-9, 1988.

3. Hasan, A. R., Kabir, C. S.: "Pressure Build-up Analysis: A Simplified Approach," JPT, January 1983, 178 - 188.

4. Duda, J. R., Salamy, S. P., Aminian, K.: "Pressure Analysis of an Unstimulated Horizontal Well Using Type Curves," SPE \#19343 presented at the 1989 SPE Eastern Regional Meeting, Morgantown, WV, October 24 -27.

5. Earlougher, R. C., Jr.: Advances in Well Test Analysis, SPE of AIME, New York City (1977), p39. 
17.0 APPENDICES

Page

A-1 $133 / 8^{n}$ CASING TALLY

104

A-2 9 5/8" CASING TALLY

105

A-3 4 1/2" CASING TALLY

106

B BOTTOM HOLE DRILLING ASSEMBLIES (BHA'S)

108

C BUILD AND WALK RATE DATA FOR HARDY HW\#1 WELL 111

D MULTISHOT SURVEY OF WELLBORE

114

E DRILLLPIPE TALLY

117

F MULTISHOT PIPE TALLY

G SINGLE SHOT SURVEYS TAKEN DURING DRILLING OPERATIONS

H GAS SHOWS FROM MUD LOGS

I DAILY DRILLING REPORTS

128

J DAILY COST REPORTS

161

K WEU COMPLETION REPORT

197

L PRE-AND POST-STIMULATION PRESSURE BUILD-UP DATA 


\section{APPENDIX A}

CASING TALLYS

105 


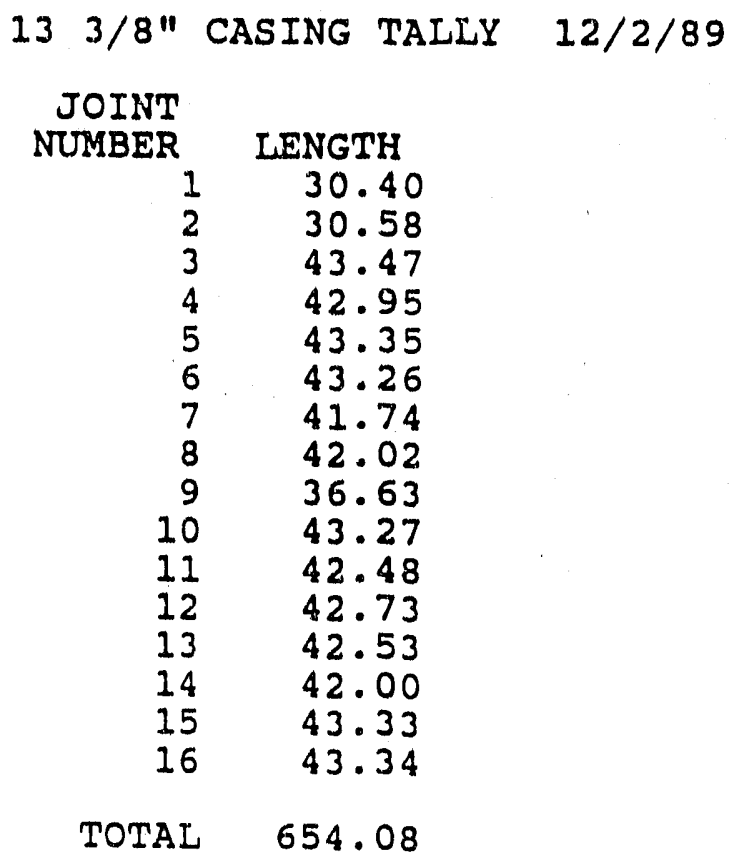




\begin{tabular}{|c|c|c|c|}
\hline 95 & 3" CASING & TALLY & $2 / 9 / 89$ \\
\hline $\begin{array}{r}\text { JOINT } \\
\text { NUMBER } \\
1 \\
2 \\
3 \\
4 \\
5 \\
6 \\
7 \\
8 \\
9 \\
10 \\
11 \\
12 \\
13 \\
14 \\
15 \\
16 \\
17 \\
18 \\
19 \\
20 \\
21 \\
22 \\
23 \\
24 \\
25 \\
26 \\
27 \\
28 \\
29 \\
30 \\
31 \\
32 \\
33 \\
34 \\
35 \\
36 \\
37 \\
38 \\
39 \\
40\end{array}$ & $\begin{array}{r}\text { LENGTH } \\
15.10 \\
43.90 \\
44.00 \\
43.55 \\
43.75 \\
43.80 \\
43.75 \\
43.80 \\
44.00 \\
43.40 \\
43.40 \\
43.65 \\
43.80 \\
43.60 \\
44.00 \\
44.00 \\
43.65 \\
43.40 \\
43.70 \\
43.70 \\
43.75 \\
43.70 \\
43.90 \\
44.25 \\
44.10 \\
43.90 \\
43.70 \\
43.65 \\
43.55 \\
43.30 \\
44.00 \\
43.95 \\
43.55 \\
43.60 \\
43.65 \\
44.25 \\
43.90 \\
43.50 \\
43.85 \\
44.05\end{array}$ & $\begin{array}{r}\text { JOINT } \\
\text { NUMBER } \\
41 \\
42 \\
43 \\
44 \\
45 \\
46 \\
47 \\
48 \\
49 \\
50 \\
51 \\
52 \\
53 \\
54 \\
55 \\
56 \\
57 \\
58 \\
59 \\
60 \\
61 \\
62 \\
63 \\
64 \\
65 \\
66 \\
67 \\
68 \\
69 \\
70 \\
71 \\
72 \\
73 \\
74 \\
75 \\
76 \\
77 \\
78 \\
79 \\
80\end{array}$ & $\begin{array}{r}\text { LENGTH } \\
44.25 \\
43.70 \\
43.95 \\
43.85 \\
43.60 \\
43.80 \\
43.75 \\
43.75 \\
43.85 \\
43.70 \\
43.35 \\
43.90 \\
44.05 \\
43.90 \\
43.70 \\
43.90 \\
42.75 \\
43.95 \\
43.80 \\
43.60 \\
43.85 \\
15.00\end{array}$ \\
\hline UUBTOTAL & 1722.05 & SUBTOTAL & 933.95 \\
\hline TOTAL & 2656.00 & & \\
\hline
\end{tabular}


$41 / 2^{\prime \prime}$ CASINO TALLY $1-1.90$

\begin{tabular}{|c|c|c|c|c|c|c|c|c|c|c|c|}
\hline JOINT & & SETTING & JOINT & & SETTINO & JOINT & & SETTINO & JOINT & & SETTINO \\
\hline NUMBER & LENOYH & DEPTH & NUMBER & LENGTH & DEPTH & NUMBER & LENOTH & DEPTH & NUMBER & LENOTH & DEPTH \\
\hline SET AT & & 6150.81 & & & & & & & & & \\
\hline 1 & 44.52 & 6106.29 & 41 & 44.33 & 4625.65 & 81 & 44.54 & 3032.67 & 121 & 44.55 & 1255.30 \\
\hline 2 & 44.33 & 6061.96 & 42 & 44.75 & 4580.90 & 82 & 44.40 & 2988.27 & 122 & 44.45 & 1210.85 \\
\hline 3 & 44.36 & 6017,60 & 43 & 44.41 & 4536.49 & 83 & 44.59 & 2943.68 & 123 & 44.40 & 1166.45 \\
\hline 4 & 7.20 & 6010.40 & 44 & 44.61 & 4491.88 & 84 & 44.52 & 2899.16 & 124 & 44.40 & 1122.05 \\
\hline 5 & 44.50 & 5965.90 & 45 & 44.48 & 4447.40 & 85 & 44.47 & 2854.69 & 125 & 44.55 & 1077.50 \\
\hline 6 & 44.62 & 5921.28 & 46 & 44.35 & 4403.05 & 86 & 44.38 & 2810.31 & 126 & 44.40 & 1033.10 \\
\hline 7 & 2.40 & 5918.88 & 47 & 9.65 & 4393.40 & 87 & 44.64 & 2765.67 & 127 & 44.40 & 988.70 \\
\hline 8 & 44.51 & 5874.37 & 48 & 7.20 & 4386.20 & 88 & 44.36 & 2721.31 & 128 & 44.65 & 944.05 \\
\hline 9 & 44.40 & 5829.97 & 49 & 44.42 & 4341.78 & 89 & 44.70 & 2676.61 & 129 & 44.45 & 899.60 \\
\hline 10 & 44.43 & 5785.54 & 50 & 44.09 & 4297.69 & 90 & 44.40 & 2632.21 & 130 & 44.30 & 855.30 \\
\hline 11 & 44.46 & 5741.08 & 51 & 44.67 & 4253.02 & 91 & 44.47 & 2587.74 & 131 & 44.40 & 810.90 \\
\hline 12 & 44.33 & 5696.75 & 52 & 44.32 & 4208.70 & 92 & 44.46 & 2543.28 & 132 & 44.40 & 766.50 \\
\hline 13 & 44.61 & 5652.14 & 53 & 44.45 & 4164.25 & 93 & 44.36 & 2498.92 & 133 & 44.40 & 722.10 \\
\hline 14 & 44.52 & 5607.62 & 54 & 44.46 & 4119.79 & 94 & 44.45 & 2454.47 & 134 & 44.40 & 677.70 \\
\hline 15 & 44.42 & 5563.20 & 55 & 9.68 & 4110.11 & 95 & 44.47 & 2410.00 & 135 & 44.40 & 633.30 \\
\hline 96 & 44.30 & 5518.90 & 56 & 7.20 & 4102.91 & 96 & 44.40 & 2365.60 & 136 & 44,40 & 588.90 \\
\hline 17 & 7.20 & 5591.70 & 57 & 44.73 & 4058.18 & 97 & 44.45 & 2321.15 & 137 & 44.40 & 544.50 \\
\hline 18 & 44.67 & 5467.03 & 58 & 2.40 & 4055.78 & 98 & 44.40 & 2276,75 & 138 & 44.35 & 500.15 \\
\hline 19 & 44.43 & 5422.60 & 59 & 44.56 & 4011.22 & 99 & 44.50 & 2232.25 & 139 & 44.45 & 455.70 \\
\hline 20 & 44.62 & 5377.98 & 60 & 44.67 & 3966.55 & 100 & 44.35 & 2187.80 & 140 & 44.40 & 411.30 \\
\hline 21 & 44.47 & 5333.51 & 61 & 44.41 & 3922.14 & 101 & 44.40 & 2143.50 & 141 & 43.80 & 367.50 \\
\hline 22 & 44.49 & 5289.02 & 62 & 44.49 & 3877.65 & 102 & 44.40 & 2099.10 & 142 & 44.50 & 323.00 \\
\hline 23 & 44.54 & 5244.48 & 63 & 44.50 & 3833.15 & 103 & 44.35 & 2054.75 & 143 & 44.30 & 278.70 \\
\hline 24 & 44.45 & 5200.03 & 64 & 44.60 & 3788.55 & 104 & 44.50 & 2010.25 & 144 & 44.40 & 234.30 \\
\hline 25 & 44.47 & 5155.56 & 65 & 44.46 & 3744.09 & 105 & 44.45 & 1965.80 & 145 & 44.45 & 189.85 \\
\hline 26 & 44.43 & 5111.13 & 66 & 44.40 & 3699.69 & 106 & 44.45 & 1921.35 & 146 & 44.40 & 145.45 \\
\hline 27 & 44.54 & 5066.59 & 67 & 44.59 & 3655.14 & 107 & 44.40 & 1876.95 & 147 & 44.55 & 100.90 \\
\hline 28 & 44.44 & 5022.15 & 68 & 44.53 & 3610.61 & 108 & 44.55 & 1832.40 & 148 & 44.45 & 56.45 \\
\hline 29 & 44.41 & 4977.74 & 69 & 44.40 & 3566.21 & 109 & 44.45 & 1787.95 & 149 & 44.45 & 12.00 BELOW KB \\
\hline 30 & 44.39 & 4933.35 & 70 & 44.58 & 3529.63 & 110 & 44.40 & 1743.55 & 150 & 44.50 & OUT \\
\hline 31 & 44.43 & 4888.92 & 71 & 44.52 & 3477.11 & 111 & 44.50 & 1699.05 & 159 & 44.50 & WT \\
\hline 32 & 44.52 & 4844.40 & 72 & 44.47 & 3432.54 & 112 & 44.45 & 1654.60 & 152 & 44.55 & WT \\
\hline 33 & 2.40 & 4842.00 & 73 & 44.45 & 3388.19 & 113 & 44.50 & 1610.10 & 153 & 44.35 & WT \\
\hline 34 & 44.64 & 4797.56 & 74 & 44.55 & 3343.64 & 116 & 44.35 & 1565.75 & 154 & 44.40 & OUT \\
\hline 35 & 14.70 & 4782.86 & 75 & 44.39 & 3299.25 & 115 & 44.40 & 1521.35 & 155 & 44.35 & OUT \\
\hline 36 & 14.50 & 4768.36 & 76 & 44.44 & 3254.81 & 116 & 43.70 & 1477.65 & 156 & 44.50 & out \\
\hline 37 & 7.20 & 4761.16 & 77 & 44.30 & 3210.51 & 117 & 44.40 & 1633.25 & 157 & 44.40 & QUT \\
\hline 38 & 44.38 & 4716.78 & 78 & 44.35 & 3166.16 & 118 & 44.45 & 1388.80 & 158 & 44.65 & OUT \\
\hline 39 & 2.40 & 4714.38 & 79 & 44.40 & 3121.76 & 119 & 44.45 & 1344.35 & 159 & 44.35 & OUT \\
\hline 40 & 44.40 & 4669.98 & 80 & 44.55 & 3077.21 & 120 & 44.50 & 1299.85 & 160 & & \\
\hline
\end{tabular}

PORT COLLARS ARE 2.401 LONG

EXTERNAL CASING PACKERS ARE 7.201 LONG 
APPENDIX B

BOTTOM HOLE DRILLING

ASSEMBLIES (BHA'S) 
BHA \#1 - RUN 12-12-89

BIT - $83 / 4^{\prime \prime}, M 84 F, 3-16^{\prime} \mathrm{S}$

EASTMAN MOTOR, $63 / 4 "$

STABILIZER, $77 / 811$

$x-0$ SUB, $6.5 \times 2$ 1/4"

ORIENTING SUB $6.25 \times 3.75 "$

MONEL, $65 / 16 \times 213 / 1611$

MONEI, $65 / 16 \times 213 / 16 "$

TOTAL
LENGTH, FT.

1.00

20.75 BEND SET AT 1.1

5.67

1.47

2.18

31.18

30.75

93.00

BHA \#2 - RUN 12-13-89

BIT - $83 / 4 ", M 84 F, 3-16^{\prime} \Xi$

EASTMAN MOTOR, $63 / 4$ " $X-O$ SUB, $6.5 \times 21 / 4 "$

ORIENTINS SUB $6.25 \times 3.75$ "

MONEI, $65 / 16 \times 213 / 16 "$

MONEI, $65 / 16 \times 2$ 13/16"

TOTAL

$\mathrm{BHA} \not 3-\mathrm{RUN} 12-14-89$

BIT - $83 / 4^{\prime \prime}, M 84 F, 3-16^{\prime} \mathrm{S}$

EASTMAN MOTOR, $63 / 4 "$

BENT SUB $1.561 / 2 "$ " 62 2 $1 / 4 "$

ORIENTING SUB $6.25 \times 3.75^{\prime \prime}$

MONEI, $65 / 16 \times 213 / 16 "$

MONEL, $65 / 16 \times 2$ 13/161"

TOTAL

$\mathrm{BHA} \nRightarrow 4-$ RUN 12-14-89

BIT - $81 / 2 "$, M84F, open

EASTMAN MOTOR, $63 / 4 "$

BENT SUB $1.561 / 2 " \times 2$ X $1 / 4$ "

ORIENIING SUB $6.25 \times 3.75 "$

MONEI, $65 / 16 \times 213 / 16 "$

MONEI, $65 / 16 \times 2$ 13/161"

TOTAL
1.00

20.75 bend set at 1.3

1.47

2.18

31.18

30.75

87.33

1.00

20.75 bend set at 1.3 1.25

2.18

31.18

30.75

87.11
1.00

20.75 bend set at 1.3

1.25

2.18

31.18

30.75

87.11 
BHA \#5 - RUN 12-16-89

BIT - $81 / 2^{\prime \prime}, M 84 F, 11-14-14$

BAKER MOTOR, $63 / 4 "$

FLOAT SUB $53 / 4 " \times 2$ 1/4"

$x-061 / 2 " x 21 / 4^{\prime \prime}$

ORIENTING SUB $6.25 \times 3.75 "$

MONEL, $65 / 16 \times 213 / 16^{\prime \prime}$

MONEL, $65 / 16 \times 213 / 16^{\prime \prime}$

TOTAL

BHA \#6 - RUN 12-20-89

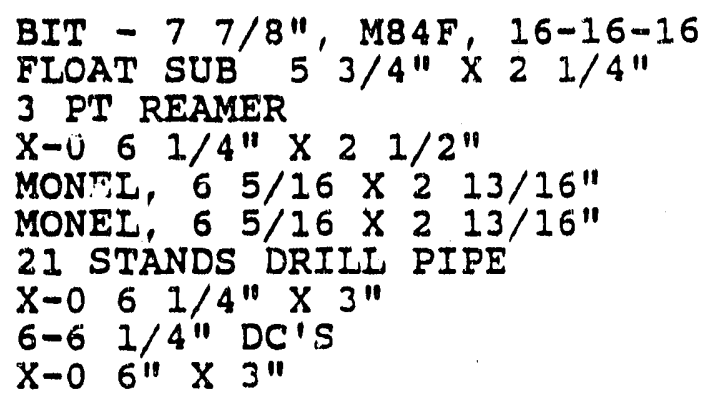

TOTAL

BHA \#7 - RUN 12-21-89

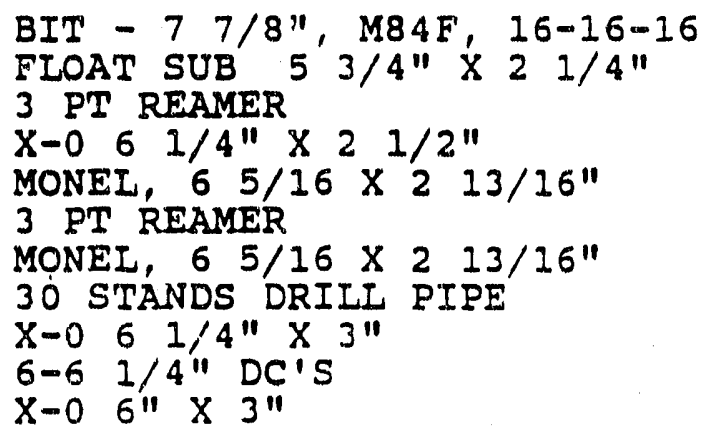

TOTAL
LENGTH, FT.

1.00

23.10 bend set at 2

1.87

1.47

2.18

31.18

30.75

91.55
1.00

1.87

4.72

1.80

31.18

30.75

1302.00

2.00

179.00

1.79

1556.11

$\begin{array}{ll}2.35 & 1.75 \\ 6.25 & 7.00\end{array}$

$2 \cdot 35$
$6 \cdot 25$

7.00

$$
\begin{array}{rrr}
1.00 & & \\
1.87 & & \\
4.72 & & \\
1.80 & & \\
31.18 & & \\
7.00 & 3.60 & 1.60 \\
30.75 & 6.25 & 7.00 \\
1860.00 & & \\
2.00 & & \\
179.00 & & \\
1.79 & &
\end{array}
$$

2121.11 


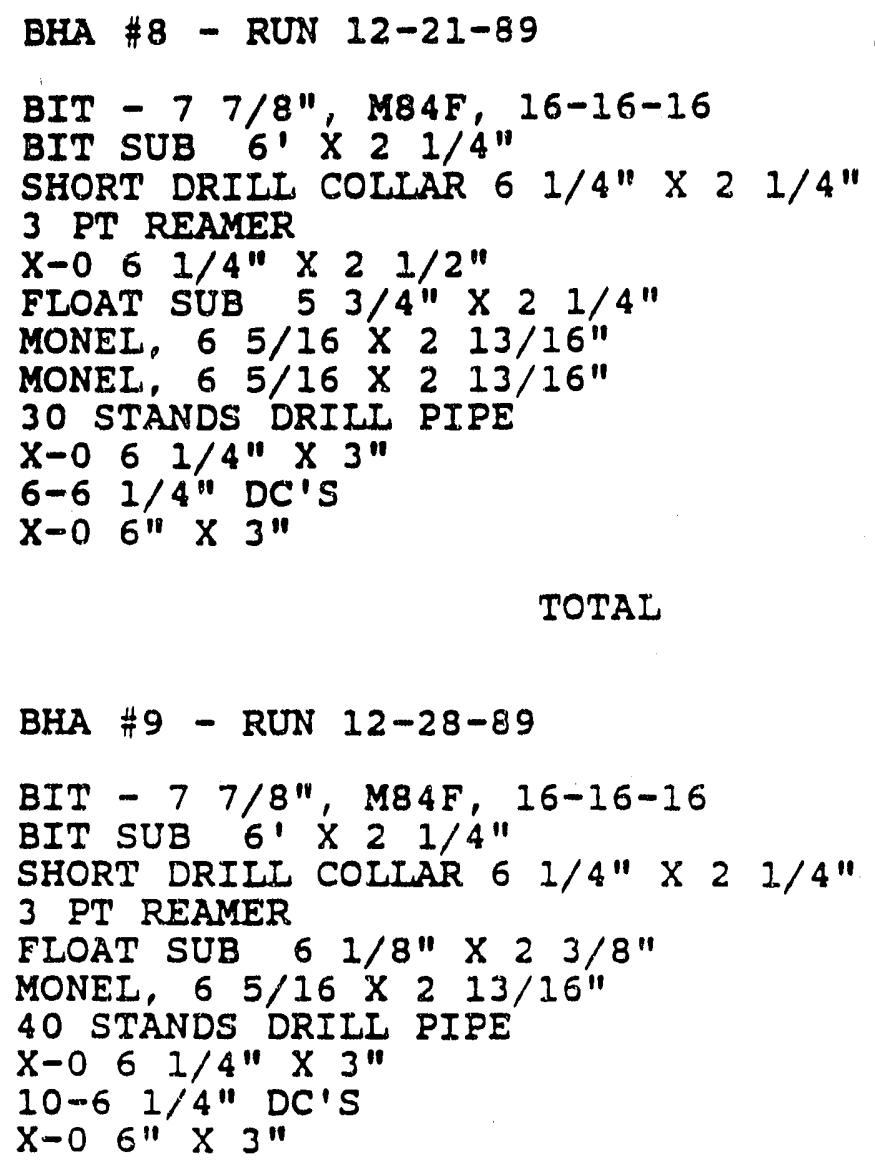

TOTAL

BHA \#9 - RUN 12-28-89

1.00

1.92

10.75

7.00

1.60

30.75

2480.00

2.00 300.05

1.79

TOTAL 


\section{APPENDIX C \\ BUILD AND WALK RATE \\ DATA FOR HARDY HW\#1 WELL}


HARDY HW NO. 1 DOE/BDMESC/CABOT

\begin{tabular}{|c|c|c|c|c|c|c|c|}
\hline $\begin{array}{l}\text { MEASURED } \\
\text { DEPTH } \\
\text { FEET }\end{array}$ & $\begin{array}{c}\text { DRIFT } \\
\text { ANGLE } \\
\text { DEGREES }\end{array}$ & $\begin{array}{l}\text { DRIFT } \\
\text { AZIMUTH } \\
\text { DEGREES }\end{array}$ & $\begin{array}{l}\text { COURSE } \\
\text { LENGTH } \\
\text { FEET }\end{array}$ & $\begin{array}{l}\text { BUILD } \\
\text { RATE } \\
\text { DEG/100 }\end{array}$ & $\begin{array}{l}\text { WALK } \\
\text { RATE } \\
\text { DEG/100 }\end{array}$ & $\begin{array}{l}\text { BOTTOMHOLE } \\
\text { ASSEMBLY }\end{array}$ & \\
\hline $\begin{array}{r}0.00 \\
3194.00 \\
3256.00 \\
3318.00 \\
3379.00\end{array}$ & $\begin{array}{l}0.00 \\
0.75 \\
1.50 \\
4.75 \\
8.75\end{array}$ & $\begin{array}{l}252.00 \\
252.00 \\
288.00 \\
322.00 \\
328.00\end{array}$ & $\begin{array}{r}0.00 \\
3194.00 \\
62.00 \\
62.00 \\
61.00\end{array}$ & $\begin{array}{l}0.00 \\
0.02 \\
1.21 \\
5.24 \\
6.56\end{array}$ & $\begin{array}{r}0.00 \\
0.00 \\
58.06 \\
54.84 \\
9.84\end{array}$ & $\begin{array}{l}\text { ROTARY } \\
\text { ROTARY } \\
\text { EASTMMAN RUN } \\
\text { EASTMAN RUN }\end{array}$ & $\begin{array}{l}1 \\
1\end{array}$ \\
\hline $\begin{array}{l}3441.00 \\
3503.00 \\
3565.00 \\
3627.00 \\
3688.00\end{array}$ & $\begin{array}{l}12.50 \\
16.25 \\
20.50 \\
24.25 \\
28.25\end{array}$ & $\begin{array}{l}328.00 \\
326.00 \\
325.00 \\
327.00 \\
330.00\end{array}$ & $\begin{array}{l}62.00 \\
62.00 \\
62.00 \\
62.00 \\
61.00\end{array}$ & $\begin{array}{l}6.05 \\
6.05 \\
6.85 \\
6.05 \\
6.56\end{array}$ & $\begin{array}{r}0.00 \\
-3.23 \\
-1.61 \\
3.23 \\
4.92\end{array}$ & $\begin{array}{ll}\text { EASTMAN } & \text { RUN } \\
\text { EASTMAN } & \text { RUN } \\
\text { EASTMMAN } & \text { RUN } \\
\text { EASTMMAN } & \text { RUN } \\
\text { EASTMAN } & \text { RUN }\end{array}$ & 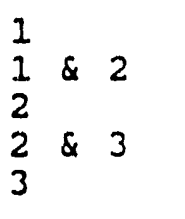 \\
\hline $\begin{array}{l}3750.00 \\
3812.00 \\
3874.00 \\
3936.00 \\
3997.00\end{array}$ & $\begin{array}{l}32.25 \\
36.50 \\
41.75 \\
46.50 \\
51.75\end{array}$ & $\begin{array}{l}330.00 \\
330.00 \\
330.00 \\
329.00 \\
328.00\end{array}$ & $\begin{array}{l}62.00 \\
62.00 \\
62.00 \\
62.00 \\
61.00\end{array}$ & $\begin{array}{l}6.45 \\
6.85 \\
8.47 \\
7.66 \\
8.61\end{array}$ & $\begin{array}{r}0.00 \\
0.00 \\
0.00 \\
-1.61 \\
-1.64\end{array}$ & $\begin{array}{ll}\text { EASTMAN } & \text { RUN } \\
\text { EASTMMAN } & \text { RUN } \\
\text { EASTMAN } & \text { RUN } \\
\text { EASTMAN RUN } \\
\text { EASTMAN RUN }\end{array}$ & $\begin{array}{l}3 \\
3 \\
4 \\
4 \\
4\end{array}$ \\
\hline $\begin{array}{l}4059.00 \\
4121.00 \\
4183.00 \\
4244.00 \\
4306.00\end{array}$ & $\begin{array}{l}57.00 \\
62.00 \\
66.75 \\
70.25 \\
72.75\end{array}$ & $\begin{array}{l}328.00 \\
330.00 \\
332.00 \\
330.00 \\
324.00\end{array}$ & $\begin{array}{l}62.00 \\
62.00 \\
62.00 \\
61.00 \\
62.00\end{array}$ & $\begin{array}{l}8.47 \\
8.06 \\
7.66 \\
5.74 \\
4.03\end{array}$ & $\begin{array}{r}0.00 \\
3.23 \\
3.23 \\
-3.28 \\
-9.68\end{array}$ & $\begin{array}{ll}\text { EASTMAN } & \text { RUN } \\
\text { EASTMAN } & \text { RUN } \\
\text { EASTMAN } & \text { RUN } \\
\text { EASTMAN } & \text { RUN } \\
\text { EASTMAN } & \text { RUN }\end{array}$ & $\begin{array}{l}4 \\
4 \\
4 \\
4 \\
4\end{array}$ \\
\hline $\begin{array}{l}4368.00 \\
4430.00 \\
4491.00 \\
4553.00 \\
4615.00\end{array}$ & $\begin{array}{l}77 \cdot 50 \\
83 \cdot 25 \\
84 \cdot 25 \\
87 \cdot 25 \\
90.50\end{array}$ & $\begin{array}{l}323.00 \\
326.00 \\
333.00 \\
337.00 \\
338.00\end{array}$ & $\begin{array}{l}62.00 \\
62.00 \\
61.00 \\
62.00 \\
62.00\end{array}$ & $\begin{array}{l}7.66 \\
9.27 \\
1.64 \\
4.84 \\
5.24\end{array}$ & $\begin{array}{r}-1.61 \\
4.84 \\
11.48 \\
6.45 \\
1.61\end{array}$ & $\begin{array}{l}\text { EASTMLN AND } \\
\text { BAKER RUN } 7 \\
\text { BAKER RUN } 7 \\
\text { BAKER RUN } 8 \\
\text { BAKER RUN } 8\end{array}$ & BAKER \\
\hline $\begin{array}{l}4677.00 \\
4739.00 \\
4800.00 \\
4862.00 \\
4924.00\end{array}$ & $\begin{array}{l}91.75 \\
92.25 \\
93.00 \\
93.25 \\
93.75\end{array}$ & $\begin{array}{l}339.00 \\
338.00 \\
338.00 \\
339.00 \\
338.00\end{array}$ & $\begin{array}{l}62.00 \\
62.00 \\
61.00 \\
62.00 \\
62.00\end{array}$ & $\begin{array}{l}2.02 \\
0.81 \\
1.23 \\
0.40 \\
0.81\end{array}$ & $\begin{array}{r}1.61 \\
-1.61 \\
0.00 \\
1.61 \\
-1.61\end{array}$ & $\begin{array}{ll}\text { ROTARY } & \text { BUILD } \\
\text { ROTARY } & \text { BUILD } \\
\text { ROTARY } & \text { BUIID } \\
\text { ROTARY } & \text { BUILD } \\
\text { ROTARY } & \text { BUIID }\end{array}$ & \\
\hline $\begin{array}{l}4986.00 \\
5047.00 \\
5109.00 \\
5171.00 \\
5233.00\end{array}$ & $\begin{array}{l}94.00 \\
94.25 \\
94.75 \\
94.00 \\
92.75\end{array}$ & $\begin{array}{l}339.00 \\
339.00 \\
339.00 \\
339.00 \\
339.00\end{array}$ & $\begin{array}{l}62.00 \\
61.00 \\
62.00 \\
62.00 \\
62.00\end{array}$ & $\begin{array}{r}0.40 \\
0.41 \\
0.81 \\
-1.21 \\
-2.02\end{array}$ & $\begin{array}{l}1.61 \\
0.00 \\
0.00 \\
0.00 \\
0.00\end{array}$ & $\begin{array}{ll}\text { ROTARY } & \text { BUILD } \\
\text { ROTARY } & \text { BUIID } \\
\text { ROTARY } & \text { BUIID } \\
\text { ROTARY } & \text { BUILD } \\
\text { ROTARY } & \text { DROP }\end{array}$ & $\&$ DROP \\
\hline $\begin{array}{l}5294.00 \\
5356.00 \\
5418.00 \\
5480.00 \\
5542.00\end{array}$ & $\begin{array}{l}91.75 \\
90.25 \\
89.00 \\
87.25 \\
85.50\end{array}$ & $\begin{array}{l}339.00 \\
339.00 \\
339.00 \\
339.00 \\
339.00\end{array}$ & $\begin{array}{l}61.00 \\
62.00 \\
62.00 \\
62.00 \\
62.00\end{array}$ & $\begin{array}{l}-1.64 \\
-2.42 \\
-2.02 \\
-2.82 \\
-2.82\end{array}$ & $\begin{array}{l}0.00 \\
0.00 \\
0.00 \\
0.00 \\
0.00\end{array}$ & $\begin{array}{ll}\text { ROTARY } & \text { DROP } \\
\text { ROTARY } & \text { DROP } \\
\text { ROTARY } & \text { DROP } \\
\text { ROTARY } & \text { DROP } \\
\text { ROTARY } & \text { DROP }\end{array}$ & \\
\hline
\end{tabular}


HARDY HW NO. 1 DOE/BDMESC/CABOT BUILD AND WALK RATE

PAGE 2

\begin{tabular}{|c|c|c|c|c|c|c|}
\hline $\begin{array}{c}\text { MEASURED } \\
\text { DEPTH } \\
\text { FEET }\end{array}$ & $\begin{array}{c}\text { DRIFT } \\
\text { ANGIE } \\
\text { DEGREES }\end{array}$ & $\begin{array}{l}\text { DRIFT } \\
\text { AZIMUTH } \\
\text { DEGREES }\end{array}$ & $\begin{array}{l}\text { COURSE } \\
\text { LENGTH } \\
\text { FEET }\end{array}$ & $\begin{array}{c}\text { BUILD } \\
\text { RATE } \\
\text { DEG/100 }\end{array}$ & $\begin{array}{l}\text { WALK } \\
\text { RATE } \\
\text { DEG/100 }\end{array}$ & $\begin{array}{l}\text { BOTTOMHOLE } \\
\text { ASSEMBLY }\end{array}$ \\
\hline $\begin{array}{l}5603.00 \\
5665.00 \\
5727.00 \\
5789.00 \\
5850.00\end{array}$ & $\begin{array}{l}83.75 \\
82.75 \\
81.00 \\
79.25 \\
78.75\end{array}$ & $\begin{array}{l}340.00 \\
340.00 \\
339.00 \\
338.00 \\
337.00\end{array}$ & $\begin{array}{l}61.00 \\
62.00 \\
62.00 \\
62.00 \\
61.00\end{array}$ & $\begin{array}{l}-2.87 \\
-1.61 \\
-2.82 \\
-2.82 \\
-0.82\end{array}$ & $\begin{array}{r}1.64 \\
0.00 \\
-1.61 \\
-1.61 \\
-1.64\end{array}$ & $\begin{array}{ll}\text { ROTARY } & \text { DROP } \\
\text { ROTARY } & \text { DROP } \\
\text { ROTARY } & \text { DROP } \\
\text { ROTARY } & \text { DROP } \\
\text { ROTARY } & \text { DROP }\end{array}$ \\
\hline $\begin{array}{l}5912.00 \\
5974.00 \\
6036.00 \\
6097.00 \\
6159.00\end{array}$ & $\begin{array}{l}77.00 \\
75.50 \\
73.25 \\
71.25 \\
69.75\end{array}$ & $\begin{array}{l}336.00 \\
335.00 \\
333.00 \\
332.00 \\
330.00\end{array}$ & $\begin{array}{l}62.00 \\
62.00 \\
62.00 \\
61.00 \\
62.00\end{array}$ & $\begin{array}{l}-2.82 \\
-2.42 \\
-3.63 \\
-3.28 \\
-2.42\end{array}$ & $\begin{array}{l}-1.61 \\
-1.61 \\
-3.23 \\
-1.64 \\
-3.23\end{array}$ & $\begin{array}{ll}\text { ROTARY } & \text { DROP } \\
\text { ROTARY } & \text { DROP } \\
\text { ROTARY } & \text { DROP } \\
\text { ROTARY } & \text { DROP } \\
\text { ROTARY } & \text { DROP }\end{array}$ \\
\hline $\begin{array}{l}6221.00 \\
6283.00 \\
6345.00 \\
6399.00\end{array}$ & $\begin{array}{l}67.75 \\
65.50 \\
64.00 \\
62.65\end{array}$ & $\begin{array}{l}329.00 \\
328.00 \\
327.00 \\
326.00\end{array}$ & $\begin{array}{l}62.00 \\
62.00 \\
62.00 \\
54.00\end{array}$ & $\begin{array}{l}-3.23 \\
-3.63 \\
-2.42 \\
-2.50\end{array}$ & $\begin{array}{l}-1.61 \\
-1.61 \\
-1.61 \\
-1.85\end{array}$ & $\begin{array}{ll}\text { ROTARY } & \text { DROP } \\
\text { ROTARY } & \text { DROP } \\
\text { ROTARY } & \text { DROP } \\
\text { ROTARY } & \text { DROP }\end{array}$ \\
\hline
\end{tabular}


APPENDIX D

MULTISHOT SURVEY

OF WELLBORE 
HARDY HW NO. 1 DOE/BDMESC/CABOT 01-Jan-90 MULTISHOT SURVEY

\begin{tabular}{|c|c|c|c|c|c|c|c|c|c|}
\hline MEASURED & DRIFT & DRIFT & COURSE & TRUE & REC T A & $N \in \cup L A R$ & CLOSURE & CLOSURE & DOQLEG \\
\hline DEPTH & ANGLE & AZIMUTH & LENGTH & VERTICAL & $C O O R D$ & INAYES & DISTANCE & AZIMUTH & SEVERITY \\
\hline FEET & DEGREES & DEGREES & FEET & DEPTH & NORTH & EAST & FEET & DEGREES & DEG/1001 \\
\hline 0.00 & 0.00 & 252.00 & 0.00 & 0.00 & 0.00 & 0.00 & 0.00 & 0.00 & 0.00 \\
\hline 3194.00 & 0.75 & 252.00 & 3194.00 & 3194.00 & 0.00 & 0.00 & 0.00 & 0.00 & 0.00 \\
\hline 3256.00 & 1.50 & 288.00 & 62.00 & 3255.99 & 0.00 & -1.20 & 1.20 & 270.00 & 1.61 \\
\hline 3318.00 & 4.75 & 322.00 & 62.00 & 3317.89 & 1.91 & -3.93 & 4.37 & 295.95 & 5.81 \\
\hline 3379.00 & 8.75 & 328.00 & 61.00 & 3378.45 & 7.78 & -8.03 & 11.18 & 314.07 & 6.65 \\
\hline 3441.00 & 12.50 & 328.00 & 62.00 & 3439.38 & 17.47 & -14.09 & 22.45 & 321.11 & 0.05 \\
\hline 3503.00 & 16.25 & 326.00 & 62.00 & 3499.43 & 30.38 & -22.47 & 37.79 & 323.51 & 6.10 \\
\hline 3565.00 & 20.50 & 325.00 & 62.00 & 3558.25 & 46.48 & -33.54 & 57.32 & 324.19 & 6.87 \\
\hline 3627.00 & 24.25 & 327.00 & 62.00 & 3615.57 & 66.04 & -46.74 & 80.91 & 324.72 & 6.17 \\
\hline 3688.00 & 28.25 & 330.00 & 61.00 & 3670.27 & 89.04 & -60.83 & 107.83 & 325.66 & 6.91 \\
\hline 3750.00 & 32.25 & 330.00 & 62.00 & 3723.82 & 116.08 & -76.44 & 138.99 & 326.64 & 6.45 \\
\hline 3812.00 & 36.50 & 330.00 & 62.00 & 3774.98 & 146.39 & .93 .94 & 173.94 & 327.31 & 6.85 \\
\hline 3874.00 & 41.75 & 330.00 & 62.00 & 3823.06 & 180.26 & -113.49 & 213.02 & 327.81 & 8.47 \\
\hline 3936.00 & 46.50 & 329.00 & 62.00 & 3867.55 & 217.45 & -135.40 & 256.15 & 328.09 & 7.74 \\
\hline 3997.00 & 51.75 & 328.00 & 61.00 & 3907.46 & 256.76 & -159.49 & 302.26 & 328.15 & 8.70 \\
\hline $4,059.00$ & 57.00 & 328.00 & 62.00 & 3943.56 & 299.48 & -186.18 & 352.64 & 328.13 & 8.47 \\
\hline 4121.00 & 62.00 & 330.00 & 62.00 & 3975.02 & 345.26 & -213.69 & 406.04 & 328.25 & 8.53 \\
\hline 4183.00 & 66.75 & 332.00 & 62.00 & 4001.82 & 394.13 & -240.78 & 461.86 & 328.58 & 8.19 \\
\hline 4244.00 & 70.25 & 330.00 & 61.00 & 4024.18 & 443.76 & -268.29 & 518.56 & 328.84 & 6.50 \\
\hline 4306.00 & 72.75 & 324.00 & 62.00 & 4043.85 & 493.05 & -300.30 & 577.30 & 328.66 & 10.02 \\
\hline 4368.00 & 77.50 & 323.00 & 62.00 & 4059.76 & 541.20 & -335.93 & 636.98 & 328.17 & 7.82 \\
\hline 4430.00 & 83.25 & 326.00 & 62.00 & 4070.12 & 590.94 & -371.41 & 697.96 & 327.85 & 10.43 \\
\hline 4491.00 & 84.25 & 333.00 & 61.00 & 4076.76 & 643.15 & -402.16 & 758.54 & 327.98 & 11.52 \\
\hline 4553.00 & 87.25 & 337.00 & 62.00 & 4081.35 & 699.17 & -428.28 & 819.92 & 328.51 & 8.05 \\
\hline 4615.00 & 90.50 & 338.00 & 62.00 & 4082.57 & 756.43 & .452 .00 & 881.19 & 329.14 & 5.48 \\
\hline 4677.00 & 91.75 & 339.00 & 62.00 & 4081.35 & 814.11 & .474 .72 & 942.41 & 329.75 & 2.58 \\
\hline 4739.00 & 92.25 & 338.00 & 62.00 & 4079.19 & 871.76 & -497.43 & 1003.69 & 330.29 & 1.80 \\
\hline 4800.00 & 93.00 & 338.00 & 61.00 & 4076.40 & 928.25 & -520.26 & 1064.11 & 330.73 & 1.23 \\
\hline 4862.00 & 93.25 & 339.00 & 62.00 & 4073.02 & 985.85 & -542.95 & 1125.48 & 331.16 & 1.66 \\
\hline 4924.00 & 93.75 & 338.00 & 62.00 & 4069.23 & 1043.43 & .565 .63 & 1186.88 & 331.54 & 1.80 \\
\hline 4986.00 & 94.00 & 339.00 & 62.00 & 4065.04 & 1100.98 & .588 .30 & 1248.30 & 331.88 & 1.66 \\
\hline 5047.00 & 94.25 & 339.00 & 61.00 & 4060.65 & 1157.79 & .610 .10 & 1308.70 & 332.21 & 0.41 \\
\hline 5109.00 & 94.75 & 339.00 & 62.00 & 4055.79 & 1215.49 & -632.25 & 1370.09 & 332.52 & 0.81 \\
\hline 5179.00 & 94.00 & 339.00 & 62.00 & 4051.06 & 1273.20 & .654 .40 & 1431.53 & 332.80 & 1.21 \\
\hline 5233.00 & 92.75 & 339.00 & 62.00 & 4047.41 & 1330.98 & -676.58 & 1493.08 & 333.05 & 2.02 \\
\hline 5294.00 & 91.75 & 339.00 & 61.00 & 4045.02 & 1387.89 & .6 .38 .43 & 1553.71 & 333.29 & 1.64 \\
\hline 5356.00 & 90.25 & 339.00 & 62.00 & 4043.93 & 1445.76 & -720.64 & 1615.41 & 333.51 & 2.42 \\
\hline 5418.00 & 89.00 & 339.00 & 62.00 & 4044.34 & 1503.64 & .742 .86 & 1677.13 & 333.71 & 2.02 \\
\hline 5480.00 & 87.25 & 339.00 & 62.00 & 4046.37 & 1561.49 & .765 .07 & 1738.84 & 333.90 & 2.82 \\
\hline 5542.00 & 85.50 & 339.00 & 62.00 & 4050.29 & 1619.25 & $\cdot 787.24$ & 1800.48 & 334.07 & 2.82 \\
\hline
\end{tabular}




\begin{tabular}{|c|c|c|c|c|c|c|c|c|c|}
\hline $\begin{array}{l}\text { MEASURED } \\
\text { DEPTH } \\
\text { FEET }\end{array}$ & $\begin{array}{c}\text { DRIFT } \\
\text { ANGLE } \\
\text { DEGREES }\end{array}$ & $\begin{array}{l}\text { DRIFT } \\
\text { AZIMUTH } \\
\text { DEGREES }\end{array}$ & $\begin{array}{l}\text { COURSE } \\
\text { LENOTH } \\
\text { FEET }\end{array}$ & $\begin{array}{c}\text { TRUE } \\
\text { VERTICAL } \\
\text { DEPTH }\end{array}$ & $\begin{array}{c}R E C C T A \\
C O O O \\
\text { NORTH }\end{array}$ & $\begin{array}{c}N Q U L A R \\
I N A T E S \\
\text { EAST }\end{array}$ & $\begin{array}{c}\text { CLOSURE } \\
\text { DISTAHCE } \\
\text { FEET }\end{array}$ & $\begin{array}{l}\text { CLOSURE } \\
\text { AZIMUTH } \\
\text { DEGREES }\end{array}$ & $\begin{array}{l}\text { DOGLEG } \\
\text { SEVERITY } \\
\text { DEG/100' }\end{array}$ \\
\hline 5603.00 & 83.75 & 340.00 & 61.00 & 4056.00 & 1676.13 & -808.51 & 1860.94 & 334.25 & 3.30 \\
\hline 5665.00 & 82.75 & 340.00 & 62.00 & 4063.29 & 1733.99 & -829.56 & 1922.21 & 334.43 & 1.61 \\
\hline 5727.00 & 81.00 & 339.00 & 32.00 & 4072.05 & 1791.48 & .851 .06 & 1983.35 & 334.59 & 3.24 \\
\hline 5789.00 & 79.25 & 338.00 & 62.00 & 4082.68 & 1848.31 & .873 .44 & 2044.29 & 334.71 & 3.24 \\
\hline 5850.00 & 78.75 & 337.00 & 61.00 & 4094.32 & 1903.63 & -896.36 & 2104.10 & 334.79 & 1.81 \\
\hline 5912.00 & 77.00 & 336.00 & 62.00 & 4107.35 & 1959.21 & .920 .53 & 2164.69 & 334.83 & 3.23 \\
\hline 5974.00 & 75.50 & 335.00 & 62.00 & 4122.08 & 2014.01 & .945 .50 & 2224.91 & 334.85 & 2.88 \\
\hline 6036.00 & 73.25 & 333.00 & 62.00 & 4138.78 & 2067.67 & .971 .67 & 2284.60 & 334.83 & 4.78 \\
\hline 6097.00 & 71.25 & 332.00 & 61.00 & 4157.38 & 2119.20 & .998 .50 & 2342.65 & 334.77 & 3.63 \\
\hline 6159.00 & 69.75 & 330.00 & 62.00 & 4178.07 & 2170.31 & -1026.83 & 2400.96 & 334.68 & 3.89 \\
\hline 6221.00 & 67.75 & 329.00 & 62.00 & 4200.54 & 2220.10 & -1056.15 & 2458.52 & 334.56 & 3.56 \\
\hline 6283.00 & 65.50 & 328.00 & 62.00 & 4225.14 & 2268.62 & .1085 .89 & 2515.11 & 334.42 & 3.92 \\
\hline 6345.00 & 64.00 & 327.00 & 62.00 & 4251.58 & 2315.91 & .1116 .02 & 2570.79 & 334.27 & 2.83 \\
\hline 6399.00 & 62.65 & 326.00 & 54.00 & 4275.83 & 2356.15 & -1142.65 & 2618.60 & 334.13 & 3.00 \\
\hline
\end{tabular}


APPENDIX E

DRILL PIPE TALLY 


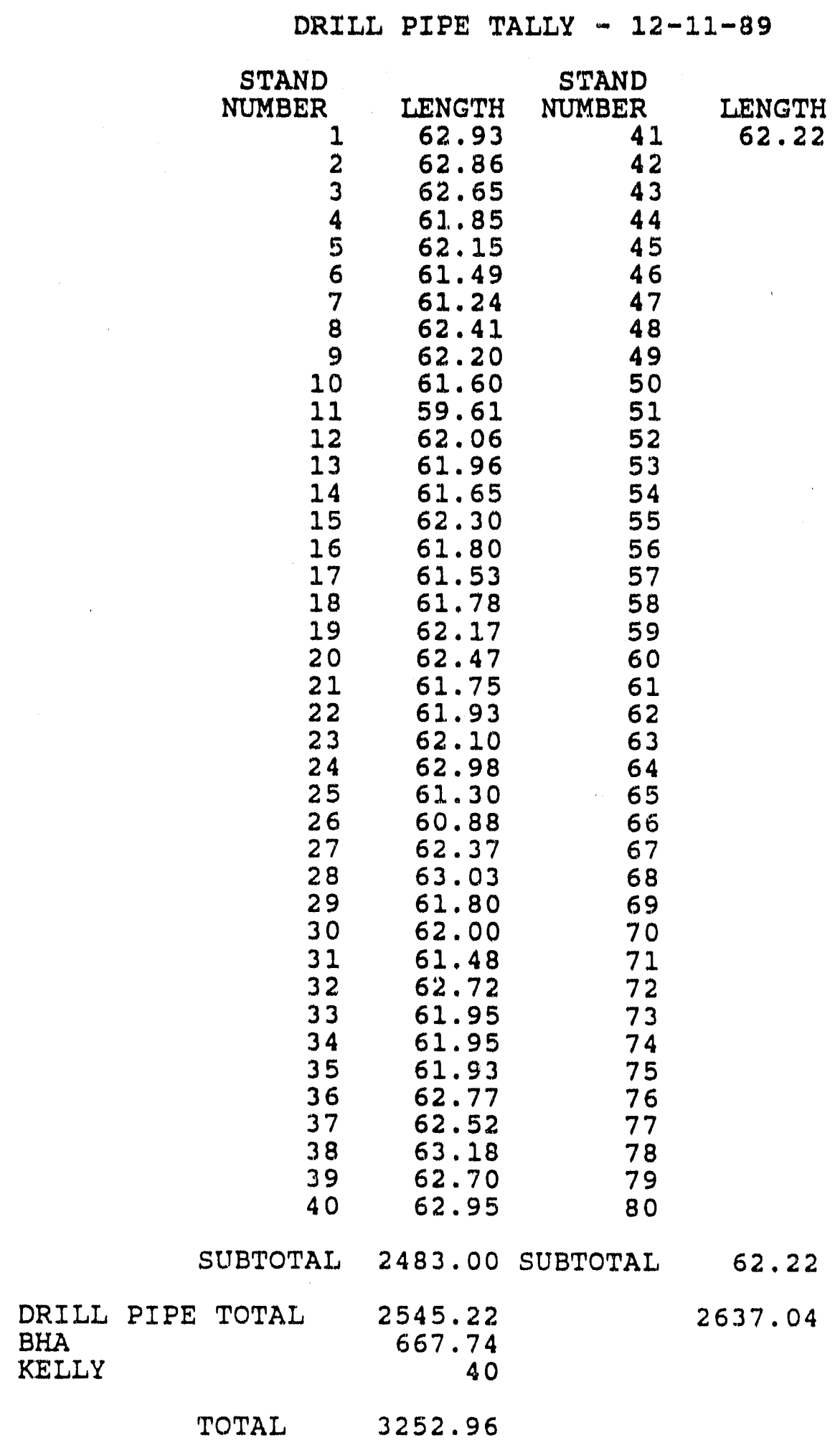




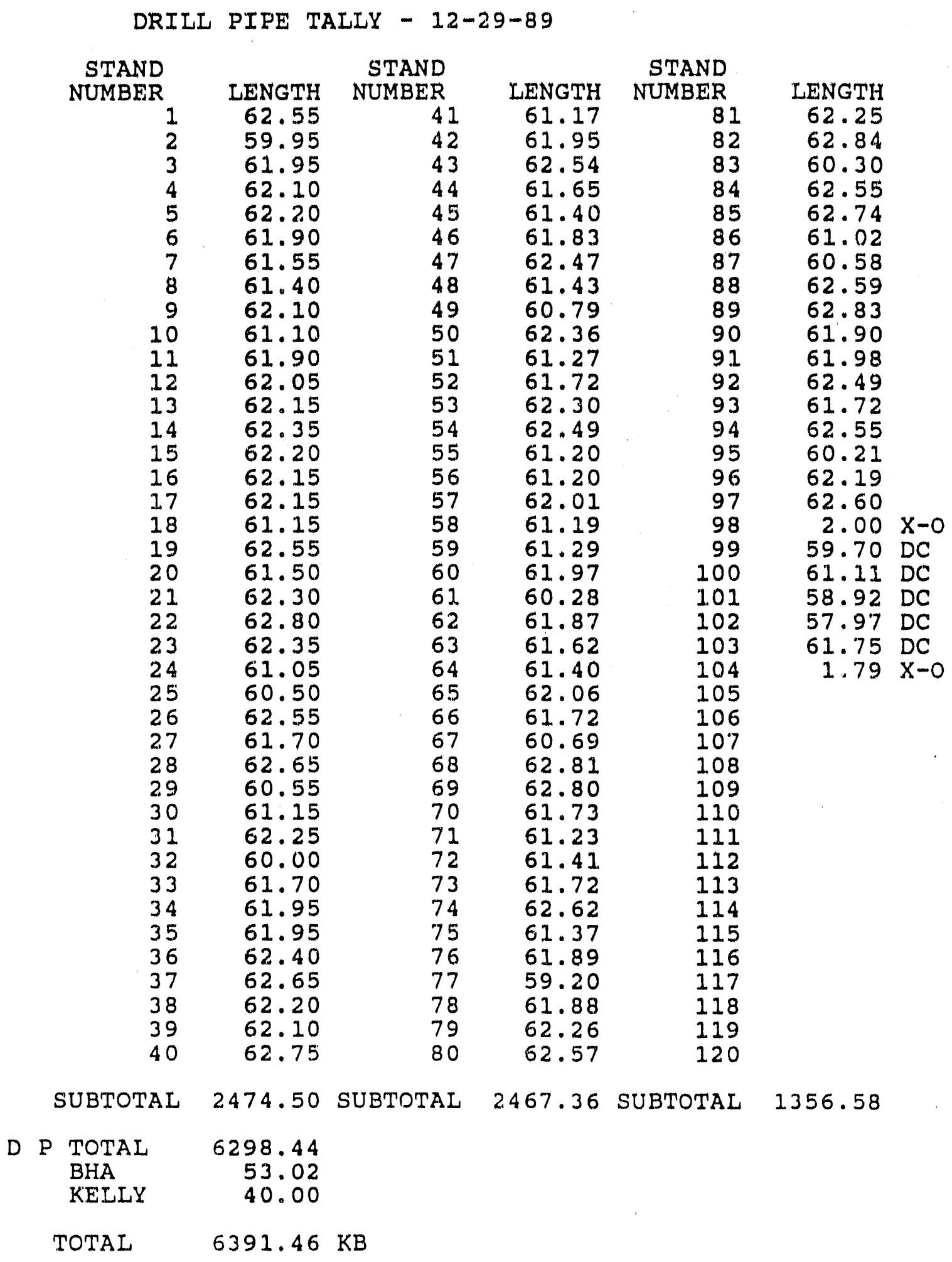


APPENDIX F

MULTISHOT PIPE TALLY

122 


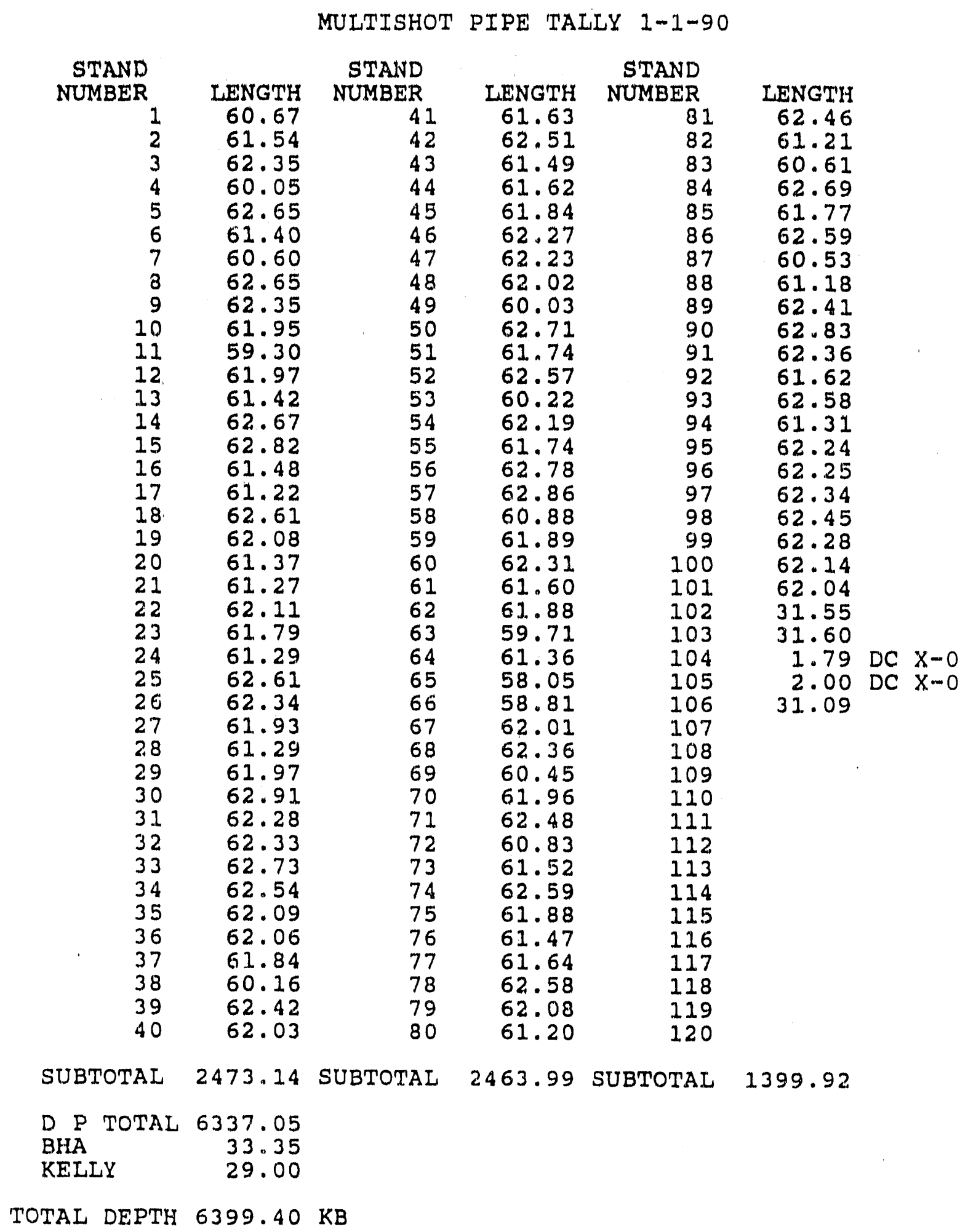




\section{APPENDIX G \\ SINGLE SHOT SURVEYS \\ TAKEN DURING DRILLING OPERATIONS}


HAROY HU NO. I DOE/BDMESC/CABOT 05-Jann90 SINQLE SHOT SURVEYS

PAOE 1

\begin{tabular}{|c|c|c|c|c|c|c|c|c|c|}
\hline $\begin{array}{l}\text { MEASURED } \\
\text { DEPTH } \\
\text { FEET }\end{array}$ & $\begin{array}{l}\text { DRIFT } \\
\text { ANOLE } \\
\text { DEQREES }\end{array}$ & $\begin{array}{l}\text { DRIFY } \\
\text { AZIKUTH } \\
\text { DEGREES }\end{array}$ & $\begin{array}{l}\text { COURSE } \\
\text { LENQTH } \\
\text { FEET }\end{array}$ & $\begin{array}{c}\text { TRUE } \\
\text { VERTICAL } \\
\text { DEPTH }\end{array}$ & $\begin{array}{l}R \text { E C T A } \\
\text { COOOR D } \\
\text { NORTH }\end{array}$ & 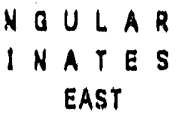 & $\begin{array}{l}\text { CLOSURE } \\
\text { DISTANCE } \\
\text { FEET }\end{array}$ & $\begin{array}{l}\text { CLOSURE } \\
\text { AZIMUTH } \\
\text { DEGREES }\end{array}$ & $\begin{array}{l}\text { DOQLEG } \\
\text { SEVERITY } \\
\text { DEG/1001 }\end{array}$ \\
\hline 0.00 & 0.00 & 279.00 & 0.00 & 0.00 & 0.00 & 0.00 & 0.00 & 0.00 & 0.00 \\
\hline 3191.00 & 1.00 & 279.00 & 3191.00 & 3191.00 & 0.00 & 0.00 & 0.00 & 0.00 & 0.00 \\
\hline 3246.00 & 1.20 & 290.00 & 55.00 & 3245.99 & 0.26 & -1.02 & 1.05 & 284.50 & 0.53 \\
\hline 3276.00 & 2.40 & 305.00 & 30.00 & 3275.97 & 0.70 & -1.85 & 1.98 & 290.62 & 4.26 \\
\hline 3307.00 & 3.80 & 317.00 & 31.00 & 3306.93 & 1.80 & -3.12 & 3.60 & 299.95 & 4.95 \\
\hline 3339.00 & 6.20 & 325.00 & 32.00 & 3338.80 & 3.96 & -4.87 & 6.28 & 309.12 & 7.79 \\
\hline 3401.00 & 9.50 & 328.00 & 62.00 & 3400.21 & 11.02 & -9.54 & 14.58 & 319.11 & 5.36 \\
\hline 3433.00 & 11.20 & 327.00 & 32.00 & 3431.69 & 15.87 & -12.63 & 20.28 & 329.48 & 5.34 \\
\hline 3461.00 & 13.40 & 326.00 & 28.00 & 3459.05 & 20.84 & -15.12 & 26.23 & 322.62 & 7.89 \\
\hline 3492.00 & 15.30 & 325.00 & 31.00 & 3489.08 & 27.17 & -20.28 & 33.91 & 323.27 & 6.18 \\
\hline 3525.00 & 17.00 & 325.00 & 33.00 & 3520.78 & 34.69 & -25.54 & 43.08 & 323.64 & 5.15 \\
\hline 3556.00 & 18.80 & 325.00 & 31.00 & 3550.27 & 42.50 & -31.01 & 52.61 & 323.89 & 5.81 \\
\hline 3587.00 & 20.20 & 325.00 & 31.00 & 3579.50 & 50.97 & -36.84 & 62.95 & 324.07 & 4.52 \\
\hline 3617.00 & 22.50 & 327.00 & 30.00 & 3607.44 & 60.03 & .43 .05 & 73.87 & 324.36 & 8.04 \\
\hline 3648.00 & 24.20 & 327.00 & 31.00 & 3635.90 & 70.33 & -49.74 & 86.14 & 324.73 & 5.48 \\
\hline 3679.00 & 27.00 & 330.00 & 31.00 & 3663.85 & 81.75 & -56.74 & 99.51 & 325.24 & 9.95 \\
\hline 3739.00 & 30.70 & 331.00 & 60.00 & 3716.39 & 106.94 & -70.99 & 128.36 & 326.42 & 6.22 \\
\hline 3770.00 & 32.70 & 331.00 & 31.00 & 3742.77 & 121.19 & -78.89 & 144.60 & 326.94 & 6.45 \\
\hline 3833.00 & 36.60 & 330.00 & 63.00 & 3794.58 & 152.36 & -96.52 & 180.36 & 327.65 & 6.26 \\
\hline 3863.00 & 39.10 & 330.00 & 30.00 & 3818.27 & 168.30 & $-105,72$ & 198.75 & 327.86 & 8.33 \\
\hline 3894.00 & 42.10 & 330.00 & 31.00 & 3841.80 & 185.77 & -115.81 & 218.91 & 328.06 & 9.68 \\
\hline 3925.00 & 44.70 & 330.00 & 31.00 & 3864.33 & 204.21 & -126.46 & 240.20 & 328.23 & 8.39 \\
\hline 3957.00 & 46.80 & 330.00 & 32.00 & 3886.65 & 224.06 & $\cdot 137.92$ & 263.11 & 328.39 & 6.56 \\
\hline 3988.00 & 49.20 & 329.00 & 39.00 & 3907.40 & 243.91 & -149.61 & 286.14 & 328.48 & 8.10 \\
\hline 4049.00 & 54.50 & 329.00 & 61.00 & 3945.06 & 285.02 & .174 .31 & 334.08 & 328.55 & 8.69 \\
\hline 4111.00 & 59.60 & 329.00 & 62.00 & 3978.78 & 329.60 & -201.09 & 386.10 & 328.61 & 8.23 \\
\hline 4179.00 & 64.10 & 332.00 & 60.00 & 4007.07 & 375.62 & .227 .14 & 438.96 & 328.84 & 8.70 \\
\hline 4202.00 & 66.80 & 333.00 & 31.00 & 4019.95 & 400.63 & -240.15 & 467.10 & 329.06 & 9.19 \\
\hline 4325.00 & 72.50 & 324.00 & 123.00 & 4062.71 & 498.82 & -300.32 & 582.25 & 328.95 & 8.27 \\
\hline 4355.00 & 74.60 & 323.00 & 30.00 & 4071.20 & 521.95 & -317.44 & 610.90 & 328.69 & 7.70 \\
\hline 4386.00 & $\pi 7.40$ & 325.00 & 39.00 & 4078.70 & 546.28 & -335.19 & 640.88 & 328.47 & 10.99 \\
\hline 4416.00 & 80.70 & 326.00 & 30.00 & 4084.40 & 570.55 & .351 .80 & 670.29 & 328.34 & 11.48 \\
\hline 4448.00 & 83.70 & 327.00 & 32.00 & 4088.74 & 596.98 & -369.29 & 701.97 & 328.26 & 9.87 \\
\hline 4479.00 & 84.90 & 331.00 & 31.00 & 4091.82 & 623.42 & -385.18 & 732.81 & 328.29 & 13.41 \\
\hline 4511.00 & 84.10 & 335.00 & 32.00 & 4094.89 & 651.79 & -399.63 & 764.55 & 328.49 & 12.69 \\
\hline 4542.00 & 84.00 & 339.00 & 31.00 & 4098.10 & 680.17 & -411.68 & 795.05 & 328.82 & 12.84 \\
\hline 4655.00 & 91.50 & 340.00 & 113.00 & 4102.54 & 785.85 & .451 .19 & 906.17 & 330.14 & 6.70 \\
\hline 4718.00 & 92.00 & 340.00 & 63.00 & 4100.61 & 845.03 & .472 .73 & 968.27 & 330.78 & 0.79 \\
\hline 4904.00 & 83.00 & 340.00 & 186.00 & 4092.50 & 1019.64 & .536 .28 & 1152.07 & 332.26 & 0.54 \\
\hline 5076.00 & 95.00 & 338.00 & 172.00 & 4080.50 & 1179.81 & .597 .77 & 1322.60 & 333.13 & 1.64 \\
\hline
\end{tabular}


HARDY HH NO. 1 DOE/BDMESC/CABOT 05-Jan-90 SINGLE SHOT SURVEYS

PAGE 2

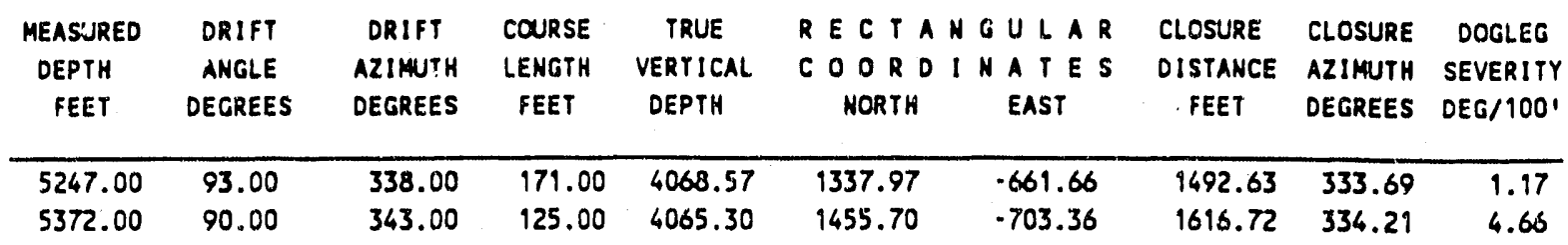




\section{APPENDIX H \\ GAS SHOWS \\ AS DETERMINED FROM HYDROCARBON MUD LOG \\ OF DRILLING OPERATION}


GAS SHOWS RECORDED IN THE HURON SHALE SECTION OF THE WELLBORE

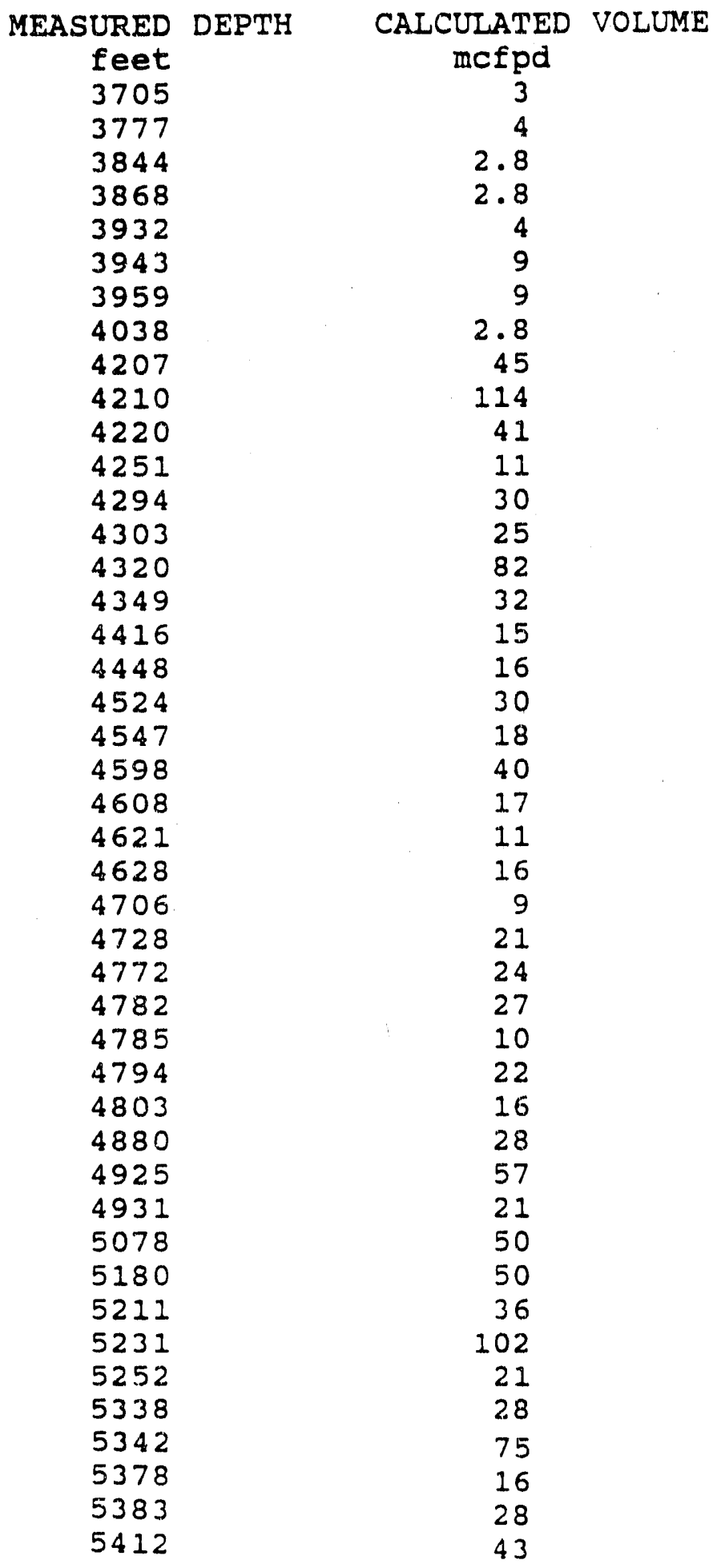




$\begin{array}{cc}\begin{array}{c}\text { MEASURED DEPTH } \\ \text { feet }\end{array} & \begin{array}{c}\text { CALCULATED VOLUME } \\ \text { mc } f p d\end{array} \\ 5434 & 25 \\ 5484 & 7.2 \\ 5500 & 28 \\ 5564 & 79 \\ 5574 & 50 \\ 5588 & 64 \\ 5603 & 64 \\ 5616 & 178 \\ 5794 & 28 \\ 5800 & 21 \\ 6030 & 36 \\ 6121 & 10.8 \\ 6140 & 10 \\ 6149 & 10 \\ 6168 & 21.6\end{array}$




\section{APPENDIX I}

DAILY ORILLING REPORTS

130 
BDM DAILY REPORT

WELL NAME: BDM/DOE CABOT HW DEPTH: 32 FOOTAGE: 32 DATE: 11-30-89 REPORT TIME: 8:00 A.M. FORMATION: SAND ACTIVITY :

ROTATING WEIGHT: 8000 HLU: 8000 HLD:

TORQUE :

BIT RECORD:

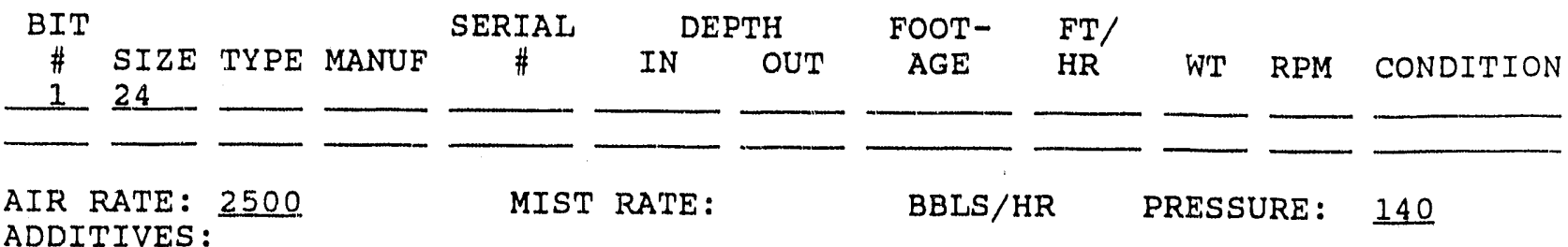
BHA :
SURVEYS
$\underline{0}, \underline{0}$
$\underline{0}, \underline{a}$
$\perp$ 의,
$\underline{0}, \underline{0}, \underline{0}, \underline{a}$

GAS: CI:

$, \mathrm{C} 2:, \mathrm{C} 3$

, C4:

C5: $\quad, \mathrm{C} 5+:$

, TOT:

SHOWS :

TIME BREAKDOWN AND COMMENTS:

\begin{tabular}{|c|c|c|c|}
\hline M & To & HRS & \\
\hline $7: 00$ & $5: 00$ & $\overline{10}$ & RIGGING UP DRIILING RIG AND AIR COMPRESSOR SYSTEM \\
\hline $5: 00$ & $7: 00$ & 2 & DRILL RAT HOLE AND REPAIR RAT HOLE DIGGER \\
\hline $7: 00$ & $9: 00$ & 2 & DRILL MOUSE HOLE \\
\hline $9: 00$ & $11: 00$ & 2 & RIG UP TO DRILL CONDUCTOR HOLE \\
\hline $11: 00$ & $5: 30$ & 6.5 & DRILLED CONDUCTOR HOLE TO $32{ }^{\prime}$ BELOW GL \\
\hline $5: 30$ & $6: 30$ & & CIRCULATE TO CLEAN HOLE \\
\hline $6: 30$ & $8: 00$ & 1.5 & TRIP OUT AND BREAK OFF BIT \\
\hline
\end{tabular}

On November 29, 1989, hauled 720 bbls of water:

each) 1-300 bbls hauled to the tanks (2 tanks at a capacity of 150 bbls $2-420$ bbls to the pit

*estimated time 10 hours, load capacity 60 bbls 
BDM DAILY REPORT

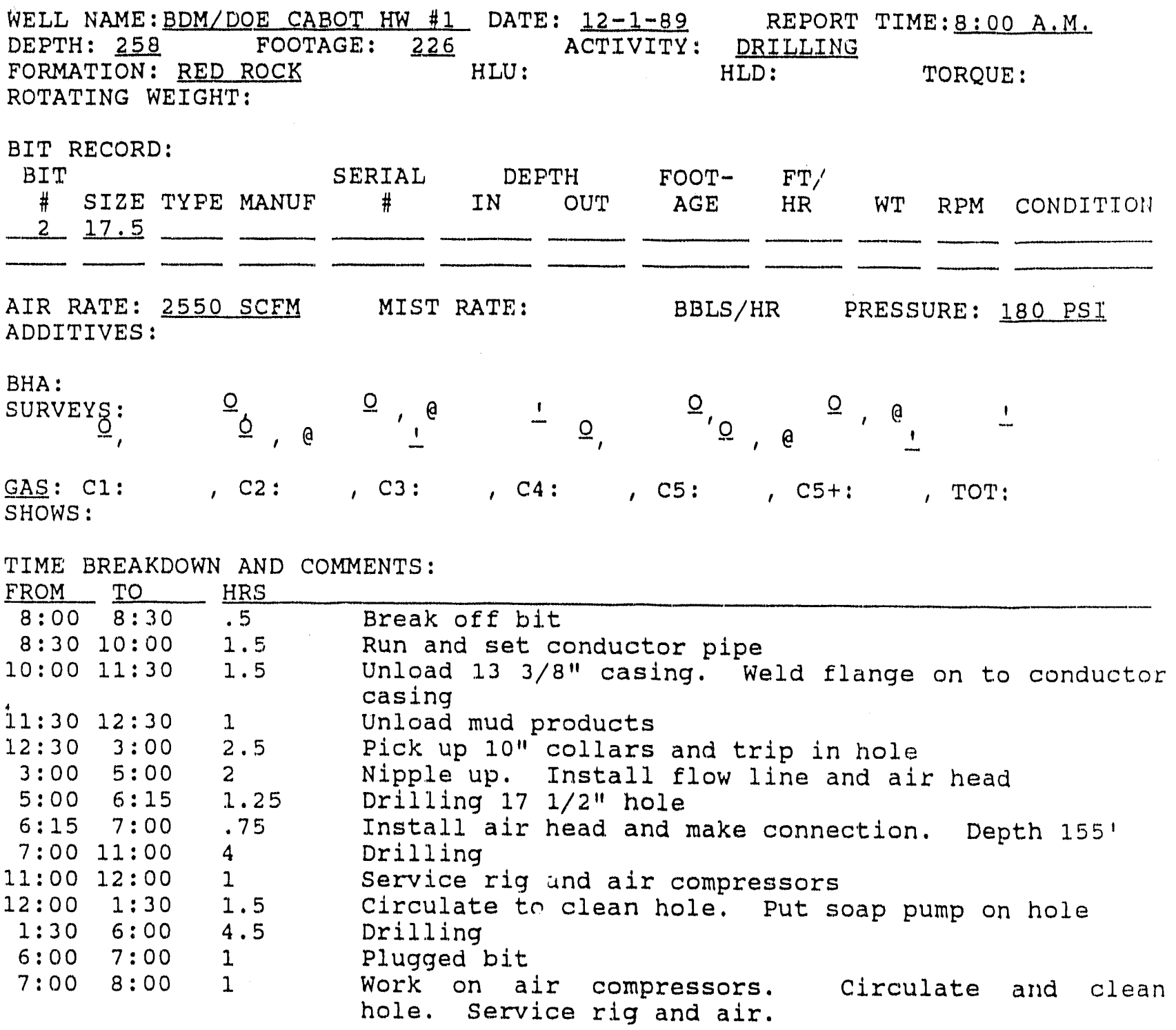


BDM DAIIY REPORT

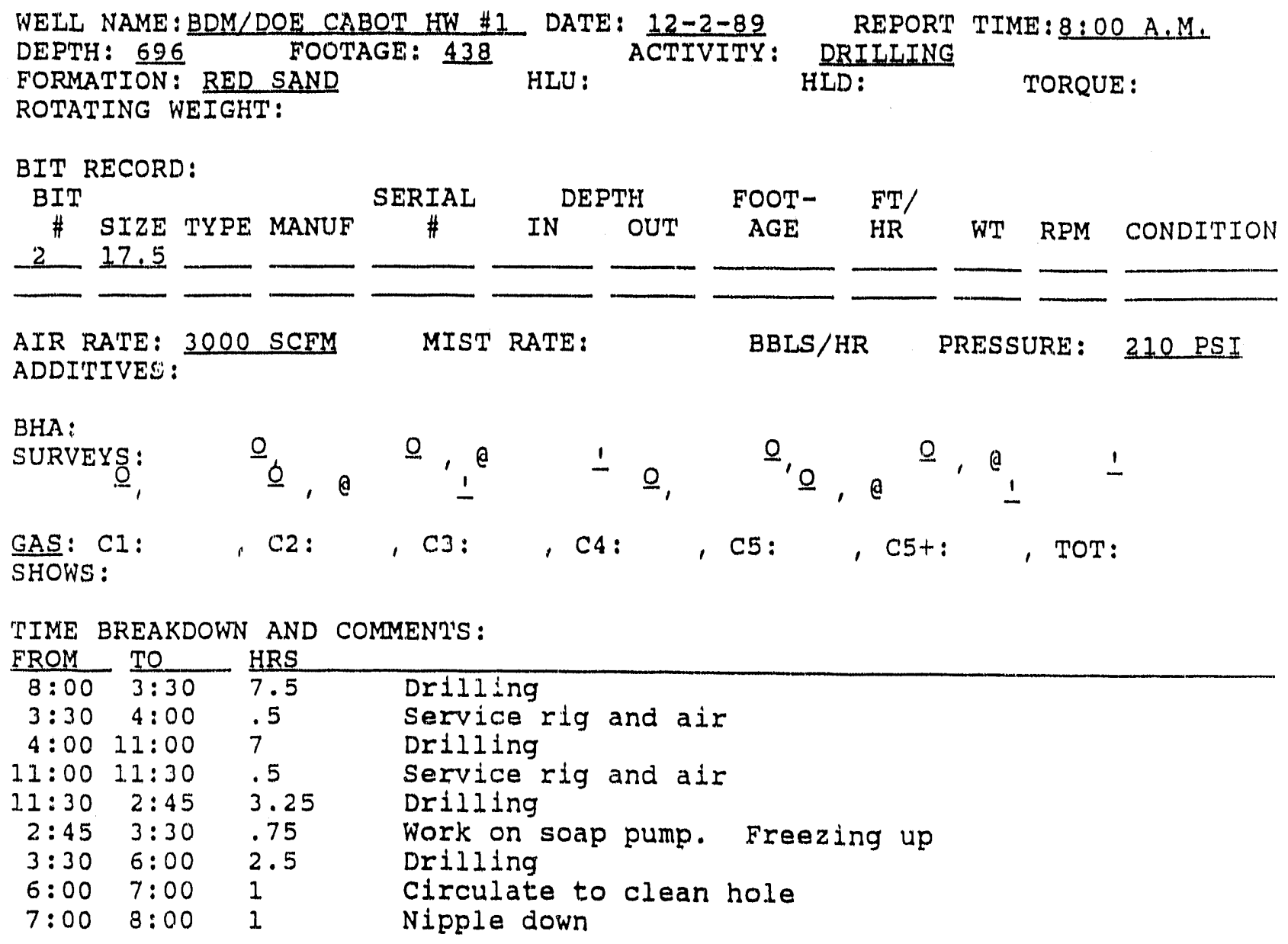


BDM DAILY REPORT

WELL NAME : BDM/DOE CABOT HW \#1 DEPTH: $\underline{696}$ FOOTAGE: $\underline{0}$

DATE: $12-3-89$ ACTIVITY: NApNIIng Up FORMATION: Sandstone HLU : ROTATING WEIGHT:

REPORT TIME: 8:00 A.M.

BIT RECORD:

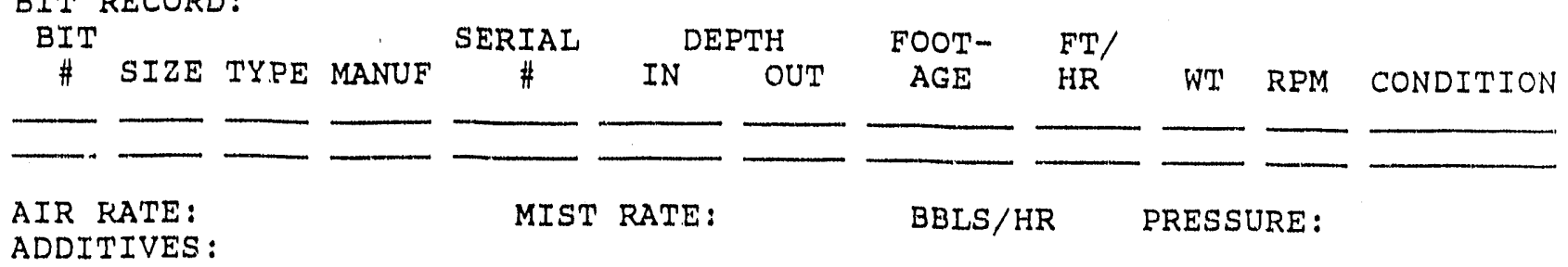

BHA :

SURVEY $\underline{\underline{O}}$,

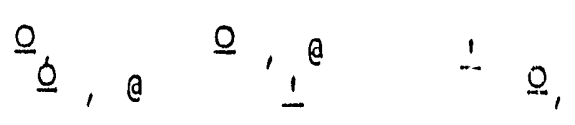

$\stackrel{0}{,}, a^{0}, \underline{a}, \underline{1}$

GAS: C1:

SHOWS:
, C2:
C3:
, C4:, C5:
, C5+:
, TOT:

TIME BREAKDOWN AND COMMENTS:

\begin{tabular}{|c|c|c|c|}
\hline FROM & I0 & HRS & \\
\hline $8: 00$ & $8: 30$ & 0.5 & Back off kelly, pull air bowl \\
\hline $8: 30$ & $10: 30$ & 2 & Trip out, lay down hammer \\
\hline $10: 30$ & $12: 30$ & 2 & Run 16 joints $13-3 / 8^{\prime \prime}$ casing (654') \\
\hline $12: 30$ & 1.00 & 0.5 & Rig up Dowell \\
\hline $\begin{array}{l}1: 00 \\
2: 30\end{array}$ & $\begin{array}{l}2: 30 \\
8: 30\end{array}$ & $\frac{1}{6} \cdot 5$ & Cement $13-3 / 8$ casing $w / 460 \mathrm{sx}$ \\
\hline $8: 30$ & $11: 30$ & 3 & Cut off 20 " conductor, break out nipole un \\
\hline $11: 30$ & $4: 00$ & 4.5 & Pick up colars, trip in hole \\
\hline $4: 00$ & $6: 00$ & 2 & start aix compressor, blow water \\
\hline $6: 00$ & $8: 00$ & 2 & Nippling up \\
\hline
\end{tabular}


BDM DAILY REPORT

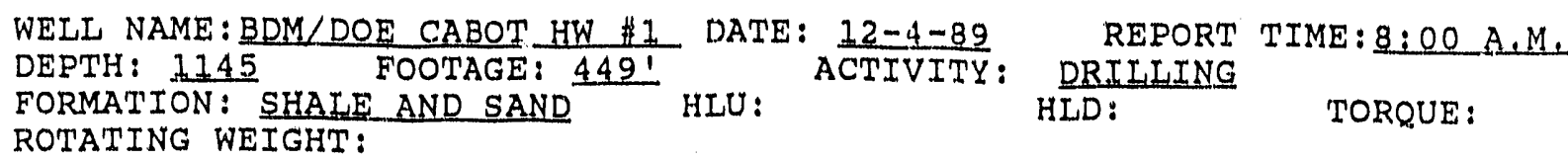

BIT RECORD:

$\begin{aligned} & \text { BIT } \\ & \#\end{aligned}$ SIZE TYPE MANUF SERIAL
3
$\begin{aligned} & \text { AIR RA'IE: } \\ & \text { ADDITIVES: }\end{aligned}$

BHA :

SURVEYS :

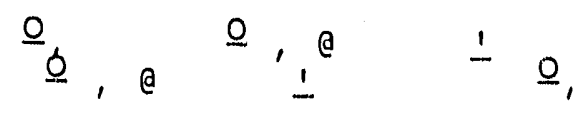

$\underline{0}, \underline{0}, \underline{0}, \underline{1}$

GAS $:$ C1: , C2:, C3:, C4:, C5:, C5+:, TOT:

SHOWS :

TIME BREAKDOWN AND COMMENTS:

\begin{tabular}{|c|c|c|c|c|c|c|}
\hline FROM & To & HRS & & & & \\
\hline $8: 00$ & $9: 00$ & 1 & SERVICE RIG AND AIR & & & \\
\hline $9: 00$ & $11: 00$ & 2 & DRILL OUT OF $133 / 8 "$ CASTING & & & \\
\hline $11: 00$ & $3: 00$ & 4 & DRILLING & & & \\
\hline $3: 00$ & $3: 30$ & .5 & SERVICE RIG & & & \\
\hline $3: 30$ & $5: 30$ & 2 & DRILLING WITH STIFF FOAM & & & \\
\hline $5: 30$ & $11: 00$ & $\begin{array}{l}5.5 \\
\text { WITH }\end{array}$ & $\begin{array}{l}\text { TRIP OUT OF HOLE FOR PLUGGED } \\
\text { METAL SHAVINGS }\end{array}$ & PIPE. & PIPE & PLUGGED \\
\hline $11: 00$ & $1: 00$ & 2 & TRIP IN HOLE & & & \\
\hline 1:00 & $2: 00$ & 1 & REPAIR AIR AND CAT HEAD & & & \\
\hline $2: 00$ & $3: 00$ & 1 & WASH TO BOTTOM & & & \\
\hline $3: 00$ & $8: 00$ & 5 & DRILIING & & & \\
\hline
\end{tabular}


BDM DAILY REPORT

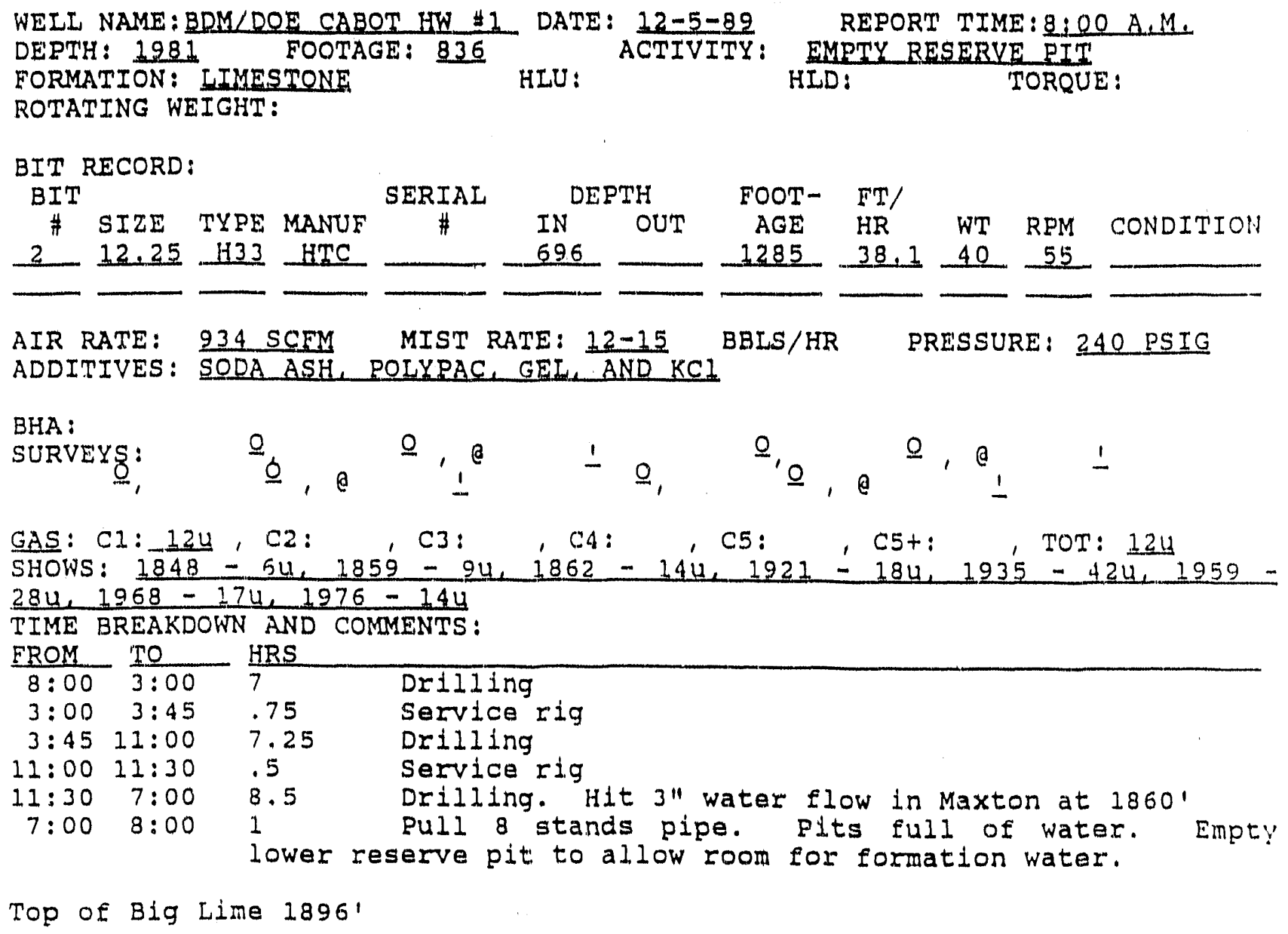


BDM DAILY REPORT

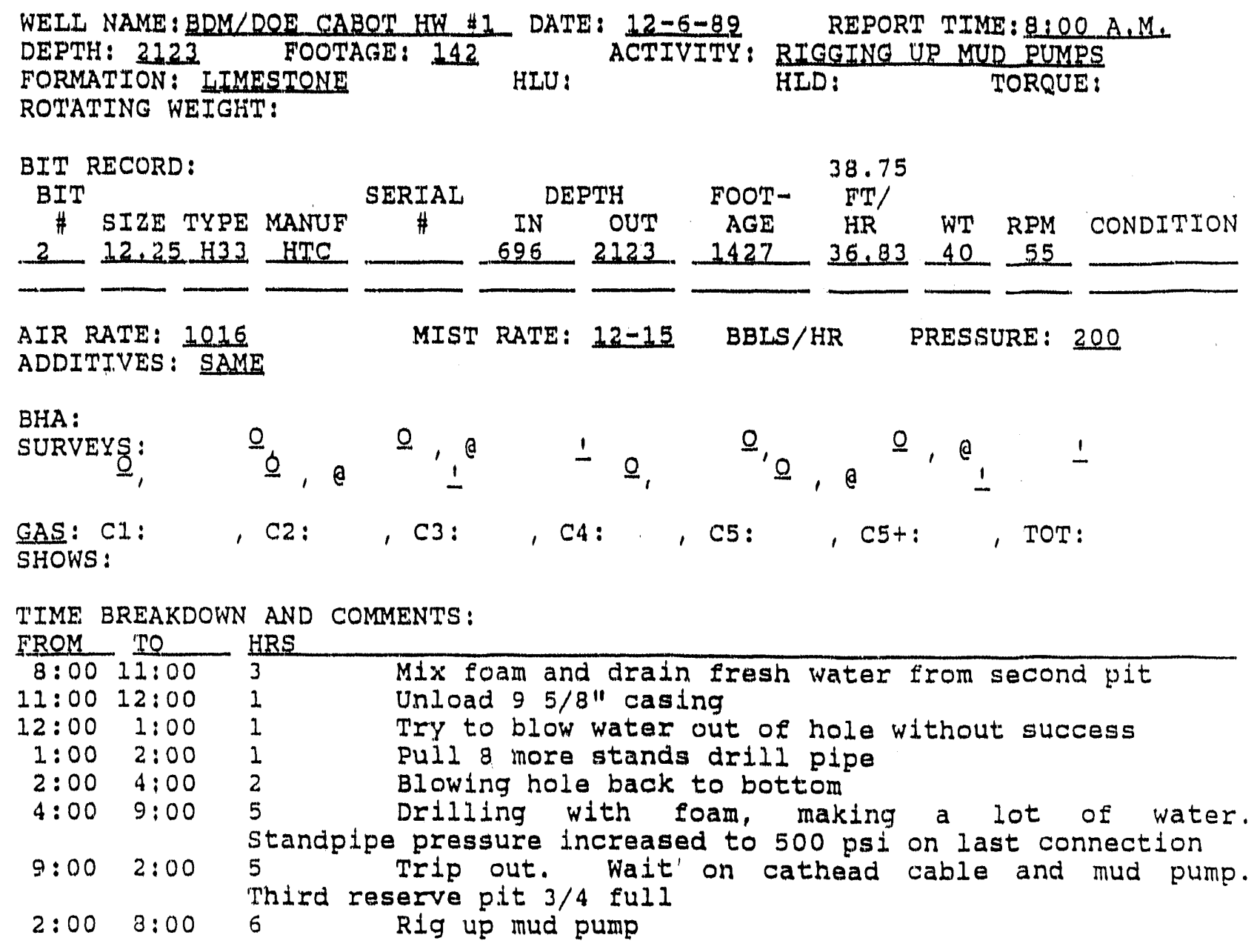


BDM DAILY REPORT

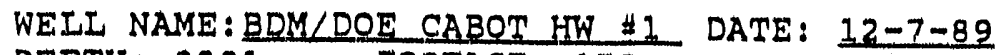
DEPTH : 2301 FOOTAGE: 178 FORMATION: ROTATING WEIGHT: ACTIVITY: HLU :

REPORT TIME: 8:00 A.M. WORK STUCK PIPE HLD: TOROUE:

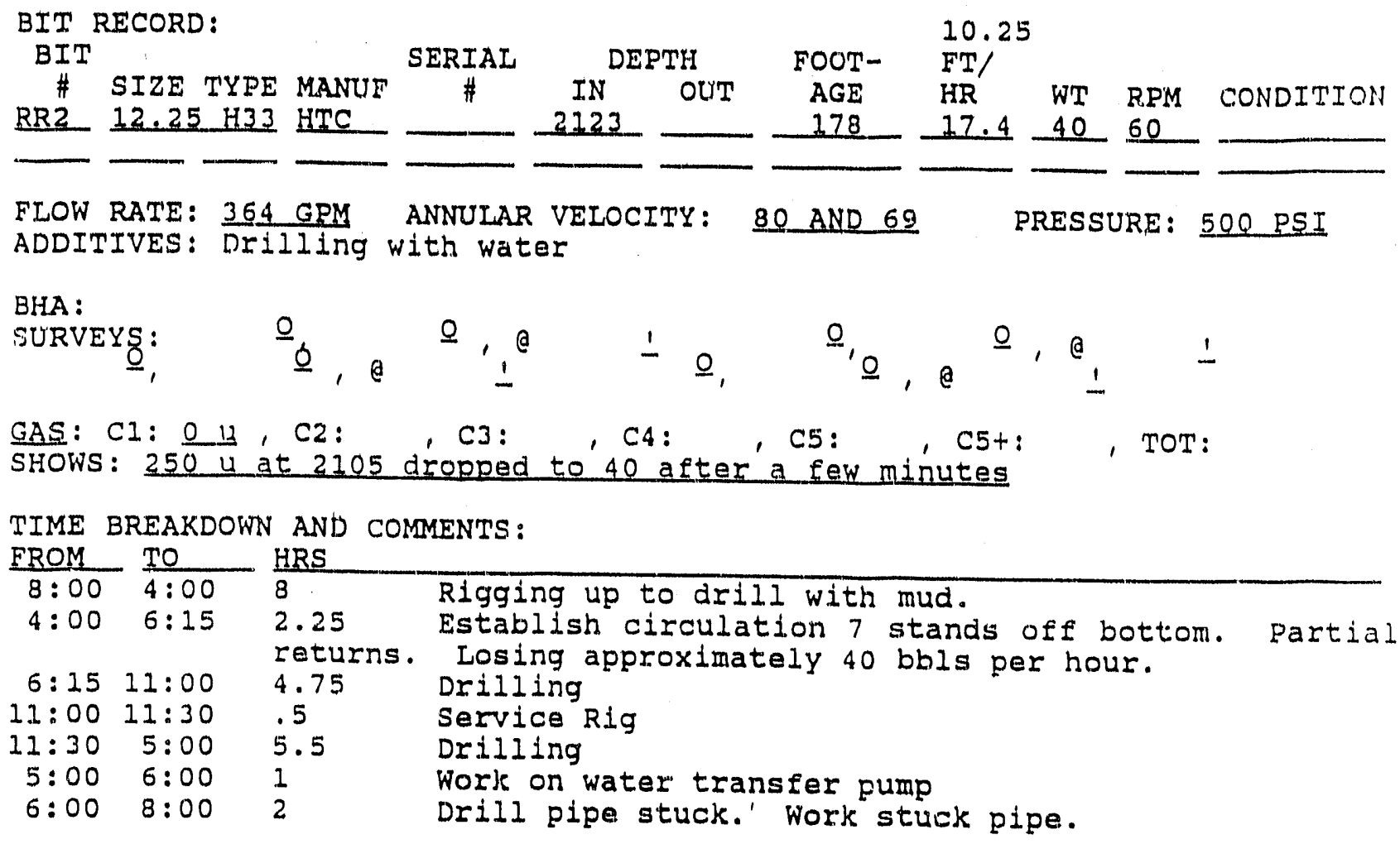

Top of Big Injun at 2105 
BDM DAILY REPORT

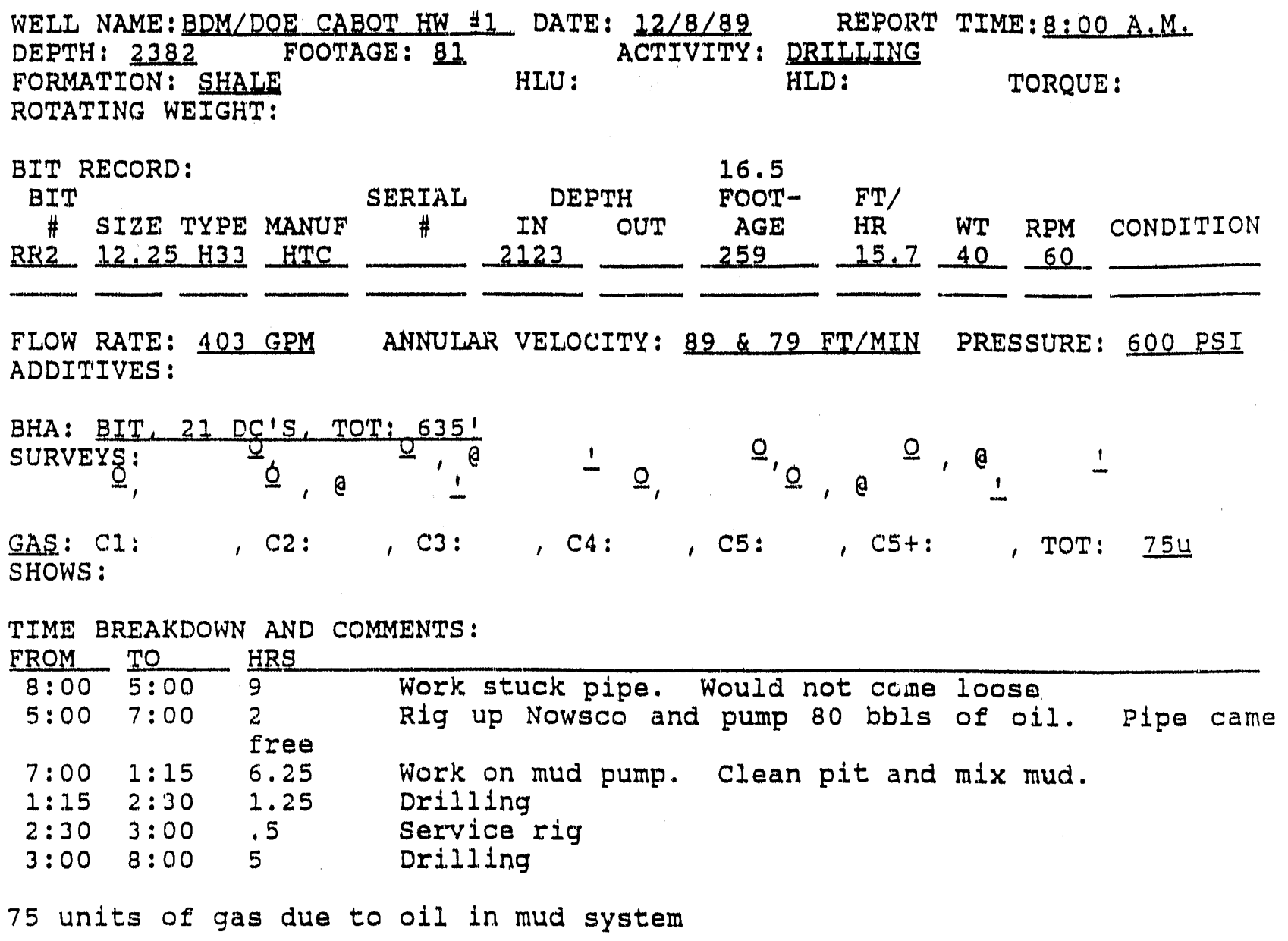


BDM DAILY REPORT

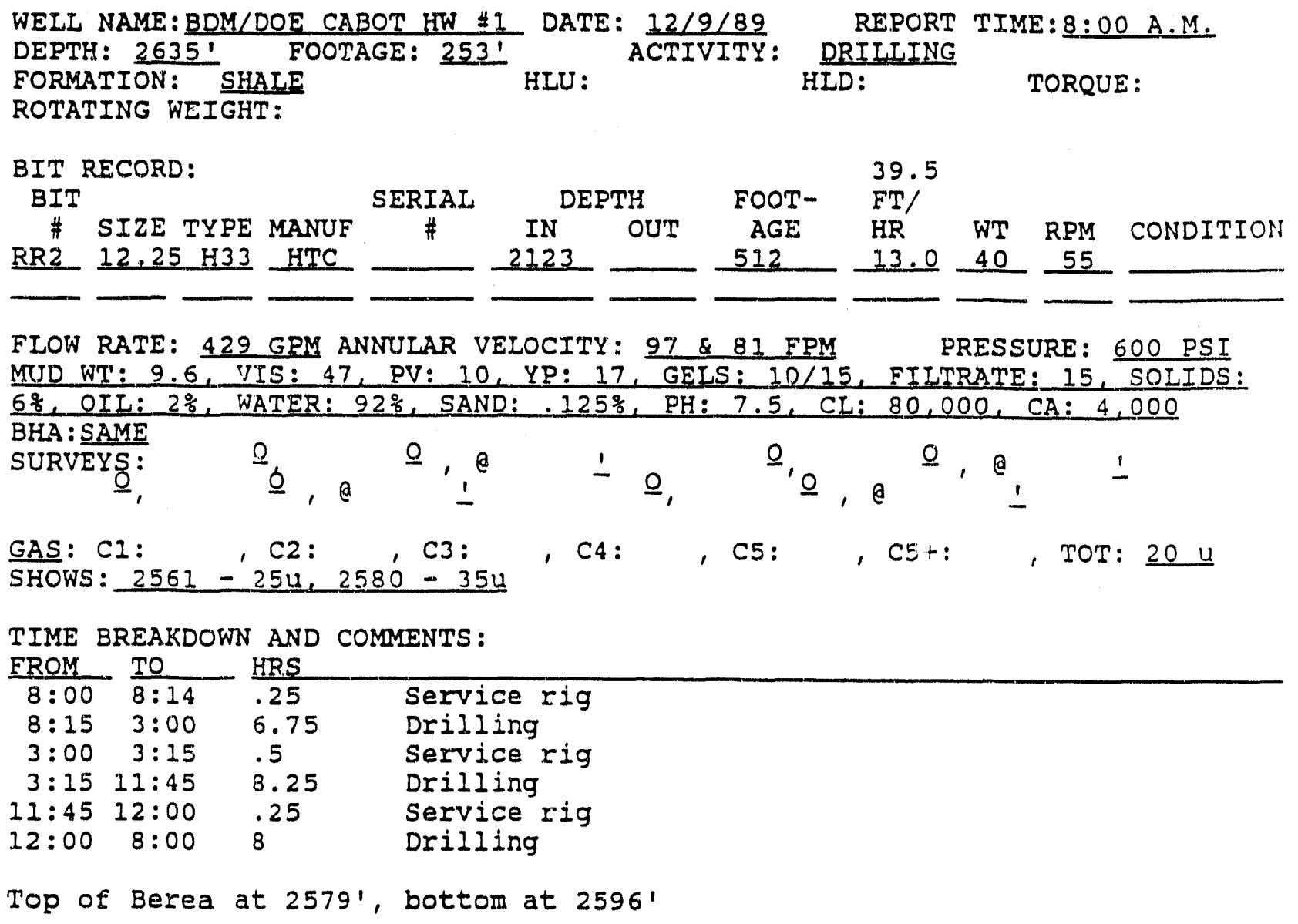


BDM DAILY REPORT

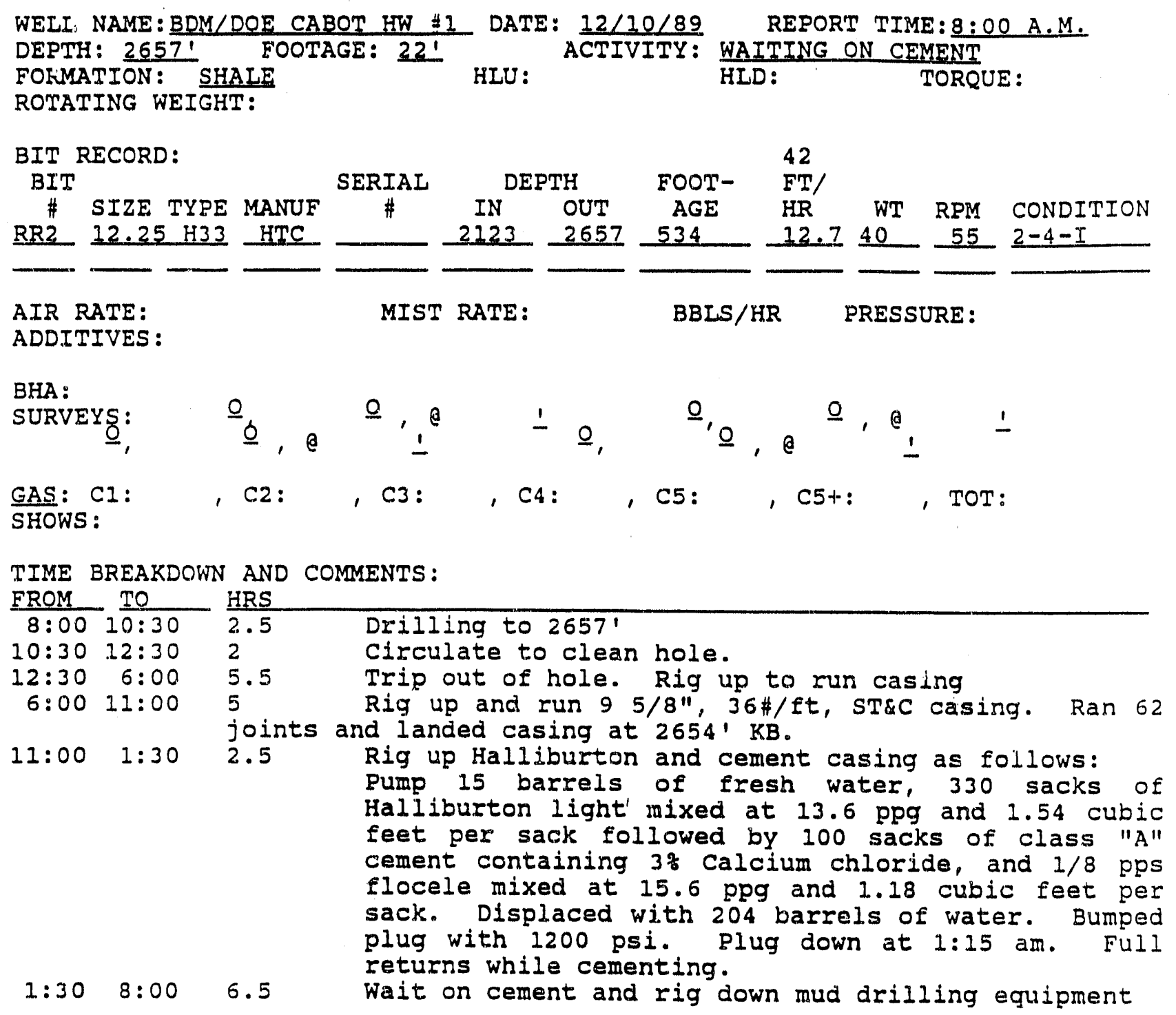


BDM DAILY REPORT

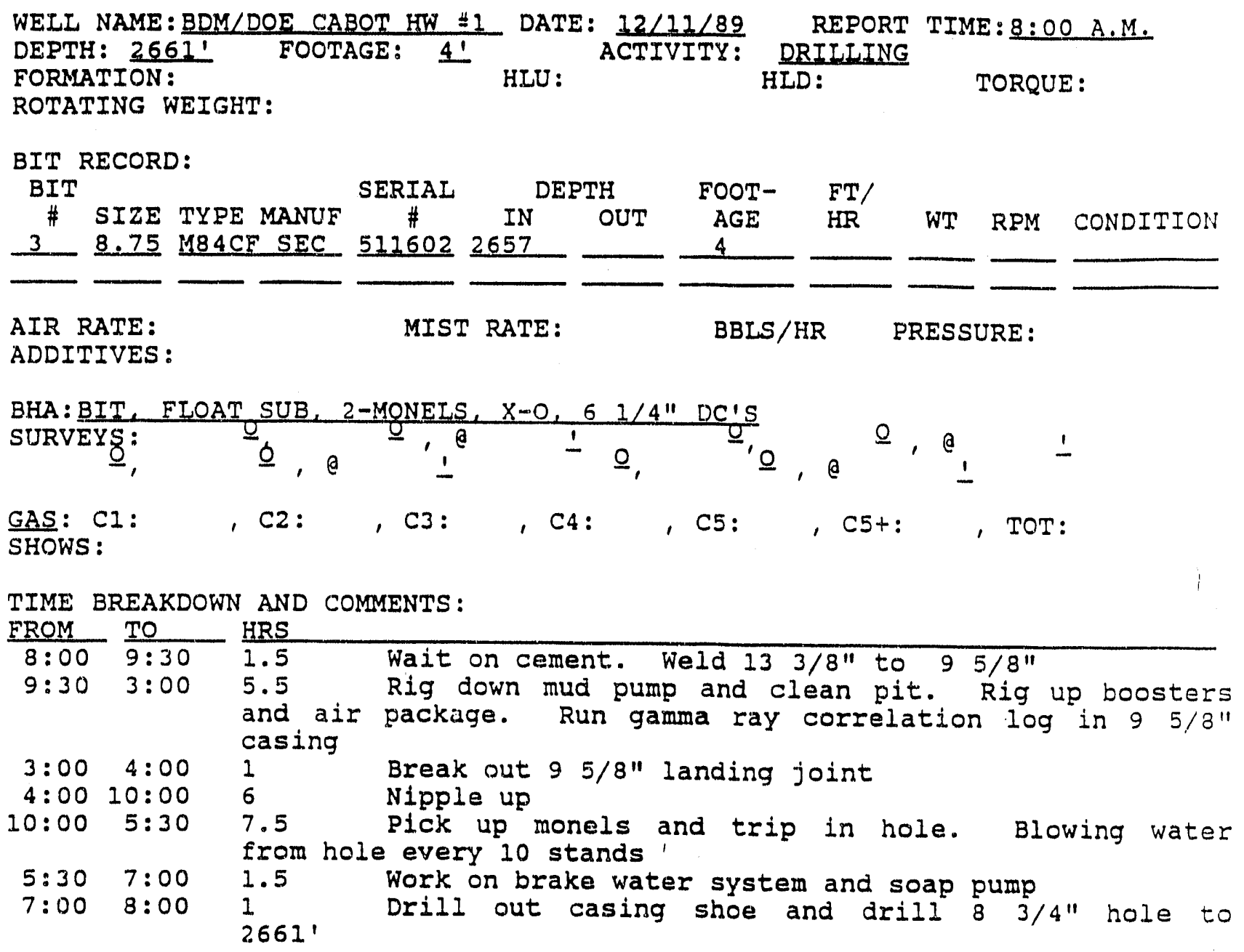


BDM DAILY REPORT

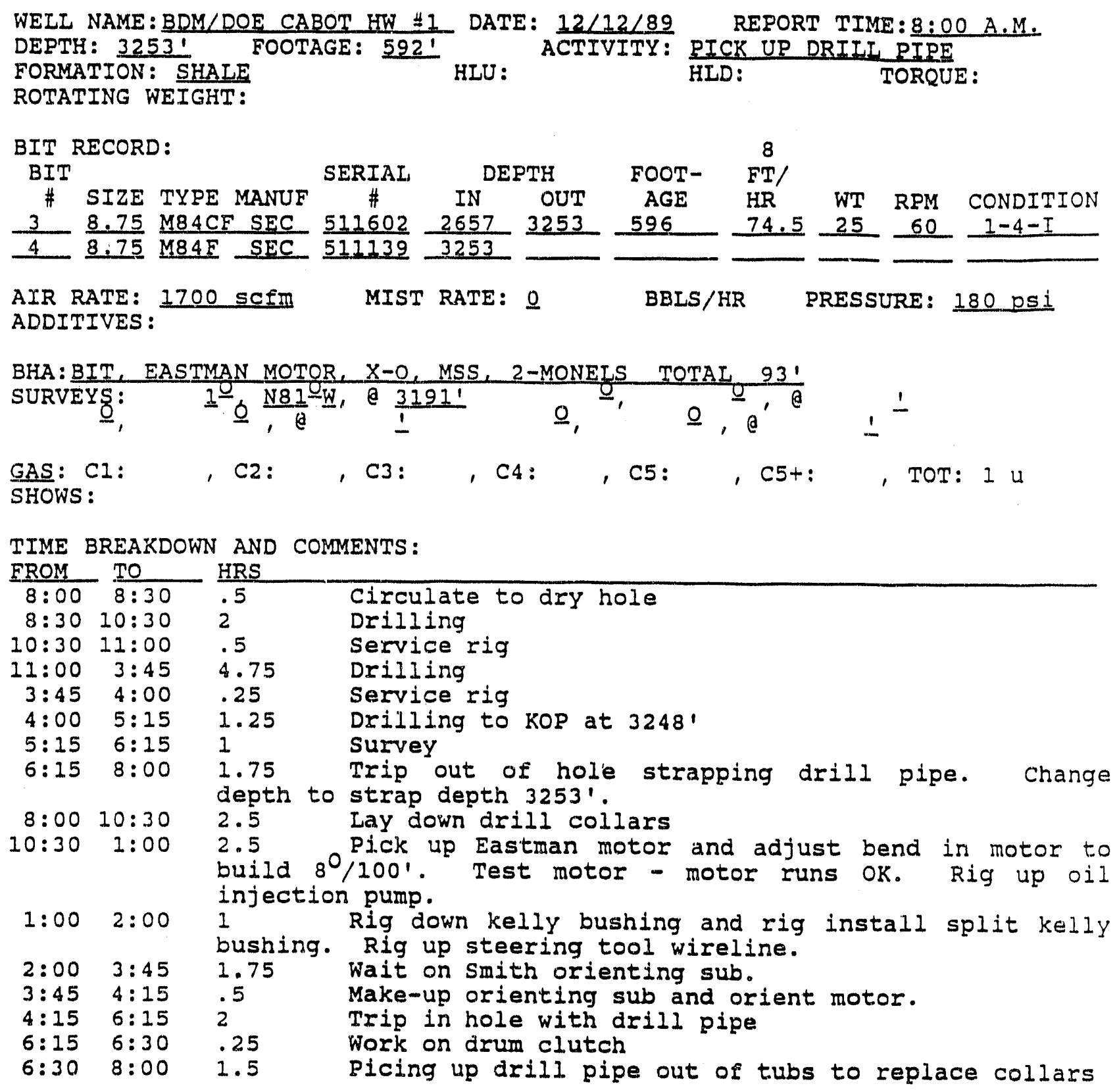


BDM DAILY REPORT

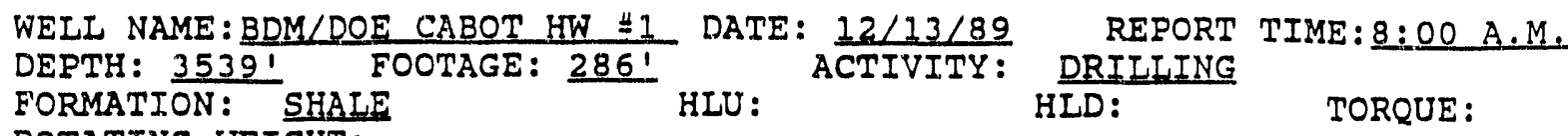

ROTATING WEIGHT:

BIT RECORD:

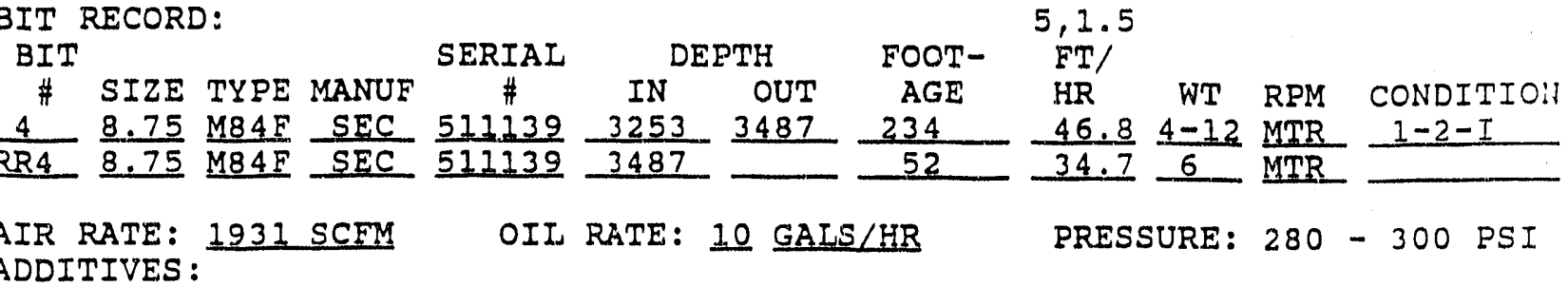

BHA : BIT, EASTMAN MOTOR, X-0, YSS, 2-MONELS TOTAL 87.13

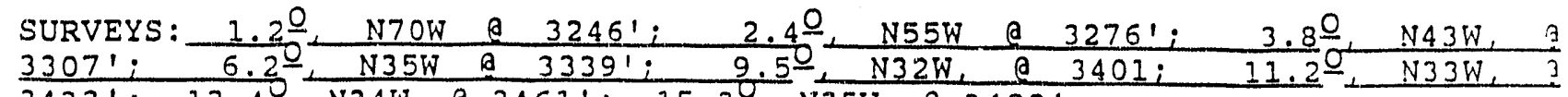

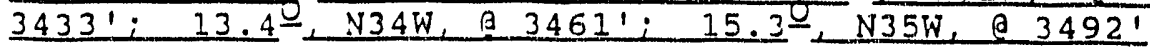

GAS: C1: , C2:, C3:, C4:, C5:, C5+:, TOT: IU

SHOWS : NONE

TIME BREAKDOWN AND COMMENTS:

\begin{tabular}{|c|c|c|}
\hline $8: 00$ & $9: 00$ & $\begin{array}{l}\text { Finish picking up drill pipe. Install new rotating } \\
\text { head rubber }\end{array}$ \\
\hline $9: 00$ & $11: 30$ & $\begin{array}{l}2.5 \text { Run steering tool through side entry sub. Install } \\
\text { string float. }\end{array}$ \\
\hline $\begin{array}{l}11: 30 \\
12: 30\end{array}$ & $\begin{array}{r}12: 30 \\
3: 00\end{array}$ & $\begin{array}{ll}5 & \text { Drilling with motor. } 1 / 2 \text { hour connections. } \\
2.5 & \text { Work on cathead and clear floor. Service rig }\end{array}$ \\
\hline & & $\begin{array}{l}4.5 \text { Drilling with motor. } 1.25 \text { hours connections. } \\
\text { Motor is building inclination at only } 5.50 / 100 \text { ' }\end{array}$ \\
\hline $\begin{array}{l}8: 45 \\
9: 30\end{array}$ & $\begin{array}{r}9: 30 \\
10: 00\end{array}$ & $\begin{array}{l}\text { Chain out to side entry sub } \\
\text { Pull steering tool }\end{array}$ \\
\hline $10: 00$ & $12: 00$ & Trip out of hole. Bit in good shape \\
\hline $12:$ & $1: 00$ & $\begin{array}{l}\text { Set motor for maximum build. Lay down the } \\
\text { izer on top of the motor. Re-orient orientation sub }\end{array}$ \\
\hline $\begin{array}{l}1: 00 \\
4: 00\end{array}$ & $\begin{array}{l}4: 00 \\
6: 00\end{array}$ & tool through side entry sub. Insta \\
\hline $6: 00$ & $8: 00$ & $\begin{array}{l}1.5 \text { Drilling } \\
\text { connections. }\end{array}$ \\
\hline
\end{tabular}

Coordinates at last survey point - 3492'MD, 3489.08' TVD, $27.17^{\prime}$ NORTH, $20.28^{\prime}$ WEST 
BDM DAILY REPORT

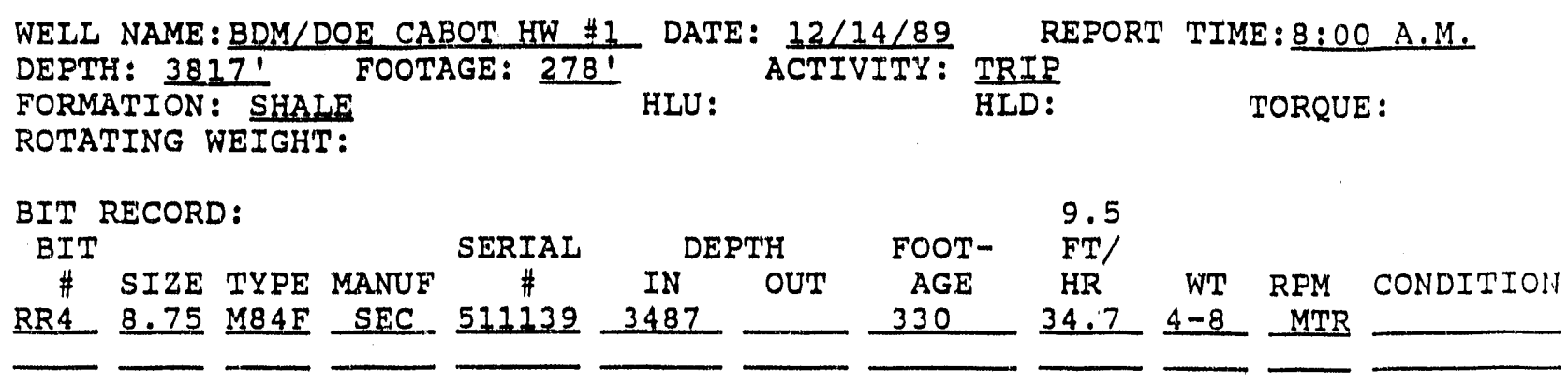

AIR RATE: 2007 SCFM OII RATE: 2 GALS/HR PRESSURE: 265 PSI

ADDITIVES :

BHA: BIT, EASTMAN MTR SET AT 1.3은.5 $1 .{ }^{\circ}$ BENT SUB, MSS, 2-MONELS, TOTAL 87.231

SURVEYS: SEE ATTACHED SURVEY SHEET

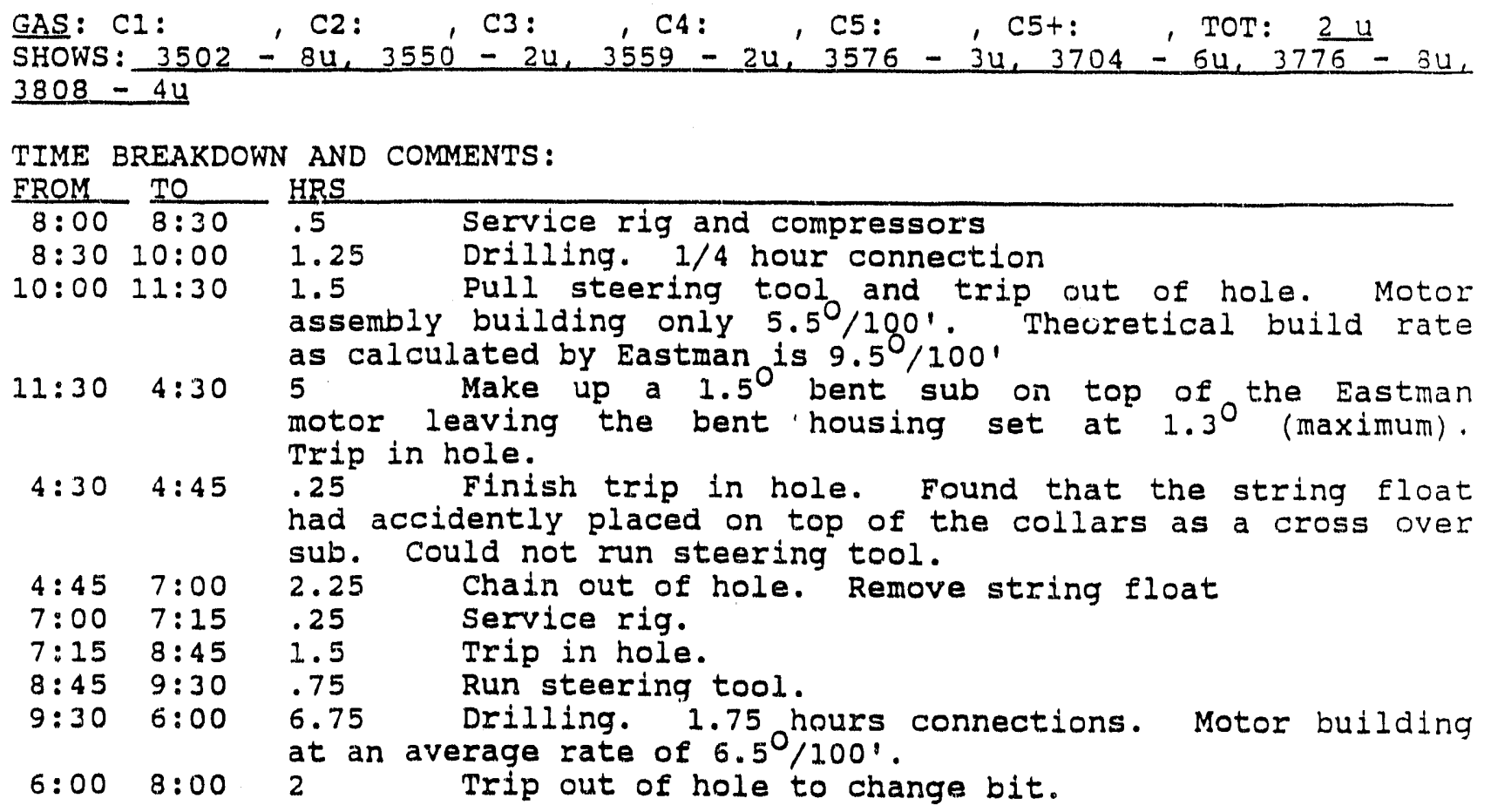


BDM DAIIY REPORT

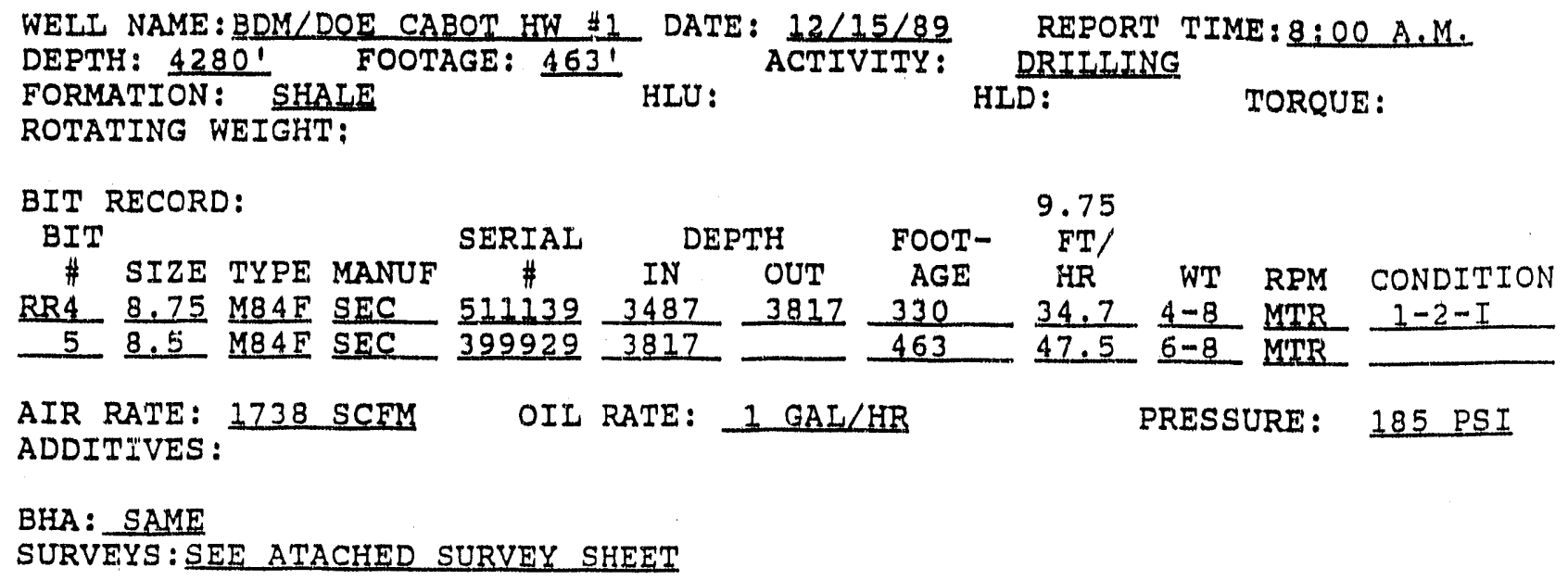

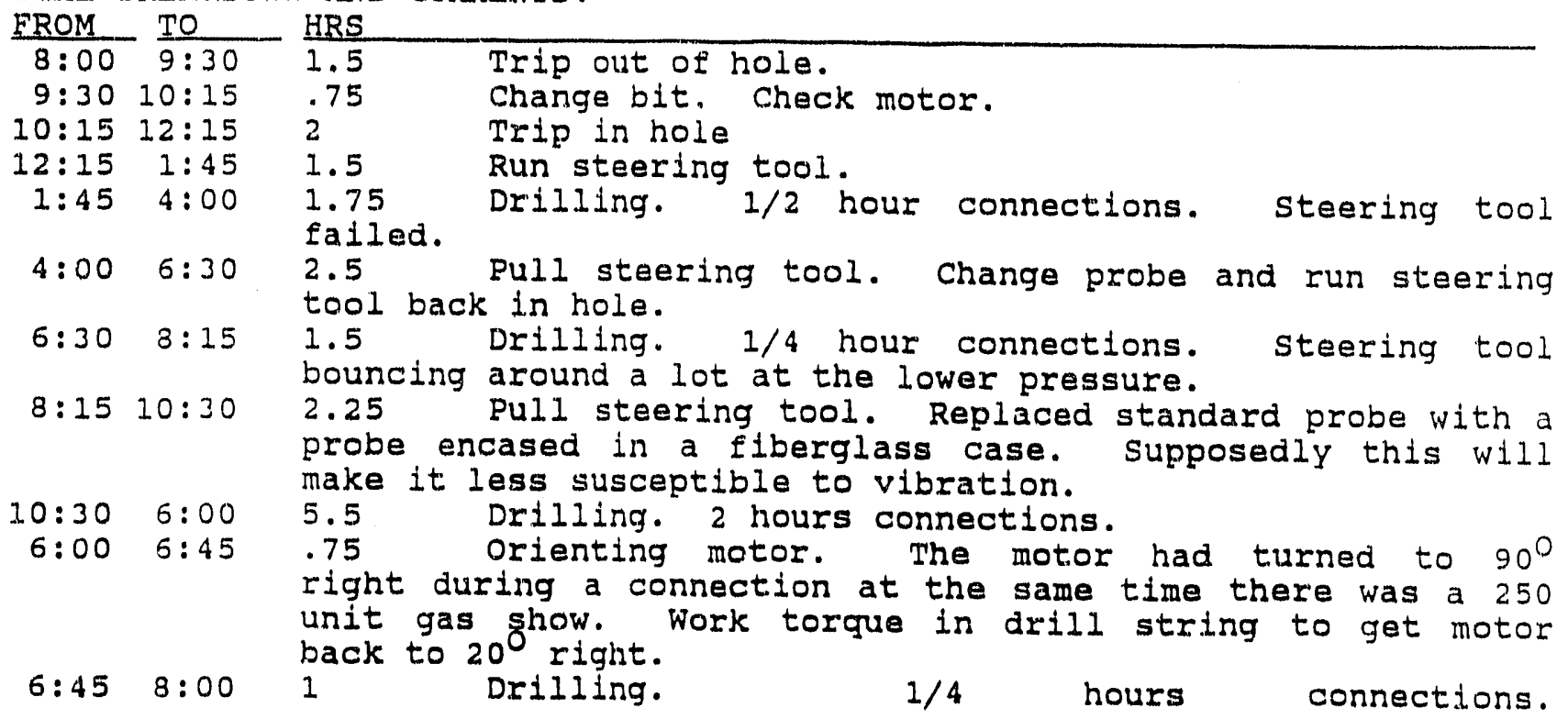


BDM DAILY REPORT

WEIL NAME: BDM LDOE CABOT HW \#1 DATE: 12/16/89 REPORT TIME: 8:00 A.M. DEPTH: 43741 FOOTAGE: 24 FORMATION: SHALE HIU : ACTIVITY: STEERING TOQL FAIIURE ROTATING WEIGHT: HID: TORQUE:

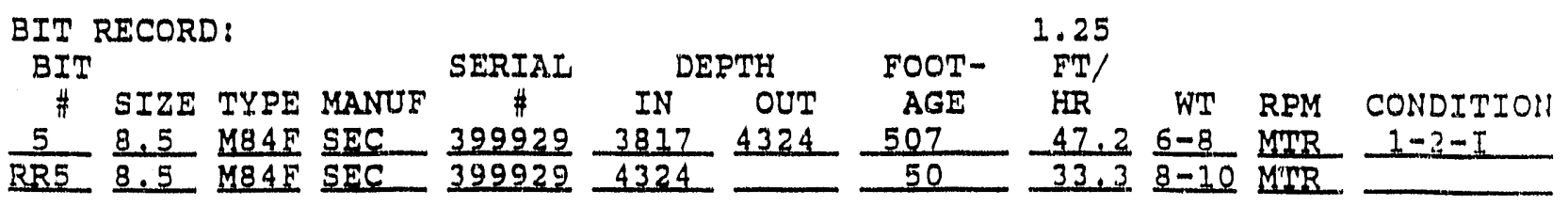

AIR RATE: 1848 SCFM OIL RATE: $1-5$ GAI/HOUR PRESSURE: 350 PSI ADDITIVES :

BHA: BIT, BAKER 20 BENT HOUSING MOTOR, FIOAT SUB, $x-0$, MSS, 2 -MONEIS SURVEYS: SEE ATTACHED SURVEY SHEET

GAS: C1: , C2:, C3: , C4:, C5:, C5+:, TOT: 50H SHOWS: $4250 \quad 404,4294$ 120u, 4303 90u, $431.2604,4319$ 200u, $4348 \quad 1204$

TIME BREAKDOWN AND COMMENTS:

\begin{tabular}{|c|c|c|}
\hline & & \\
\hline $\begin{array}{l}8: 00 \\
9: 15\end{array}$ & $\begin{array}{l}9: 15 \\
9: 45\end{array}$ & $\begin{array}{l}\text { Drilling. } 1 / 4 \text { hour connection } \\
\text { steering tool problems. The }\end{array}$ \\
\hline & & $\begin{array}{l}\text { turning to the lefti but can't get good information out of } \\
\text { the steering tool. Will pull the steering tool to make sure } \\
\text { it is stili oriented properly. Take single shot surrey with } \\
\text { steering tool. No picture. }\end{array}$ \\
\hline $9: 45$ & $12: 30$ & $\begin{array}{l}2.75 \text { Pull out of hole to side entry sub. The hole was } \\
\text { tight } 2 \text { stands off bottom. Had to wash out } 8 \text { joincs until } \\
\text { it pulled free. Hole cleaning is the problem. }\end{array}$ \\
\hline $12: 30$ & $1: 30$ & $\begin{array}{l}\text { Pull steering tool. The orienting stinger had } \\
\text { pulled loose from the steering tool when the steering tool } \\
\text { was pulled from the hole. Can't tell if the tool had been } \\
\text { orienced properly. }\end{array}$ \\
\hline $1: 30$ & $5: 00$ & $\begin{array}{l}3.5 \text { Trip out of the hole. orienting sub still properly } \\
\text { positioned. }\end{array}$ \\
\hline $5: 00$ & $9: 00$ & $\begin{array}{l}\text { Lay down Eastman motor. Plck up Baker motors. } \\
\text { Took shims out of second motor so that the first motor could } \\
\text { be shimmed up to a } 2 \text { bent housing. Plck up rest of BHA } \\
\text { and orient motor. }\end{array}$ \\
\hline $\begin{aligned} 9: 00 \\
11: 00\end{aligned}$ & $\begin{aligned} 11: 0 \\
2: 4 !\end{aligned}$ & $\begin{array}{l}\text { Trip in hole. } \\
3.75 \text { Ran steering tool. Tool would not fall past } \\
60^{\circ} \text { Pulled } 4 \text { stand from hole. Rus and seat steering }\end{array}$ \\
\hline $\begin{array}{l}2: 45 \\
3: 15 \\
4: 15\end{array}$ & 5 & $\begin{array}{l}\text { Drilling. Steering tool still not working right. } \\
\text { i work on booster clutch. } \\
2.75 \text { Pull steering tool and change probes. Run } \\
\text { steering tool. }\end{array}$ \\
\hline $7: 00$ & $7: 45$ & $\begin{array}{l}75 \text { Driliing. Steering tool failed half way whrough } \\
\text { kelly. Cannor tell which way the well has turned or what } \\
\text { the inclination is. All four probes on location have } \\
\text { failed. }\end{array}$ \\
\hline
\end{tabular}


$7: 458: 00 \quad .25$ Attempt to take single shot. No plcture. 
BDM DAILY REPORT

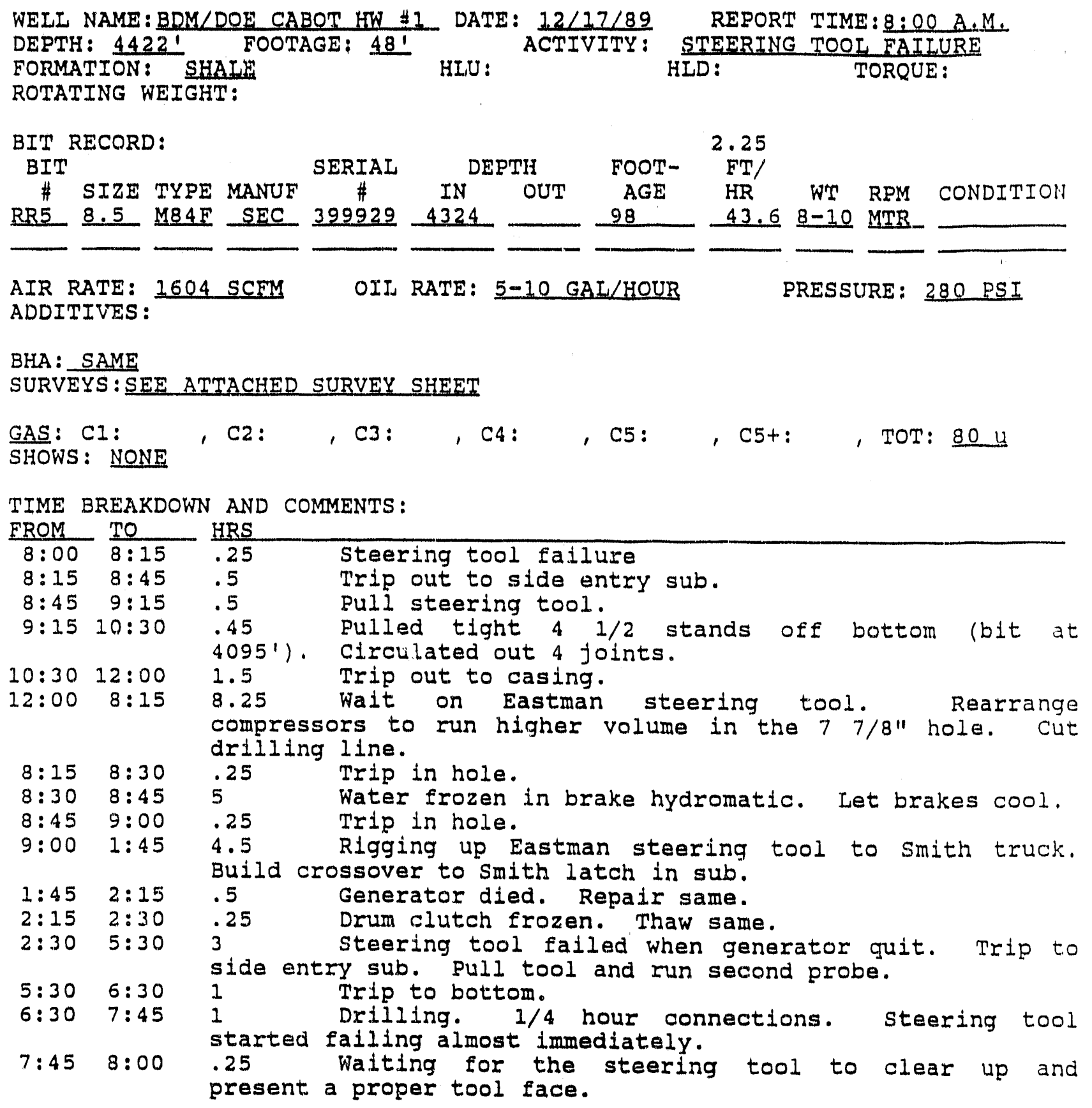


BDM DAILY REPORT

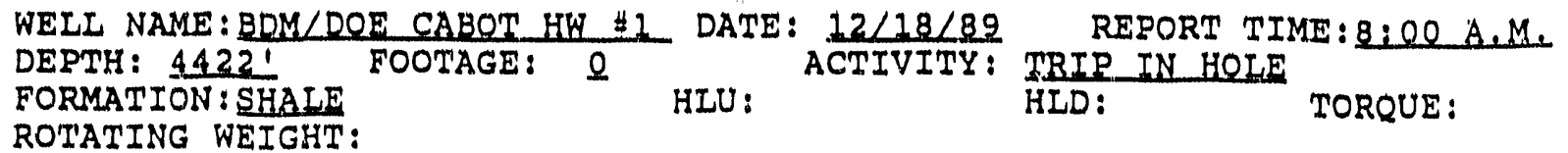

BIT RECORD:

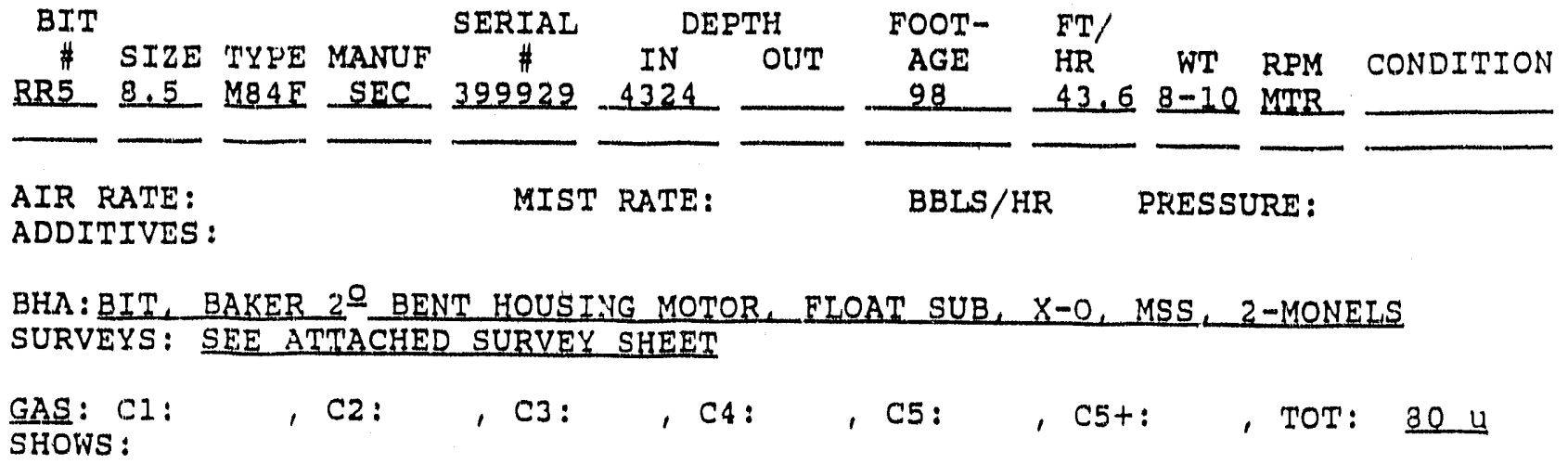

TIME BREAKDOWN AND COMMENTS:

\begin{tabular}{|c|c|c|}
\hline & ro & HRS \\
\hline $8: 00$ & $8: 45$ & $\begin{array}{l}.75 \text { Tryling to get a tool face. steering tool won' } \\
\text { settle down. }\end{array}$ \\
\hline $8: 45$ & $11: 00$ & $\begin{array}{l}2.25 \text { Trip out to side entry sub. Hole tight at the same } \\
\text { place. Circulated out one foint. puli steering tool. }\end{array}$ \\
\hline $\begin{array}{l}1: 00 \\
3: 00\end{array}$ & $\begin{array}{l}3: 00 \\
5: 00\end{array}$ & $\begin{array}{l}4 \\
2 \text { Rig up geoscience WWD. change fet nozzles f } \\
11-14-14 \text { to } 11-11-14 .\end{array}$ \\
\hline $5: 00$ & $9: 45$ & $\begin{array}{l}4.75 \text { Trip in hole surveying with the MWD every } 4 \text { to } \\
\text { stands. }\end{array}$ \\
\hline $9: 45$ & $11: 00$ & $\begin{array}{l}1.25 \text { Tagged up approximately } 70 \text { off bottom. Tried to } \\
\text { wash to bottom but it reamed hard. Quit washing to bottom } \\
\text { because we could not get a tool face. Dld not want to } \\
\text { sidetrack. The electromagnetic MWD was unable to send } \\
\text { signals back to the surface. }\end{array}$ \\
\hline$: 00$ & $2: 00$ & $\begin{array}{l}\text { Trip out of the hole. Had to circulate out through } \\
\text { the same tight spot. Checked the MWD on the way out of the } \\
\text { hole. The tool is still workling good, fust could not get a } \\
\text { signal from TD. }\end{array}$ \\
\hline $\begin{array}{l}2: 00 \\
2: 30 \\
4: 30\end{array}$ & $\begin{array}{l}30 \\
30\end{array}$ & $\begin{array}{l}\text { Work on derrick lights. } \\
\text { Trip out of hole. } \\
\text { Lay down MWD equipment. }\end{array}$ \\
\hline & & $\begin{array}{l}\text { Check orientation of motor } \\
\text { on Smith steering tool probes. }\end{array}$ \\
\hline
\end{tabular}


BDM DAILY REPORT

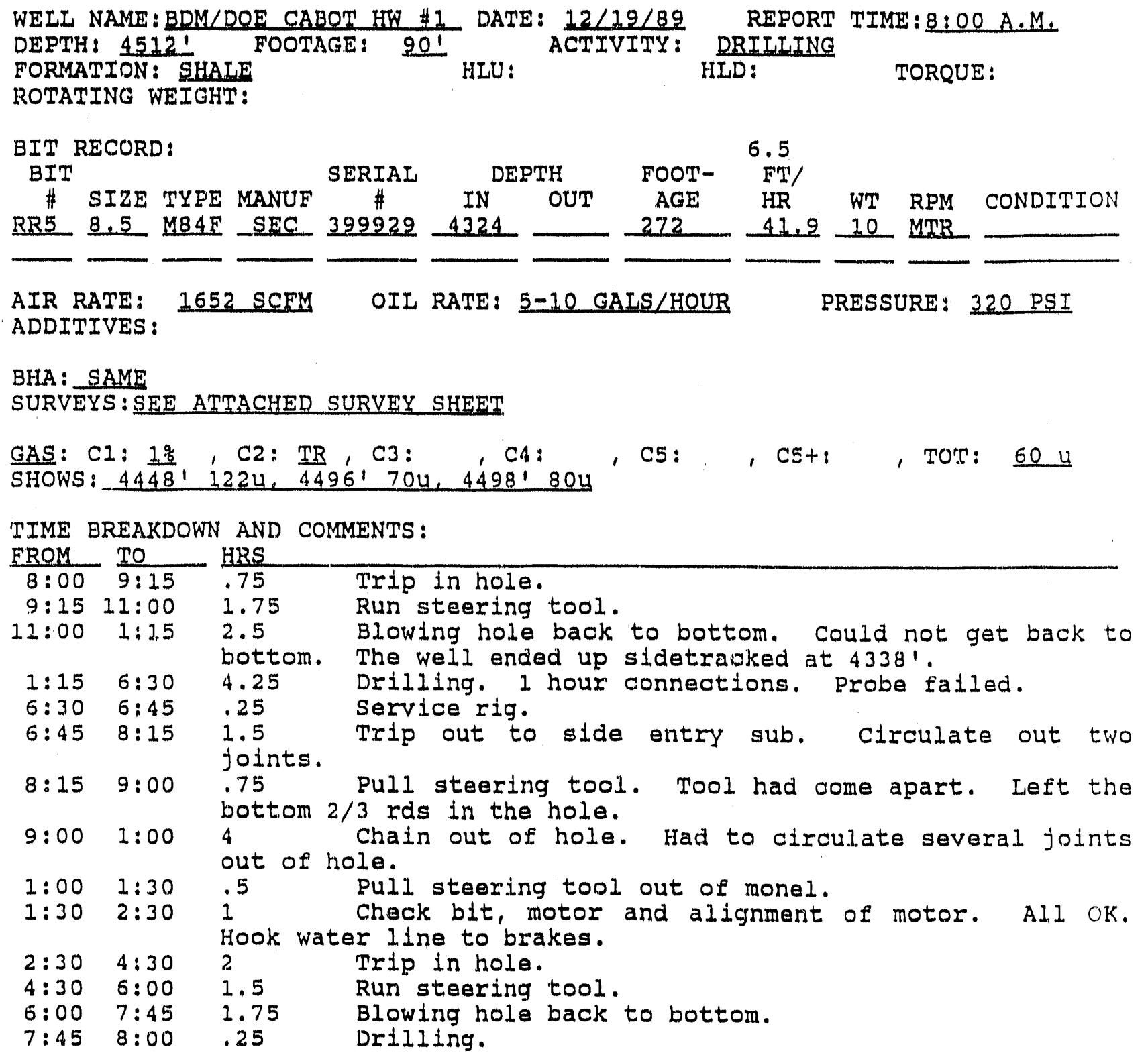


BDM DAILY REPORT

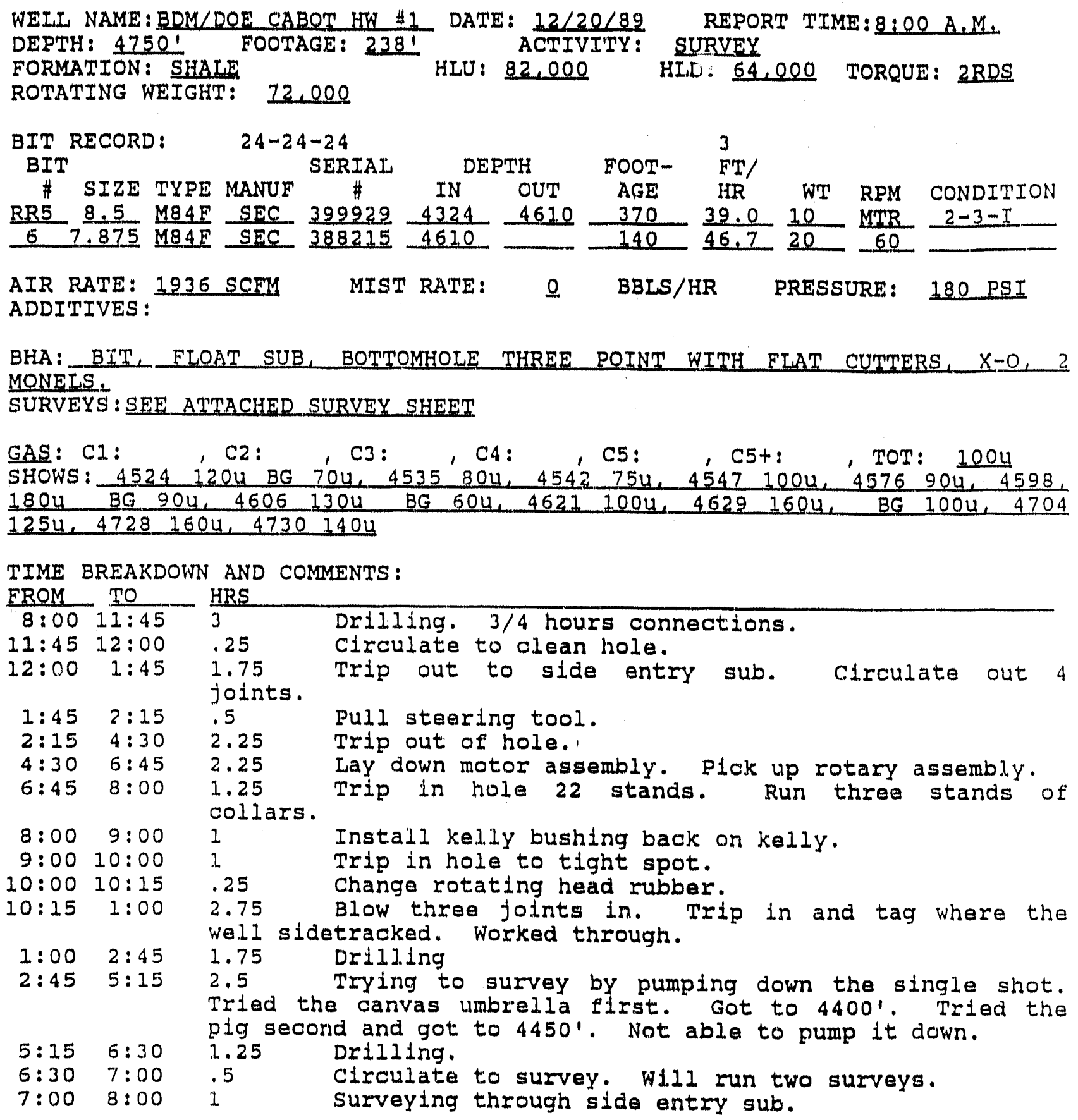


BDM DAILY REPORT

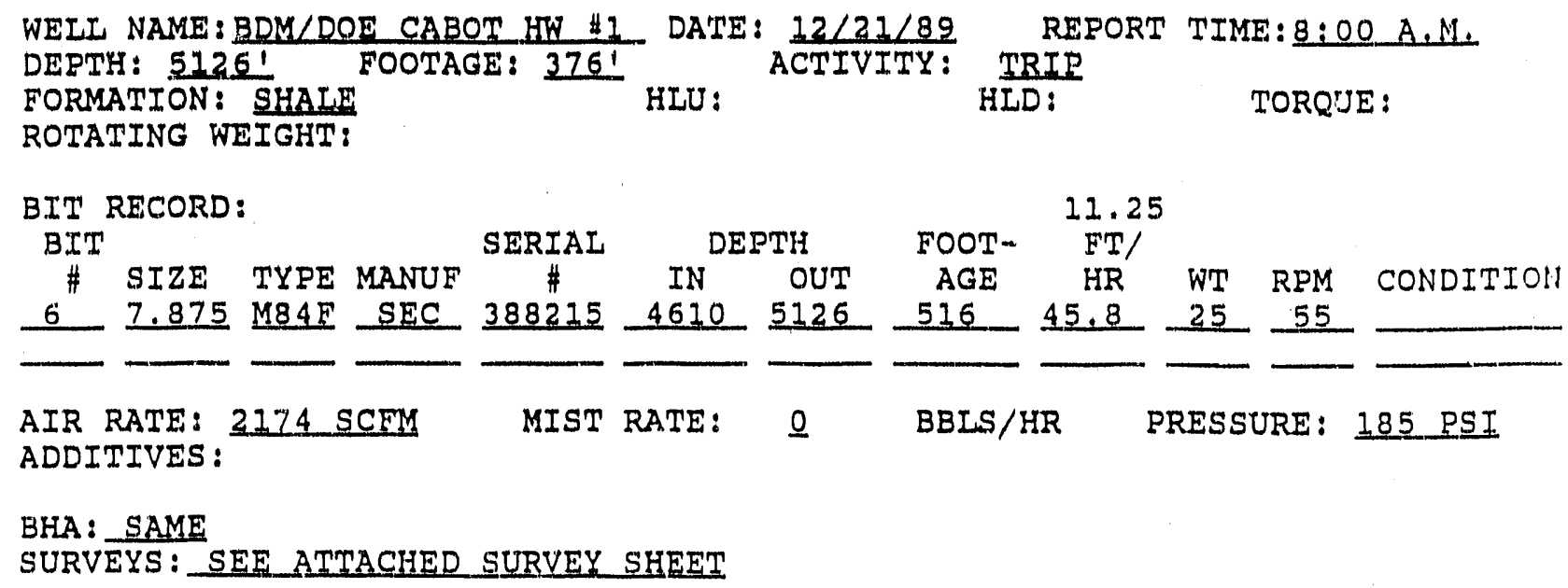

AIR RATE: 2174 SCFY MIST RATE: $\underline{0}$ BBLS/HR PRESSURE: 185 PSI ADDITIVES :

BHA : SAME

SURVEYS: SEE ATTACHED SURVEY SHEET

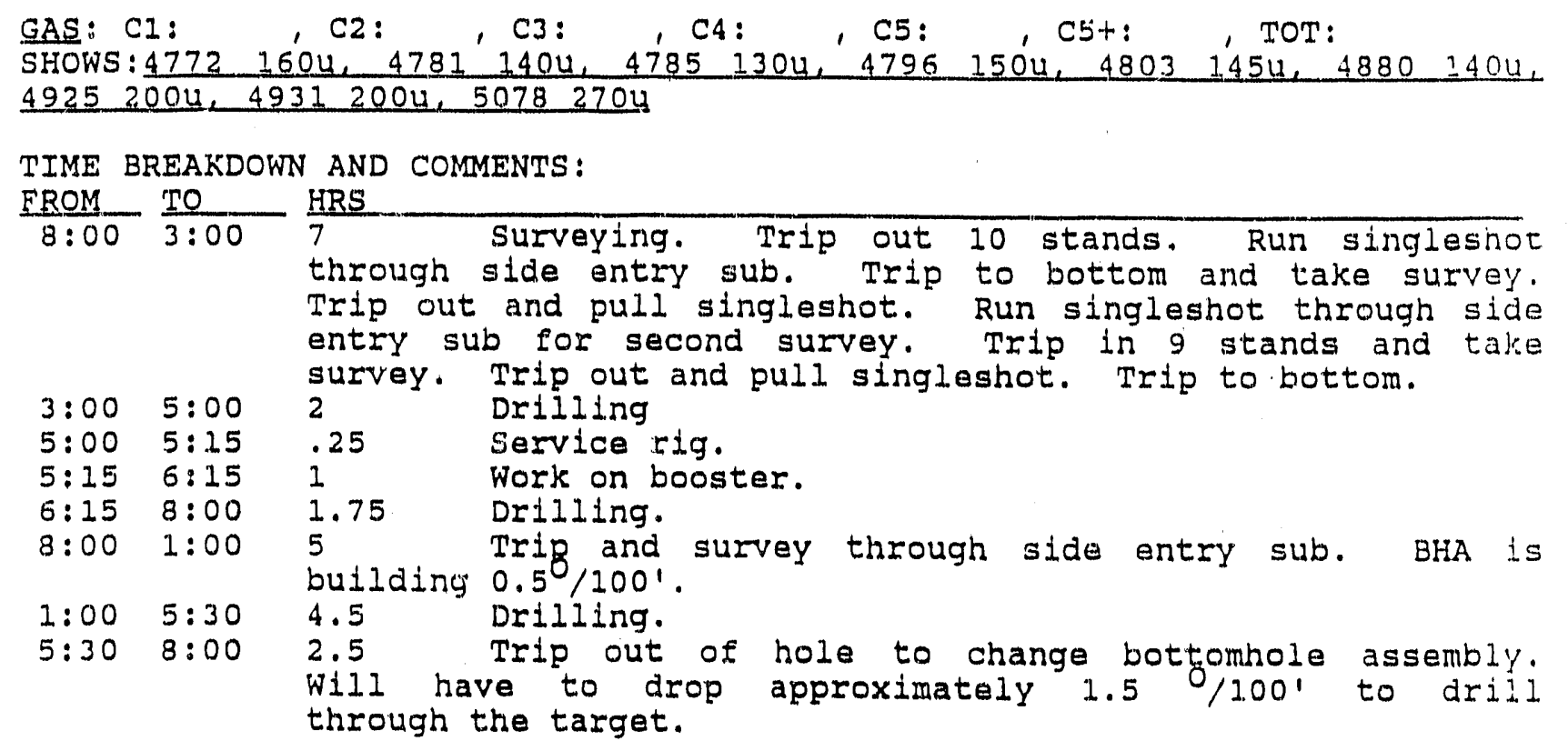


BDM DAILY REPORT

WELI NAME: BDM/DOE CABOT HW 1 -1 DATE: $12 / 22 / 89$
DEPTH: 5126 FOOTAGE: 0
FORMATION: SHAIE ROTATING WEIGHT:

BIT RECORD:

AIR RATE: $N$ N/A ADDITIVES :

BHA: BIT, FLOAT SUB, 10.75-FOOT PONY COLLAR, BOTTOMHOLE 3-PT W/ FLAT CUTTERS, $X-0,2$ MONELS

SURVEYS: SEE ATTACHED SURVEY SHEET

GAS: C1: , C2:, C3:, C4:, C5:, C5+:, TOT:

SHOWS :

TIME BREAKDOWN AND COMMENTS:

\begin{tabular}{|c|c|c|c|}
\hline & & & \\
\hline 0800 & 0900 & 1 & Tripping out. \\
\hline 0900 & 1230 & 3.5 & $\begin{array}{l}\text { Trip in with new BHA as follows: bit, near-bit } 3-p t \\
\text { reamer, } 30-f t \text { collar, } 3 \text {-pt string reamer, } x-0 \text {, } \\
\text { monel. }\end{array}$ \\
\hline 1230 & 1300 & 0.5 & $\begin{array}{l}\text { Run single shot w/ timer set for } 75 \text { minuters on } \\
\text { SMITH (ON COURSE) wire line through side entry sub. }\end{array}$ \\
\hline 1300 & 1400 & 1 & $\begin{array}{l}\text { Trip in; bit won't go down past sidetrack point } \\
\text { (approx. 4338); worked string up and down, blew air } \\
\text { but still wouldn't go. }\end{array}$ \\
\hline 1400 & 1500 & 1 & $\begin{array}{l}\text { Pull } 3 \text { stands. Pull side entry sub, wireline, and } \\
\text { single shot. }\end{array}$ \\
\hline 1500 & 1545 & 0.75 & $\begin{array}{l}\text { Run in to sidetrack point; apply torque, drill } \\
\text { string rolls into old hole, can't make it go. }\end{array}$ \\
\hline $\begin{array}{l}1545 \\
1845\end{array}$ & $\begin{array}{l}1845 \\
2000\end{array}$ & $\begin{array}{l}3 \\
1.25\end{array}$ & $\begin{array}{l}\text { trip out. Break out BHA. } \\
\text { Rig down loggers. }\end{array}$ \\
\hline 2000 & 2030 & 0.5 & $\begin{array}{l}\text { Pick up bit, subs, reamer; new BHA consists of bit, } \\
\text { float sub, } 10.75-\mathrm{ft} \text { pony collar, } 3 \text {-pt reamer, } \mathrm{X}-0 \text {, } \\
\text { collars }\end{array}$ \\
\hline $\begin{array}{l}2030 \\
2345\end{array}$ & 2345 & 3.25 & Run in hole. \\
\hline 2345 & 0215 & 2.5 & $\begin{array}{l}\text { Run single shot survey using wilson Downhole's } \\
\text { S.S.Tool, smith's releasing overshot tool, and } \\
\text { rig's slick line unit. }\end{array}$ \\
\hline $\begin{array}{l}0215 \\
0345 \\
041.5 \\
0700\end{array}$ & $\begin{array}{l}0345 \\
0415 \\
0700 \\
0800\end{array}$ & $\begin{array}{l}1.5 \\
0.5 \\
2.75 \\
1\end{array}$ & $\begin{array}{l}\text { Pull } 20 \text { stands of pipe. } \\
\text { Fish out single shot w/ sl. line. } \\
\text { Trip out to casing point. } \\
\text { Shutting down; set "dry watch". }\end{array}$ \\
\hline
\end{tabular}




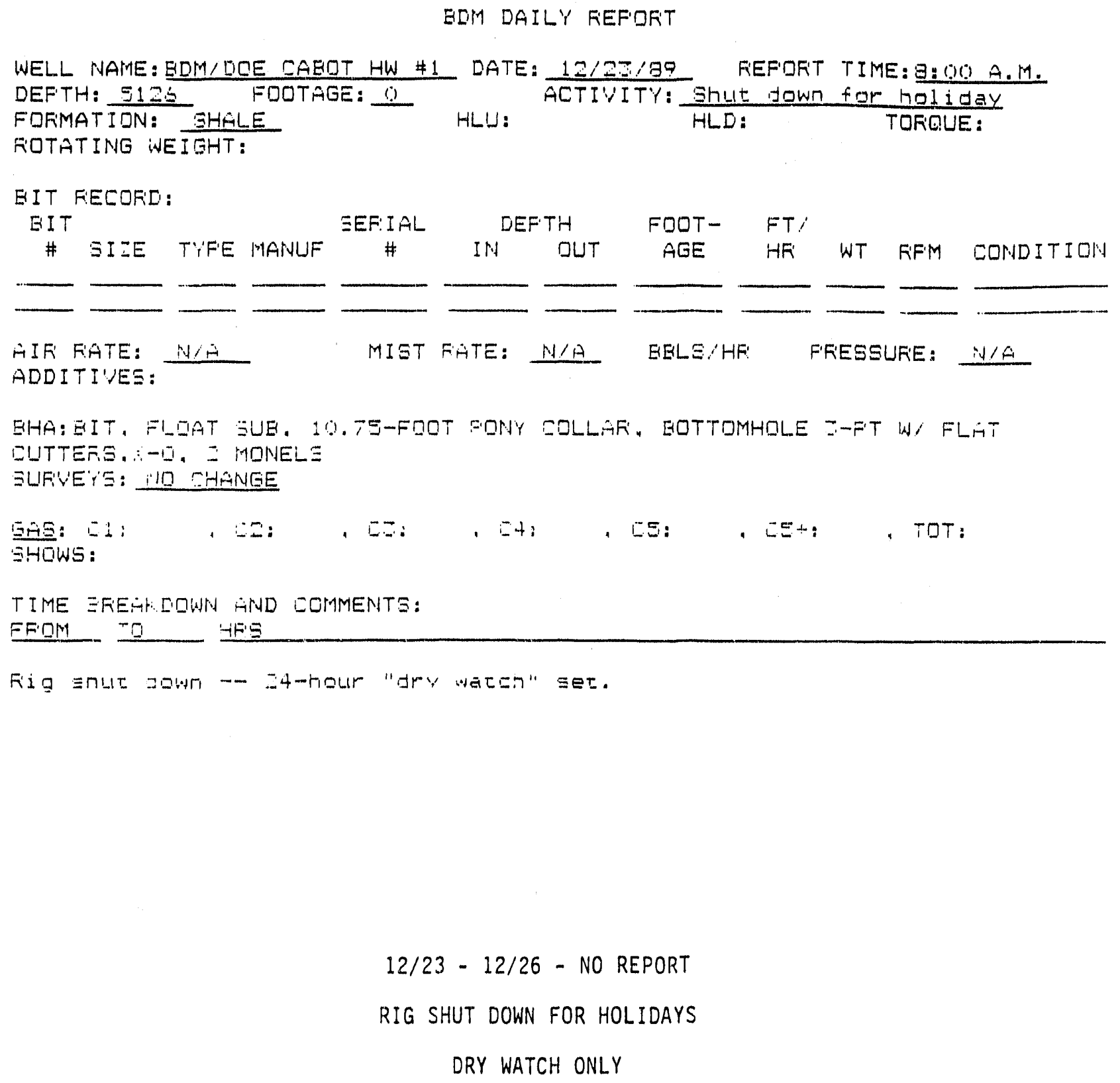


BDM DAILY REPORT

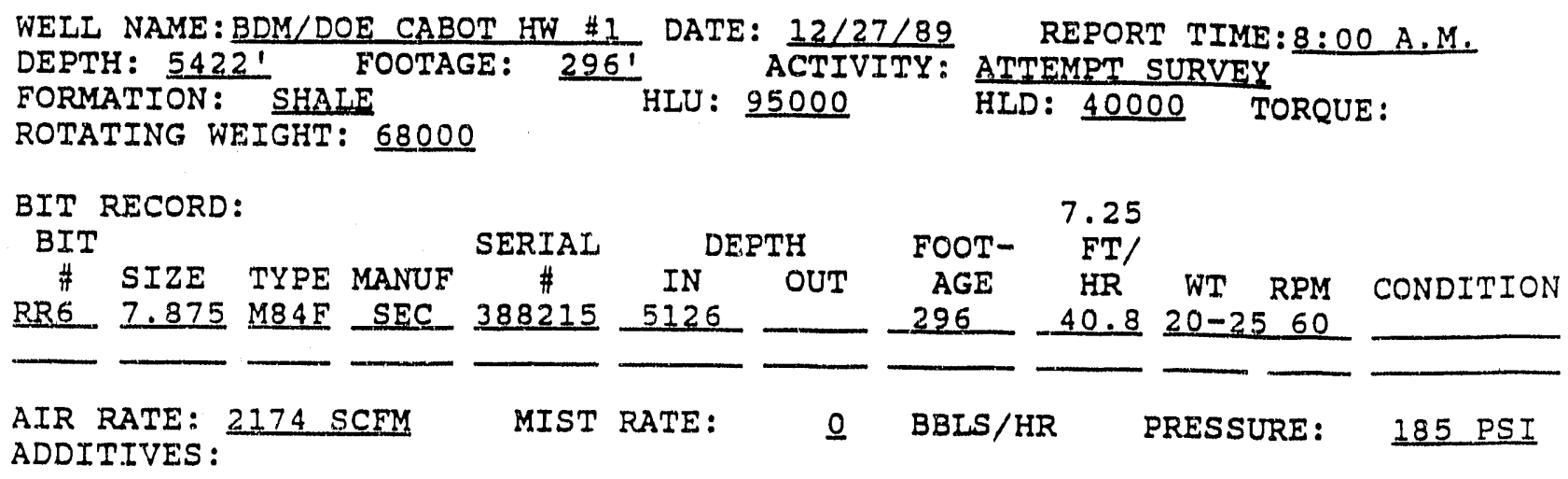

BHA: $B I T, x-0$, SHORT DRILI, COLLAR, THREE POINT, $x-0$, FLOAT SUB, 2-MONELS, 30 STANDS DRILL PIPE, $x-0,6$-DRILL COLIARS, $x-0$

SURVEYS: SEE ATTACHED SURVEY SHEET

$\begin{array}{ll}\text { GAS }: ~ C 1: & \text { C2: } \\ \text { SHOWS: } & \text { C3:, C4:, C5:, C5+:, TOT: }\end{array}$

TIME BREAKDOWN AND COMMENTS:

\begin{tabular}{|c|c|c|}
\hline & -1 & HRS \\
\hline $\begin{array}{r}8: 00 \\
11: 00\end{array}$ & $\begin{array}{r}11: 00 \\
1: 30\end{array}$ & $\begin{array}{l}\text { Start up rig. Service rig and air. } \\
\text { Trip in hole. No problem getting into the right }\end{array}$ \\
\hline $\begin{array}{l}2: 00 \\
5: 15 \\
5: 30 \\
5: 45\end{array}$ & $\begin{array}{l}5: 15 \\
5: 30 \\
5: 45 \\
7: 00\end{array}$ & 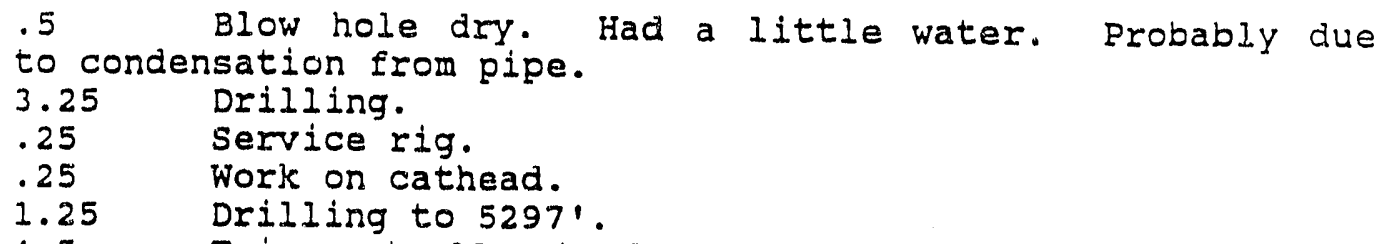 \\
\hline 00 & $11: 30$ & $\begin{array}{l}4.5 \text { Trip out } 19 \text { stands. Run survey tool on smith } \\
\text { releasing overshot. pull slick line and trip to bottom. } \\
\text { Trip out and retrieve survey tool. Trip to bottom. Survey } \\
\text { read } 93^{\circ} \text { slow. The direction change is probably due to } \\
\text { the singleshot moving to the top of the monels or into the } \\
\text { first joint of drill pipe causing magnetic interference. } \\
\text { Actual survey depth is probably } 40 \text { to } 70^{\prime} \text { higher than shown } \\
\text { on the survey sheet. }\end{array}$ \\
\hline & & $\begin{array}{ll}.5 & \text { Service rig. } \\
2.75 & \text { Drilling to } 5422^{\prime}\end{array}$ \\
\hline & & $\begin{array}{l}5.25 \text { Atteint survey. pulled } 21 \text { stands pipe. Run survey } \\
\text { tool on releasing overshot. Trip in hole. Got into the } \\
\text { short hole. Would not go past } 4423 \text {. Made three attempts } \\
\text { at getting into the long hole with no luck. Pull out and } \\
\text { retrieve survey tool. Trip in to see if the pipe would go } \\
\text { into the long hole and it did. Pull bit to } 4390 \text { (bit below } \\
\text { sidetrack). Ran survey tool to see if it will go down and } \\
\text { it }\end{array}$ \\
\hline
\end{tabular}


BDM DAILY REPORI

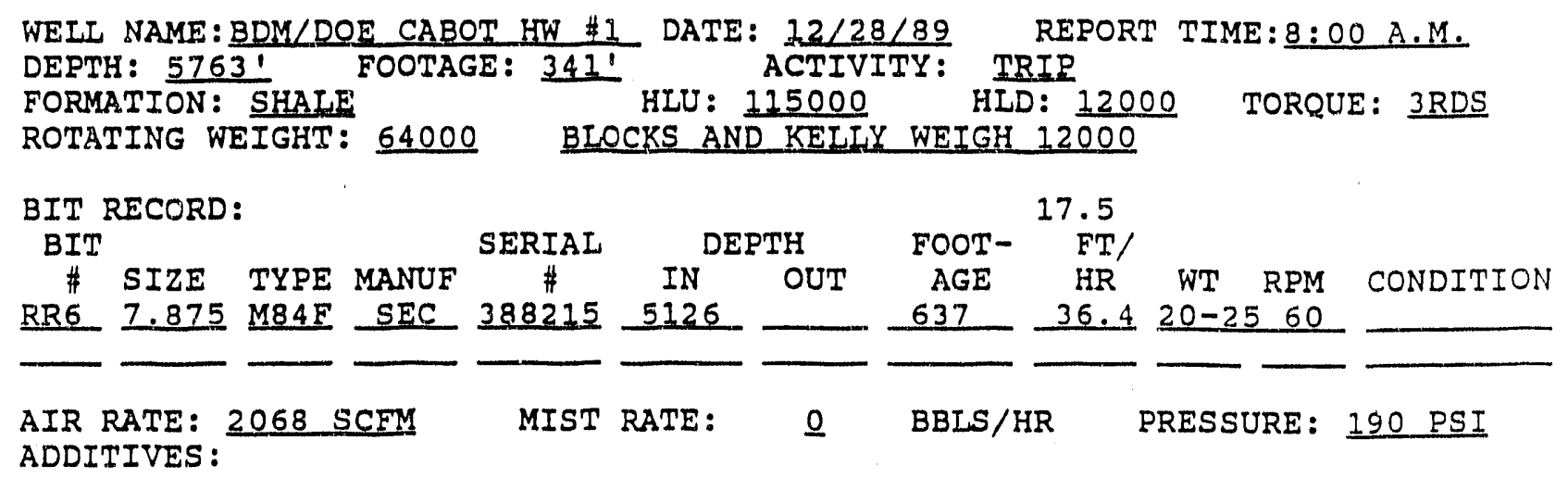

BHA: BIT, $X-0$, SHORT DRILI COLIAR, THREE POINT REAMER, FLOAT SUB, 1MONEI, 40 STANDS DRILL PIPE, $x-0,10-D R I L I$ COLIARS, $x-0$

SURVEYS: SEE ATTACHED SURVEY SHEET

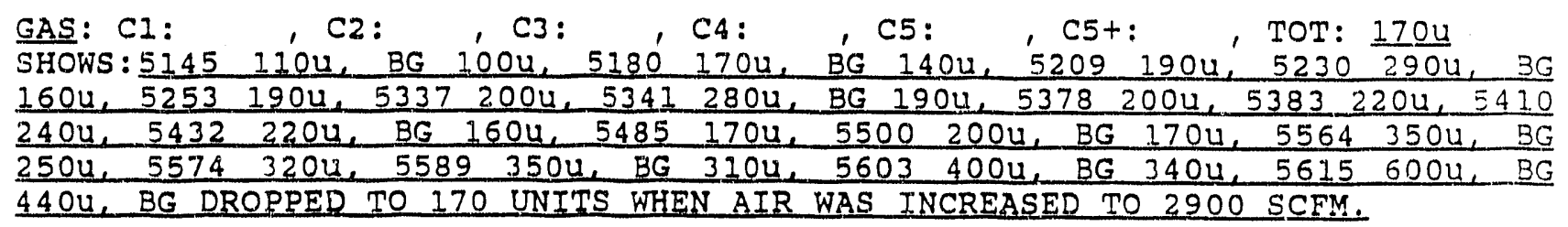

TIME BREAKDOWN AND COMMENTS:

\begin{tabular}{|c|c|c|}
\hline EROM & TO & IRS \\
\hline $8: 00$ & $12: 30$ & $\begin{array}{l}4.5 \\
\text { to } 43901 \text { and retrieve survey tool. Trip back to bottom. }\end{array}$ \\
\hline $12: 30$ & $8: 30$ & $\begin{array}{l}8 \text { Drilling. After the connection at } 5670^{\prime} \text {, the pipe } \\
\text { will no longer fall into the hole. Increasd air rate from } \\
2000 \text { scfm to } 2900 \text { scfm on next two kellys down. Didn't make } \\
\text { any difference. Not a hole cleaning problem. Now having to } \\
\text { rotate the pipe to get it in the hole. }\end{array}$ \\
\hline $\begin{array}{l}8: 30 \\
8: 45\end{array}$ & $\begin{array}{r}8: 45 \\
11: 00\end{array}$ & $\begin{array}{l}\text { Service rig. } \\
\text { Drililing. Rotating the pi }\end{array}$ \\
\hline & & $\begin{array}{l}\text { connection. Connections taking } 30 \text { to } 45 \text { mins. Will not be } \\
\text { able to take any more surveys by tripping in with pipe. The } \\
\text { maximum time on the timer is not long enough to reach } \\
\text { bottom. }\end{array}$ \\
\hline$: 00$ & $11: 45$ & $\begin{array}{l}\text { Tried pumping down a survey with the latest } \\
\text { revision of the pump down equipment. Would not go through } \\
\text { the collars at } 3600^{\prime} \text {. }\end{array}$ \\
\hline $\begin{array}{l}1: 45 \\
2: 00 \\
4: 15\end{array}$ & $\begin{aligned} 12: & 00 \\
4: & 15 \\
5: & 30\end{aligned}$ & $\begin{array}{l}\text { Service rig. } \\
\text { Trip out to move the drill collars up the hole. } \\
\text { Lay down one monel drill collar to help reduce }\end{array}$ \\
\hline & & $\begin{array}{l}\text { Trip in } 40 \text { stands drill pipe and } 6 \text { drill collars. } \\
\text { Pick up } 4 \text { more drill collars. }\end{array}$ \\
\hline
\end{tabular}


BDM DAILY REPORT

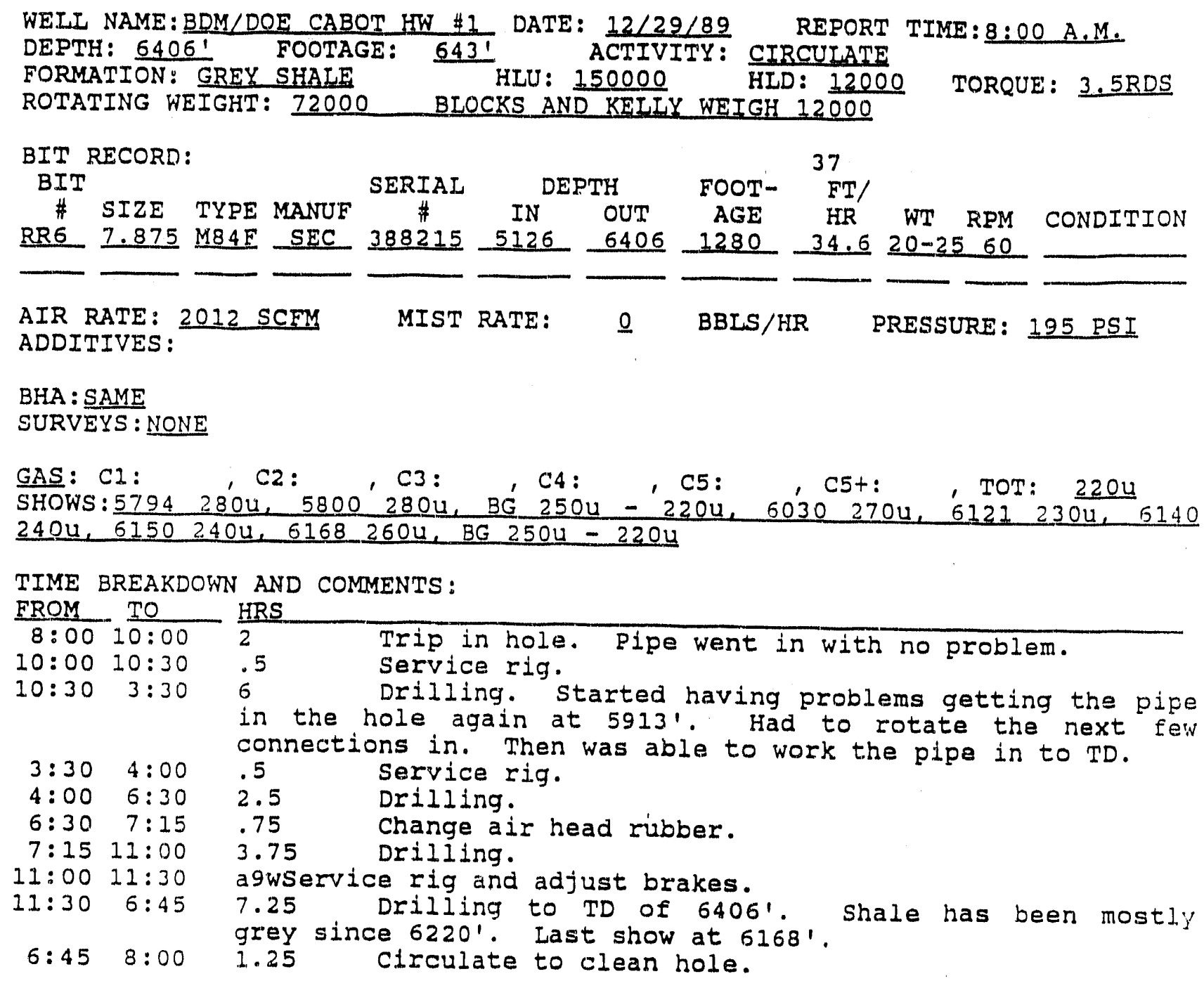


BDM DAIIY REPORT

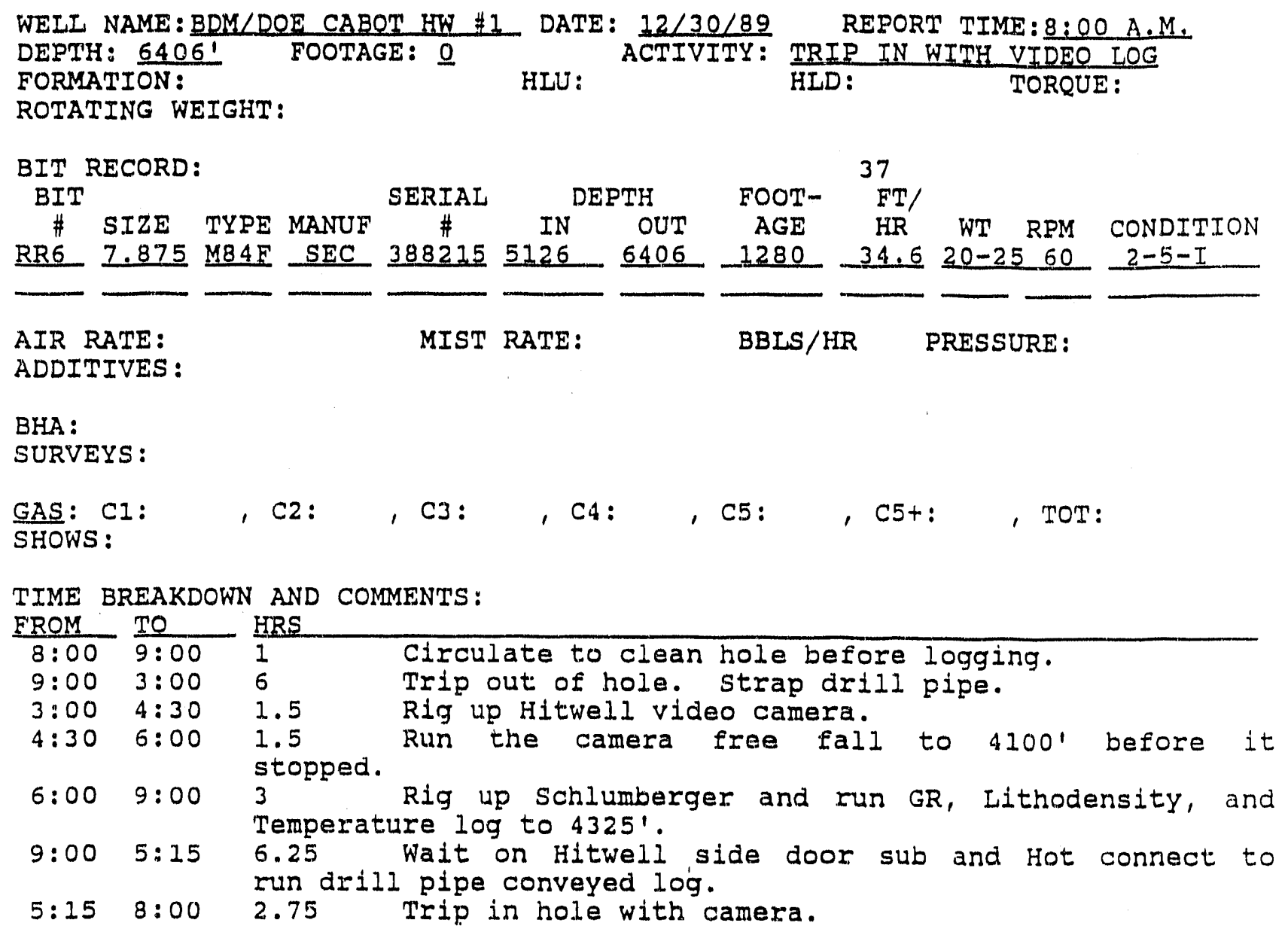


BDM DAILY REPORT

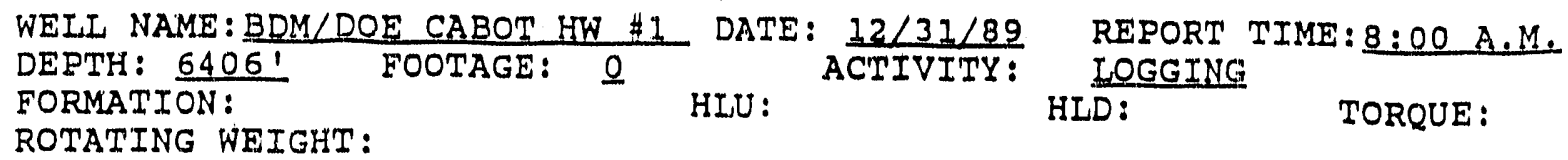

BIT RECORD:

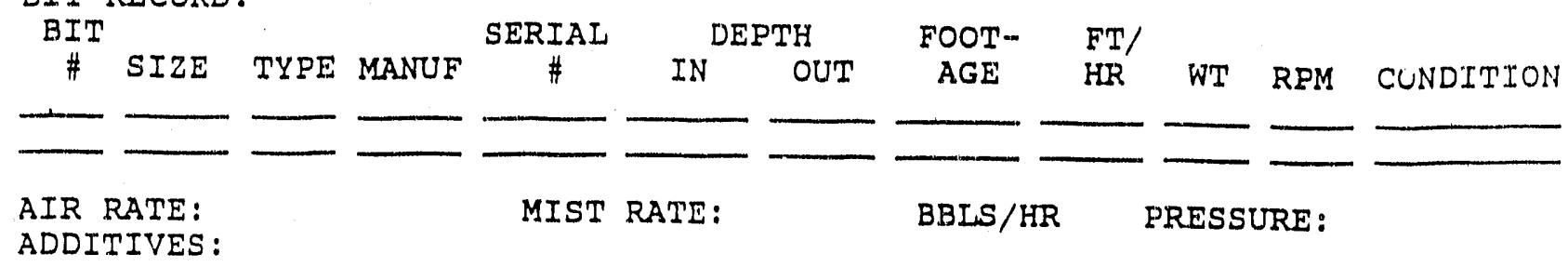

BHA :

SURVEYS:

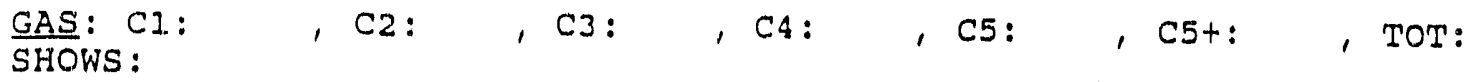

TIME BREAKDOWN AND COMMENTS:

\begin{tabular}{|c|c|c|}
\hline$O M$ & TO & RS \\
\hline $8: 00$ & $9: 30$ & Trlp in hole with video camera. \\
\hline $9: 30$ & $10: 30$ & $\begin{array}{l}\text { Hang wireline sheave and rig up side entry sub. } \\
\text { Pull air head rubber. }\end{array}$ \\
\hline $10: 30$ & $4: 00$ & $\begin{array}{l}5.5 \text { The side entry sub that Hitwell brought out had } \\
\text { ST\&C connections. Did not know if the connections would } \\
\text { take the compressive loads necessary to push the pipe in the } \\
\text { hole. Wait on Schlumberger's side entry sub. }\end{array}$ \\
\hline $4: 00$ & $9: 00$ & $\begin{array}{l}\text { Rig up schlumberger's side entry sub and run hot } \\
\text { connect. Had trouble getting the tool to work. Did not } \\
\text { make good contact. }\end{array}$ \\
\hline $9: 00$ & $11: 00$ & $\begin{array}{l}\text { Logging with the video camera. } \\
\text { connection to the tool. could not log to TD. }\end{array}$ \\
\hline $\begin{aligned} & 11: 00 \\
& 12: 00 \\
& 1:\end{aligned}$ & $\begin{aligned} & 12: 00 \\
& 1: 15 \\
& 2: 45\end{aligned}$ & $\begin{array}{l}\text { Trip out to side entry sub. } \\
\text { Puli wire line and rig down side entry sub. } \\
\text { Trip out of hole. }\end{array}$ \\
\hline $2: 45$ & $4: 30$ & 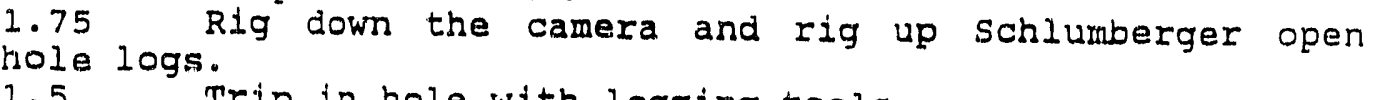 \\
\hline $\begin{array}{l}4: 30 \\
6: 00\end{array}$ & $\begin{array}{l}6: 00 \\
8: 00\end{array}$ & $\begin{array}{ll}1.5 & \text { Trip in hole with logging tools. } \\
2 & \text { Pick up side entry sub and run wet connect. } \\
\text { logging. }\end{array}$ \\
\hline
\end{tabular}


BDM DAILY REPORT

WELL NAME: $\frac{\text { BDM }}{\text { DEPOE CABOT HW }}$ \#1

DATE: $1 / 1 / 89$ ACTIVITY: FORMATION : HLU :

REPORT TIME: 8:00 A.M. ROTATING WEIGHT:

BIT RECORD:

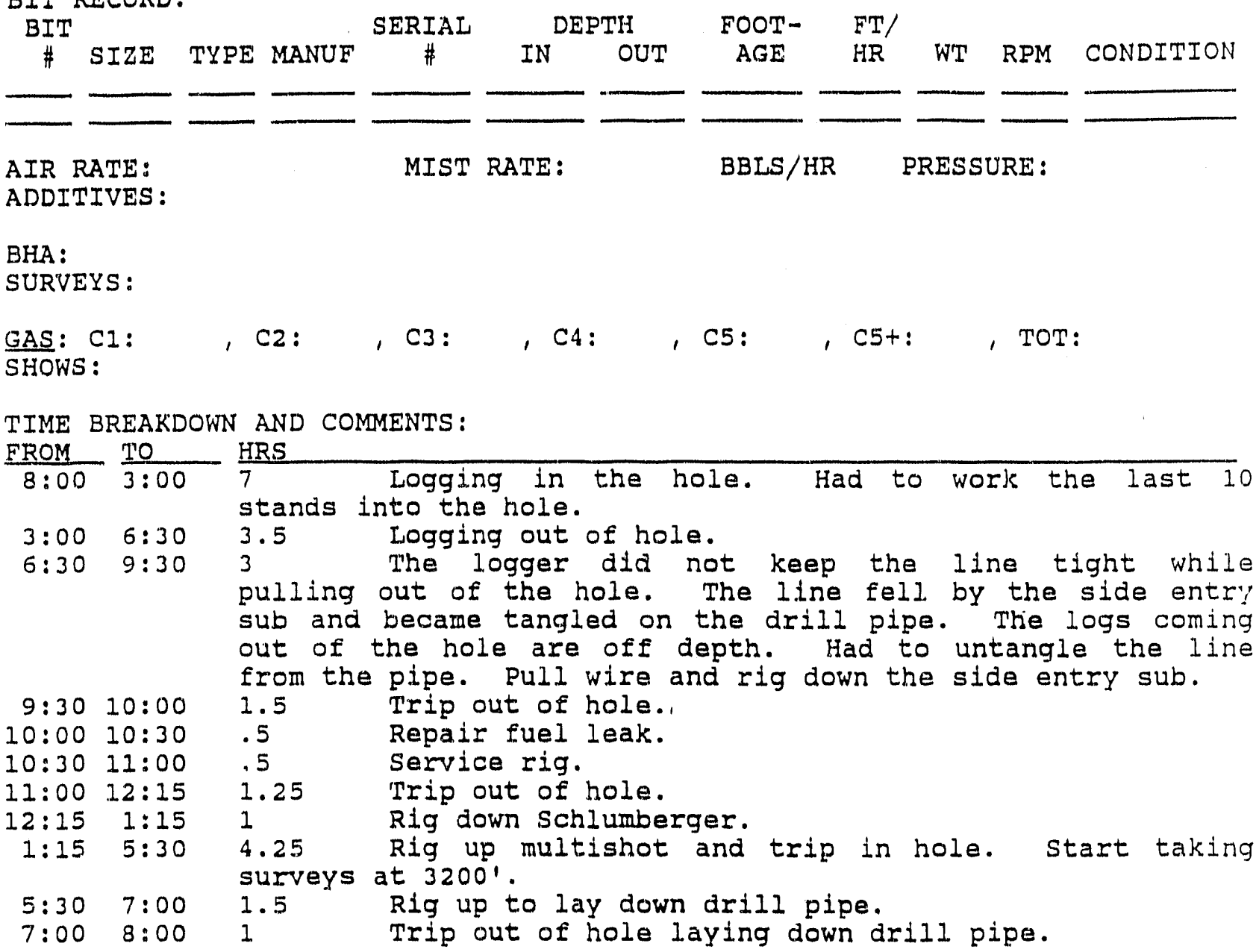


BDM DAILY REPORT

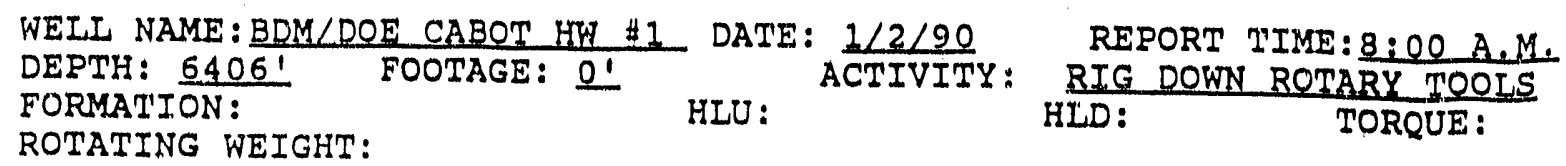

BIT RECORD:

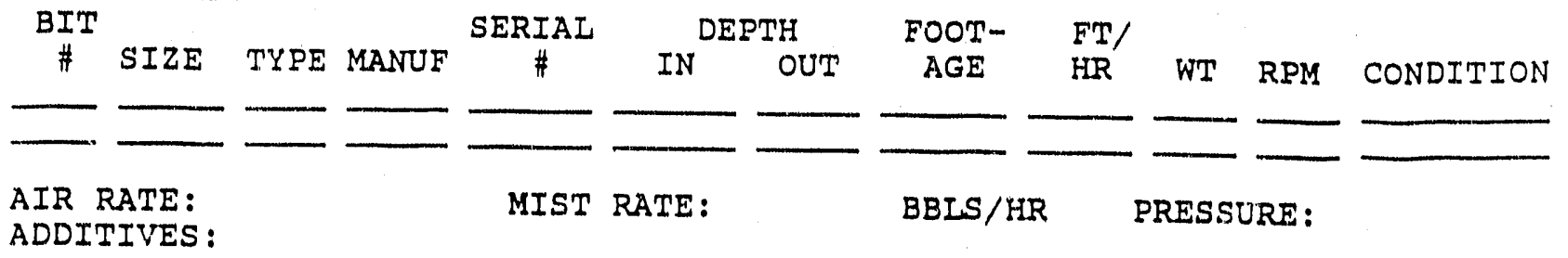

$\mathrm{BHA}$ :

SURVEYS: SEE ATTACHED SURVEY SHEEY FOR MULTISHOT DATA

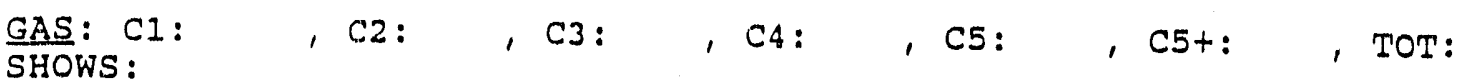

TIME BREAKDOWN AND COMMENTS:

\begin{tabular}{|c|c|c|}
\hline EROM & TO & HRS \\
\hline $8: 00$ & $5: 00$ & Lay down drili pipe and collars. \\
\hline $5: 00$ & $6: 00$ & Nipple down BOp's and rig up power tongs. \\
\hline $6: 00$ & $7: 15$ & $\begin{array}{l}1.25 \text { Strap casing on racks and work out setting depth of } \\
\text { external casing packers and port collars. }\end{array}$ \\
\hline $7: 15$ & $12: 30$ & $\begin{array}{l}5.25 \text { Ran } 140 \text { jolnts of } 41 / 2 ", 10.5 \text { ppf, } 1-55 \text {, ST\&C } \\
\text { casing (including } 4 \text { pup joints). Casing contained five } \\
\text { external casing packers (Tam) and four port collars. Landed } \\
\text { casing in wellhead slips. }\end{array}$ \\
\hline $12: 30$ & $8: 00$ & Rigging down rotary tools. \\
\hline
\end{tabular}


APPENDIX J

DAILY COST REPORT

163 


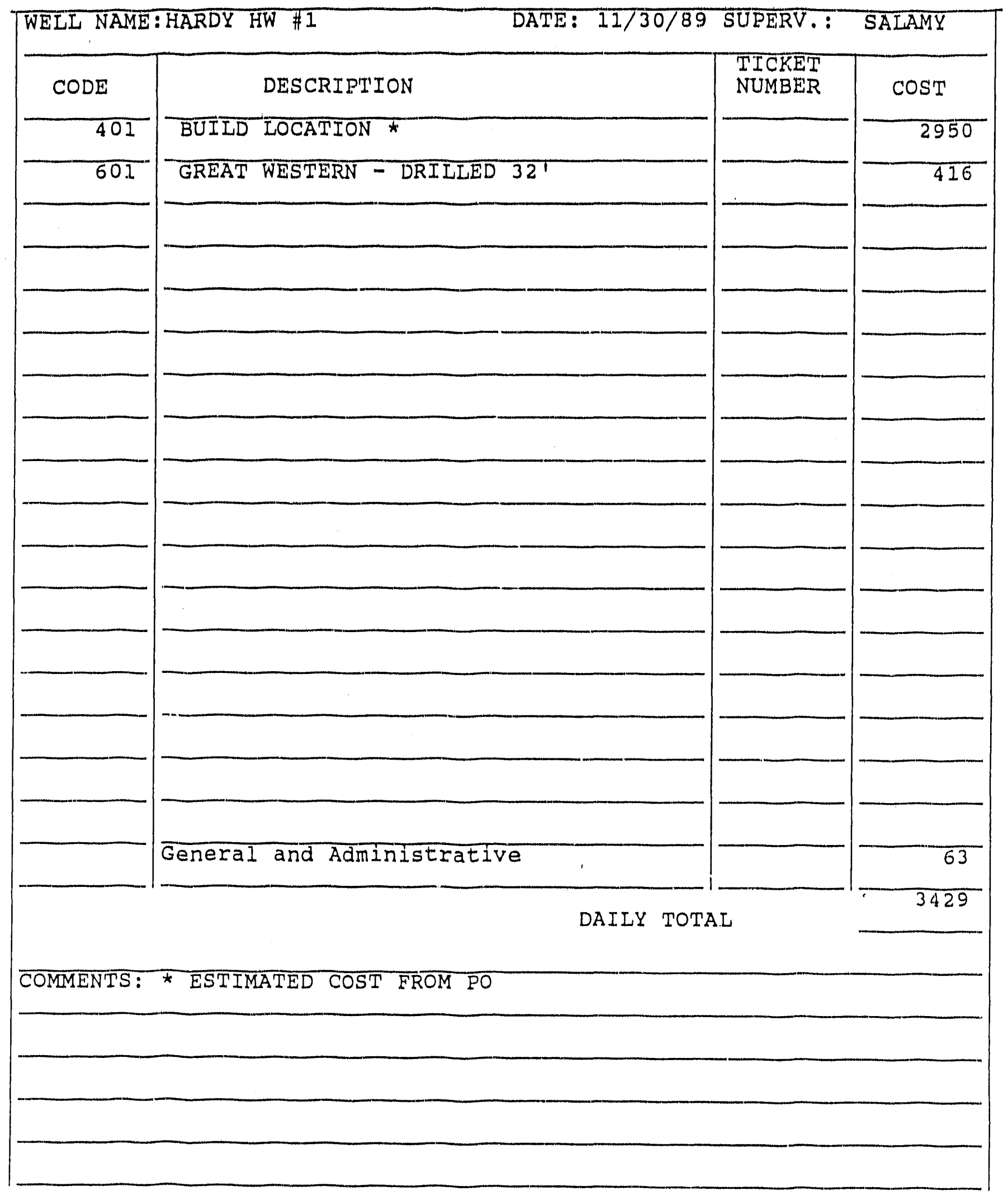




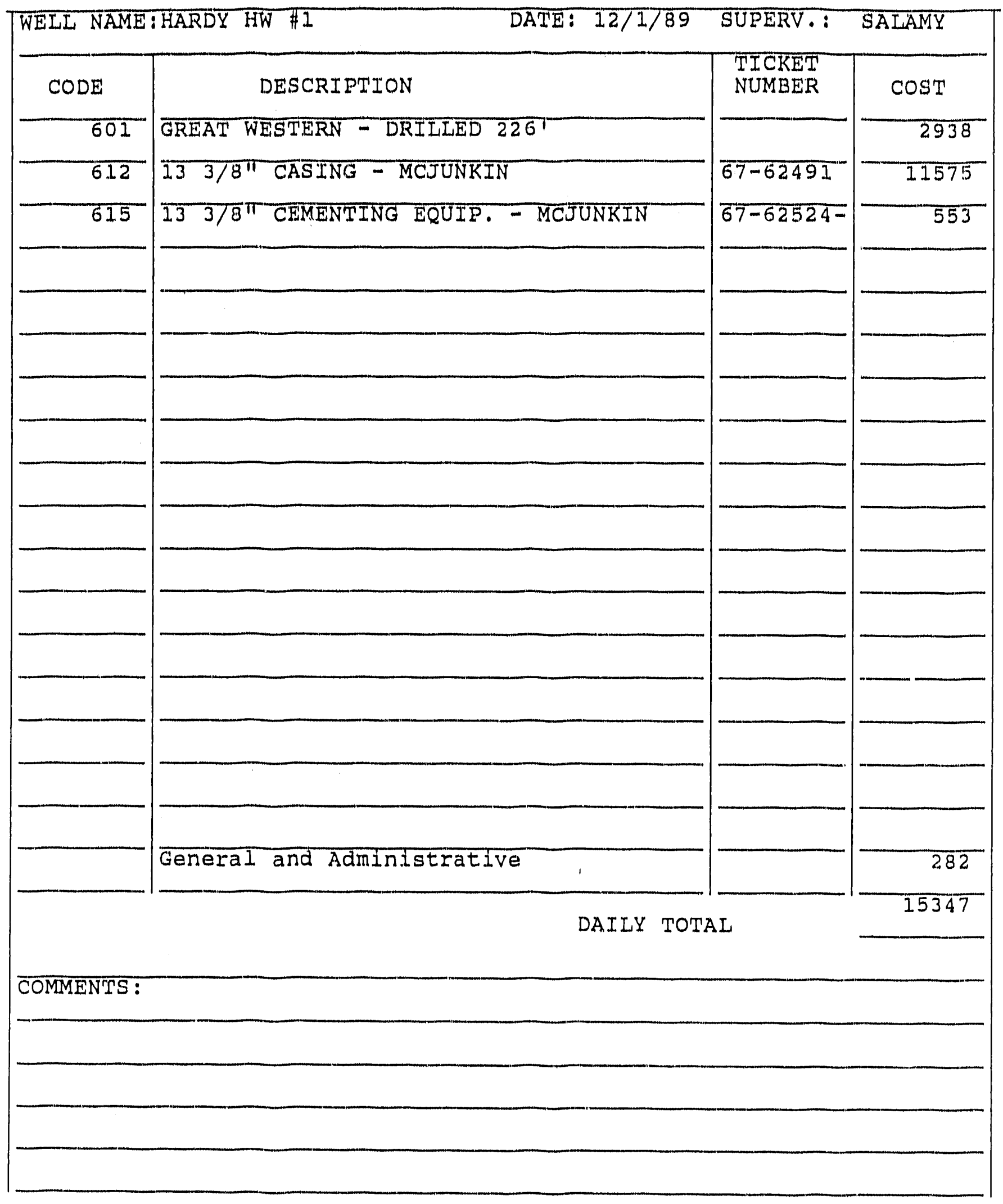




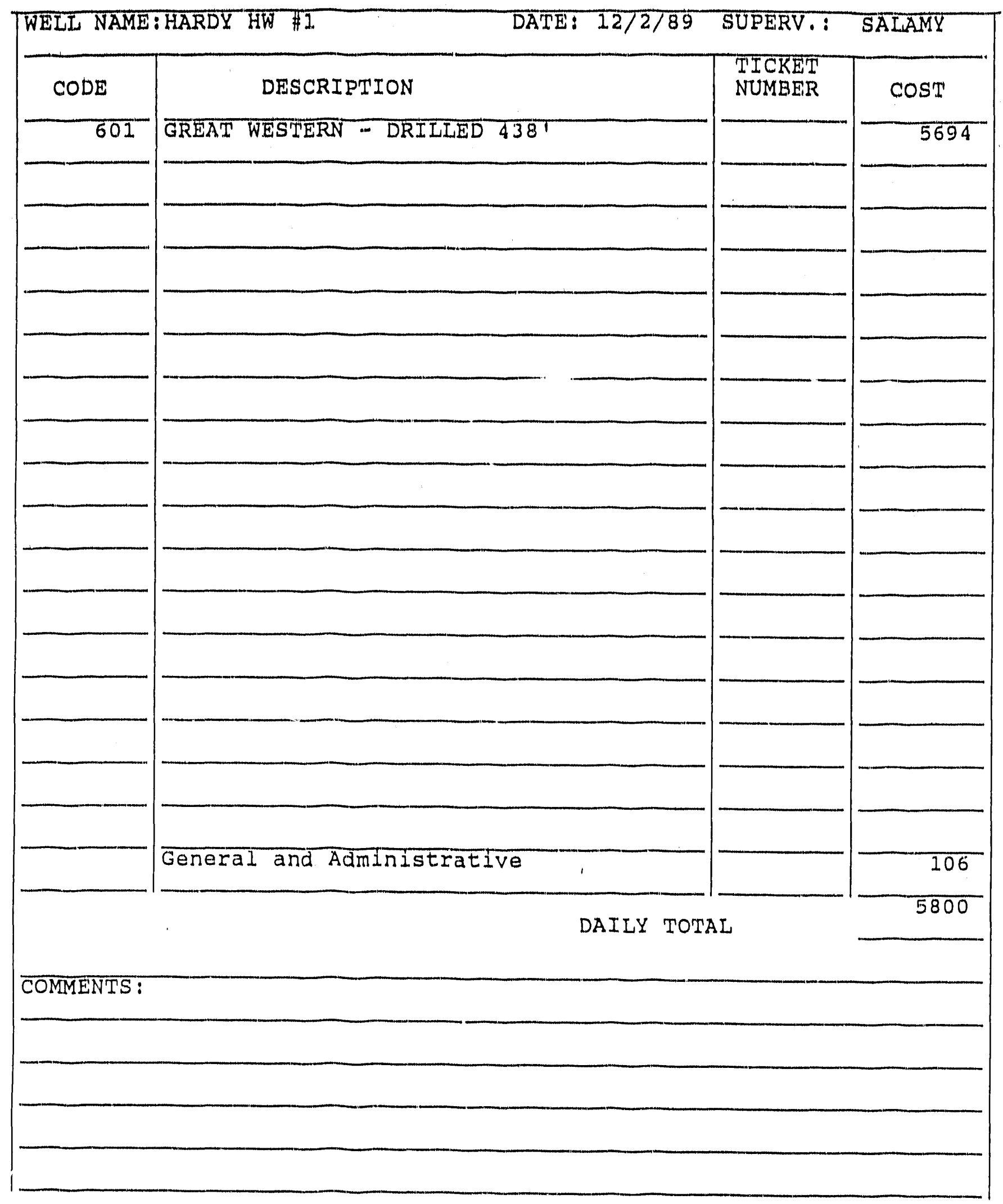




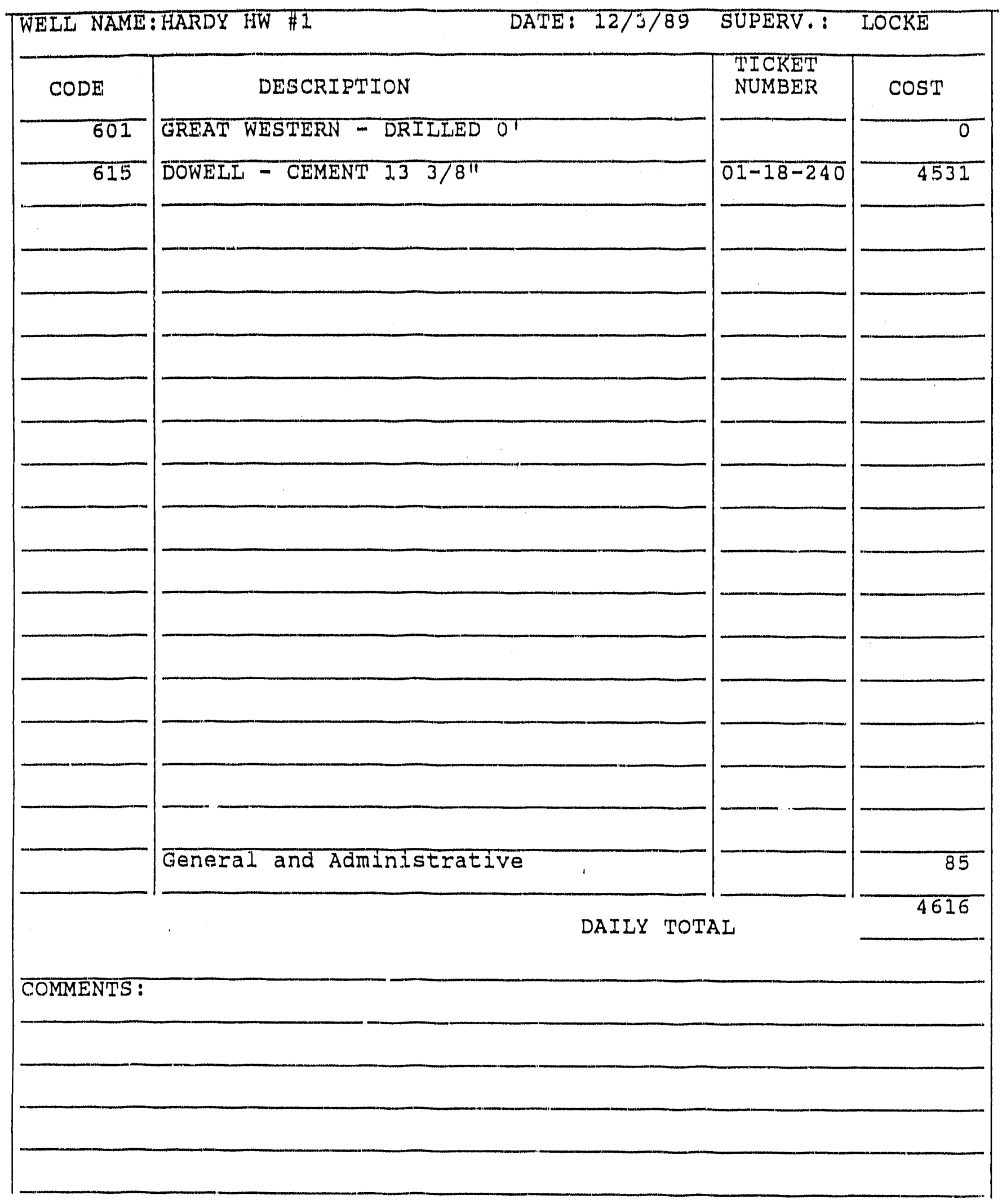




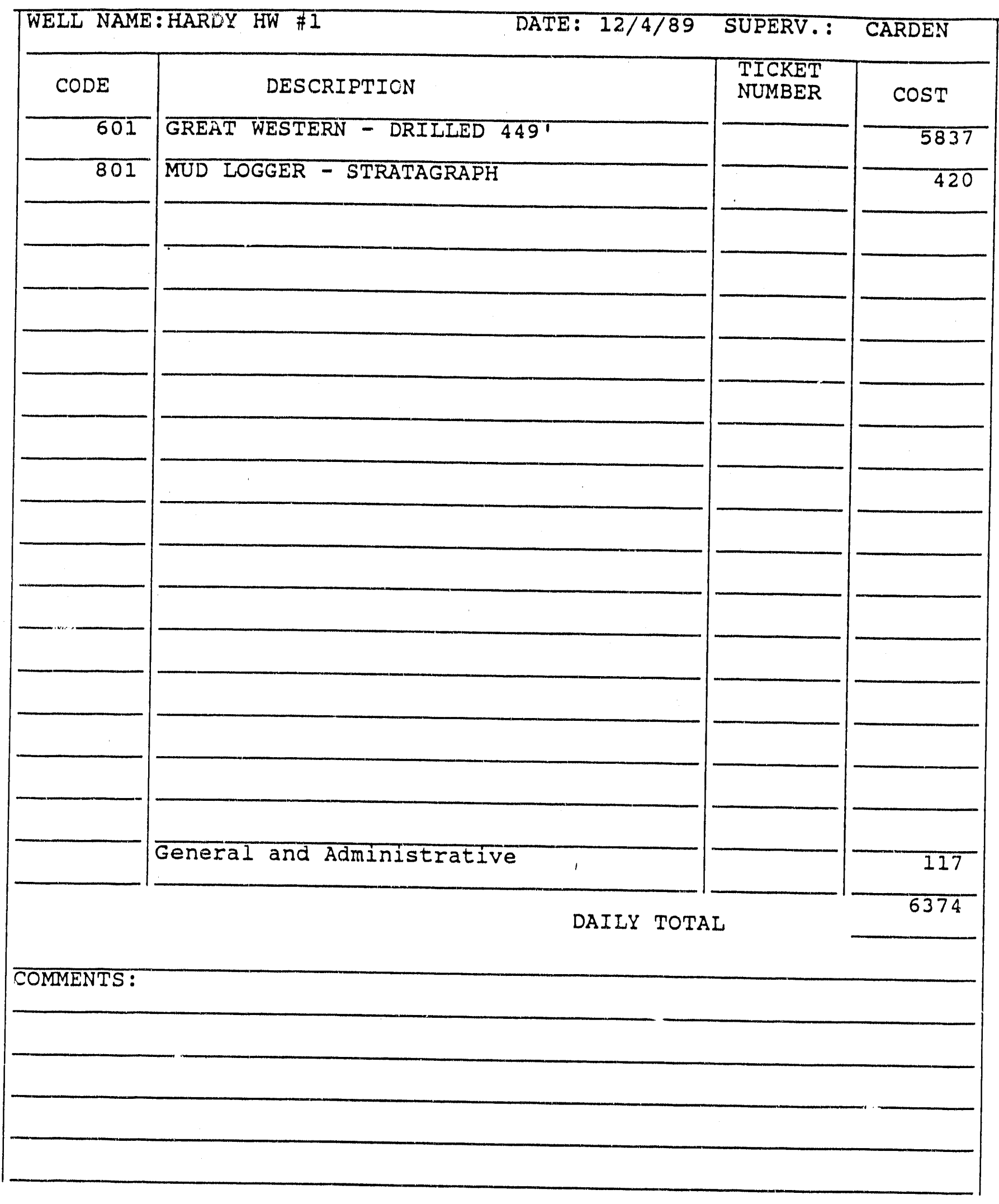




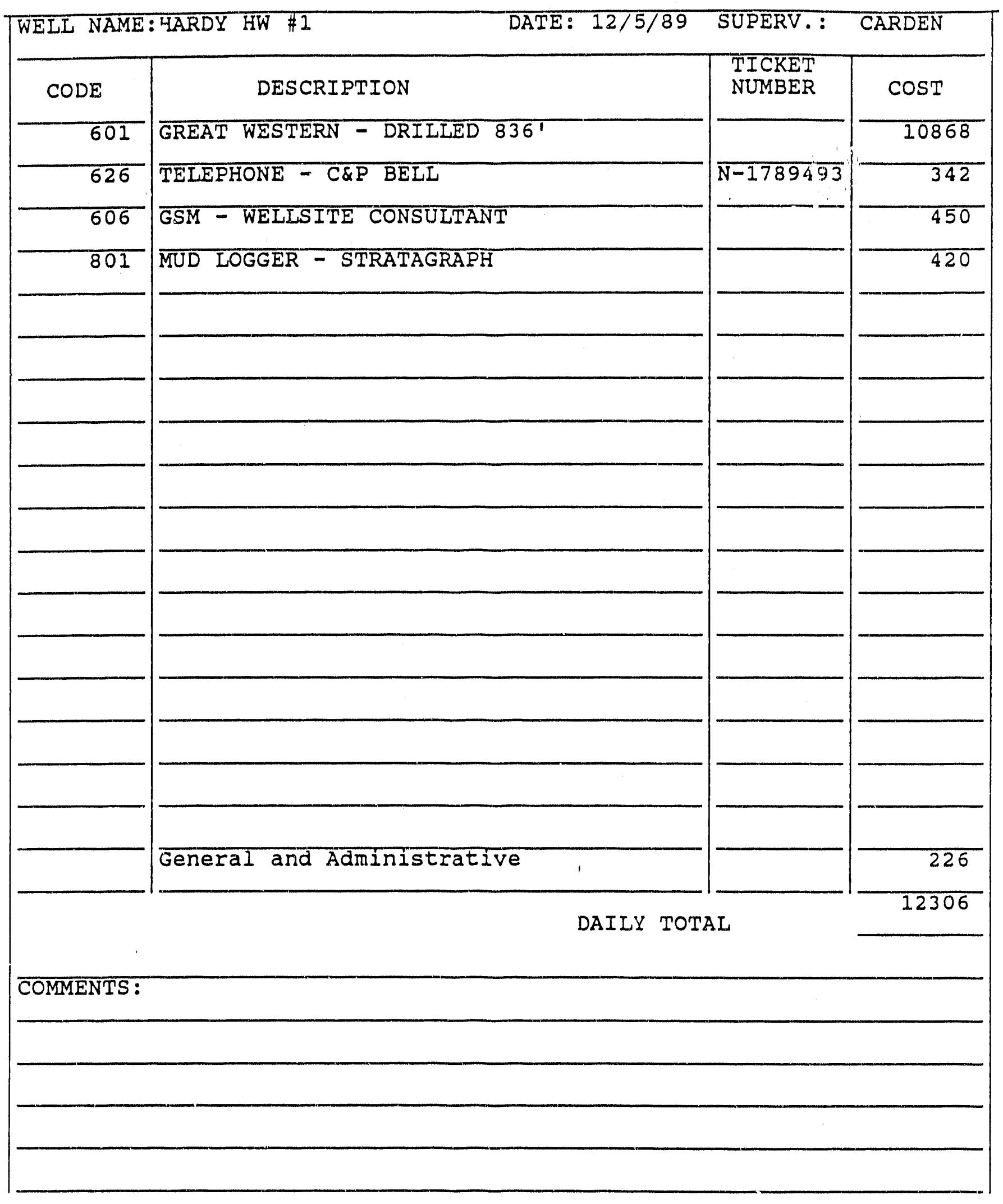




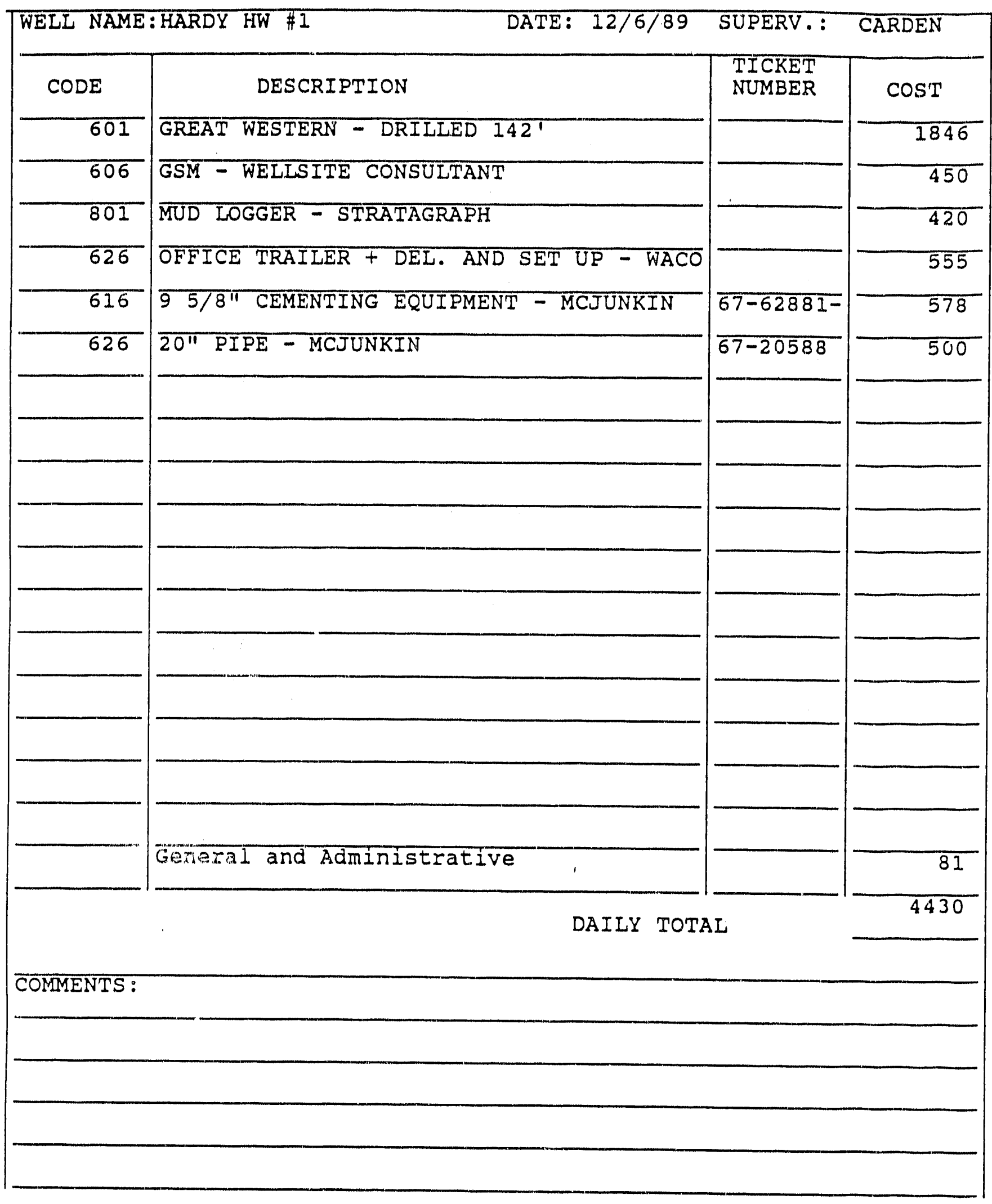




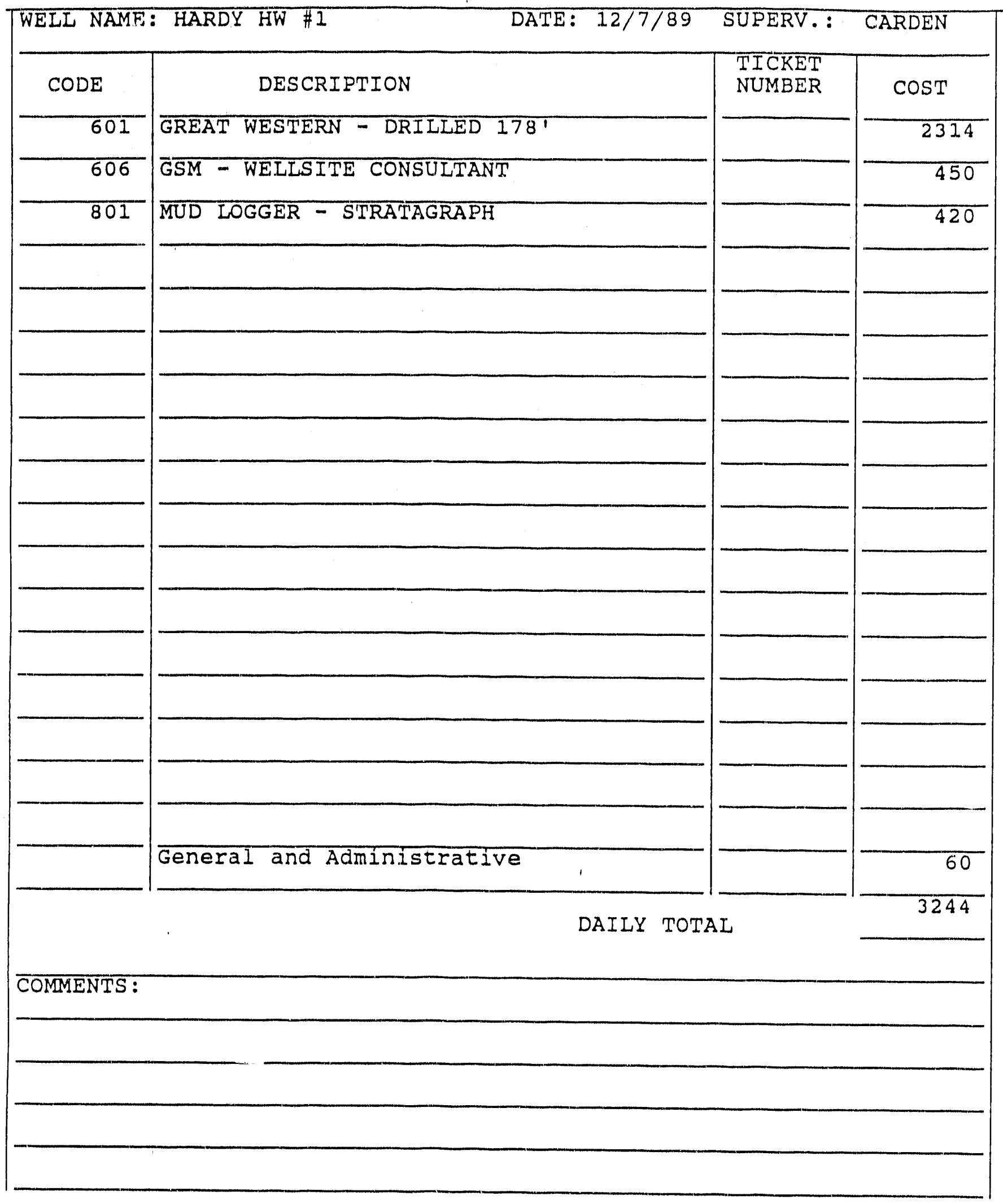




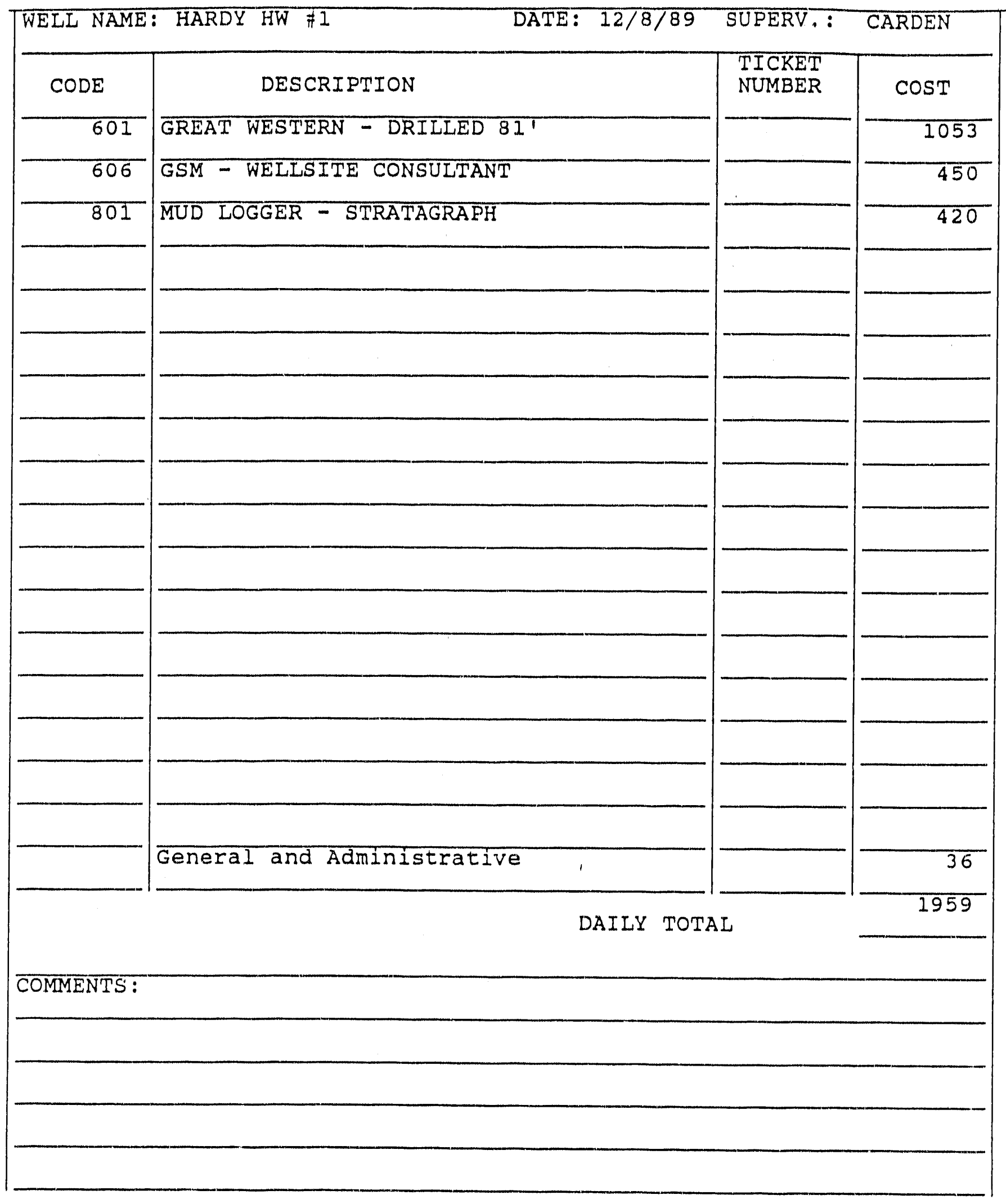




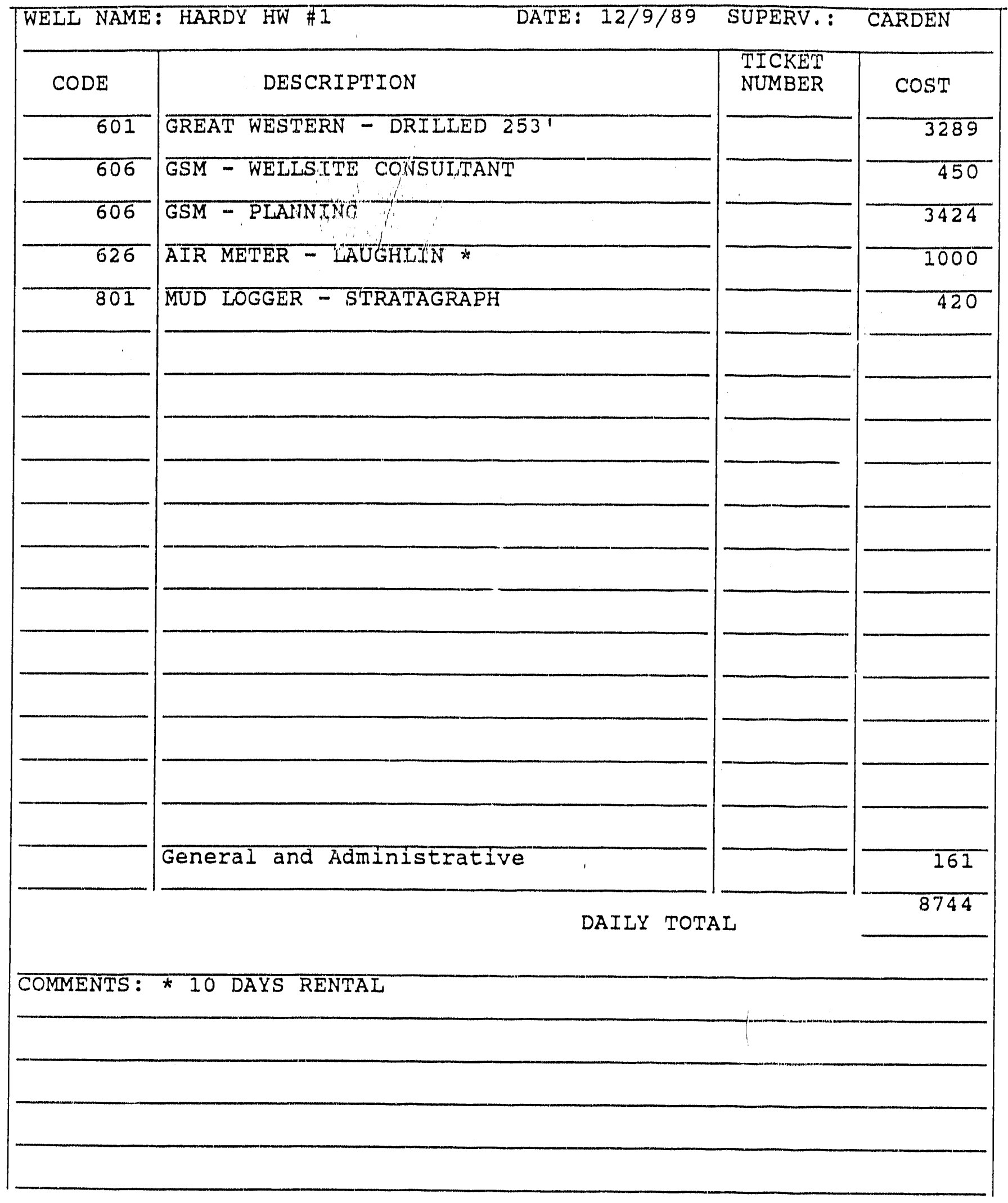




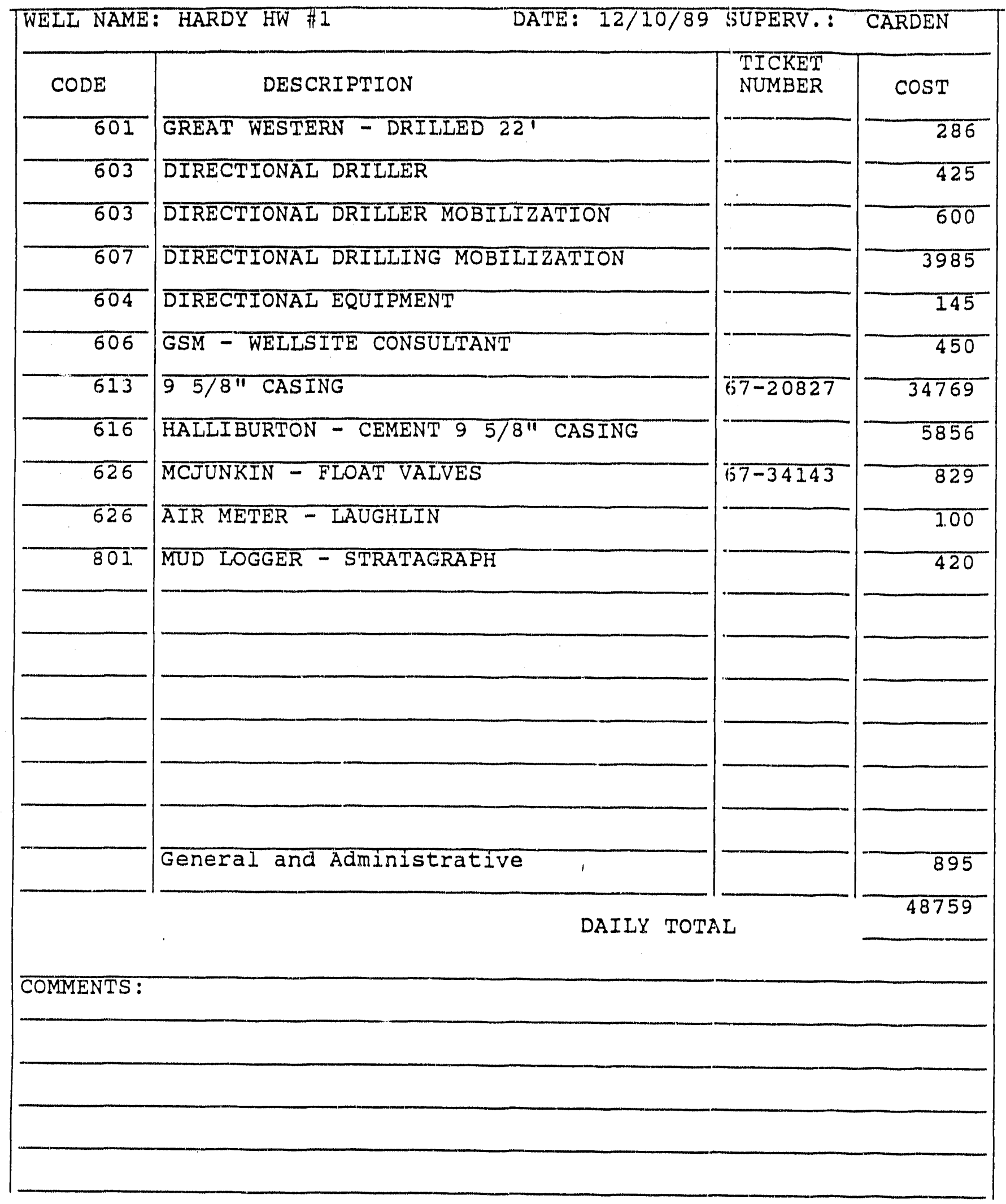




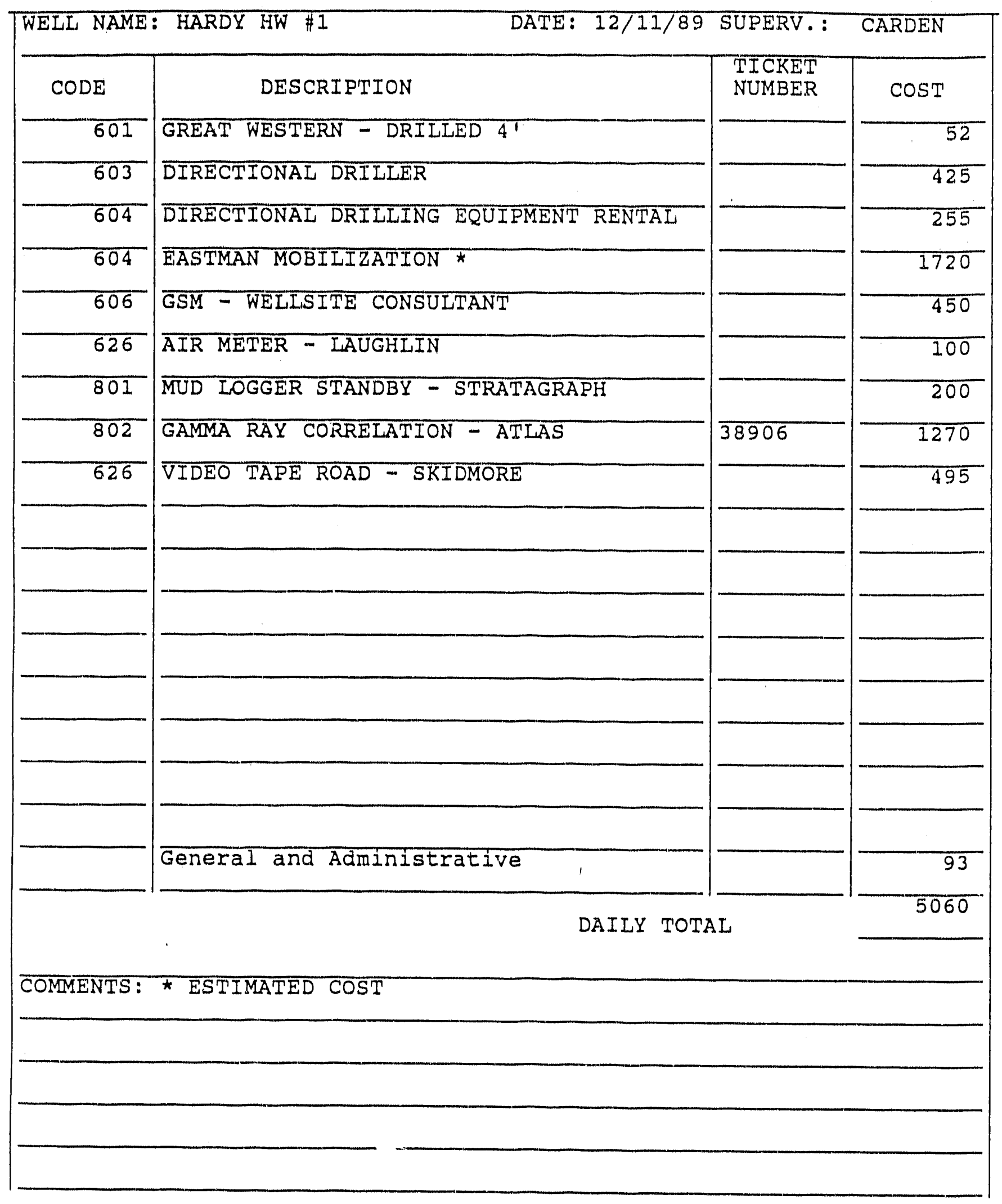




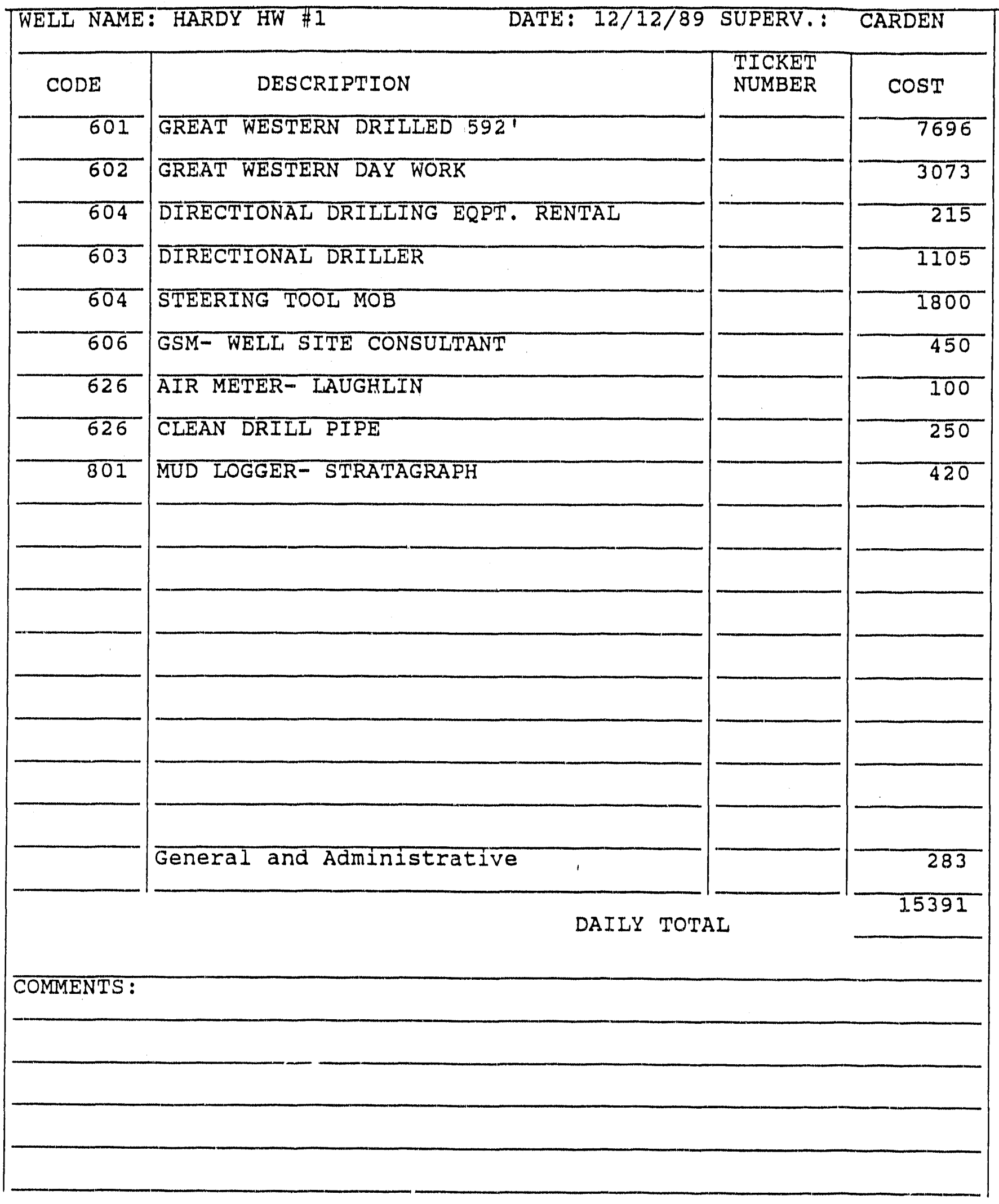




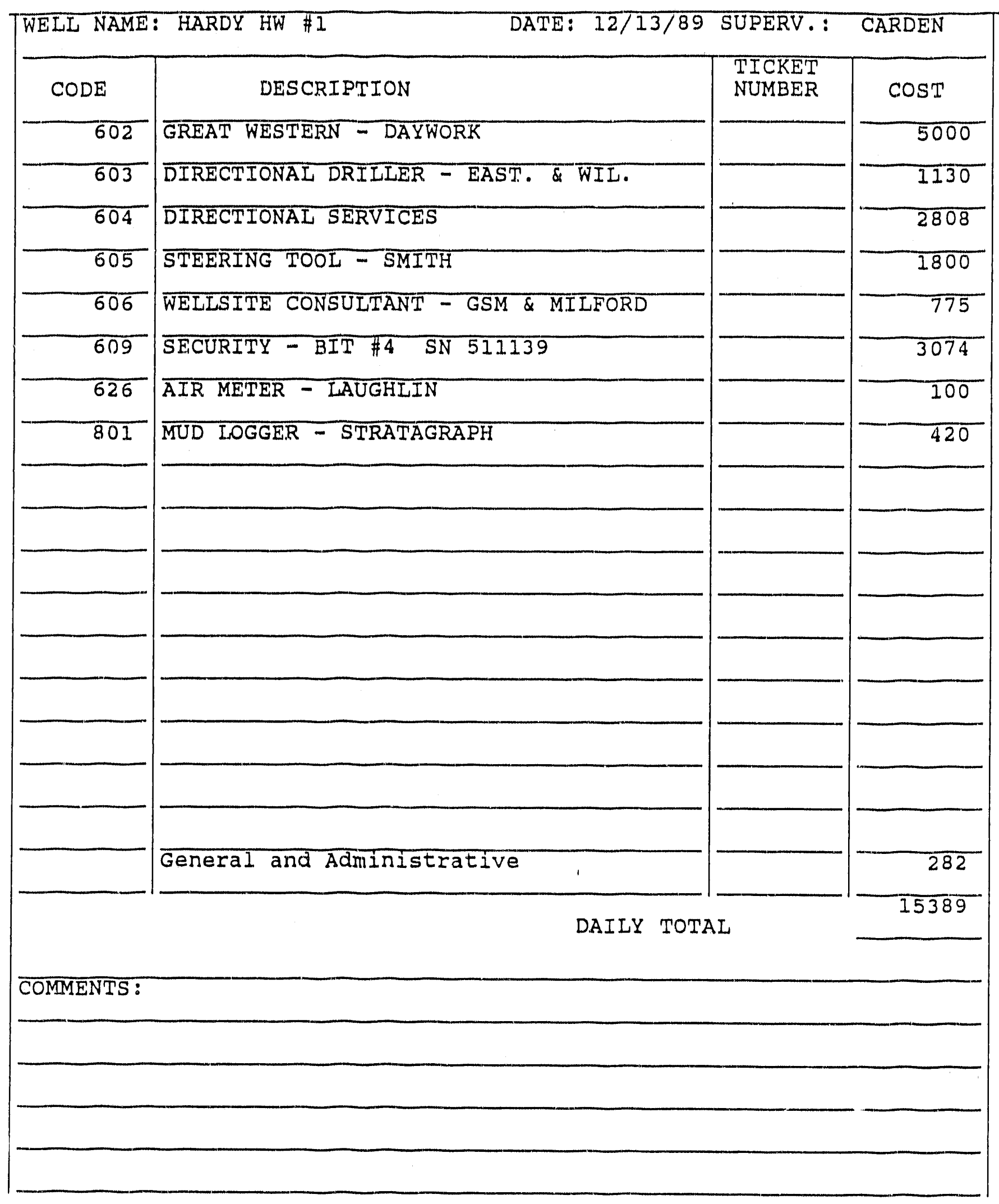




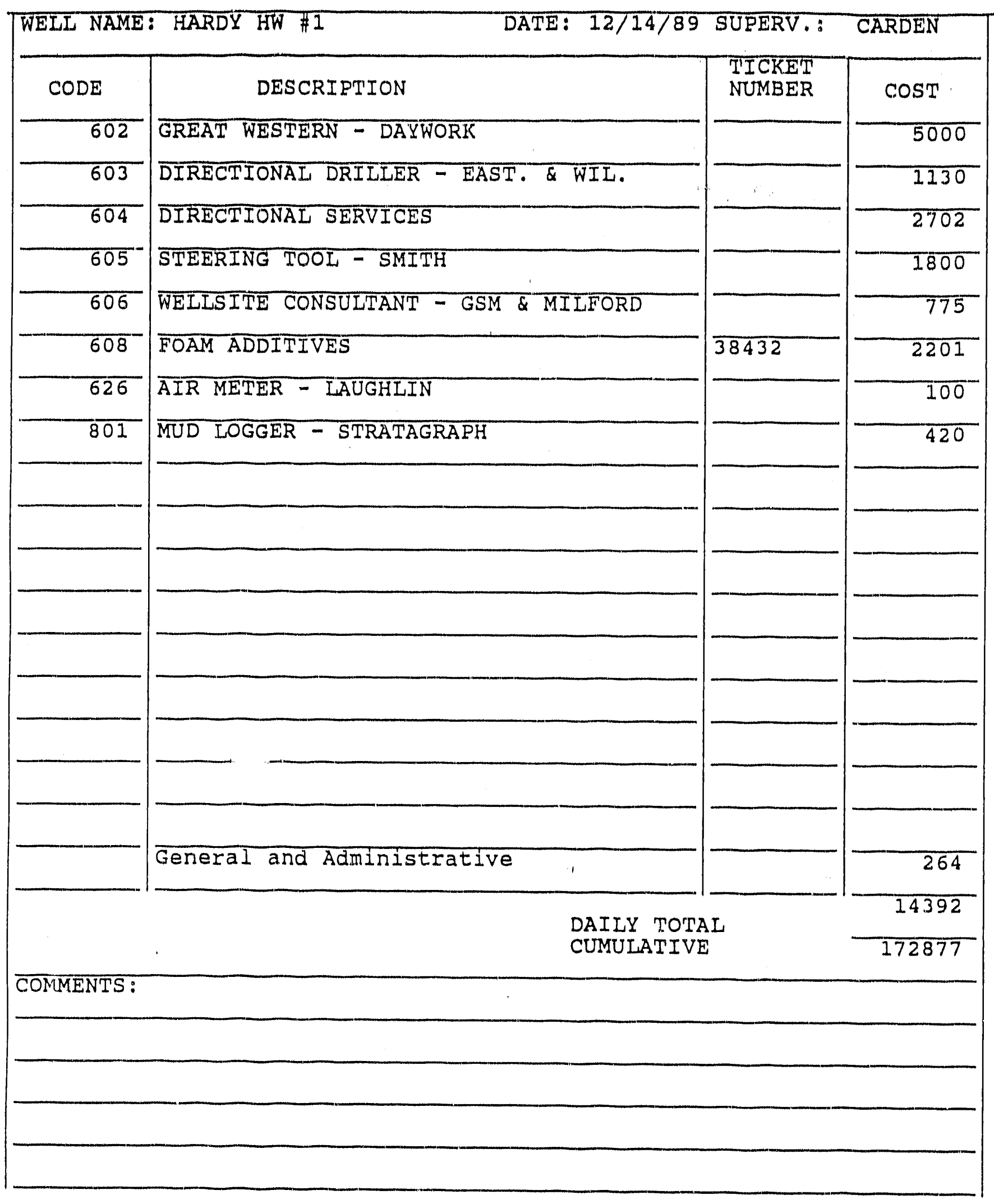




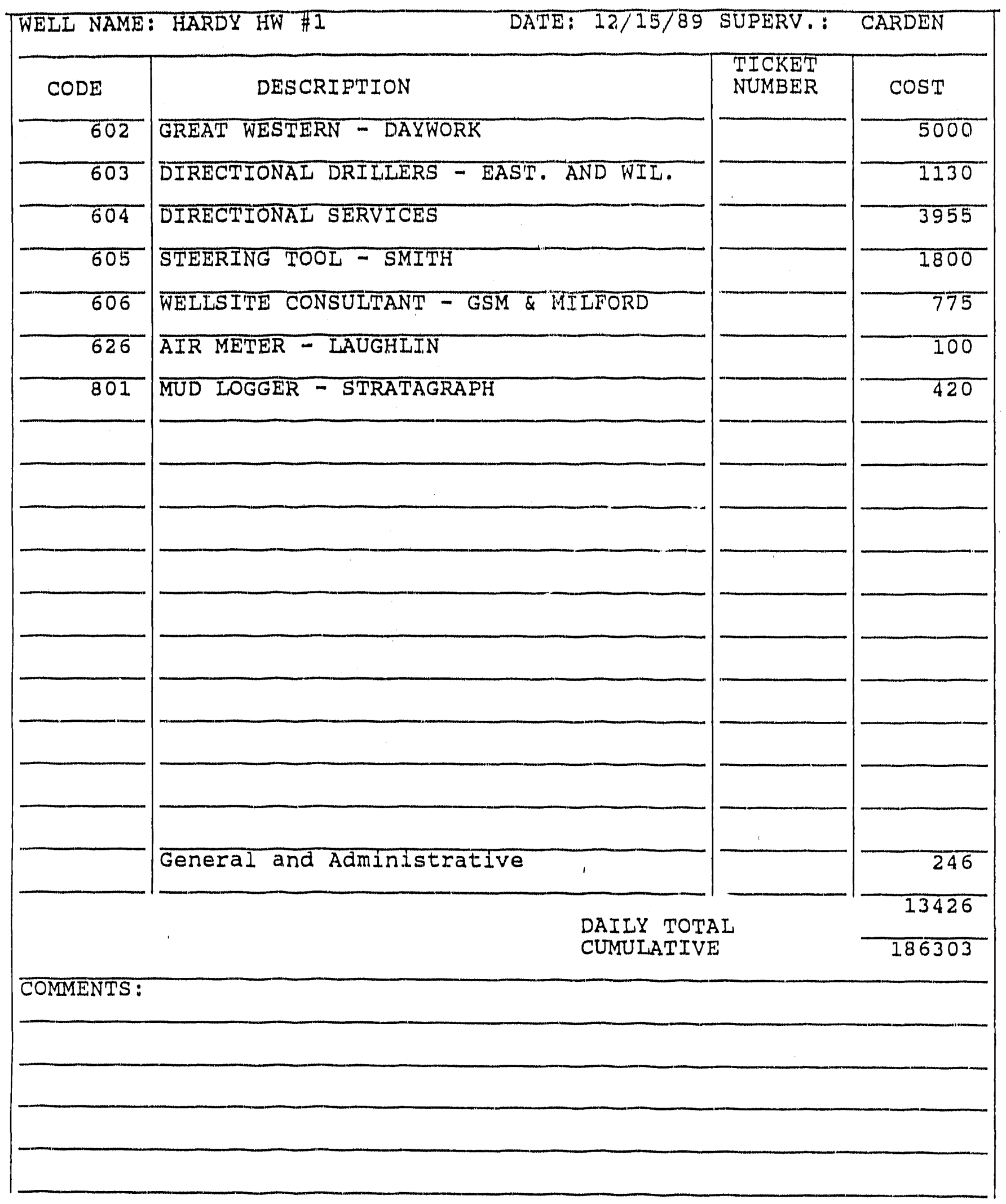




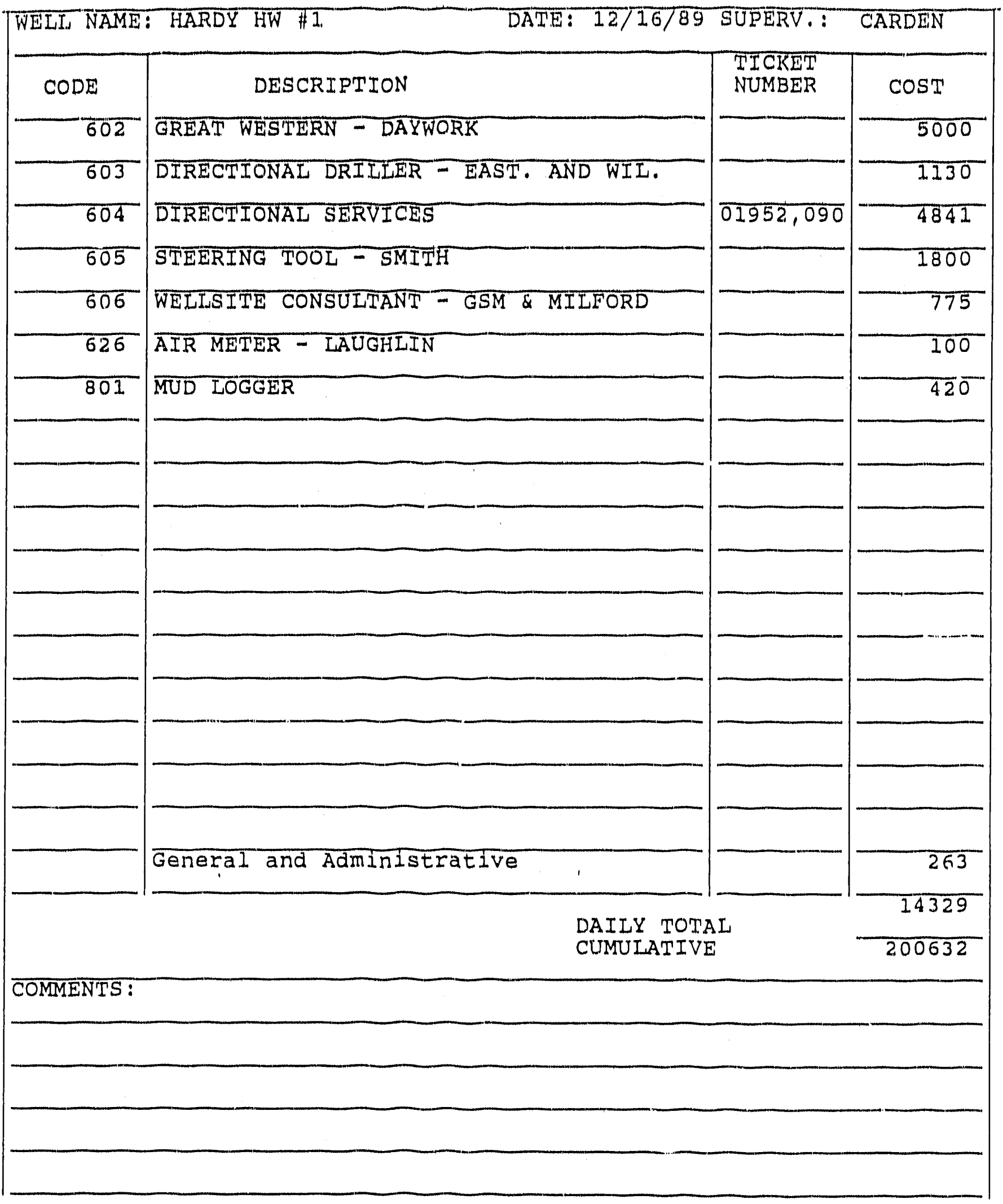




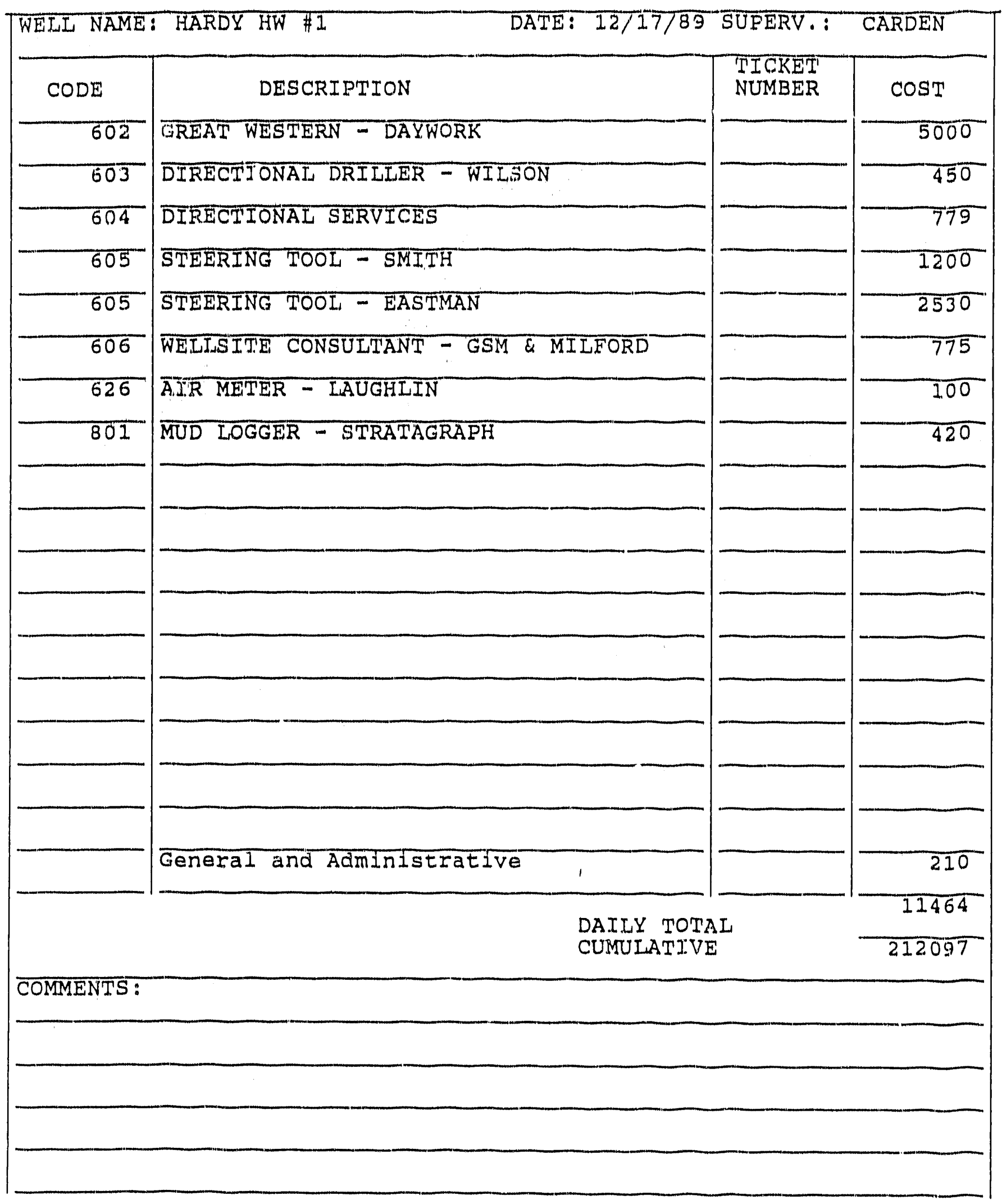




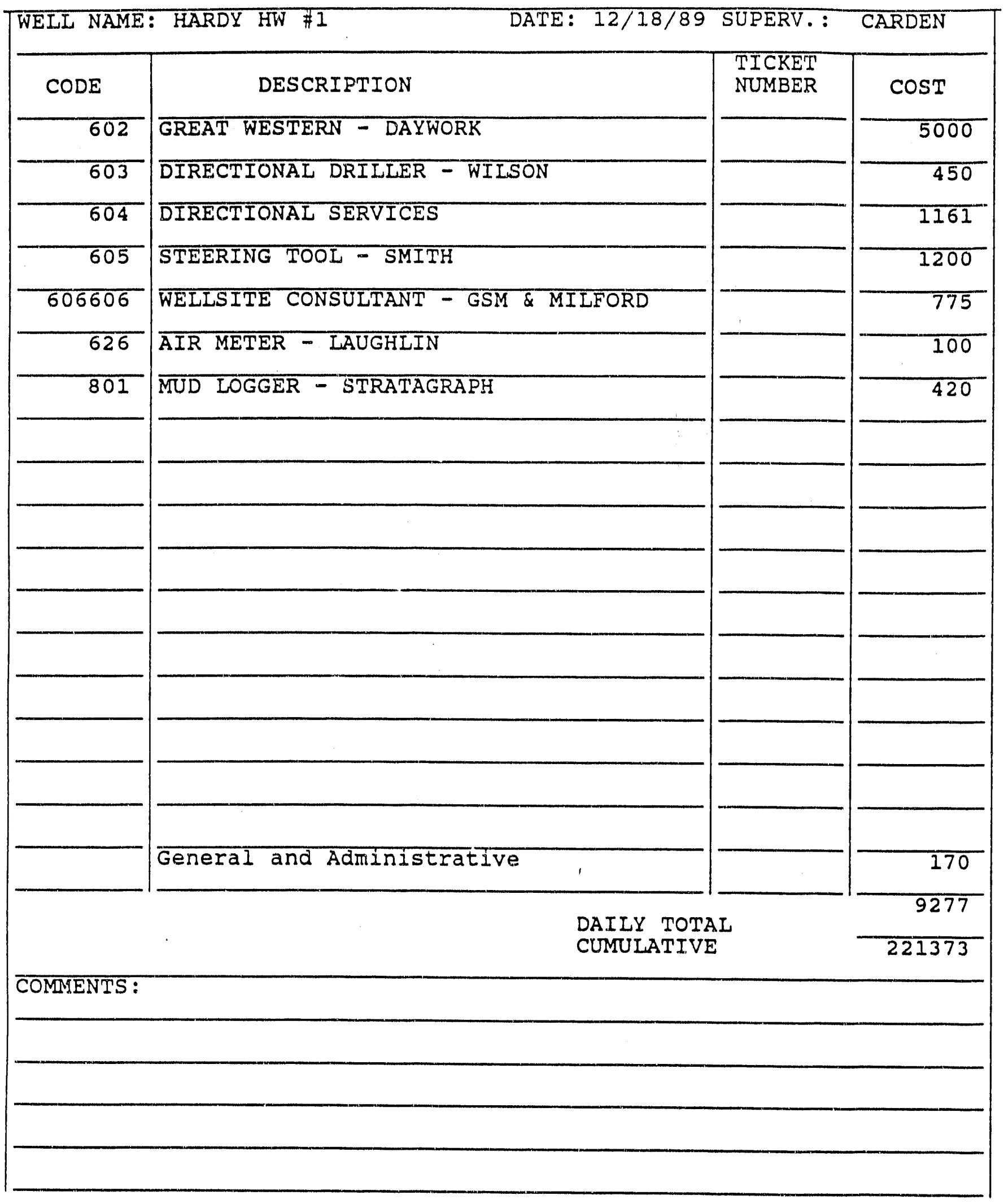




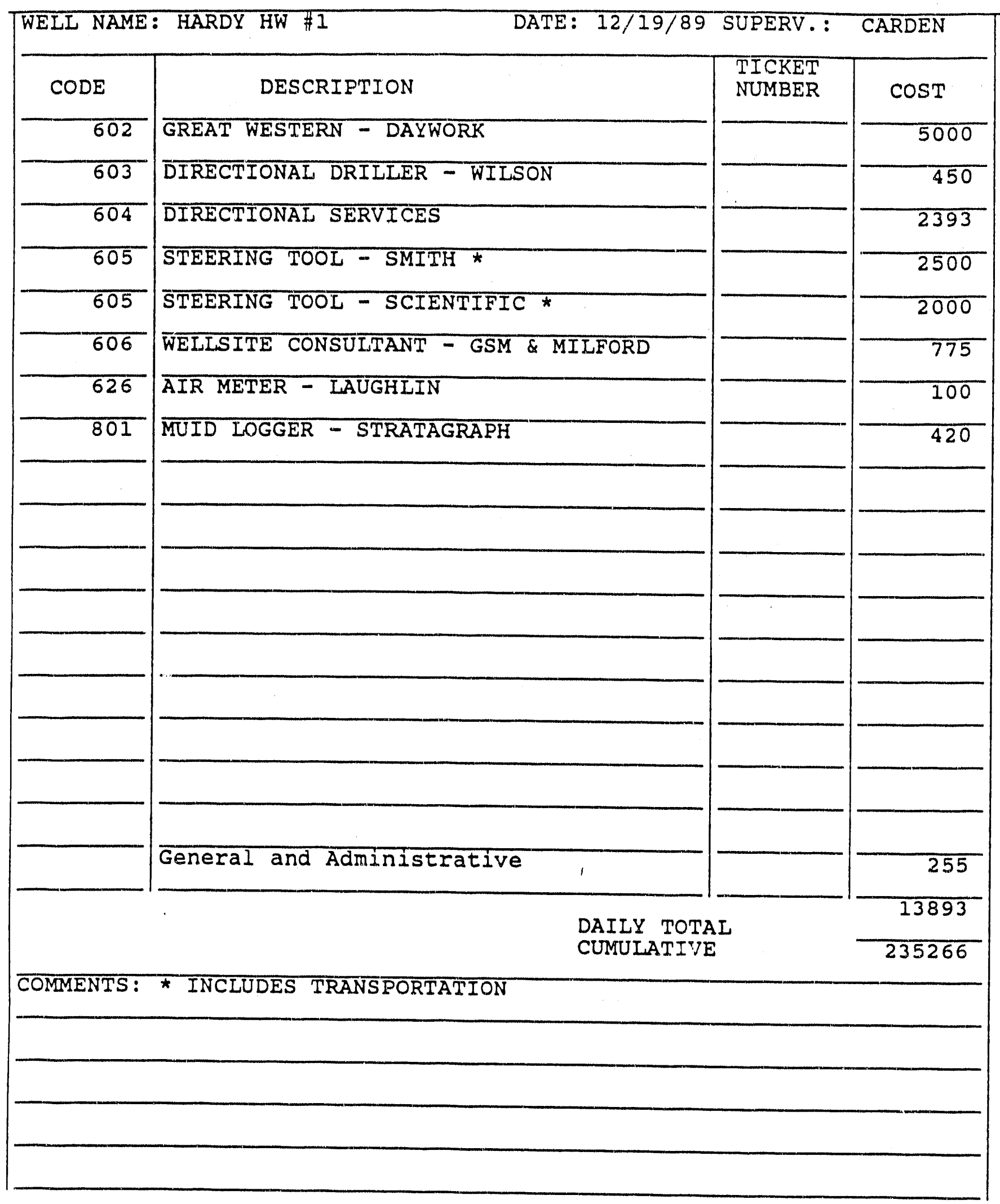




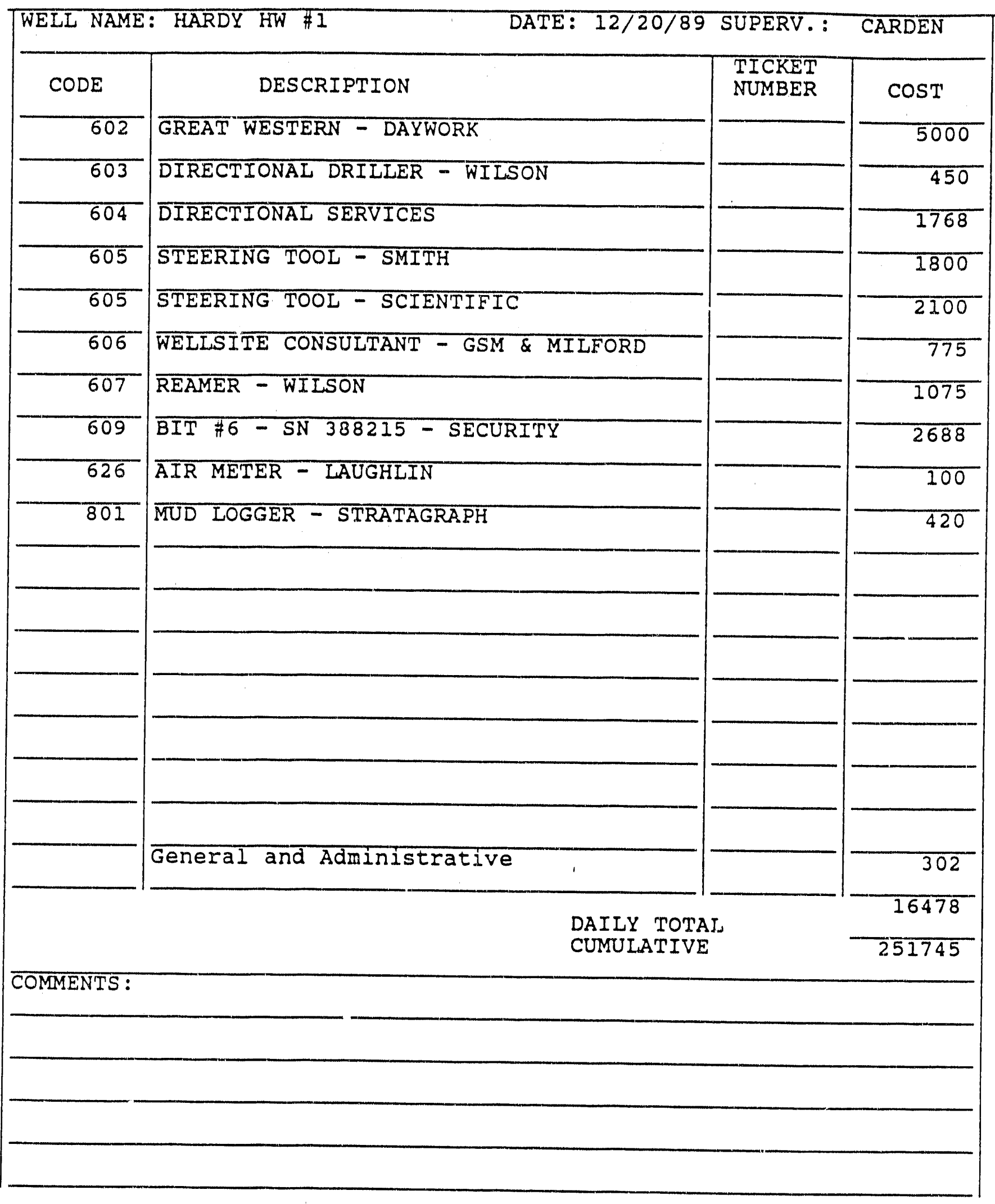




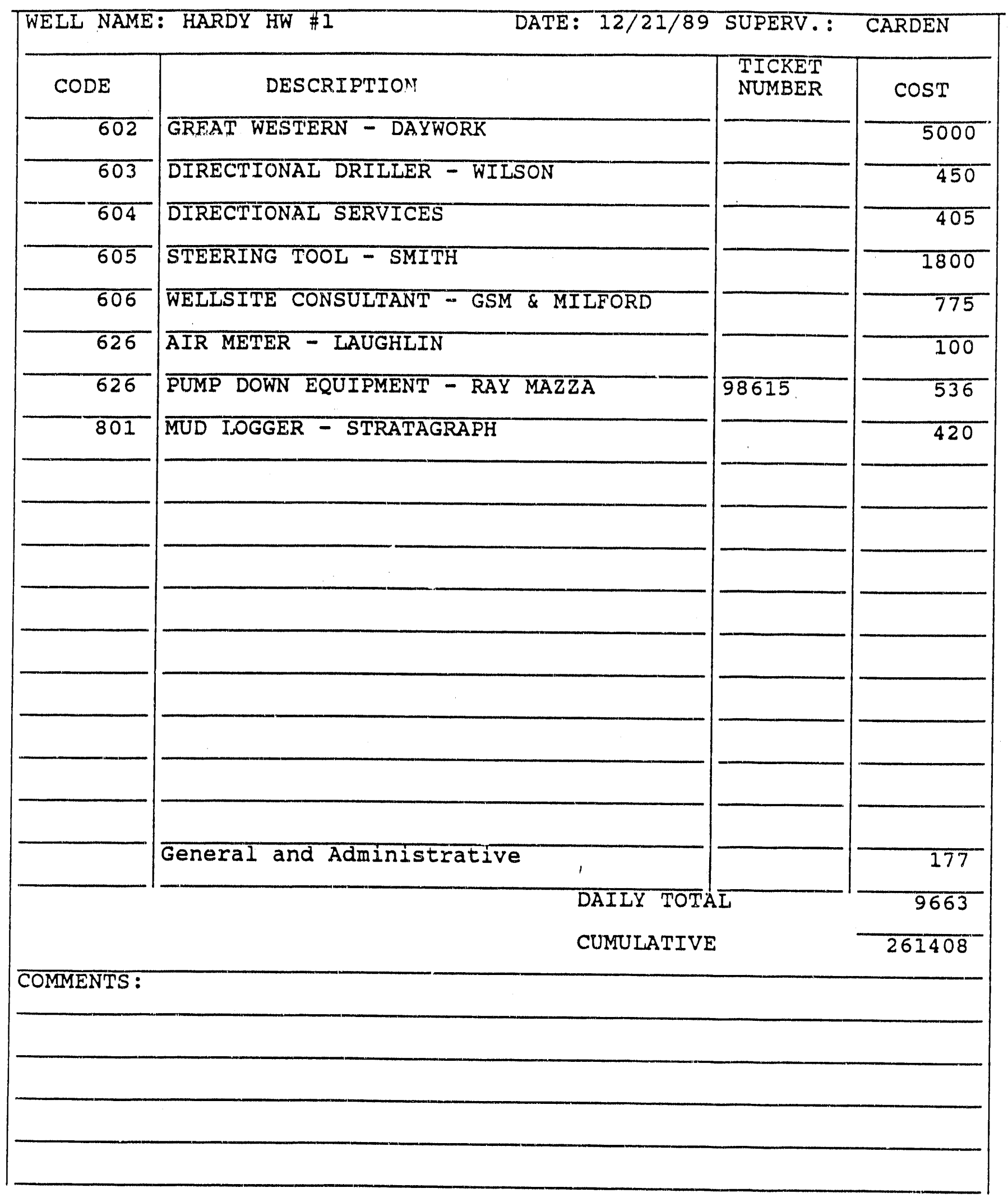




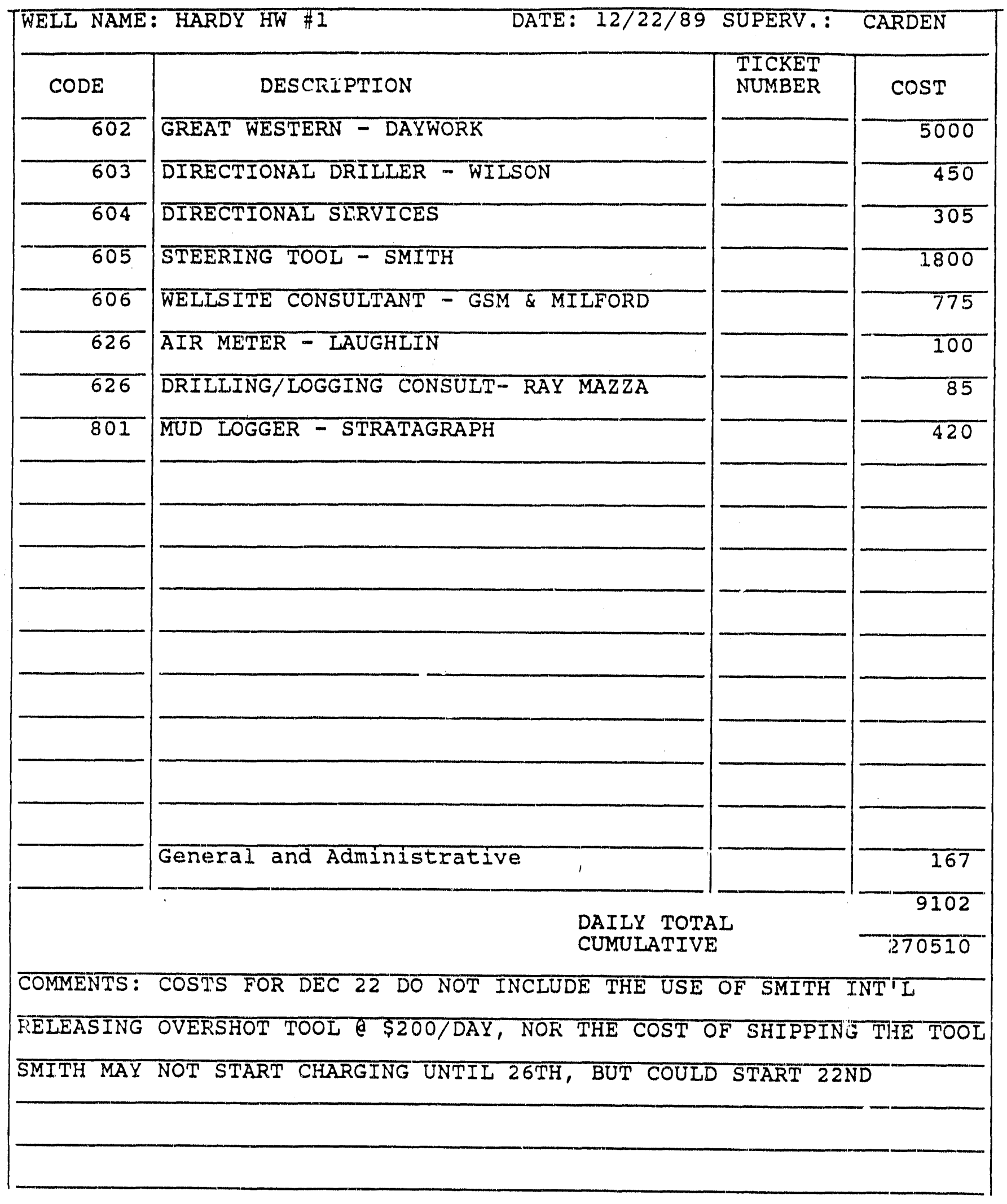




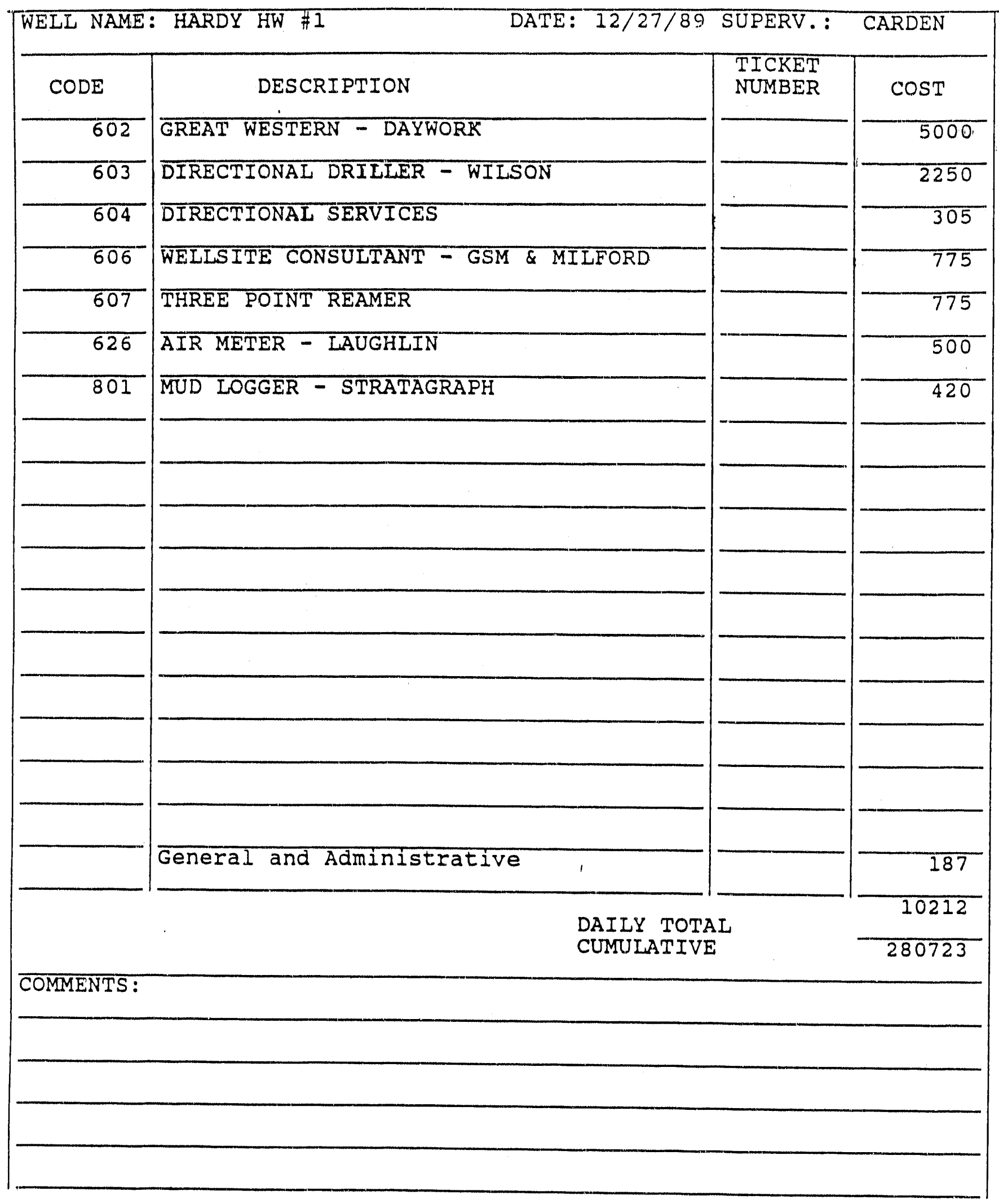




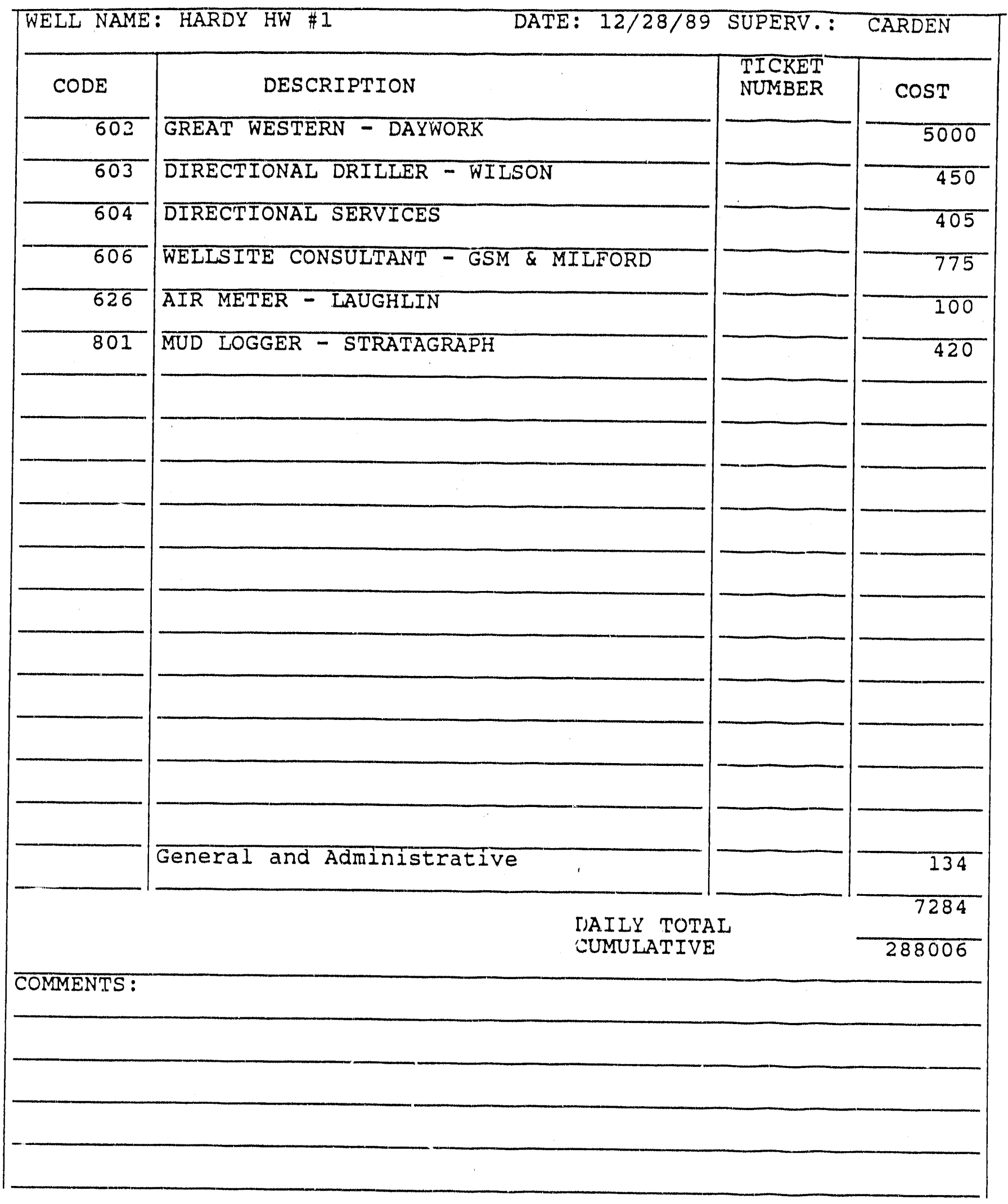




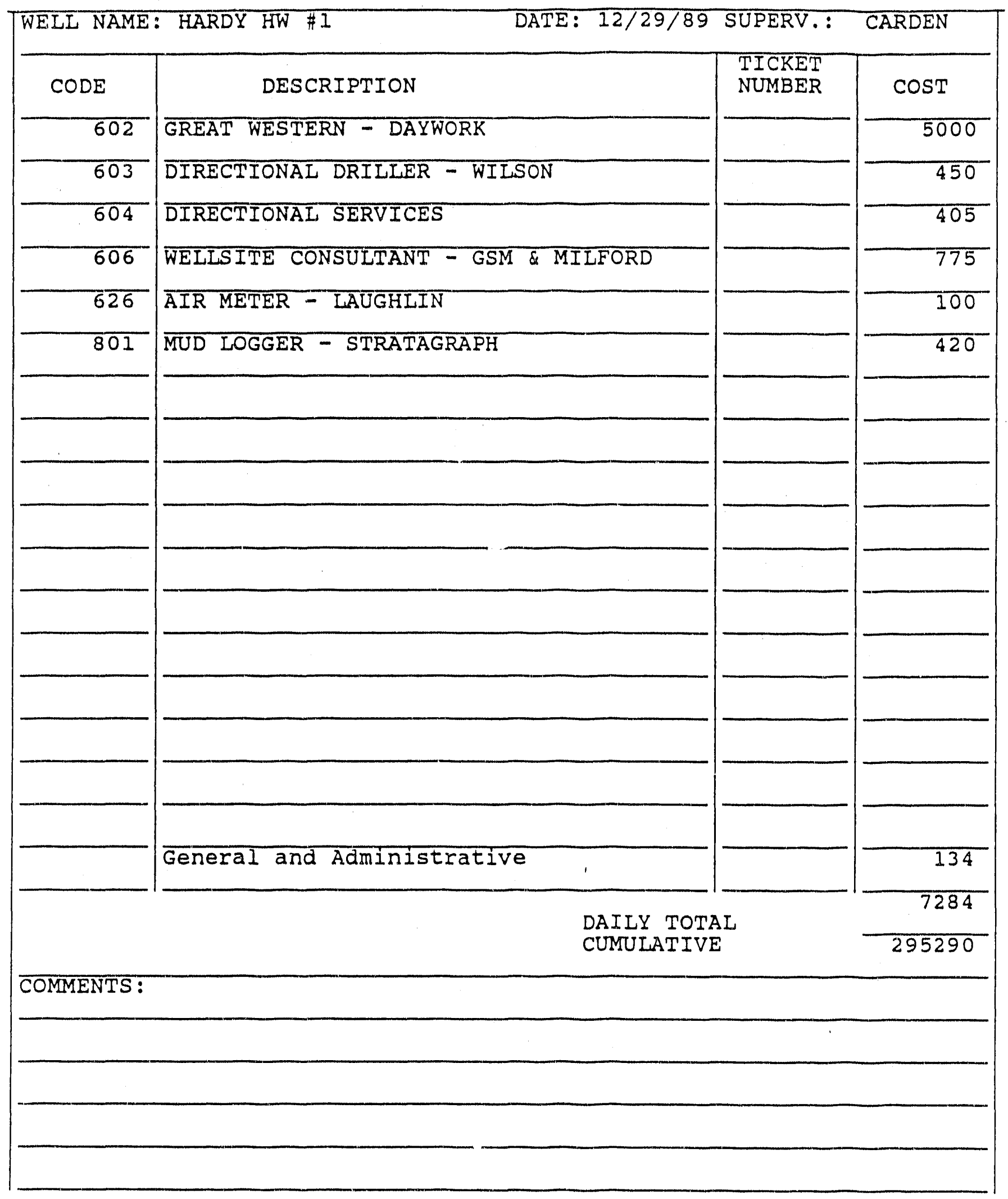




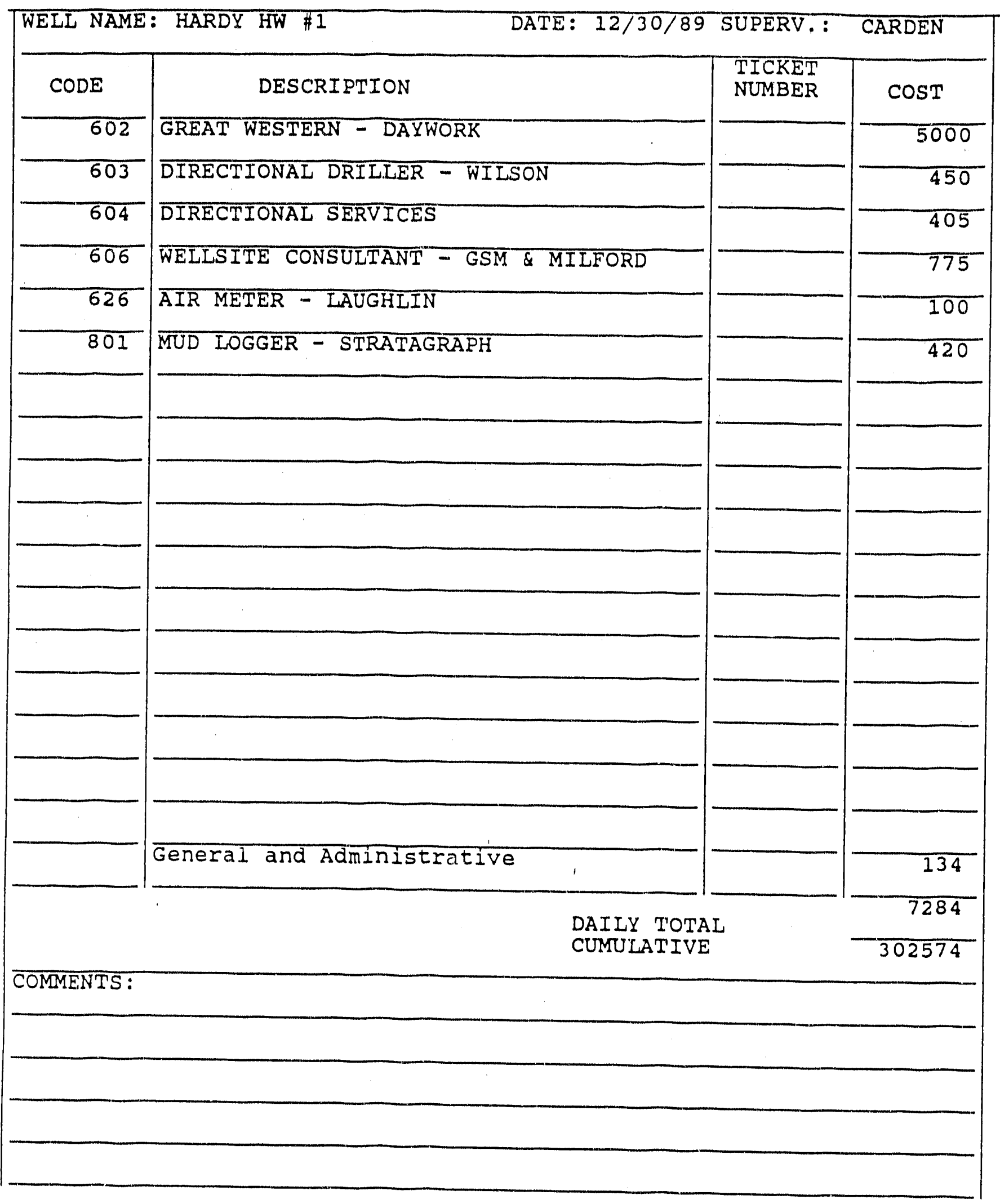




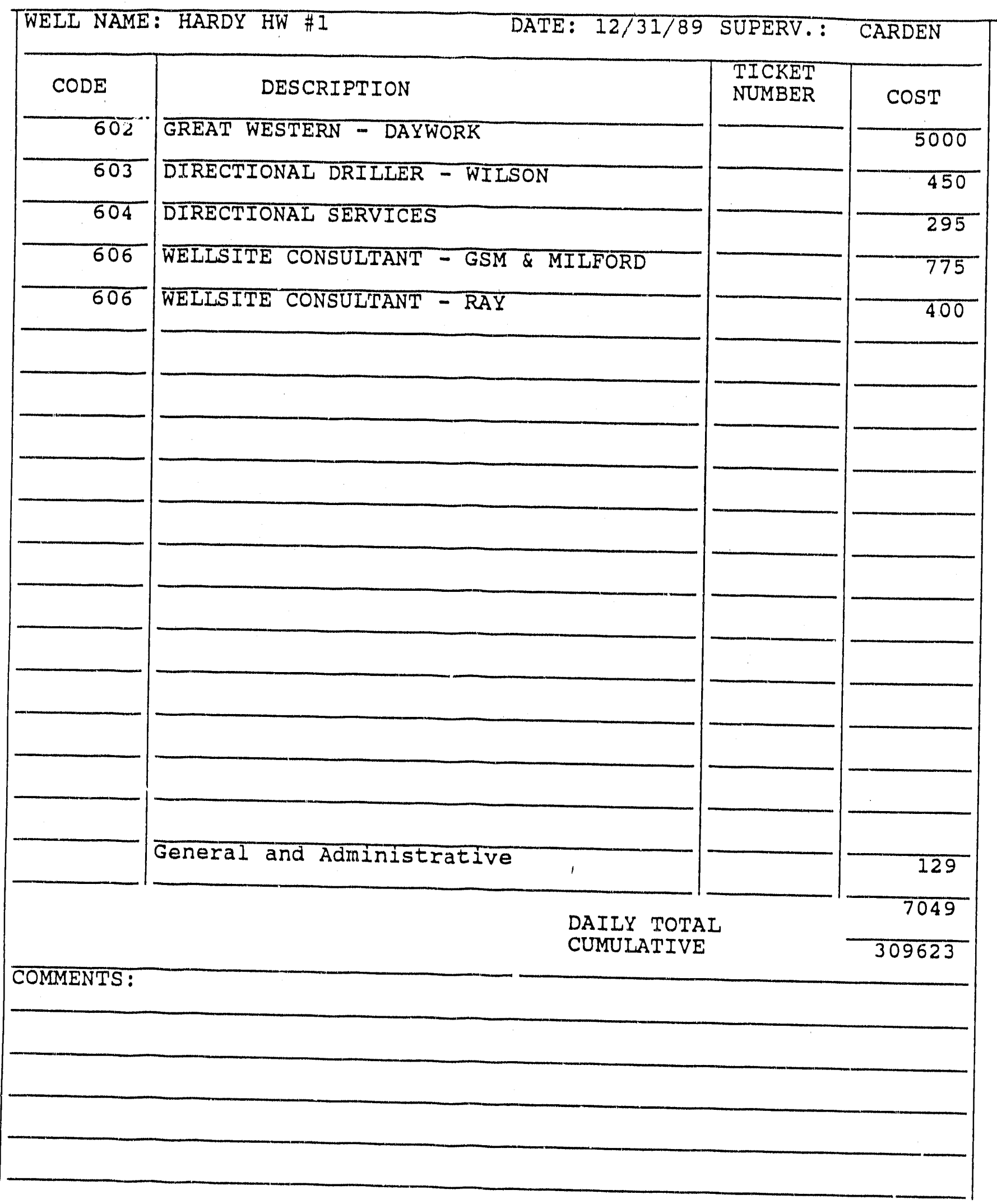




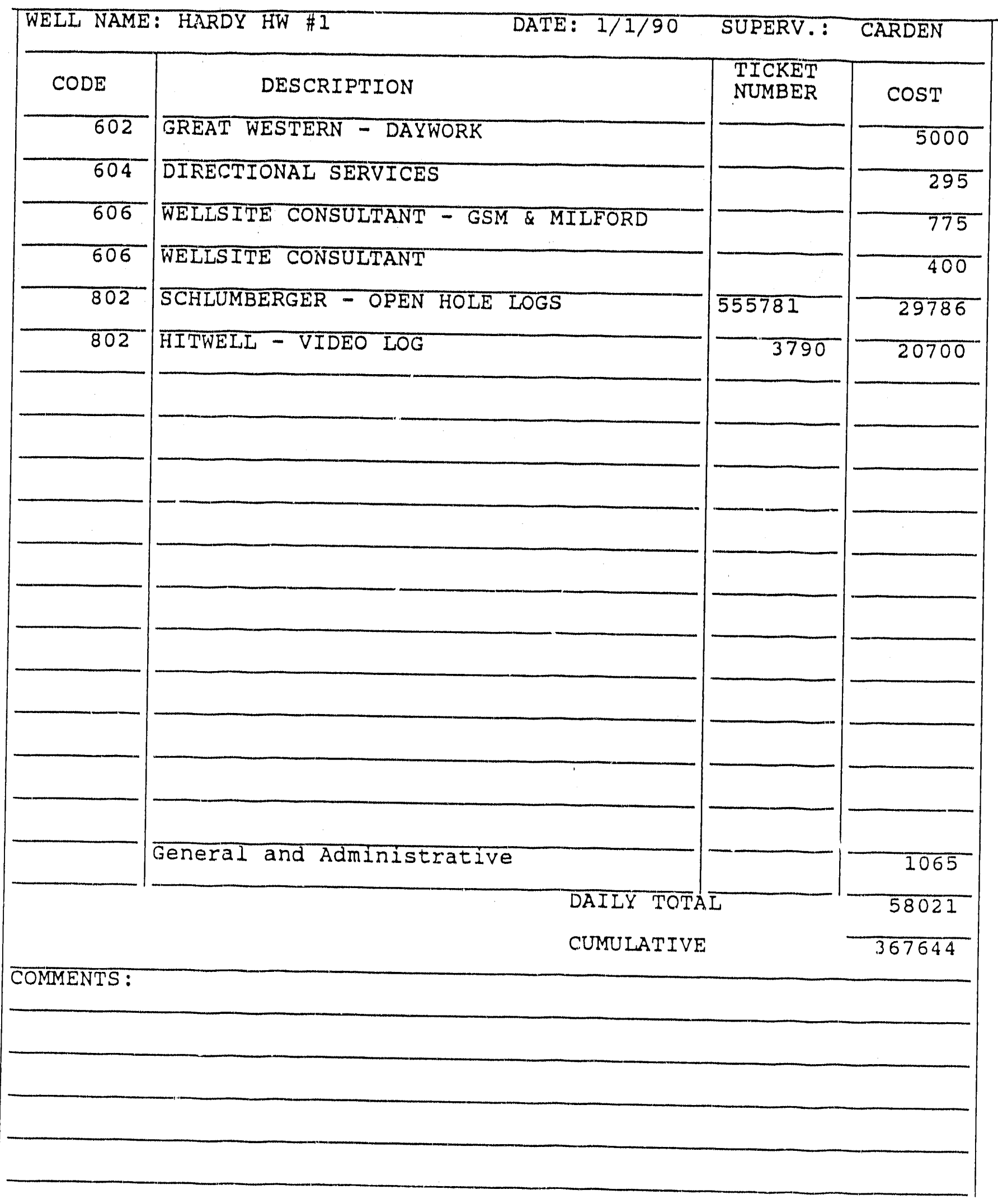




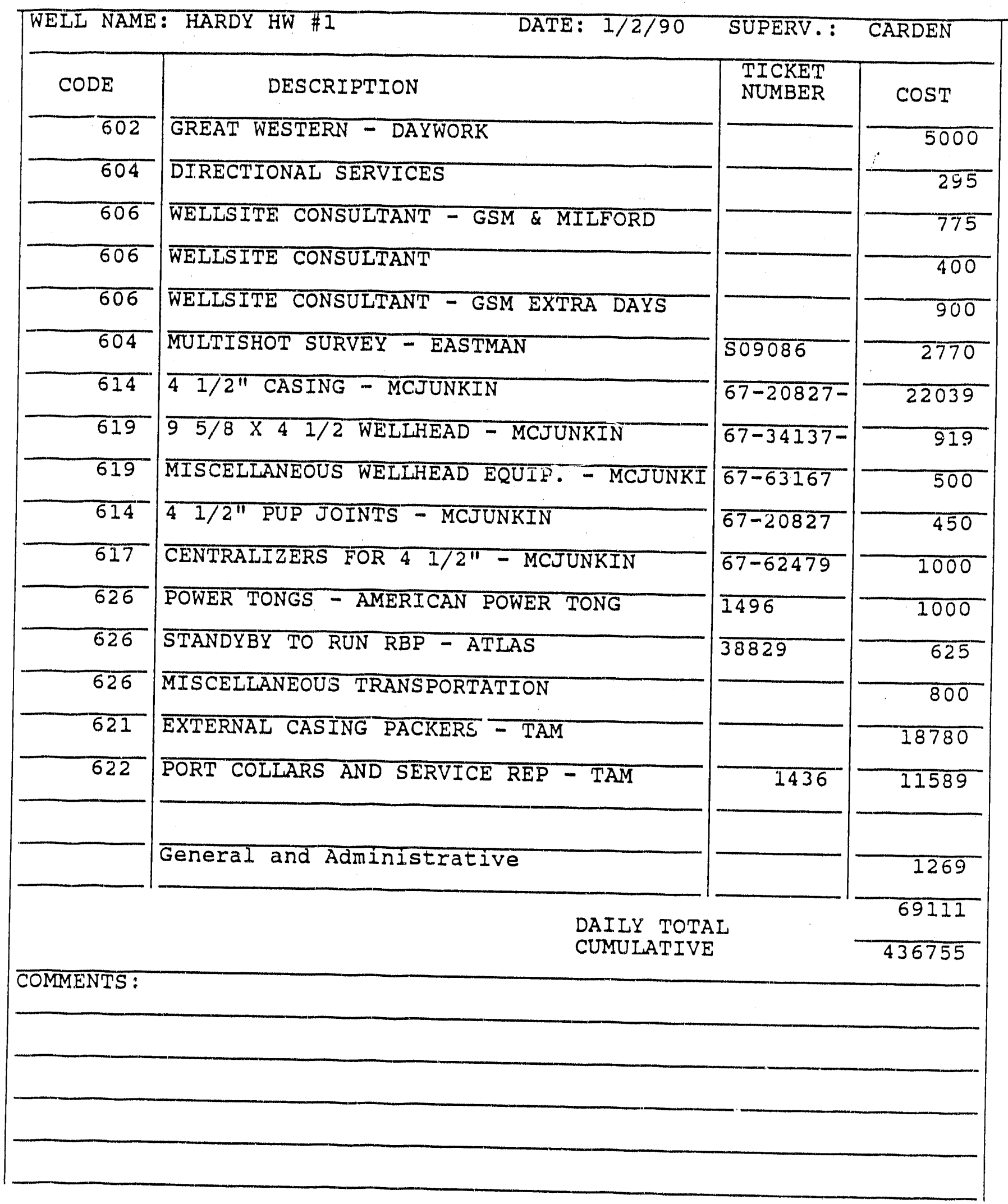


WELL NAME: HAROY HW \#1

YEAR: 1989

\begin{tabular}{|c|c|c|c|c|c|c|c|c|c|c|c|c|}
\hline TASK & & SREVIOU & & & & DATE & & & & WEEKLY & $P O$ & PO \\
\hline COOE & DESCRIPTION & WEEK & $11 / 30$ & $12 / 1$ & $12 / 2$ & $12 / 3$ & $12 / 4$ & $12 / 5$ & $12 / 6$ & TOTAL & BUDGET & VARIANCE \\
\hline 401 & ROAOS AND LCCATION & 0 & 2950 & & & & & & & 2950 & 2950 & 0 \\
\hline & SUBTOTAL TASK 4 & & 2950 & 0 & 0 & 0 & 0 & 0 & 0 & 2950 & 2950 & 0 \\
\hline 501 & CONSULTING ENAINEERING & 7494 & & & & & & & & 7494 & 4743 & 2751 \\
\hline & SUBTOTAL TASK 5 & 7494 & 0 & 0 & 0 & 0 & 0 & 0 & 0 & 7494 & 4743 & 2751 \\
\hline 601 & FOOTAGE CONTRACT & 0 & 416 & 2938 & 5694 & 0 & 5837 & 10868 & 1846 & 27599 & 426,84 & .14885 \\
\hline 602 & DAY WORK CONTRACT & 0 & & & & & & & & 0 & 85000 & -85000 \\
\hline 603 & DIRECTIONAL DRILLER & 0 & & & & & & & & 0 & 0 & 0 \\
\hline 604 & DIRECTIOHAL SERVICES & 0 & & & & & & & & 0 & 0 & 0 \\
\hline 605 & STEERING TOOL & 0 & & & & & & & & 0 & 23400 & -23600 \\
\hline 606 & CONSULTING ENGINEER & 0 & & & & & & 450 & 450 & 900 & 0 & 900 \\
\hline 607 & RENTALS-REAMERS \& STABILIZERS & 0 & & & & & & & & 0 & 7680 & -7660 \\
\hline 608 & DRILLING FLUID ADDITIVES & 0 & & & & & & & & 0 & 2951 & -2951 \\
\hline 609 & ORILL BITS & 0 & & & & & & & & 0 & 10316 & -10316 \\
\hline 610 & WATER HAULING & 0 & & & & & & & & 0 & 1200 & -1200 \\
\hline 611 & WATER TANK RENTAL & 0 & & & & & & & & 0 & 900 & .900 \\
\hline 612 & $133 / 8 "$ CASING & 0 & & 11575 & & & & & & 11575 & 11102 & 473 \\
\hline 613 & 9 5/8" CASING & 0 & & & & & & & & 0 & 31189 & -31189 \\
\hline 614 & $41 / 2 "$ CASING & 0 & & & & & & & & 0 & 21632 & -21632 \\
\hline 615 & EEMENTING $133 / 8 "$ CASING & 0 & & 553 & & 4531 & & & & 5084 & 5084 & 0 \\
\hline 616 & CEMENTING Q 5/8" CASING & 0 & & & & & & & 578 & 578 & 6434 & .5856 \\
\hline 617 & CEMENTING $41 / 2 "$ CASING & 0 & & & & & & & & 0 & 4651 & -4651 \\
\hline 618 & PRDOUCTION TUBING $23 / 81$ & 0 & & & & & & & & 0 & 0 & 0 \\
\hline 619 & WELLHEAD $95 / 811 \times 41 / 211$ & 0 & & & & & & & & 0 & 919 & .919 \\
\hline 620 & WELLHEAD $133 / 8 \times 95 / 81$ & 0 & & & & & & & & 0 & 1678 & -1678 \\
\hline 621 & EXTERNAL CASING PACKERS & 0 & & & & & & & & 0 & 11290 & -11290 \\
\hline 622 & PORT COLLARS & 0 & & & & & & & & 0 & 0 & 0 \\
\hline 623 & COMPLETION RIG & 0 & & & & & & & & 0 & 0 & 0 \\
\hline 624 & WITROGEN-SERVICE-PACKERS & 0 & & & & & & & & 0 & 0 & 0 \\
\hline 625 & SET-TOOL RENTAL & 0 & & & & & & & & 0 & $a$ & 0 \\
\hline 626 & MISCELLAMEOUS & 0 & & & & & & 342 & 1055 & 1397 & 8501 & .7104 \\
\hline & SUBTOTAL YASK 6 & & 416 & 15066 & 5694 & $453 i$ & 5837 & 19660 & 3929 & 47133 & 276391 & .229258 \\
\hline 801 & MUD LOGGER & 0 & 0 & 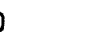 & & & 420 & 420 & 420 & 1260 & 7110 & .5850 \\
\hline 802 & WELL LOGGING & 0 & 0 & 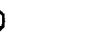 & & & & & & 0 & 27349 & .27341 \\
\hline & SUBTOTAL TASK 8 & & 0 & 0 & 0 & 0 & 420 & 420 & 420 & 1260 & 34459 & .33191 \\
\hline ¡101 & FRAC SOB & 0 & & & & & & & & 0 & 0 & 0 \\
\hline 1102 & WORKOVER RIS & 0 & & & & & & & & 0 & 0 & 0 \\
\hline 1103 & PERFORATING & 0 & & & & & & & & 0 & 0 & 0 \\
\hline 1104 & WELLHEAD PLUMBING & 0 & & & & & & & & 0 & 0 & 0 \\
\hline 1105 & MISCELLANEOUS & 0 & & & & & & & & 0 & 0 & 0 \\
\hline 1106 & LOCATION RECLAMATION & 0 & & & & & & & & 0 & 0 & 0 \\
\hline & SUBTOTAL TASK 11 & & 0 & 0 & 0 & 0 & 0 & 0 & 0 & 0 & 0 & 0 \\
\hline & TOTAL COST & & 3366 & 15066 & 5694 & 4531 & 6257 & 12080 & 4349 & 58837 & 318535 & -259698 \\
\hline & OVERHEAD AHD G\&A ( $1.87 x)$ & & 63 & 282 & 106 & 85 & 117 & 226 & 81 & 1100 & 5957 & .4856 \\
\hline & TOTAL COSTS W/ OH/GEA & & 3429 & 15348 & 5800 & 4616 & 6374 & 12306 & 4430 & 59937 & 324492 & 264554 \\
\hline
\end{tabular}


WELL NAME: HAROY HW \#1

YEAR: 1989

\begin{tabular}{|c|c|c|c|c|c|c|c|c|c|c|c|c|}
\hline $\begin{array}{l}\text { TASK } \\
\text { COOE }\end{array}$ & DESCRIPTION & $\begin{array}{c}\text { PREVIO } \\
\text { HEEK }\end{array}$ & & $12 / 8$ & 1210 & $\begin{array}{l}\text { OAYE } \\
12 / 10\end{array}$ & $12 / 11$ & $112 / 1 ?$ & $212 / 13$ & HEEKLY & PO & $\begin{array}{l}\text { PO } \\
\text { ARIAN }\end{array}$ \\
\hline 200 & ROADS AND LOCATION & 2950 & & & & & & & & 2950 & 2950 & 0 \\
\hline & SUBTOTAL TASK 4 & 2950 & 0 & 0 & 0 & 0 & 0 & 0 & 0 & 2950 & 2950 & 0 \\
\hline 501 & CONSULTING ENGINEERING & 7494 & & & & & & & & 7494 & 4743 & 2751 \\
\hline & SUBTOTAL TASK 5 & 7494 & 0 & 0 & 0 & 0 & 0 & 0 & 0 & 7494 & 4743 & 2751 \\
\hline 601 & FOOTAGE COHTRACT & 27599 & 2314 & 1053 & 3289 & 286 & 52 & 27696 & & 422319 & 42484 & -195 \\
\hline 602 & DAY WORK CONTRACT & 0 & & & & & & 3073 & 35000 & 8073 & 85000 & -76927 \\
\hline 603 & DIRECTIONAL DRILLER & 0 & & & & 1025 & 425 & 51105 & $5 \quad 1130$ & 3685 & 0 & $3,5 \times 15$ \\
\hline 604 & DIRECTIONAL SERVICES & 0 & & & & 145 & 1975 & $5 \quad 2015$ & $5 \quad 2808$ & 6943 & 0 & 6943 \\
\hline 605 & STEERING TOOL & 0 & & & & & & & 1800 & 1800 & 23400 & -21600 \\
\hline 606 & CONSULTING ENGINEER & 900 & 450 & 450 & 3874 & 450 & 450 & 450 & 775 & 7799 & 0 & 7799 \\
\hline 607 & RENTALS-REAMERS \& STABILIZERS & 0 & & & & 3985 & & & & 3985 & 7660 & .3675 \\
\hline 608 & DRILSING FLUIO ADDITIVES & 0 & & & & & & & & 0 & 2951 & -2959 \\
\hline 609 & DRILL BITS & 0 & & & & & & & 3074 & 3074 & 10316 & .7242 \\
\hline 610 & WATER HAULING & 0 & & & & & & & & 0 & 1200 & -1200 \\
\hline 611 & WATER TANK RENTAL & 0 & & & & & & & & 0 & 900 & .900 \\
\hline 612 & $133 / 811$ CASING & 11575 & & & & & & & & 19575 & 11102 & 473 \\
\hline 613 & $95 / 810$ CASING & 0 & & & & 34769 & & & & 34769 & 31189 & 3580 \\
\hline 614 & $41 / 2 "$ CASING & 0 & & & & & & & & 0 & 21632 & -21632 \\
\hline 615 & CEMENTING $133 / 8 "$ CASING & 5084 & & & & & & & & 5084 & 5134 & .50 \\
\hline 616 & CEMENTING 9 5/8" CASING & 578 & & & & 5856 & & & & 6434 & 6585 & .151 \\
\hline 617 & CEMENTING $41 / 2 "$ CASING & 0 & & & & & & & & 0 & 4651 & -4651 \\
\hline 618 & PROOUCTION TUBING $23 / 8 "$ & 0 & & & & & & & & 0 & 3 & 0 \\
\hline 619 & HELLHEAD $95 / 811 \times 41 / 21$ & 0 & & & & & & & & 0 & 919 & $-\$ 19$ \\
\hline 620 & WELLHEAD $133 / 8 \times 95 / 8 "$ & 0 & & & & & & & & 0 & 1678 & -1678 \\
\hline 621 & EXTERMAL CASING PACKERS & 0 & & & & & & & & 0 & 11290 & -11290 \\
\hline 622 & PORT COLLARS & 0 & & & & & & & & 0 & 0 & 0 \\
\hline 623 & COMPLETION RIG & 0 & & & & & & & & 0 & 0 & 0 \\
\hline 624 & NITROGEN-SERVICE-PACKERS & 0 & & & & & & & & 0 & 0 & 0 \\
\hline 625 & SET-TOOL RENTAL & 0 & & & & & & & & 0 & 0 & 0 \\
\hline 626 & MISCELLANEQUS & 1397 & & & 1000 & 929 & $595^{\prime}$ & 350 & 900 & 4371 & 8501 & -4130 \\
\hline & SUBTOTAL TASK 6 & 47133 & 2764 & 1503 & 8163 & 47445 & 3497 & 14689 & 14687 & 139881 & 276592 & -136711 \\
\hline 801 & MUD LOGGER & 1260 & 420 & 420 & 420 & 420 & 200 & 420 & 420 & 3980 & 7910 & -3930 \\
\hline 802 & WELL LOGGING & & & & & & 1270 & & & 1270 & 27349 & -26079 \\
\hline & SUBTOTAL TASK 8 & 1260 & 420 & 420 & 420 & 420 & 1470 & 420 & 420 & 5250 & 34451 & -29201 \\
\hline 1101 & FRAC JOB & 0 & & & & & & & & 0 & 0 & 0 \\
\hline 1902 & WORKOVER RIG & 0 & & & & & & & & 0 & 0 & 0 \\
\hline 9103 & PERFORATING & 0 & & & & & & & & 0 & 0 & 0 \\
\hline 1104 & WELLHEAD PLUMBEING & 0 & & & & & & & & 0 & 0 & 0 \\
\hline 1105 & MISCELLANEOUS & 0 & & & & & & & & 0 & 0 & 0 \\
\hline 1106 & LOCATIOH RECLAMATION & 0 & & & & & & & & 0 & 0 & 0 \\
\hline & SUBTOTAL TASK 11 & 0 & 0 & 0 & 0 & 0 & 0 & 0 & 0 & 0 & 0 & 0 \\
\hline & TOTAL COST & 58837 & 3184 & 1923 & 8583 & 47865 & 4967 & 15109 & 15107 & 155575 & 318736 & 161 \\
\hline & OVERHEAD AND G\&A ( 1.877$)$ & 9100 & 60 & 36 & 161 & 895 & 93 & 283 & 283 & 2909 & 5960 & .3051 \\
\hline & TOTAL COSTS W/ OH/GRA & 59937 & 3244 & 1959 & 8744 & 48760 & 5060 & 15392 & 15390 & 158485 & 324696 . & -1606212 \\
\hline
\end{tabular}


WELL NAME: HAROY HW \#1

YEAR: 1989

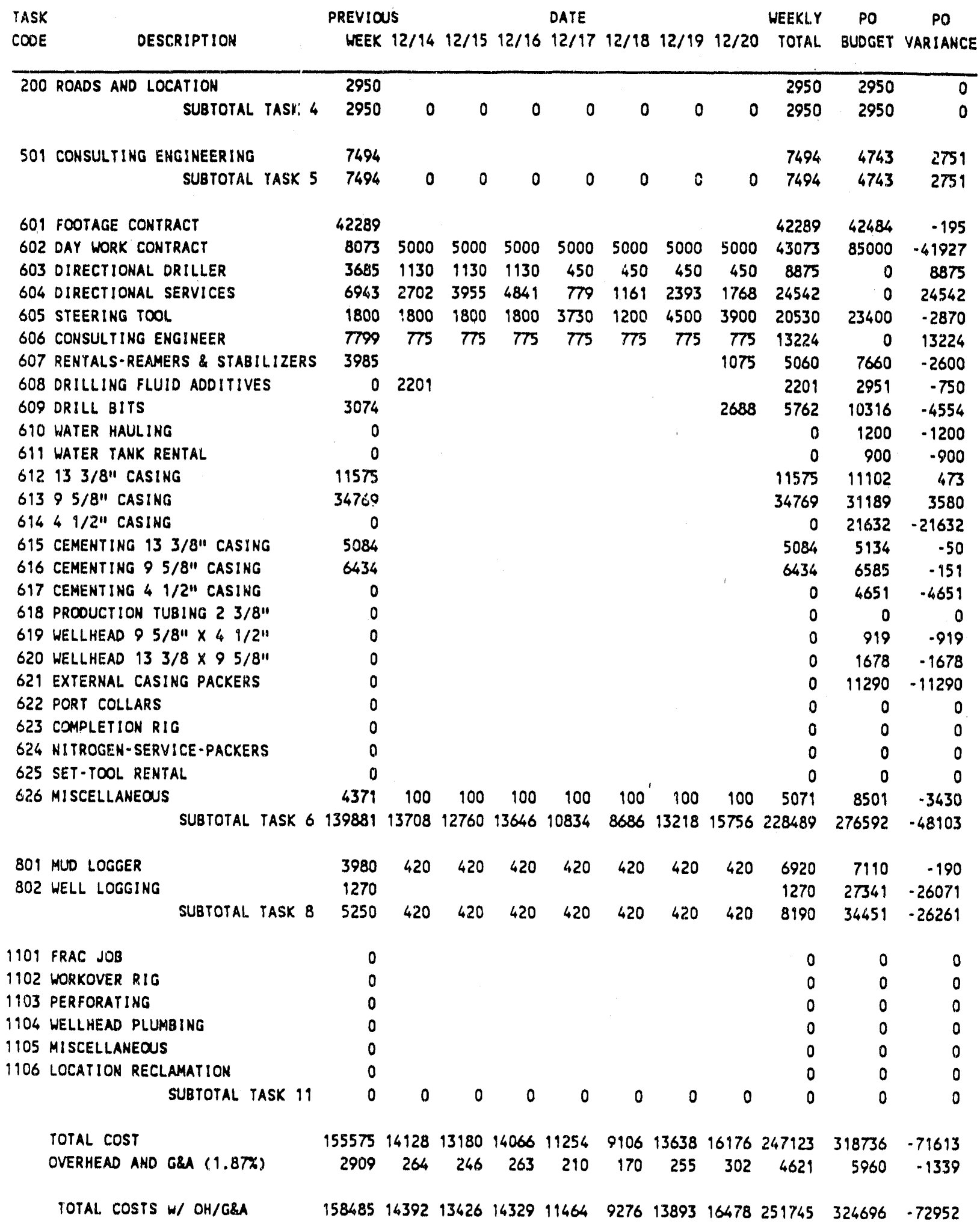


WELL NAME: HAROY HH \#1 YEAR: 1989

\begin{tabular}{|c|c|c|c|c|c|c|c|c|c|c|c|c|}
\hline TASK & nece & PREVIOU & & & & DATE & & & 12131 & WEEKLY & PO & $\begin{array}{c}P O \\
\text { YARIANCE }\end{array}$ \\
\hline 200 & ROIIOS AND LOCATION & 2950 & & & & & & & & 2950 & 2950 & 0 \\
\hline & SUBTOTAL TASK 4 & 2950 & 0 & 0 & 0 & 0 & 0 & 0 & 0 & 2950 & 2950 & 0 \\
\hline 501 & CONSULTING ENGINEERING & 7494 & & & & & & & & 7494 & 4743 & 2751 \\
\hline & SUBTO'AL TASK 5 & 7494 & 0 & 0 & 0 & 0 & 0 & 0 & 0 & 7494 & 4743 & 2751 \\
\hline 601 & FOOTAGE CONTRACT & 42289 & & & & & & & & 42289 & 42484 & -195 \\
\hline 602 & DAY WORK CONTRACT & 43073 & 5000 & 5000 & 5000 & 5000 & 5000 & 5000 & 5000 & 78073 & 85000 & .6927 \\
\hline 603 & DIRECTIONAL DRILLER & 8875 & 450 & 450 & 2250 & 450 & 450 & 450 & 450 & 13825 & 0 & 13825 \\
\hline 604 & DIRECTIONAL SERVICES & 24542 & 405 & 305 & 305 & 405 & 405 & 405 & 295 & 27067 & 0 & 27067 \\
\hline 605 & STEERING TOOL & 20530 & 1800 & 1800 & & & & & & 24130 & 23400 & 730 \\
\hline 606 & CONSULTING ENGINEER & 13224 & 775 & 775 & 775 & 775 & 775 & 775 & 1175 & ; 19049 & 0 & 19049 \\
\hline 607 & RENTALS-REAMERS \& STABILIZERS & 5060 & & & 775 & & & & & 5835 & 7660 & -1825 \\
\hline 608 & DRILLING FLUID ADDITIVES & 2201 & & & & & & & & 2201 & 2951 & -750 \\
\hline 609 & DRILL BITS & 5762 & & & & & & & & 5762 & 10316 & -4554 \\
\hline 610 & WATER HAULING & 0 & & & & & & & & 0 & 1200 & .1200 \\
\hline 611 & WATER TANK RENTAL & 0 & & & & & & & & 0 & 900 & .900 \\
\hline 612 & $133 / 8 "$ CASING & 11575 & & & & & & & & 11575 & 19102 & 473 \\
\hline 613 & 9 5/8" CASING & 34769 & & & & & & & & 34769 & 31189 & 3580 \\
\hline 614 & $41 / 2 "$ CIASIHG & 0 & & & & & & & & 0 & 29632 & -21632 \\
\hline 615 & CEMENTINIS $133 / 8$ " CASING & 5084 & & & & & & & & 5084 & 5134 & .50 \\
\hline 616 & CEMENTINIA $95 / 8 "$ CASING & 6434 & & & & & & & & 6434 & 6585 & -151 \\
\hline 617 & CEMENTINIO $41 / 2 "$ CASING & 0 & & & & & & & & 0 & 4651 & .4651 \\
\hline 618 & PROOUCTISIN TUBING $23 / 811$ & 0 & & & & & & & & 0 & 0 & 0 \\
\hline 699 & WELLHEAD $95 / 811 \times 41 / 2 "$ & 0 & & & & & & & & 0 & 919 & .919 \\
\hline 620 & WELLHEAD $133 / 8 \times 95 / 81$ & 0 & & & & & & & & 0 & 1678 & -1678 \\
\hline 621 & EXYERNAL CASING PACKERS & 0 & & & & & & & & 0 & 11290 & -11290 \\
\hline 622 & PORT COLLARS & 0 & & & & & & & & 0 & 0 & 0 \\
\hline 623 & COMPLETION RIG & 0 & & & & & & & & 0 & 0 & 0 \\
\hline 624 & NITROGEN-SERVI CE - PACKERS & 0 & & & & & & & & 0 & 0 & 0 \\
\hline 625 & SET-TOOL RENTAL & 0 & & & & & & & & 0 & 0 & 0 \\
\hline 626 & MISCELLANEOUS & 5071 & 636 & 185 & 500 & 100 & $100^{\prime}$ & 900 & & 6692 & 8501 & .1809 \\
\hline & SUBTOTAL TASK 6 & 228489 & 9066 & 8515 & 9605 & 6730 & 6730 & 6730 & 6920 & 282785 & 276592 & 6193 \\
\hline 801 & MUD LOGGER & 6920 & 420 & 420 & 420 & 420 & 420 & 420 & & 9440 & 7190 & 2330 \\
\hline 802 & WELL LOGGING & 1270 & & & & & & & & 1270 & 27341 & -26071 \\
\hline & SUBTOTAL TASK 8 & 8190 & 420 & 420 & 420 & 420 & 420 & 420 & 0 & 10710 & 34459 & -23741 \\
\hline 1101 & FRAC JOB & 0 & & & & & & & & 0 & 0 & 0 \\
\hline 1102 & WORKOVER RIG & 0 & & & & & & & & 0 & 0 & 0 \\
\hline 1103 & PERFORATING & 0 & & & & & & & & 0 & 0 & 0 \\
\hline 1104 & WELLHEAD PLUMBING & 0 & & & & & & & & 0 & 0 & 0 \\
\hline 1105 & MISCELLANEOUS & 0 & & & & & & & & 0 & 0 & 0 \\
\hline 1106 & LOCATION RECLAMAYION & 0 & & & & & & & & 0 & 0 & 0 \\
\hline & SUBTOTAL TASK 11 & 0 & 0 & 0 & 0 & 0 & 0 & 0 & 0 & 0 & 0 & 0 \\
\hline & TOTAL COST & 247123 & 9486 & 8935 & 10025 & 7150 & 7150 & 7150 & 6920 & 303939 & 318736 & -14797 \\
\hline & OVERHEAD ANO G\&A $(1.87 \%)$ & 4621 & $i 7$ & 167 & 187 & 134 & 134 & 134 & 129 & 5684 & 5960 & $-2 \pi$ \\
\hline & TOTAL COSTS W/ OH/G\&A & 251745 & 9663 & 9102 & 10292 & 7284 & 7284 & 7284 & 7049 & 309623 & 324696 & -15073 \\
\hline
\end{tabular}


MELL NAME: HARDY HW \#1

YEAR: 1990

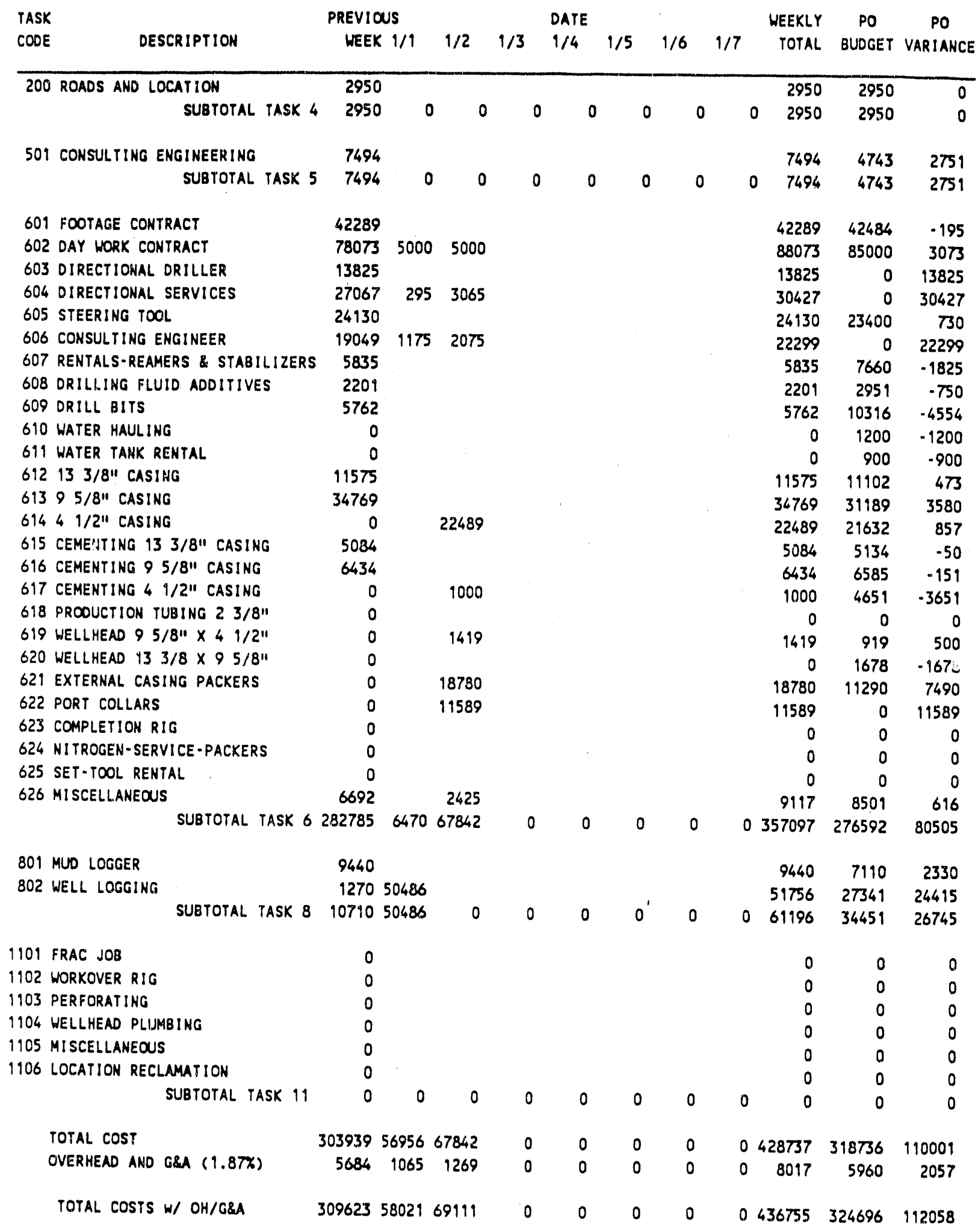




\section{State of West Virginia \\ DEPARTMENT OF ENERGY \\ Division of 011 and Gas}

Well Operator's Report of Well Work

Farm name: WALKER, CHARLEY

Location: Elevation: 862.00
Operator Well No.: HARDY HW \#1 Quadrangle: ELMWOOD

District: ONION

County: PUTNAY

Lat1tude: 13600 Feet South of 38 Deg. $40 \mathrm{Min} .0 \mathrm{Sec}$. Long1tude: 3400 Feet West of 81 Deg. $50 \mathrm{MIn} .0$ Sec.

Company: CABOT OIL \& GAS CORPORATION P. 0. BOX 1473

Charleston, WV 25325

Agent: DAVID G. MCCLUSKEY

Inspector: JERRY TEPHABOCK

Permit Issued:

WeIl Work Commenced:

Well Work Completed:

$\frac{11 / 4 / 89}{\frac{11 / 29 / 89}{5 / 16 / 90}}$

Verbal Plugging

Permission granted on:

Rotary $x$ Cable Rig

Total Depth (feet) TVD 4276, MD 6399

Fresh water depths ( $f t) 705$

Salt water depths (ft) 1790,2109, 2118

Is coal being mined in area $(Y / N): \underline{N}$ Coal Depths ( $f t)$ : None Reported

\begin{tabular}{|c|c|c|c|}
\hline $\begin{array}{c}\text { Casing } \\
\text { Tubing }\end{array}$ & $\begin{array}{l}\text { Osed In } \\
\text { Drt11ing }\end{array}$ & $\begin{array}{l}\text { Left } \\
\text { In Well }\end{array}$ & $\begin{array}{l}\text { Cement } \\
\text { F111 Up } \\
\text { Cu. Ft. }\end{array}$ \\
\hline $20 "$ & $32^{\prime}$ & $32^{\circ}$ & CTS \\
\hline $13-3 / 8 "$ & $668^{\circ}$ & $668^{\circ}$ & $\begin{array}{l}460 \text { sks } \\
\text { CL-A w/ } \\
3 \% \mathrm{CC}\end{array}$ \\
\hline $9-5 / 8 "$ & $2654^{\prime}$ & $\begin{array}{r}2654^{\prime} \\
\mathrm{CL} \\
\end{array}$ & $\begin{array}{l}330 \text { sks } \\
\text { Howco Lt } \\
100 \text { sks } \\
A \text { w CC }\end{array}$ \\
\hline $4-1 / 2^{n}$ & & $6151^{\prime} \mathrm{MD}$ & $\begin{array}{l}130 \text { sks } \\
\text { CL-A } \\
\text { BOC } 4103 \\
\text { TOC } 3560\end{array}$ \\
\hline $2-3 / 8^{n}$ & & $5550^{\prime} \mathrm{MD}$ & $\mathrm{N} / \mathrm{A}$ \\
\hline
\end{tabular}

\section{OPEN FLOW DATA}

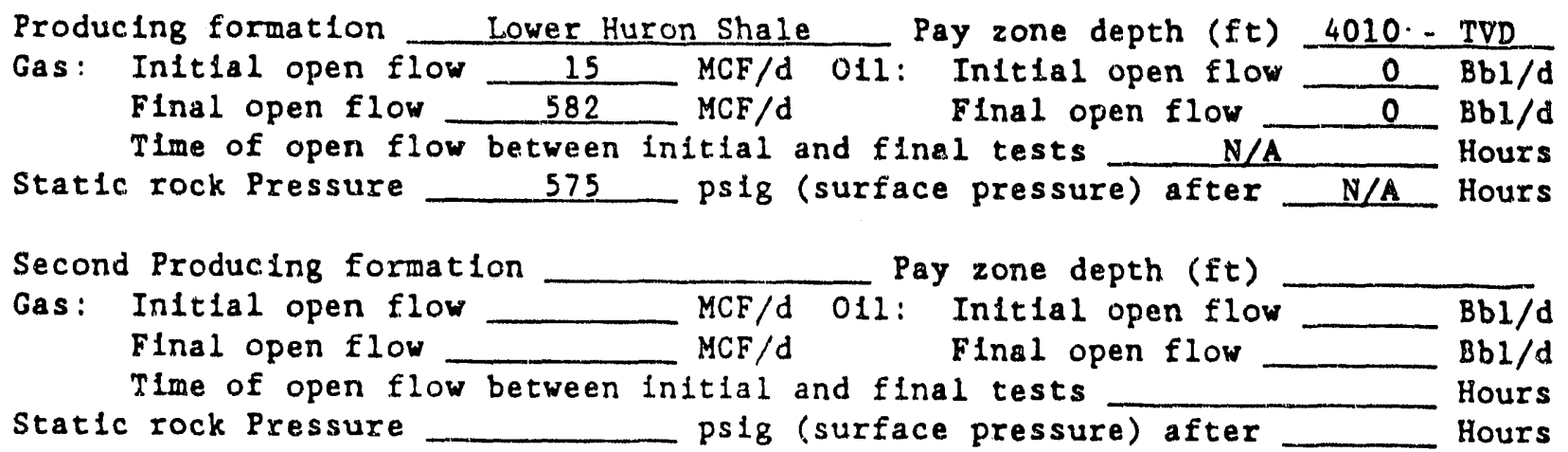

NOTE: ON BACK OF THIS FORM PUT THE FOLLOWING: 1), DETAILS OF PERFORATED INTERVALS, FRACTURING OR STTMULATING, PHYSICAL CHANGE, ETC. 2). THE WELL LOG WHICH IS A SYSTEMATIC DETAILED GEOLOGICAL RECORD OF ALI FORMATIONS, INCLODING COAL ENCOUNTERED BY THE WELLBORE.

For: CABOT OIL \& GAS CORPORATION

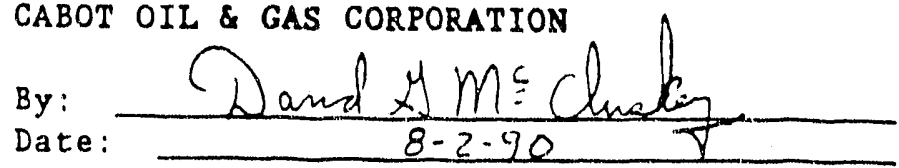


DETAILS OF PERFORATED INTERVALS, FRACTURING OR STIMULATING, PHYSICAL CHANGE, ETC.

\begin{tabular}{cc} 
PORT COLLARS \\
NUMBER & MD \\
\hline 1 & 5919 \\
2 & 4842 \\
3 & 4714 \\
4 & 4056
\end{tabular}

\begin{tabular}{lll}
\multicolumn{3}{c}{ PERFORATIONS } \\
ZONE & RANGE & NOMBER \\
1 & & \\
2 & $5579-5585$ & 12 \\
3 & $4864-4880$ & 30 \\
4 & $4430-4475$ & 10 \\
& $4207-4370$ & 32
\end{tabular}

\section{ZONE TABLE OR STIMULATION/TREATMENT}

1 Treat $w / 140,000$ 非 $20 / 40$ sand in $75 Q$ foam.

2 Attempt to frac $w /$ no success.

$3 \& 4$ Treated $w /$ approximately 29,000 非 $20 / 40$ sand in $75 Q$ foam.

$3 \& 4$ Treat w/ 1.8 million $\operatorname{scf} \mathrm{N}_{2}$.

FORMATION

Sindstone
Sandy Shale
Sandstone
Sandy Shale
Sandstone
Limestone (B1g Lime)
Shale
Sandstone (Infun)
Silty Shale
Sunburn Shale
Berea Sand
Devonian Shale

Sinds tone

Sandy Shale

Sandstone

Limestone (B1g Lime)

Shale

Sandstone (Infun)

Silty Shale

Berea Sand

Devontan Shale
TOP

BOTTOY

700

1200

1280

1810

1900

2080

2106

2166

2560

2580

2594

4403 


\section{APPENDIX L}

\section{TABLE L-1 \\ TABLE L-2 \\ TABLE L-3}

201 


\section{TABLE L-1}

PRE-STIMULATIDN PRESSURE BUILD-UR DATA ANALYSIS FOR HARDYII

DATA ARE CONVERTED TO ADJUSTED PRESSURES AND ADJUSTED EFFECTIVE TIHE

TO ACCOUNT FOR GAS PRDPERTIES SUCH AS VISCOSITY AND COHPRESSIBILITY

\begin{tabular}{|c|c|c|c|c|c|c|c|c|c|c|c|c|c|}
\hline $\begin{array}{l}\text { TIHE-HAS } \\
2= \pm=2=z\end{array}$ & $\begin{array}{l}\text { PRSS } \\
x=t x \geq x \geq x\end{array}$ & $\begin{array}{l}\text { PSUDP } \\
\text { Dazxass }\end{array}$ & $\begin{array}{l}\text { PSUW1S } \\
=\geq \pm= \pm=:\end{array}$ & $\begin{array}{l}P S U=-l \\
z=x= \pm=x\end{array}$ & $\begin{array}{l}\text { PSUCONP } \\
z=\pi a z x:\end{array}$ & $P-A \cup B$ & $\begin{array}{l}A D J-P R S \\
\forall x= \pm=z= \pm\end{array}$ & 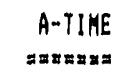 & $\begin{array}{l}\text { BuTIME } \\
x= \pm \geq E \pm x\end{array}$ & $\begin{array}{l}\text { C-TIME } \\
\text { zxyzazy }\end{array}$ & $\begin{array}{l}\text { PSU-TIHEE } \\
=x= \pm x= \pm x=\end{array}$ & 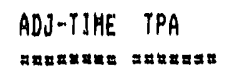 & $\begin{array}{l}\text { ADJ EFF T } \\
\geq x \geq z= \pm x=\end{array}$ \\
\hline 0 & 0 & & & & & 500.02517931 & & & & 0 & 0 & 0677.2278 & A \\
\hline 0.017 & 20.938 & 39074.30 & 0.011507 & 0.996618 & 0.048598 & & 0.136986 & 1788.061 & 894.0307 & 15.19852 & 15.1985233 & 0,000333 & 0.000333 \\
\hline 0.034 & 20.938 & 39074.30 & 0.0111507 & 0.996618 & 0,048598 & & 0.436986 & & & 30.39704 & 45.5935700 & 0.001000 & .001000 \\
\hline 0.051 & 23.134 & 48715.00 & 0.011507 & 0.996263 & 0.014938 & VIS-AVG & 0.544803 & 1933.686 & 1860.873 & 31.63485 & 77.2304271 & 0,001694 & 0.001694 \\
\hline 0.068 & 23.134 & 48715.00 & 0.011507 & 0.996263 & 0.044938 & 0.012159812 & 0.544803 & 1933.686 & 1933.686 & 32.87266 & 110.103094 & 0.002415 & 0.002415 \\
\hline 0.085 & 23.992 & 52481.73 & 0.011507 & 0.996124 & 0.043508 & & 0.586928 & 1997.239 & 1965.462 & 33.41287 & 143.515965 & 0.003148 & 0,003148 \\
\hline 0.102 & 23.992 & 52491.73 & 0.011507 & 0.996124 & 0.043508 & & 0.586928 & 1997.239 & 1997.239 & 33.95307 & 177.469038 & 0.003893 & 0.003893 \\
\hline 0.119 & 26.733 & 64515.05 & 0.011507 & 0.995682 & 0.038940 & $l-A \cup B$ & 0.721503 & 2231.543 & 2114,391 & 35.94465 & 213.413691 & 0,004682 & 0,004682 \\
\hline 0.136 & 26.733 & 64515.05 & 0.011507 & 0.995682 & 0.038940 & 0.919754928 & 0.721503 & 2231.543 & 2231.543 & 37.93623 & 251.349925 & 0.005514 & 0.005514 \\
\hline 0.153 & 23.653 & 50993,48 & 0.011507 & 0.996179 & 0.044073 & & 0.570284 & 1971.636 & 2101.589 & 35.72702 & 287.076953 & 0,006298 & 0,006298 \\
\hline 0.17 & 23.653 & 50993.48 & & 0.996179 & 0.044073 & COMP-AVG & 0.570284 & 1971.636 & 1971.636 & 33.51782 & 320.594775 & 0.007034 & 0.007034 \\
\hline 0.187 & 23.781 & $\$ 1555.41$ & 0.011507 & 0.996159 & 0.043860 & $0.0018,14389$ & 0.576569 & 1981.226 & 1976.431 & 33.59933 & 354.194109 & $0.00777 !$ & $0.00777 !$ \\
\hline 0.204 & 23.781 & 51555.11 & 0.011507 & 0.996159 & 0.043860 & & 0.576569 & 1981.226 & 1981.226 & 33.68084 & 4956 & 0.008510 & 0.008510 \\
\hline 0.221 & 23,845 & 51836.38 & 0.0 & 0.996148 & $0.043,53$ & & 0.5 & 1986 & 641 & 33.72190 & 96857 & 250 & 0.009250 \\
\hline 0.238 & 23.845 & 51836.38 & 0.011507 & 0,996148 & 0.043753 & PRS-CONST & 0.579711 & 1986.036 & 1986.056 & 33.76295 & 455.359813 & 0.009991 & 0,009990 \\
\hline 0.255 & 24.606 & 55177.26 & 0.01 & 0.996025 & 0,042185 & 0.0000111835 & 0.617074 & 2045.345 & 2015.700 & 34.26691 & 489.626729 & 0.010742 & 0,010742 \\
\hline 0.272 & 24.606 & 5517 & 0.0 & 0.996025 & 0.012485 & & 0.6 & & & & 524.397605 & & 0.011505 \\
\hline 0.289 & 23.996 & 5249 & 0.01 & 0.996124 & 0.043502 & & 0.5 & 199 & 202 & 457 & 558 & 259 & 0.012259 \\
\hline 0.306 & 23.996 & 5249 & 0.0 & 0.996124 & 0.043502 & & 24 & & & 927 & 157 & 004 & 0.013004 \\
\hline 0.323 & 23.514 & 50383.25 & 0.01 & 0.996202 & 4305 & & & 327 & & 042 & 878 & 743 & 0.013742 \\
\hline 0.34 & 23.514 & 50383.25 & 0.0 & 0.996202 & 0.044305 & & 160 & 327 & & 256 & & 474 & 0.014474 \\
\hline 0.357 & 22.926 & 47801.86 & 0.01 & 0.996297 & 0.045285 & & 0.5 & 883 & & & 692 & 198 & 0.015198 \\
\hline 0.374 & 22.926 & 4780 & 0.0 & 0.996297 & 0.045285 & & 0.5 & 883 & 19 & 102 & 729 & 914 & 0.015913 \\
\hline 0.391 & 23.762 & 51472,00 & 0.01 & 0.996162 & 0.043992 & & 0.5 & 796 & & 378 & 758 & & 0.016640 \\
\hline 0.408 & 23.762 & 51472.00 & 0.01 & 0.996162 & 0.043892 & & & 796 & & 33. & & & 0.017379 \\
\hline 0.425 & 23.733 & 51344,69 & 0.011507 & 0.9 & 0.043940 & & & 19 & & 803 & & & 8117 \\
\hline 0.442 & 23.733 & 51344,69 & 0.0 & 0.9 & 940 & & 0.5 & 19 & 19 & 952 & 859 & & 0.018854 \\
\hline 0.459 & 23.744 & 513 & 0.0 & 0.9 & 0.043922 & & 0.5 & & & & & $j 93$ & 0.019592 \\
\hline 0.476 & 23.744 & 51392.98 & & 0.9 & 0.0 & & 0.5 & 44 & & 33. & $92 b$ & 331 & 0.020330 \\
\hline 0.493 & 23.717 & 51274.41 & 0.0 & 0.996169 & 0.043967 & & 0.573426 & 119 & 197 & 33. & 960 & 0.0 & 0.021068 \\
\hline 0.51 & 23.717 & 51274,44 & & 0.996169 & 0.043967 & & 0.573426 & 419 & 197 & 33. & 993.6 & 0.0 & 0.021805 \\
\hline 0.527 & 23.771 & 51511 & 0.01 & 0.996160 & 0.043877 & & 0.5 & 198 & & & 102 & & 0.022543 \\
\hline 0.544 & 23.771 & $515 !$ & 0.0 & 0.996160 & 0.043877 & & 0.5 & & & 305 & 640 & 282 & 0,023281 \\
\hline 0.561 & 23.83 & 517 & 0. & 0.9 & 0.043778 & & 174 & & 97 & 586 & 109 & 022 & 0.024021 \\
\hline 0.578 & 23.83 & 5177 & 0.0 & 0.996151 & 0.043778 & & 974 & 922 & 922 & 1367 & 112 & 762 & 0.029761 \\
\hline 0.595 & 23.879 & 51985,64 & 0.011507 & 0.996143 & 0.043697 & & 0.581380 & 1988.631 & 1986.776 & 33.77520 & 7111 & 0.025503 & 0.025502 \\
\hline 0.612 & 23.879 & 51985.64 & 0.011507 & 0,996143 & 0.043697 & & 0.581380 & 1988.631 & 1998,631 & 33.80673 & 1788 & 0.02 & 0,026244 \\
\hline 0.629 & 23.927 & 5219 & & 0,996135 & 0.043617 & & 0.58 & 1992.279 & & & & 0.0 & 0.026986 \\
\hline 0.640 & 23,927 & 5219 & 0.0 & 0.9 & 0.0 & & 0.5 & 279 & & 33. & & 0.0 & 0.027729 \\
\hline 0.063 & 23.952 & 523 & 0. & 0.9 & 0.0 & & 64 & 84 & 31 & 33. & 129 & 174 & 0.028473 \\
\hline 1.313 & 24.949 & 56683.07 & 0.011507 & 0.995970 & 0.041913 & & 0.633914 & 241 & .712 & 1382.924 & 9411 & 0.058817 & 0.058812 \\
\hline 2.023 & 24.465 & 54558.26 & 0.011507 & 0.996048 & 0.012720 & & 0.610151 & 2034.041 & 2053.668 & 1396.494 & 4077,18852 & 0,089457 & 0,089445 \\
\hline 2.703 & 23.612 & 50813.18 & 0.011507 & 0.996186 & 0.041142 & & 0.568271 & 1968.584 & 2001.339 & 1360.910 & 5438,09942 & 0.119317 & 0.119296 \\
\hline 3.383 & 27.18 & 66477.43 & 0.0111507 & 0.995610 & 0.038195 & & 0.743449 & 2273.068 & 2121.826 & & 6880. & 0.150974 & 0.150941 \\
\hline 4.063 & 590.819 & 343 & 0.012118 & 0.90 & 0.001864 & & & & & & & 0.49 & 0.489749 \\
\hline 4.713 & 595.498 & 34889816 & 0.012434 & 0.904781 & 0.001851 & & 390.1897 & 43436.23 & & & & 1.1 & 1.134389 \\
\hline 5.423 & 599.452 & 35375752 & 0.012447 & 0.904165 & 0.001840 & & 393.6241 & 43651.58 & 13543.91 & 29609,85 & 81398.3570 & 1.785963 & 1.781266 \\
\hline 6.103 & 603.042 & 35823953 & 0.012459 & 0.903607 & 0.001830 & & 400.6354 & 43844,90 & 43748.24 & 29748.80 & 111147,163 & 2.438683 & 2.429933 \\
\hline 6.783 & 606.122 & 36296913 & 0.012470 & 0.903081 & 0.001821 & & 405.3667 & 44028.11 & 43936.51 & 29876.82 & 141023.970 & 3.094211 & 3.080138 \\
\hline 7.463 & 609.629 & 36648319 & 0.012481 & 0.902582 & 0.001812 & & 409.8558 & 44203.73 & 14115.92 & 29998.83 & 171022.821 & 3.752417 & 3.731740 \\
\hline
\end{tabular}


$8.143 \quad 612.684370368290 .0124910 .9021080 .001804$

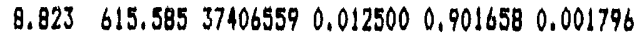
$9.503 \quad 618.379 \quad 37762652 \quad 0.0125090 .9012240 .001789$ $10.183 \quad 621.06 \quad 381067740.0125180 .9008080 .001782$ $10.863 \quad 623.621384390450 .0125260 .9004110 .001775$ $\begin{array}{lllllll}11.543 & 626.088 & 38759119 & 0.012534 & 0.900029 & 0.001769\end{array}$ $12.223 \quad 628.45839066609 \quad 0.012542 \quad 0.8996610 .001763$

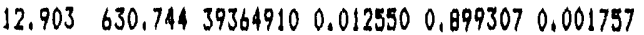
$\begin{array}{llllllll}13.583 & 632.958 & 3965725 ! & 0.012557 & 0.898965 & 0.001752\end{array}$ $\begin{array}{llllllll}14.263 & 635.096 & 39939555 & 0.012564 & 0.898634 & 0.001746\end{array}$ $14.913 \quad 637.164402126180 .0125710 .8983140 .001741$ $\begin{array}{lllllll}15.623 & 639.167 & 40477097 & 0.012577 & 0.898004 & 0.001736\end{array}$ $16.303 \quad 641.092 \quad 40733797 \quad 0.012583 \quad 0.897707 \quad 0.001732$ $\begin{array}{lllllll}16.983 & 642.965 & 40985433 & 0.012589 & 0.897417 & 0.001727\end{array}$ $\begin{array}{lllllll}17.663 & 644.783 & 11229680 & 0.012595 & 0.897137 & 0.001723\end{array}$ $18.343 \quad 646.546 \quad 414665370.0126010 .8968650 .001718$

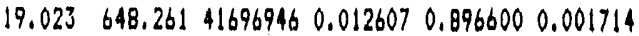
$19.703 \quad 649.93419211750 .0126120 .8963420 .001710$ $20.383 \quad 651.537421406350 .0126170 .8960940 .001706$ $\begin{array}{llllllll}21.063 & 653.098 & 12353970 & 0.012622 & 0.095854 & 0.001703\end{array}$ $21.743 \quad 654.602 \quad 425595150.0126270 .895622 \quad 0.001699$ $22.423 \quad 656.076 \quad \begin{array}{lllll}2760960 & 0.012632 & 0.895395 & 0.001696\end{array}$ $23.103 \quad 657.502 \quad 429558450.0126370 .8951750 .001693$ $23.783 \quad 658.883 \quad 431445800.0126410 .894962 \quad 0.001689$ $26.258 \quad 663.615 \quad 137997450.012656 \quad 0.8942340 .001679$ $29.578 \quad 669.396 \quad 496033430.0126720 .0933440 .001665$ $32.898 \quad 674.5545330744 \quad 0.0126840 .892553 \quad 0.001654$ $36.218 \quad 679.114 \quad 45976165 \quad 0.0126940 .8919520 .001644$ $39.538 \quad 683.262 \quad 465707750.0127030 .8912160 .001635$ $42.858 \quad 687.104 \quad 471235380.0127110 .890628 \quad 0.001627$ $46.178 \quad 690.597 \quad 476275630.0127190 .890093 \quad 0.001619$ $49.51 ! 693.692 \quad 480804990.0127250 .8896190 .001613$ $52.831 \quad 696.658 \quad 48514557 \quad 0.012732 \quad 0.889166 \quad 0.001607$ $56.151 \quad 699.42148918906 \quad 0.0127370 .8887440 .001601$ 59.471701 .947492934040 .0127430 .8883580 .001596 62.791704 .274496397220 .0127480 .8880030 .001591 $66.111 \quad 706.523 \quad 499744310.0127530 .8876600 .001587$ $69.431 \quad 708.63 \quad 502880080.012757 \quad 0.8873380 .001583$ $72.751 \quad 710.572505784540 .0127610 .8870420 .001579$ $76.07 ! \quad 7 ! 2.408508562760 .0127650 .886763 \quad 0.001575$ $79.391 \quad 714.23511319800 .0127690 .8864850 .001571$ $82.711715 .926513806617 \quad 0.012773 \quad 0.886227 \quad 0.001568$ $86.031 \quad 717.486516246750 .0127760 .8859900 .001565$ 89.351719 .001518539240 .0127800 .8857390 .001562 $92.67 ! 720.49520804640 .0127830 .8855330 .001559$ $95.991 \quad 721.87652293662 \quad 0.0127860 .8853220 .001556$ $99.337 \quad 723.117 \quad 524845550.0127880 .8851340 .001554$ $\begin{array}{llllllll}102.657 & 724.408 & 52683139 & 0.012791 & 0.884938 & 0.001552\end{array}$ $105.977 \quad 725.67852878493 \quad 0.0127940 .8847450 .001549$ $\begin{array}{lllllll}109.297 & 726.851 & 53058926 & 0.012796 & 0.884567 & 0.001547\end{array}$ $\begin{array}{lllllll}112.617 & 727.998 & 53235360 & 0.012799 & 0.884392 & 0.001545\end{array}$ $\begin{array}{lllll}115.937 & 729.13953410871 & 0.012801 & 0.884219 & 0.001543\end{array}$ $\begin{array}{lllllll}119.257 & 730.24153580989 & 0.012804 & 0.884052 & 0.001541\end{array}$ $\begin{array}{llllll}122.577 & 731.255 & 53739914 & 0.012806 & 0.883898 & 0.001539\end{array}$ $125.897 \quad 732.253 \quad 53,755380.012808 \quad 0.883747 \quad 0.001537$ $\begin{array}{llllll}129.217 & 733.25154051562 & 0.012810 & 0.883596 & 0.001535\end{array}$
414.200744366 .9744285 .3530114 .04201136 .8644 .413130 $418.3356 \quad 44522.6444444 .8130222 .47231359 .3365 .076262$ $422.318044673 .88 \quad 44598.2630326 .81261666 .1555 .741664$ $126.166544818 .01 \quad 44745.9430427 .24292113 .4006 .409269$ 129.882444953 .5344885 .7730522 .32322635 .7287 .078960 433.461945085 .0745019 .3030613 .13353248 .8587 .750644 436.900745212 .3645148 .7230701 .13383949 .9908 .424258 $440.2368 \quad 45334.1945273 .4330785 .93414735 .9239 .099733$ 443.506245450 .5045392 .4930866 .89449602 .8239 .776985 $446.6633 \quad 45563.25 \quad 15506.88 \quad 30944.67 \quad 476547,502 \quad 10.45594$ 449.717145672 .9945618 .1231020 .32507567 .82911 .13656 $452.674945779 .93 \quad 45726.4631093 .99538661 .824 \quad 11.81879$ $455.545745881 .12 \quad 45830.5231164 .75969826 .583 \quad 12.50258$ $458.3599 \quad 45978.50 \quad 45929.8131232 .27601058 .856 \quad 13.18785$ $461.0914 \quad 46073.5346026 .0231297 .69632356 .550 \quad 13.87459$ $463.7403 \quad 46166.3746119 .8531361 .50663718 .05114 .56265$ $466.317146256 .7446211 .4531423 .79695141 .843 \quad 15.25212$ $468.824746345 .3246301 .03 \quad 31484.70726626 .547 \quad 15.94293$ $471.279146428 .0146386 .6731542 .93758169 .483 \quad 16.63502$ $473.664946508 .5746468 .2931596 .14789767 .923 \quad 17.32832$ $475.9636 \quad 46586.52 \quad 46547.5431652 .33821420 .257 \quad 18.02280$ $478.216546663 .2546624 .8931704 .92 \quad 053125.183 \quad 18.71814$ $480.3960 \quad 46737.7946700 .52 \quad 31756.35 \quad 884881.53819 .41521$ $182.506746810 .2646774 .02 \quad 31806.34916687 .87820 .11307$ $489.833747058 .3446934 .30 \quad 116162.41032850 .2822 .66180$ $198.820747364 .9747211 .65 \quad 156742.6 \quad 1189592.9826 .10089$ $\begin{array}{lllll}506.9556 & 47647.28 & 47506.13 & 157720.3 \quad 1347313.33 & 29.56144\end{array}$ $514.173747901 .16 \quad 47774.22 \quad 158610.41505923 .77 \quad 33.04152$ $520.823548128 .64 \quad 40014.90159409 .1 \quad 1665333.2636 .53912$ $527.0053 \quad 48340.08 \quad 48234.36 \quad 160138.0 \quad 1825471.36 \quad 10.05272$ $532.642048533 .1448436 .61 \quad 160809.51986280 .9243 .58105$ 537.707448701 .0748617 .10162040 .82148321 .7447 .13639 $542.561748863 .29 \quad 48782.18 \quad 161956.8 \quad 2310278.5950 .68989$ $547.083849015 .5548939 .42 \quad 162478.82472757 .4854 .25484$ $551.2719 \quad 49152.2949083 .92 \quad 162958.62635716 .10 \quad 57.83032$ 555.145049278 .1149215 .20163394 .42799110 .5861 .41537 $558.8882 \quad 49400,4349339.27 \quad 163806.32962916 .9765 .00945$ 562.395149515 .6849458 .05164200 .73127117 .7268 .61210 $565.643349621 .4849568 .58 \quad 164567.6 \quad 3291685.4272 .22297$ 568.750349719 .7549670 .62164906 .43456591 .8875 .84118 $571.83364981 \% .7349768 .74165232 .23621824 .1379 .46655$ $574.703749909 .3549863 .54165546 .93767371 .09 \quad 83.09882$ $577.343749993 .9749951 .66 \quad 165839.53953210 .6186 .7375 !$ $579.907550076 .4750035 .22 \quad 166116.9 \quad 4119327.5590 .38229$ $582.4410 \quad 50157.0450116 .76 \quad 166387.6 \quad 4285715.1994 .03301$ 584.825350230 .7450193 .89166643 .74452358 .9397 .68934 $586.960150296 .9550263 .05 \quad 168182.8 \quad 4620541.77101 .3794$ $589.1810 \quad 50366.0450331 .50167100 .5 \quad 4787642.36 \quad 105.0458$ 591.365750434 .2350400 .14167328 .44954970 .84108 .7171 $593.383650497 .4150465 .82 \quad 167546.55122517 .38 \quad 112.3933$ 595.356750559 .3750529 .39167754 .25290271 .65116 .0740 $597.319650621 .1850590 .27 \quad 167959.75458231 .37 \quad 119.7592$ $599.222150680 .65 \quad 50650.91 \quad 168161.05626392 .42 \quad 123.4480$ $600.994950734 .20 \quad 30707.42 \quad 168348.65794741 .08 \quad 127.1425$ $602.739850787 .0450760 .62 \quad 168525.25963266 .35130 .0402$ $604.484750840,0150813.52168700 .96131967 .26134 .5416$
4.384578 5.038495 5.693394 6.349180 7.005730 7,662914 8.320754 8.979084 9.637845 10.29696 10.95639 11.61607 12.27595

12.93594

13.59600

14.25610

14.91619

15.57624

16.23620

16.09600

17.55560

18.21498

18.87411

19.53296

$21.9280 ?$

25. 13227

28.32503

31.50443

34.66861

37.81619

40.94608

44.06909

47.16000

50.23070

53.28055

56.30891

59.31554

62.30033

65.26299

68.20326

71.12113

74.0166 .5

76.88969

79.74022

82.56839

B5. 37421

B8. 17922

90.93997

93.67968

96.39544

99.09034

101.7636

104.4154

107.0458

109,6549

112.2 .429 
$\begin{array}{llllll}132.537 & 734,20154200082 & 0.012812 & 0.883452 & 0.001533\end{array}$ $135.857 \quad 733.104543412550 .0128140 .8933150 .001531$ $139.177 \quad 735.99954481176 \quad 0.012816 \quad 0.8931790 .001530$ $142.197 \quad 736,862 \quad 546160950.0128180 .8830490 .001528$ $\begin{array}{llllllll}145.843 & 737.643 & 54738194 & 0.012820 & 0.882930 & 0.001527\end{array}$ $149.163 \quad 738.411548582600 .0128210 .8828140 .001525$ $\begin{array}{lllllll}152.483 & 739.186 & 54979421 & 0.012823 & 0.882696 & 0.001524\end{array}$ $\begin{array}{llllll}155.803 & 739,979 & 55103396 & 0.012825 & 0.882576 & 0.001522\end{array}$ $\begin{array}{llllllll}159.123 & 740.729 & 55222491 & 0.012826 & 0.882463 & 0.001521\end{array}$ $162.443 \quad 741.449533368720 .012828 \quad 0.882354 \quad 0.001520$ $\begin{array}{llllll}165.763 & 742.201 & 55456337 & 0.012829 & 0.882240 & 0.001518\end{array}$ $169.083 \quad 742.9255570560 \quad 0.0128310 .882132 \quad 0.001517$ $\begin{array}{llllll}172.403 & 743.584 & 55676045 & 0.012832 & 0.882031 & 0.001516\end{array}$ $\begin{array}{llllll}179.723 & 744.255 & 55782642 & 0.012834 & 0.881930 & 0.001515\end{array}$

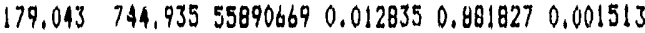
$\begin{array}{lllllll}182.363 & 745.601 & 55996472 & 0.012857 & 0.881726 & 0.001512\end{array}$ $185.683 \quad 746.232560967150 .0128380 .8816310 .001511$ $\begin{array}{llllll}189,003 & 746,825 & 56190921 & 0.012839 & 0,881541 & 0,001510\end{array}$ $192.349 \quad 74 \% .3656275913 \quad 0.012840 \quad 0.8814600 .001509$ $195.669 \quad 747.87456357568 \quad 0.0128420 .881383 \quad 0.001508$

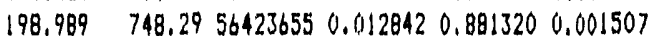
$202.309 \quad 748.72256492284 \quad 0.012843 \quad 0.881255 \quad 0.001507$ $205.629749,148565599600.0128440 .8811900 .001506$ $208.949 \quad 749.57 ! 566271590.0128450 .8811260 .001505$ $212.269 \quad 749.9566794250 .0128460 .8810770 .001504$ $215.589 \quad 750.157567206510 .012846 \quad 0.8810380 .001504$ $218.909 \quad 739.167549764510 .012823 \quad 0.8826990 .001524$ $222.229 \quad 744.7315585826 ! 0.0128350 .8818580 .001514$ $225.549 \quad 747.85156353914 \quad 0.012842 \quad 0.8813860 .001508$ $228.869 \quad 750,01356697410 \quad 0.0128460 .8810590 .001504$ $232.189 \quad 751.701569698520 .012850 \quad 0.8808050 .001501$ $235.509 \quad 753.048571872570 .0128530 .8806020 .001499$ $238.829 \quad 754.177 \quad 573694780.012855 \quad 0.880432 \quad 0.001497$ $242.175 \quad 755.177 \quad 57530877 \quad 0.0128570 .8802810 .001495$ $245.495 \quad 756.08357677105 \quad 0.0128590 .8801440 .001493$ $248.815 \quad 756.86578025130 .0128610 .88002 . " 0.001492$ $\begin{array}{llllllll}252.135 & 757.574 & 57917752 & 0.012862 & 0.879919 & 0.001491\end{array}$ $255.455 \quad 758.296 \quad 580342830.0128640 .879810 \quad 0.001490$ $258.775 \quad 759.001581480690 .0128650 .879704 \quad 0.001488$ $262.095 \quad 759.6158246362 \quad 0.0128670 .879612 \quad 0.001487$
$606.145750890,5550865.28 \quad 168872.76300840,00138.2469$ $607.724550938 .7050914 .63 \quad 169036.96469876 .57 \quad 141.9557$ $609.289350986 .5450962 .62 \quad 169195.96639072 .48 \quad 145.6680$ $610.798251032 .7651009 .65169352 .06808424 .53 \quad 149.3838$ $\$ 12.163751074 .6851053 .72 \quad 170825.76979250 .29 \quad 153.1319$ $613.506451115 .9851095 .33 \quad 169636.57148886 .79 \quad 156.8539$ $614.861451157 .7351136 .05169774 .37318661 .16 \quad 160.5789$ $616.247951200 .5451179 .14169914 .7 \quad 7480575,92164,3070$ $617.579851239,9251220.23 \quad 170051.17658627 .11 \quad 168.0381$ $618.8590 \quad 51277.7651258 .84 \quad 170179.37828806 .48 \quad 171.7720$ $620.195051317 .36 \quad 51297.96 \quad 170307.97999114 .40 \quad 175.5088$ $621.472451355 .2851336 .32 \quad 170436.58169550 .99 \quad 179.2483$ $622.652151390 .3651372 .82 \quad 170557.78340108 .77 \quad 182.9905$ $623.844251425 .8751408 .12 \quad 170674.98510783 .73 \quad 186.7353$ $625.052451461 .9251443 .89 \quad 170793.7 \quad 8681577.47 \quad 190.4827$ $626.2356 \quad 51497,285 \$ 479.60 \quad 170912.2 \quad 8852489.75 \quad 194.2327$ $627.3567 \quad 51530.8351514 .06 \quad 171026.6 \quad 9023516.43 \quad 197.9852$ $628.410251562 .4251546 .63 \quad 171134,89194651.25201 .7401$ $629.360751590 .9551576 .68 \quad 172575.69367226 .25 \quad 205.5266$ $630.273951618 .4051604 .68 \quad 171327.59538554 .39209 .2857$ $631.013051640 .6451629 .92 \quad 171410.09709964 .42 \quad 213.0466$ $631.780551663 .7651652 .20 \quad 171485.39881449 .75216 .8091$ 632.537451686 .5951675 .17171561 .510053011 .3220 .5734 $633.288951709 .2751697 .93 \quad 171637.110224648 .4224 .3393$ $633.873451726 .9351718 .10 \quad 171704.1 \quad 10396352.6 \quad 228.1066$ $634.334451740 .4951733 . \% 1171755.910568108 .5231 .8751$ $614.828251156 .7151448 .60 \quad 170809.310738917 .9235 .6229$ $624.689951451 .1051303 .90 \quad 170328.910909246 .8239 .3601$ 630.233051617 .1751534 .13171093 .311080340 .2243 .1140 $634.074551732 .9851675 .08171561 .2 \quad 11251901.4246 .8783$ $637.121451821 .1551777 .07171899 .811423801 .3250,6499$ $639.592751891,7751856.46 \quad 172163.4 \quad 11595964,8 \quad 254,4274$ $641.590651951 .1451921 .45172379 .2 \quad 11768344.0258 .2096$ $643.395652003 .8551977 .50 \quad 173916.7 \quad 11942260.7 \quad 262.0255$ $645.030952051 .73 \quad 52027.79 \quad 172732.2 \quad 12114993.0265 .8154$ $646.433452092 .8752072 .30 \quad 172880.0 \quad 12287873.1269 .6086$ $647.722252130 .7452111,80173011.212460804 .3 \quad 273.4046$ $649.025452169 .1052149 .92 \quad 173137,7 \quad 12634022.0277,2034$ $650.297952206,6352187.07 \quad 173263.712807285 .6 \quad 281,0050$ $651.3972 \quad 52239.1052222 .86 \quad 173379,912980665.7284,8091$
114,8100

117.3563 119.8820 122.3874 124,8919 127,3566 129,8014 132.2266 134,6323 137.0186 139,3858 141.7342 144,0637 146.3747 148,6673 150,9417 153.1982 155.4368 157.6750 159,8781 162.0636 164.2317 166.3825 168.5163 170.6332 172.7332 174,8014 176.8530 178.8934 180.9238 182.9412 184,9453 186.9357 188.9276 190.8900 192.8384 194.7726 196.6929 198.5993 200.4919 


\section{TABLE L-2}

POST-STIMULATION PRESSURE BUILD-UP DATA ANALYSIS FOR HARDYII DATA ARE CONVERTED TO ADJUSTED PRESSURES AND ADJUSTED EFFECTIVE TIME TO ACCDUNT FOR GAS PROPERTIES SUCH AS VISCOSITY AND COMPRESSIBILITY

\begin{tabular}{|c|c|c|c|c|c|c|c|c|c|c|c|c|c|}
\hline 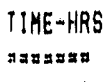 & 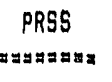 & 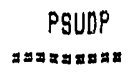 & 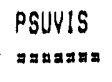 & 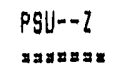 & $\begin{array}{l}\text { PSUCONP } \\
x= \pm x=x=\end{array}$ & $P$-AYG & 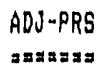 & $\begin{array}{l}A-T 1 M E \\
x=\pi y=\pi=\end{array}$ & $\begin{array}{l}B-\lceil 1 M E \\
\geq \geq x \geq B=Z\end{array}$ & $\begin{array}{l}\text { C-TIHE } \\
\text { มมะมมะม }\end{array}$ & 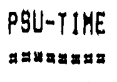 & 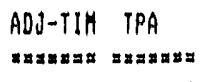 & 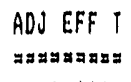 \\
\hline 0 & & & & & & 12.4 .84056014 & & & & 0 & 0 & $0,000 \quad 129,4114$ & 0.000 \\
\hline 1.75 & 115.35 & 11933790 & 0,011961 & 0,981370 & 0,008850 & & 9.318 & 4773,469 & 4886.754 & 8551,786 & 8552 & 0.170 & 0.169 \\
\hline 3.5 & 285.21 & $754 ; 5340$ & 0.011792 & 0.954001 & 0.003675 & & 58,435 & 23070.35 & 11535.17 & 20186.55 & 28738 & 0.570 & 0.568 \\
\hline 5.25 & 379.98 & 13640810 & 0.011972 & 0.938820 & 0.002801 & VIS-AVE & 106.514 & 29810.33 & 14905.16 & 26004,04 & 54822 & 1.080 & 1.079 \\
\hline 7 & 428.33 & 174906750 & 0,012051 & 0.931115 & 0.002505 & 0.0127926 & 136.576 & 33115.82 & $\lfloor 6557 . \therefore !$ & 28976.34 & 83799 & 1,663 & 1.642 \\
\hline 8.75 & 473.23 & 215370710 & 0.012111 & 0.923990 & 0.002284 & & 168.172 & 36138,14 & $18069 \mathrm{~V} 1$ & 31620.07 & 115420 & 2.291 & 2.251 \\
\hline 10.5 & 497.37 & 239013960 & 0,012155 & 0.920174 & 0,002182 & & 186.634 & 37698.55 & 18019,27 & 32986.23 & 148406 & 2.945 & 2.880 \\
\hline 12.25 & 530.28 & 27340856 & 0.012214 & 0.414989 & 0.002057 & $l-A Y B$ & 213.491 & 39788.80 & 19894,40 & 34815.20 & $1832: 1$ & 3.636 & 3.537 \\
\hline 14 & 546.73 & 291573700 & 0.012265 & 0.912405 & 0.002001 & 0.884872364 & 227.675 & 40742.32 & 20371.16 & 35649.57 & 218871 & 4,344 & 4.203 \\
\hline 15,75 & 574.50 & 32355882 & 0.012361 & 0.908057 & 0.001912 & & $252.65 !$ & 42290.71 & 21145.35 & 37004.3. & 255875 & 5.078 & 4.886 \\
\hline 17.5 & 585.69 & 336943020 & 0.012400 & 0.906309 & 0,001879 & COMP-AVE & 263.102 & 42904.12 & 21452.06 & 37541.10 & 293416 & 3.823 & 5.572 \\
\hline 19,25 & 596.89 & 350605600 & 0.012439 & 0.904565 & 0,001847 & 0.001551326 & 273.770 & 43511.59 & 21755.79 & 38072.64 & 331489 & 6.579 & 6.260 \\
\hline 21 & 608.08 & 364548420 & 0.012476 & $0.9028: 3$ & 0,001816 & & 284.657 & 44118.87 & 22059.43 & 38604.01 & 370093 & 7.345 & 6.950 \\
\hline 22.75 & 619.28 & 37877375 & 0.012512 & 0.901084 & 0.001786 & & 295.765 & 44722.88 & 22361.41 & 39132.52 & 409225 & 8.121 & 7.642 \\
\hline 24.5 & 624.88 & 38602014 & 0.017530 & 0.900216 & 0,001772 & PRS-CONST & 301.423 & 45020.39 & 22510.19 & 39392.84 & 448618 & 8,903 & 8.330 \\
\hline 26.25 & 630.48 & 39329398 & 0,012549 & 0.899349 & 0.001758 & 0,0000078085 & 307.103 & 45320.45 & 22660,22 & 396.55 .39 & 488273 & 9.690 & 9.015 \\
\hline 28 & 641.67 & 40811580 & 0.012585 & 0,897617 & 0,001730 & & 318.677 & 45911.16 & 22955.58 & 40172.27 & 528446 & 10.487 & 9.701 \\
\hline 29,75 & 645.03 & 41262829 & 0.612596 & 0.897099 & $0.00: i 22$ & & 322.200 & 46086.47 & 23043.23 & 40125.66 & 568771 & 11.280 & 10.382 \\
\hline 31.5 & 652.87 & $4: 3223830$ & 0,012622 & 0.895889 & $0,00170, i$ & & $330 .: 74$ & & & 40084.54 & 609456 & 12.095 & 11.061 \\
\hline 33.25 & 656.23 & $\$ 27814110$ & 0.01 & 0.895372 & 0,001691 & & 334.058 & 466 & & 40837.17 & 650293 & 12.905 & 11.735 \\
\hline 35 & $66 ! .82$ & 435507290 & 0.012650 & 0.891509 & $0.06168^{\circ}$, & & 340.065 & 4696 & 231 & 41093.78 & 691387 & 13.721 & 12.406 \\
\hline 36.75 & 664.06 & 43861990 & 0.012657 & 0.894165 & 0.001678 & & 342.496 & 470 & .95 & 6.67 & 732584 & 14.538 & 13.070 \\
\hline 38.5 & 666.30 & 441732520 & 0.01 & 0.893820 & 0,001672 & & 344.926 & 472 & 23600.12 & 41300.21 & 773884 & 19.358 & 13.729 \\
\hline 40,25 & 666.30 & 14173252 & 0.012663 & 0.893820 & 0.001672 & & 344.926 & .24 & 23600.12 & 41300.21 & 815184 & 16.178 & 14.380 \\
\hline 12 & 673.02 & 45114310 & 0,012681 & 0.892788 & 0,001657 & & 352.275 & 475 & 23781,42 & 41617.49 & 856802 & 17.004 & 15.029 \\
\hline 43.75 & 675.26 & 45430965 & 0,012686 & 0.092444 & 0.001653 & & 354.747 & 47686.90 & 23843.25 & 41725.69 & 898527 & 17.032 & 15.672 \\
\hline 45.5 & 678.62 & 45905940 & 0,012673 & 0.891928 & 0,001645 & & 358.456 & 47873.39 & 23936.69 & 41889.21 & 910416 & 18.663 & 16.311 \\
\hline 47.25 & 680.86 & 46224709 & 0.012698 & 0.891585 & 0.001640 & & 360.945 & 47997.36 & 23998.68 & 41997.69 & 992414 & 19.496 & 16.944 \\
\hline 19 & 681.98 & 46385780 & 0,012700 & 0.091413 & 0,001638 & & 362.203 & 48050.36 & 24029,18 & 12051.07 & 1024465 & 20.331 & 17.571 \\
\hline 50.75 & 684.22 & 16707947 & 0.012705 & 0.891070 & 0,001633 & & 364.718 & 48180.91 & 24090.15 & 42158.30 & 1066624 & 21.168 & 18.192 \\
\hline 52.5 & 685.34 & 46869027 & 0.012707 & 0.890899 & 0,001631 & & 365,976 & 48242.46 & & 2.15 & 1108836 & 22.005 & 18.807 \\
\hline 54.25 & 693.24 & 48014352 & & 0.889689 & 0.001614 & & 920 & & & 1.90 & 1151428 & 22.051 & 19.421 \\
\hline 56 & 693.24 & 480143552 & & 0.889689 & 0.001614 & & & & & .90 & 1194019 & 23.696 & 20.029 \\
\hline 57.75 & 693.24 & 18014352 & 0.01 & 0.889689 & 0.001614 & & 374 & 486 & 243 & 1.90 & 1236611 & 24.541 & 20.629 \\
\hline 59.5 & 694.37 & 48179853 & 0.01 & 0.889516 & 0,001612 & & 376.212 & 487 & .04 & .83 & 1279257 & 25.387 & 21.224 \\
\hline 61.25 & 696.63 & 48510855 & 0.012731 & 0.889170 & 0.001607 & & 378.796 & 48861.90 & 24430.95 & 42754.16 & 1322011 & 26.236 & 21.814 \\
\hline 63 & 701.16 & 49175728 & 0.012741 & 0,888479 & 0.001598 & & 383.988 & 49109.71 & 24554,85 & 42970.99 & 1364982 & 27.089 & 22.400 \\
\hline 64,75 & 703.42 & 49512342 & 0.012746 & 0.888134 & 0.001593 & & 386.617 & 49231.74 & 24615.87 & 43077.77 & 1408060 & 27.944 & 22.981 \\
\hline 66.5 & 704.55 & 49680619 & 0.012749 & 0.887961 & 0,001591 & & 387.931 & 49293.03 & 24646,51 & 43131.40 & 1451192 & 28.800 & 23.557 \\
\hline 68.25 & 706.81 & 50017264 & 0.012753 & 0.887616 & 0.001586 & & 390.559 & 49416.13 & 24700.06 & 43239.12 & 1494431 & 29.658 & 24.128 \\
\hline 70 & 707.94 & 50185571 & 0.012756 & 0.887443 & 0.001584 & & 391.873 & 49477.96 & 24738.98 & 43293.22 & 1537724 & 30.517 & 24.694 \\
\hline 71.75 & 710.20 & 50522693 & 0,012761 & 0.087098 & 0,001579 & & 394.506 & 49601.81 & 24800.90 & 43401.58 & 1581125 & 31.378 & 25.255 \\
\hline 73.5 & 715.86 & 51378328 & 0.012773 & 0.986238 & 0.001568 & & 401.187 & 49905.67 & 24952.83 & 43667.46 & 1624793 & 32.245 & 25.813 \\
\hline 75.25 & 715.86 & 51378328 & 0.012773 & 0.886238 & 0,001568 & & 401.187 & 49905.67 & 249 & 43667.46 & 1668460 & 33.111 & 26.365 \\
\hline 77 & 718.12 & 51720582 & 0.01 & 0.885893 & 0.001564 & & 403.860 & 5002 & & 43774.89 & 1712235 & 33.980 & 26.913 \\
\hline 78.75 & 719.25 & 51891709 & 0.012780 & 0.08572 .1 & 0.001562 & & 105.196 & 50090.10 & 250 & 43828.83 & 1756064 & 34.850 & 27.456 \\
\hline 80.5 & 719.25 & 51891709 & 0.012780 & 0.885721 & 0.001562 & & 405.196 & 50090.10 & 25045.05 & 43828.83 & 1799893 & 35.720 & .27 .993 \\
\hline 82.25 & 720.38 & 52063790 & 0.012783 & 0.885549 & 0.001559 & & 406.540 & 50151.29 & 25075.64 & 43882.38 & 1843175 & 36.591 & 28.525 \\
\hline 84 & 720.38 & 52063790 & 0.012783 & 0.8855549 & 0,001559 & & 406.540 & 50151.29 & 25075.64 & 43982.38 & 1087658 & 37.461 & 29.052 \\
\hline 85.75 & 720.38 & 52063790 & 0.012783 & 0.885549 & 0.001559 & & 406.540 & 50151.29 & 25075.64 & 43882.38 & 1931540 & 38.332 & 29.573 \\
\hline
\end{tabular}


$67.5 \quad 720.38 \quad 52063790 \quad 0.012783 \quad 0.8855490 .001559$

$\begin{array}{llllllll}89.25 & 721.51 & 52237748 & 0.012785 & 0.885377 & 0.001557\end{array}$

$\begin{array}{lllllllll}91 & 723.77 & 5258.9662 & 0.012790 & 0.885034 & 0.001553\end{array}$

$92.75 \quad 727.17 \quad 53107534 \quad 0.012797 \quad 3.8845190 .001546$

$94.5 \quad 729.43 \quad 534554490,012802 \quad 0.8841750,001542$

$96.25 \quad 731.69 \quad 538076150.012807 \quad 0.8838320 .001538$

$\begin{array}{lllllll}98 & 733.95 & 54161218 & 0.012812 & 0.883489 & 0.001534\end{array}$

$99,75 \quad 733.95 \quad 541612180,0128120.8834890 .001534$

$\begin{array}{llllllll}101.5 & 735.08 & 54338019 & 0.012814 & 0.883318 & 0.001531\end{array}$

$\begin{array}{lllllllll}103.25 & 736.21 & 54514820 & 0.012817 & 0.883147 & 0.001529\end{array}$

$\begin{array}{lllllll}105 & 737.35 & 54691621 & 0.012819 & 0.882975 & 0.001527\end{array}$

$\begin{array}{llllllll}106.75 & 737.35 & 54691621 & 0.012819 & 0.882975 & 0.001527\end{array}$

$108.5 \quad 737.35 \quad 546916210.012819 \quad 0.8829750 .001527$

$\begin{array}{lllllll}110.25 & 737.35 & 54691621 & 0.012819 & 0.082975 & 0.001527\end{array}$

$\begin{array}{llllllll}112 & 737.35 & 54691621 & 0.012819 & 0.882975 & 0.001527\end{array}$

$\begin{array}{lllllll}113.75 & 737.35 & 51691621 & 1.012819 & 0.882975 & 0.001527\end{array}$

$\begin{array}{llllllll}115.5 & 738.48 & 54868423 & 0.012821 & 0.882804 & 0.001525\end{array}$

$\begin{array}{lllllllll}117.25 & 738.48 & 54868423 & 0.012821 & 0.882804 & 0.001525\end{array}$

$\begin{array}{llllllll}119 & 738.48 & 54868423 & 0.01282 ! & 0.882804 & 0.001525\end{array}$

$120.75 \quad 738.48 \quad 54868123 \quad 0.012821 \quad 0.8828040 .001525$

$\begin{array}{llllllll}122.5 & 738.48 & 54868423 & 0.012821 & 0.882804 & 0.001525\end{array}$

$124.25 \quad 738.48 \quad 54868423 \quad 0.0128210 .882804 \quad 0.001525$

$\begin{array}{llllllll}1.26 & 739.61 & 55045224 & 0.012824 & 0.882633 & 0.001523\end{array}$

$\begin{array}{llllllll}127.75 & 739.61 & 55045224 & 0.012824 & 0.882633 & 0.001523\end{array}$

$\begin{array}{llllllll}129.5 & 740.74 & 55223889 & 0.012826 & 0.882462 & 0.001521\end{array}$

$131.25 \quad 740.74 \quad 552238890.012826 \quad 0.882462 \quad 0.001521$

$\begin{array}{lllllll}133 & 740.74 & 55223889 & 0.012826 & 0.882462 & 0.001521\end{array}$

$\begin{array}{llllllll}134.75 & 740.74 & 55223889 & 0.01<626 & 0.882462 & 0.001521\end{array}$

$\begin{array}{llllllll}136.5 & 740.74 & 55223889 & 0.012826 & 0.882462 & 0.001521\end{array}$

$\begin{array}{lllllll}138.25 & 740.74 & 55223889 & 0.012826 & 0.882462 & 0.001521\end{array}$

$140 \quad 740.74 \quad 552238890.012826 \quad 0.882462 \quad 0.001521$

$\begin{array}{lllllll}141.75 & 740.74 & 55223889 & 0.012826 & 0.882462 & 0.001521\end{array}$

$143.5 \quad 741.87 \quad 55403548 \quad 0.012829 \quad 0.8822910 .001519$

$\begin{array}{llllllll}145.25 & 741.87 & 55403548 & 0.012829 & 0.882291 & 0.001519\end{array}$

$\begin{array}{llllllll}147 & 741.87 & 55403548 & 0.012829 & 0.882291 & 0.001519\end{array}$

$\begin{array}{llllllll}148.75 & 741.87 & 55403548 & 0.012829 & 0.882291 & 0.001519\end{array}$

$\begin{array}{lllllll}150.5 & 744.13 & 55762864 & 0.012834 & 0.881949 & 0.001515\end{array}$

$\begin{array}{lllllll}152.25 & 745.26 & 55942523 & 0.012836 & 0.881778 & 0.001513\end{array}$

$\begin{array}{lllllll}154 & 746.39 & 5612218 ! & 0.012838 & 0.881607 & 0.001511\end{array}$

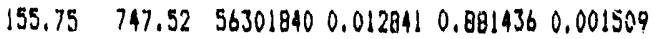

$\begin{array}{llllll}157.5 & 748.65 & 56181498 & 0.012843 & 0.881265 & 0.001507\end{array}$

$159.25 \quad 749.79 \quad 56661156 \quad 0.012846 \quad 0.8810940 .001505$

$161 \quad 753.18 \quad 572081920.0128530 .880582 \quad 0.001499$

$\begin{array}{llllllll}162.75 & 754.31 & 57390718 & 0.012855 & 0.890412 & 0.001497\end{array}$

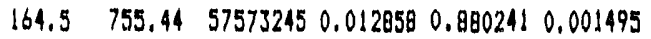

$166.25 \quad 755.44 \quad 57573245 \quad 0.0128580 .0802410 .001493$

$\begin{array}{lllllll}168 & 756.57 & 57755772 & 0.012860 & 0.880071 & 0.001493\end{array}$

$169.75 \quad 756.57 \quad 577557720.0128600 .8800710 .001493$

$\begin{array}{llllllll}171.5 & 757.70 & 57938299 & 0.012863 & 0.879900 & 0.001491\end{array}$

$\begin{array}{llllll}173.25 & 758.83 & 58120826 & 0.012865 & 0.879730 & 0.001489\end{array}$

$\begin{array}{llllll}175 & 758.83 & 58120826 & 0.012865 & 0.879730 & 0.001489\end{array}$

$\begin{array}{lllllll}176.75 & 758.83 & 58120826 & 0.012865 & 0.879730 & 0.001489\end{array}$

$\begin{array}{lllllll}178.5 & 759.96 & 58303352 & 0.012868 & 0.874559 & 0.001487\end{array}$

$\begin{array}{lllllll}180.25 & 759.96 & 58303352 & 0.012868 & 0.879559 & 0.001487\end{array}$

$\begin{array}{lllllll}182 & 759.96 & 58303352 & 0.012868 & 0.879359 & 0.001487\end{array}$

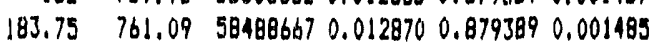

$406.540 \quad 50151.2925075 .64 \quad 43882.38 \quad 1975423 \quad 39.203$ $407.89850211 .3925105 .69 \quad 43934.96 \quad 2019357 \quad 40.075$ $410.615 \quad 50332.10 \quad 25166.05 \quad 14040.59 \quad 2063398 \quad 40.949$

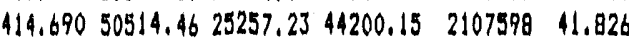

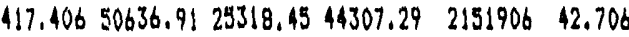

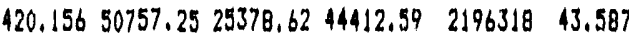
$422.91750877 .3125438 .65 \quad 44517.65 \quad 2240836 \quad 44.470$ $\begin{array}{llllll}422.917 & 50877.31 & 25438.65 & 44517.65 & 2285353 & 45.354\end{array}$ $\begin{array}{llllll}424.298 & 50937.60 & 25468.80 & 44570.40 & 2329924 & 46.238\end{array}$

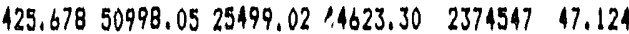
$427.05951058 .0825529,34: 14676.34 \quad 2419223 \quad 48.011$ $427.05951058 .6825529 .34 \quad 44676.34 \quad 2463900 \quad 48.697$ $427.05951058 .68 \quad 25529.34 \quad 44676.34 \quad 2508576 \quad 49.784$ $427.05951058 .6825529 .34 \quad 44676.34 \quad 2593253 \quad 50.671$ $427.05951058 .6825529 .3444676 .34 \quad 2597929 \quad 51.557$ $427.05951058 .68 \quad 25529.34 \quad 44676.34 \quad 2642605 \quad 52.444$ $128.43951119 .48 \quad 25559.7444729 .54 \quad 2687335 \quad 53.331$ $428.43951119 .48 \quad 25559.74 \quad 44729.54 \quad 2732064 \quad 54.219$ $420.43951119 .1825559 .7444729 .54 \quad 2776794 \quad 55.107$ $428.139 \quad 51119.48 \quad 25559.74 \quad 44729.54 \quad 2821523 \quad 55.995$ $428.43951119 .48 \quad 25559,7444729.54 \quad 2866253 \quad 56.882$ $428.43951119 .4825559 .74 \quad 44729.54 \quad 2910982 \quad 57.770$ $429.82051180 .4425590 .22 \quad 44782.892955765 \quad 58.659$ $429.820 \quad 51180.44 \quad 25390.22 \quad 44782.89 \quad 3000548 \quad 59.547$ $431.215 \quad 51240.3825620 .1944835 .34 \quad 3045384 \quad 60.437$ $431.21551240 .38 \quad 25620.1944835 .34 \quad 3090219 \quad 61.327$ $431.21551240 .3825620 .1944835 .34 \quad 3135054 \quad 62.217$ $431.21551240 .3825620 .1944835 .34 \quad 3179890 \quad 63.106$ $431.21551240 .38 \quad 25620.1944835 .34 \quad 3224729 \quad 63.996$ $431.21551240 .3825620 .1944835 .34 \quad 3269560 \quad 64.686$ $431.21551240 .38 \quad 25620.1944839 .34 \quad 3314396 \quad 65.776$ $431.215 \quad 51240.3825620 .1944835 .34 \quad 335923166.666$ $432.618 \quad 51299.85 \quad 25649.92 \quad 14887.37 \quad 3404118 \quad 67.956$ $432.618 \quad 51299.85 \quad 25644.92 \quad 14887.37 \quad 3449006 \quad 68.447$ $432.61851299 .85 \quad 25649.9244887 .37 \quad 3493893 \quad 69.338$ $432.61851299 .85 \quad 25649.92 \quad 44887.37 \quad 3538781 \quad 70.229$ $\begin{array}{llllll}435.424 & 51419.28 & 25709.64 & 44991.87 & 3583772 & 71.122\end{array}$ $431.627 \quad 51479.2425739 .62 \quad 45044.33 \quad 3628817 \quad 72.016$ $458.22951539 .37 \quad 25769.68 \quad 45096.95 \quad 3673914 \quad 72.911$ $\begin{array}{lllllll}439.632 & 51599.66 & 25799.83 & 45149.70 & 3719063 & 73.807\end{array}$ $441.03551660 .13 \quad 25830.06 \quad 45202.61 \quad 3764266 \quad 74.704$ $442.43851720 .7625860 .3845255 .66 \quad 3809522 \quad 75.602$ 446.709 51898.58 25949.2945411.26 $3854933 \quad 76.503$ $448.13551958 .07 \quad 25979.03 \quad 43463.31 \quad 3900396 \quad 77.405$ $\begin{array}{llllll}149.560 & 52017.71 & 26008.85 & 45515.50 & 3945912 & 78.309\end{array}$ $\begin{array}{llllll}449.560 & 52017.71 & 26008.85 & 45515.50 & 3991427 & 79.212\end{array}$ $450.98552077 .52 \quad 26038.7645567 .03 \quad 4036995 \quad 80.116$ $\begin{array}{lllllll}450.985 & 52077.52 & 26038.76 & 45567.83 & 4082563 & 01.020\end{array}$ $452.41152137 .5026068 .75 \quad 45620.31 \quad 4128183 \quad 81.926$ 453.836 $52197.6426098 .82 \quad 45672.93 \quad 4173856 \quad 02.832$ $\begin{array}{lllllll}453.836 & 52197.64 & 26098.82 & 45672.93 & 4219529 & 03.739\end{array}$ $453.836 \quad 52197.6426098 .82 \quad 45672.93 \quad 4265203 \quad 84.645$ 459.261 $52257.94 \quad 26128.97 \quad 45725.70 \quad 4310928 \quad 05.552$ $455.26152257 .9426128 .97 \quad 45725.70 \quad 4356653 \quad 86.460$ 455.26! $52257.94 \quad 26128.97 \quad 45725.70 \quad 4402379 \quad 87.367$ $456.70852316 .7026158 .35 \quad 45777.11 \quad 4448156 \quad 88.276$
30.080

30.399

31.106

31.610

32.110

32.605

33.097

33.584

34.067

34.545

35.019

35.488

35.953

36.413

36.869

37.320

37.767

38.210

38.649

39.084

39.514

39.940

40.363

40.782

41.197

41.609

42.017

42.420

42.821

43.217

43.610

43.999

44.386

14.769

45.148

45.524

45.897

46.268

46.636

47.001

47.363

47.722

48.080

48.455

48. $78 \%$

49.136

49,482

49.826

50.167

50.505

50.841

51.174

51.504

$51.03 !$

52.156

52.479 


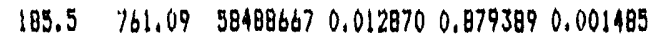

$187.25 \quad 761.09 \quad 584886670.012870 \quad 0.8793890 .001485$

$\begin{array}{llllll}189 & 758.83 & 58120826 & 0.012865 & 0.879730 & 0.001489\end{array}$

$\begin{array}{lllllll}190.75 & 758.03 & 58120826 & 0.012865 & 0.879730 & 0.001489\end{array}$

$\begin{array}{lllllll}192.5 & 758.83 & 58120826 & 0.012865 & 0.879730 & 0.001489\end{array}$

$194.25 \quad 759.96 \quad 58303352 \quad 0.012868 \quad 0.8795590 .001487$

$\begin{array}{lllllll}196 & 761.09 & 58488667 & 0.012870 & 0.879389 & 0.001485\end{array}$

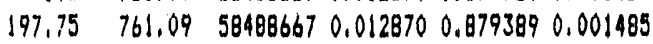

$\begin{array}{lllllll}199,5 & 761.09 & 584886667 & 0.012870 & 0.879389 & 0.001485\end{array}$

$201.25 \quad 761.09 \quad 58488667 \quad 0.0128700 .8793890 .001485$

$\begin{array}{lllllll}203 & 761.09 & 58488667 & 0.012870 & 0.879389 & 0.001485\end{array}$

$204.75 \quad 761.09 \quad 58488667 \quad 0.012870 \quad 0.8793890 .001485$

$\begin{array}{lllllll}206.5 & 761.09 & 58488667 & 0.012870 & 0.879389 & 0.001485\end{array}$

$\begin{array}{lllllll}208.25 & 762.22 & 58674075 & 0.012872 & 0.679219 & 0.001483\end{array}$

$\begin{array}{lllllll}210 & 762.22 & 58674075 & 0.012872 & 0.879219 & 0.001483\end{array}$

$211.75 \quad 761.09 \quad 58488667 \quad 0.012870 \quad 0.8793890 .001485$

$\begin{array}{lllllll}213.5 & 761.09 & 58188667 & 0.012870 & 0.879389 & 0.001485\end{array}$

$215.25 \quad 761.09 \quad 584886670.012870 \uparrow .0793890 .001485$

$\begin{array}{lllllll}217 & 761.09 & 58488667 & 0.012870 & 0.879389 & 0.001485\end{array}$

$218.75 \quad 761.09 \quad 58488667 \quad 0.012870 \quad 0.8793890 .001485$

$\begin{array}{lllllll}220.5 & 761.09 & 58488667 & 0.012870 & 0.879389 & 0.001485\end{array}$

$\begin{array}{lllllll}222.25 & 761.09 & 58488667 & 0.012870 & 0.879389 & 0.001485\end{array}$

$\begin{array}{llllllll}224 & 761.09 & 58488667 & 0.012870 & 0.879389 & 0.001485\end{array}$

$225.75 \quad 762.22 \quad 586740750.0128720 .8792190 .001483$

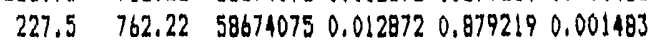

$229.25 \quad 762.22 \quad 58674075 \quad 0.012872 \quad 0.0792190 .001483$

$\begin{array}{lllllll}231 & 762.22 & 58674075 & 0.012872 & 0.879219 & 0.001483\end{array}$

$\begin{array}{llllll}232.75 & 762.22 & 58674075 & 0.012872 & 0.879219 & 0.001483\end{array}$

$\begin{array}{lllllll}234.5 & 763.36 & 58859483 & 0.012875 & 0.879049 & 0.001481\end{array}$

$236.25 \quad 763.36 \quad 58859483 \quad 0.0128750 .8790490 .001481$

$\begin{array}{llllllll}238 & 763.36 & 58859483 & 0.012875 & 0.879049 & 0.001481\end{array}$

$239.75 \quad 763.36 \quad 58859403 \quad 0.0128750 .8790490 .001481$

$241.5 \quad 763.36 \quad 58859483 \quad 0.012875 \quad 0.8790490 .001481$

$\begin{array}{lllllll}243.25 & 763.36 & 58859483 & 0.012875 & 0.879049 & 0.001481\end{array}$

$\begin{array}{lllllll}245 & 763.36 & 58859483 & 0.012875 & 0.079049 & 0.00148 !\end{array}$

$\begin{array}{llllllll}246.75 & 763.36 & 58859183 & 0.012875 & 0.079049 & 0.001481\end{array}$

$\begin{array}{lllllll}248.5 & 763.36 & 58859483 & 0.012875 & 0.879049 & 0.001481\end{array}$

$250.25 \quad 763.36 \quad 58859483 \quad 0.012875 \quad 0.8790490 .001481$

$\begin{array}{lllllll}252 & 763.36 & 58859483 & 0.012875 & 0.879049 & 0.001481\end{array}$

$\begin{array}{llllll}253.75 & 763.36 & 58859483 & 0.012875 & 0.879049 & 0.001481\end{array}$

$\begin{array}{llllllll}255.5 & 764.49 & 59044892 & 0.012877 & 0.078879 & 0.001479\end{array}$

$\begin{array}{lllllll}257.25 & 764.49 & 59044892 & 0.012877 & 0.878879 & 0.001479\end{array}$

$\begin{array}{lllllllll}259 & 764.49 & 59044892 & 0.012877 & 0.878879 & 0.001479\end{array}$

$260.75 \quad 765.62 \quad 59230300 \quad 0.0128800 .8787090 .001477$

$\begin{array}{llllllll}262.5 & 766.75 & 59415708 & 0.012882 & 0.878538 & 0.001475\end{array}$

$\begin{array}{lllllll}264.25 & 766.75 & 59415708 & 0.012882 & 0.878538 & 0.001475\end{array}$

$\begin{array}{llllllll}266 & 766.75 & 59415708 & 0.012882 & 0.878538 & 0.001475\end{array}$

$\begin{array}{lllllll}267.75 & 766.75 & 59415708 & 0.012882 & 0.878538 & 0.001475\end{array}$

$269.5 \quad 76 \% .88 \quad 59601117 \quad 0.0128850 .8783680 .001473$

$\begin{array}{llllllll}271.25 & 767.88 & 59601117 & 0.012885 & 0.878368 & 0.001473\end{array}$

$\begin{array}{llllllllll}273 & 769.01 & 59786525 & 0.012887 & 0.878198 & 0.001471\end{array}$

$274.75 \quad 769.01 \quad 59786525 \quad 0.0128870 .8781980 .001471$

$276.5 \quad 770.14 \quad 599722940.0128890 .8780280 .001469$

$278.25 \quad 770.14 \quad 599722940.0128890 .8780280 .001469$

$\begin{array}{lllllll}280 & 770.14 & 59972294 & 0.012889 & 0.878028 & 0.001469\end{array}$

$281.75 \quad 770.14 \quad 59972294 \quad 0.0128890 .8780280 .001469$
$456.700 \quad 52316.70 \quad 26158.35 \quad 45777.11 \quad 1493933 \quad 89.184$ 456.708 $52316.7026158 .35 \quad 45777.11 \quad 4539711 \quad 40.093$ $\begin{array}{llllll}453.836 & 52197.64 & 26098.82 & 45672.93 & 4585383 & 90.999\end{array}$ $\begin{array}{llllll}453.836 & 52197.64 & 26098.82 & 45672.93 & 4631056 & 91.906\end{array}$ $\begin{array}{lllllll}453.836 & 52197.64 & 26099.82 & 45672.93 & 4676729 & 92.812\end{array}$

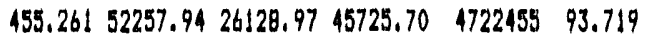

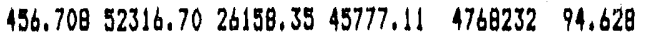

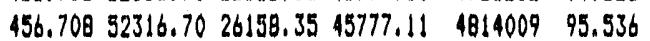
$\begin{array}{lllllll}456.708 & 52316.70 & 26158.35 & 45777.11 & 4859786 & 96.445\end{array}$ $\begin{array}{lllllll}456.708 & 52316.70 & 26158.35 & 45777.11 & 4905563 & 97.353\end{array}$ $\begin{array}{llllllll}456.708 & 52316.70 & 26158.35 & 45777.11 & 495134 ! & 98.262\end{array}$ $\begin{array}{llllll}456.708 & 52316.70 & 26158.35 & 15777.11 & 4997118 & 99.170\end{array}$ $456.708 \quad 52316.70 \quad 26158.35 \quad 45777.11 \quad 5042895100.079$ $458.156 \quad 52375.56 \quad 26187.78 \quad 45928.61 \quad 5088723 \quad 100.980$ $458.156 \quad 52375.56 \quad 26187.78 \quad 45828.6 ! \quad 5134552 \quad 101.898$ $456.708 \quad 52316.7026158 .35 \quad 45777.11 \quad 5180329 \quad 102.806$ $\begin{array}{llllll}456.708 & 52316.70 & 26158.35 & 45777.11 & 9226106 & 103.715\end{array}$ 156.70日 $52316.7026158 .35 \quad 45777.11 \quad 5271883 \quad 104.623$ $\begin{array}{llllllll}456.708 & 52316.70 & 26158.35 & 45777.11 & 531766 ! & 105.532\end{array}$ $456.70052316 .7026158 .3555777 .11 \quad 5363438 \quad 106.440$ $456.708 \quad 52316.70 \quad 26158.35 \quad 45777.11 \quad 5409215 \quad 107.349$ $\begin{array}{llllllll}456.708 & 52316.70 & 26158.35 & 45777.11 & 5454992 & 108.257\end{array}$

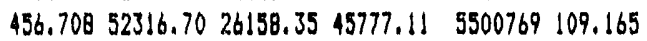
$458.156 \quad 52375.56 \quad 26187.78 \quad 45828.61 \quad 5546598 \quad 110.075$ $458.156 \quad 52375.56 \quad 26187.78 \quad 45828.61 \quad 5592426 \quad 110.984$ $458.156 \quad 52375.56 \quad 26187.78 \quad 45828.61 \quad 5638255 \quad 111.894$ $458.156 \quad 32375.5626187 .78 \quad 45828.61 \quad 5684083 \quad 112.803$ $458.156 \quad 52375.56 \quad 26187.78 \quad 45828.61 \quad 5729912 \quad 113.713$ $459.60452434 .57 \quad 26217.28 \quad 45880.25 \quad 5775792 \quad 114.623$ $459.604 \quad 52434.57 \quad 26217.28 \quad 45880.25 \quad 5821673 \quad 115.534$ $459.604 \quad 52434.57 \quad 26217.28 \quad 45880.25 \quad 5867553 \quad 116.444$ $459.604 \quad 52434.57 \quad 26217.28 \quad 45880.25 \quad 5913433 \quad 117.355$ $459.604 \quad 52434.5726217 .28 \quad 45880.25 \quad 5959313 \quad 110.266$ $459.604 \quad 52434.57 \quad 26217.28 \quad 45880.25 \quad 6005194 \quad 119.176$ $459.604 \quad 52434.57 \quad 26217.28 \quad 458890.25 \quad 6051074 \quad 120.087$ $459.604 \quad 52434.57 \quad 26217.28 \quad 45880.25 \quad 6096954 \quad 120.997$ $459.604 \quad 52434.57 \quad 26217.38 \quad 45880.25 \quad 6142834 \quad 121.908$ $459.604 \quad 52434.57 \quad 26217.28 \quad 45880.25 \quad 6188715 \quad 122.018$ $459.604 \quad 52434.57 \quad 26217.28 \quad 45880.25 \quad 6234595 \quad 123.729$ $459.604 \quad 52434.57 \quad 26217.28 \quad 45880.25 \quad 6280475 \quad 124.639$ $161.05 ! 52493.75 \quad 26246.87 \quad 45932.03 \quad 6326407 \quad 125.55 !$ $461.05152493 .75262 .46 .87 \quad 45932.03 \quad 6372339 \quad 126.462$ $461.05152493 .75 \quad 26246.87 \quad 45932.03 \quad 641827 ! \quad 127.374$ $462.49952553 .08 \quad 26276.54 \quad 45983.95 \quad 6464255 \quad 128.286$ $463.94752612 .58 \quad 26306.29 \quad 46036.01 \quad 6510291 \quad 129.200$ $463.947 \quad 52612.58 \quad 26306.29 \quad 46036.01 \quad 6556327 \quad 130.114$ $463.947 \quad 52612.58 \quad 26306.2946036 .01 \quad 6602363 \quad 131.027$ $463.94752612 .58 \quad 26306.2946036 .01 \quad 6648399 \quad 131.941$ $465.39552672 .2426336 .12 \quad 46088.21 \quad 6694487 \quad 132.855$ $465.395 \quad 52672.24 \quad 26336.12 \quad 46088.21 \quad 6740576 \quad 133.770$ $466.94252732 .0526366 .02 \quad 46140.55 \quad 6786716 \quad 134.686$ $466.042 \quad 52732.0526366 .02 \quad 46140.55 \quad 6832857 \quad 135.601$ $468.293 \quad 52791.82 \quad 26395.9146192 .84 \quad 6879050 \quad 136.518$ 468.293 52791.82 26395.91 46192.84 $6925242 \quad 137.435$

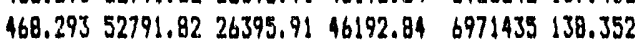
$468.29352791 .82 \quad 26395.9146192 .84 \quad 7017628139.268$
52.798

53.115

53.429

53.740

54.049

54.359

54.660

54.962

$55.26 !$

55.558

55.853

56.145

56.435

56.723

57.009

57.292

57.573

57.852

58.129

58.404

58.676

58.946

59.215

$59.48 !$

59.746

60.008

60.269

60.528

60.785

61.040

61.293

61.544

61.791

62.042

62.287

62.531

62.774

63.014

63.253

63.490

63.726

63.960

64.192

64.423

61.653

64.881

65.107

65.332

65.555

65.777

65.998

66.217

66.135

66.651

66.866

67.080 
$\begin{array}{lllllll}283.5 & 711.27 & 60160593 & 0.012892 & 0.877858 & 0.001467\end{array}$

$\begin{array}{llllllll}285.25 & 771.27 & 60160593 & 0.012892 & 0.877858 & 0.001467\end{array}$

$\begin{array}{llllllll}287 & 771.27 & 60160593 & 0.012892 & 0.877858 & 0.001467\end{array}$

$\begin{array}{llllllll}288.75 & 771.27 & 60160593 & 0.012892 & 0.877858 & 0.001467\end{array}$

$\begin{array}{llllllll}290.5 & 772.40 & 60348891 & 0.012894 & 0.877689 & 0.001465\end{array}$

$292.25 \quad 772.40 \quad 60348891 \quad 0.012894 \quad 0.8776890 .001465$

$\begin{array}{llllllll}294 & 772.40 & 60348891 & 0.012894 & 0.877689 & 0.001465\end{array}$

$\begin{array}{lllllllll}295.75 & 772.40 & 60318891 & 0.012894 & 0.877689 & 0.001465\end{array}$

$\begin{array}{llllllll}297.5 & 772.40 & 60348891 & 0.012894 & 0.877689 & 0.001465\end{array}$

$\begin{array}{lllllllll}299.25 & 772.40 & 60348891 & 0.012894 & 0.877689 & 0.001465\end{array}$

$\begin{array}{llllllll}301 & 772.40 & 60348891 & 0.012894 & 0.877689 & 0.001465\end{array}$

$\begin{array}{lllllllll}302.75 & 772.40 & 60348891 & 0.012894 & 0.877689 & 0.001465\end{array}$

$\begin{array}{lllllll}304.5 & 772.40 & 60348891 & 0.012894 & 0.877689 & 0.001465\end{array}$

$306.25 \quad 772.40 \quad 603488910.012894 \quad 0.8796890 .001465$

$\begin{array}{lllllllll}308 & 772.40 & 60348891 & 0.012894 & 0.877689 & 0.001465\end{array}$

$\begin{array}{llllllll}309.75 & 772.10 & 60348891 & 0.012894 & 0.877689 & 0.001465\end{array}$

$\begin{array}{lllllll}311.5 & 772.40 & 60348891 & 0.012894 & 0.877689 & 0.001465\end{array}$

$313.25 \quad 772.40 \quad 603488910.012894 \quad 0.8776890 .001465$

$\begin{array}{llllllll}315 & 772.40 & 60348891 & 0.012894 & 0.877689 & 0.001465\end{array}$

$\begin{array}{llllllll}316.75 & 772.40 & 60348891 & 0.012894 & 0.877689 & 0.001465\end{array}$

$\begin{array}{lllllllll}3 i 8.5 & 772.40 & 60348891 & 0.012894 & 0.877689 & 0.001465\end{array}$

$\begin{array}{llllllll}320.25 & 772.40 & 60348891 & 0.012894 & 0.877689 & 0.001465\end{array}$

$\begin{array}{llllllll}322 & 772.40 & 60348891 & 0.012894 & 0.877689 & 0.001465\end{array}$

$\begin{array}{lllllllll}323.75 & 772.40 & 6034889 ! & 0.012894 & 0.877689 & 0.001465\end{array}$

$\begin{array}{lllllllll}325.5 & 772.40 & 60348891 & 0.012894 & 0.877689 & 0.001465\end{array}$

$\begin{array}{llllllll}327.25 & 772.40 & 60348891 & 0.012894 & 0.877689 & 0.001465\end{array}$

$\begin{array}{llllllll}329 & 772.40 & 60348891 & 0.012894 & 0.877689 & 0.001465\end{array}$

$\begin{array}{lllllllll}330.75 & 772.40 & 60348891 & 0.012894 & 0.877689 & 0.001465\end{array}$

$\begin{array}{llllllll}332.5 & 772.40 & 60348891 & 0.012894 & 0.877689 & 0.001465\end{array}$
$469.763 \quad 52850.23 \quad 26425.1146243 .95 \quad 7063872 \quad 140.186$ $469.76352850 .2326425 .1146243 .95 \quad 7110116 \quad 141.104$ $469.763 \quad 52850.23 \quad 26425.1146243 .95 \quad 7156360 \quad 142.021$ $469.76352850 .2326425 .1146243 .95 \quad 7202604 \quad 143.939$ $471.23452908 .7926454 .3946295 .19 \quad 7246899 \quad 143.858$ $\begin{array}{llllll}471.234 & 52908.79 & 26454.39 & 46295.19 & 7295194 & 144.777\end{array}$ $471.23452908 .7926454 .3946295 .19 \quad 7341490 \quad 145.695$ $471.23452908 .7926454 .3946295 .19 \quad 7387785 \quad 146.614$ $471.23452908 .79 \quad 26454.3946295 .19 \quad 7434080 \quad 147.533$

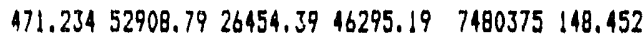
$\begin{array}{lllllll}471.234 & 52908.79 & 26454.39 & 46295.19 & 7526670 & 149.370\end{array}$ $\begin{array}{lllllll}471.234 & 52908.79 & 26454.39 & 46295.19 & 7572966 & 150.289\end{array}$ $471.23452908 .7926454 .3946295 .19 \quad 761926 ! 151.208$

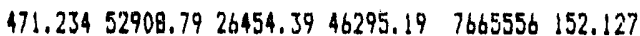
$471.23452908 .7926454 .3946295 .19 \quad 7711851 \quad 153.045$ $471.23452908 .79 \quad 26454.39 \quad 462.95 .19 \quad 7758146 \quad 153.964$ $\begin{array}{lllllll}471.234 & 52908.79 & 26454.39 & 46295.19 & 7804442 & 154.883\end{array}$ $471.23452908 .7926454 .3946295 .19 \quad 7850737 \quad 155.802$ $471.234 \quad 52908.7926454 .3946295 .19 \quad 7897032 \quad 156.720$ $471.23452408 .7926454 .3946295 .19 \quad 7943327 \quad 157.639$ $471.23452908 .79 \quad 26454.3946295 .19 \quad 7989622 \quad 158.558$ $\begin{array}{lllllll}471.234 & 52908.79 & 26454.39 & 16295.19 & 8035918 & 159.477\end{array}$ $471.23452908 .7926454 .3946295 .19 \quad 8082213 \quad 160.395$ $471.23452908 .79 \quad 26454.39 \quad 46295.19 \quad 8128508 \quad 161.314$ $471.23452908 .7926454 .3946295 .19 \quad 8174803 \quad 162.233$ $471.23452908 .79 \quad 26454.3946295 .19 \quad 8221098 \quad 163.152$ $471.23452908 .79 \quad 26454.39 \quad 46295.19 \quad 8267393 \quad 164.070$ $471.23452908 .7926454 .39 \quad 46295.19 \quad 8313689 \quad 164.989$ $471.23452908 .7926454 .3946295 .19 \quad 8359984 \quad 165.908$
67.292

67.502

67.712

67.920

68.126

68.332

68.536

68.738

68.940

69.140

69.338

69.536

69.732

69.926

70.120

70.312

70.503

70.693

70.881

71.069

71.255

71.440

71.624

71.806

71.788

72.168

72.347

72.525

72.702 
TWO RATE TEST ANALYSIS FOR HAROY II DURING PYODUCTION

$\begin{aligned} t !,(h p)=144 \quad & q !=6 ! \\ q 2 & =100\end{aligned}$

ADJUSTED ADJUSYED ACTUAL PRESSURE EFF-TIME TIME

$A$ A $C$

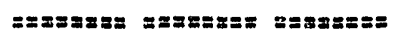

$444.9944 \quad 0 \quad 0$

$429.0316 \quad 2.276799 \quad 1.742$

$421.20094 .520595 \quad 3.484$

$421.20096 .746407 \quad 5.226$

$421.20098 .961824 \quad 6.968$

$421.200911 .16692 \quad 8.71$

$421.2009 \quad 13.36176 \quad 10.452$

$421.2009 \quad 15.54643 \quad 12.194$

$421.2009 \quad 17.72099 \quad 13.936$

$421.2009 \quad 19.88551 \quad 15.678$

$421.200922 .04006 \quad 17.42$

$413.3701 \quad 24.17766 \quad 19.162$

$405.6896 \quad 26.29125 \quad 20.904$

$401.081328 .38385 \quad 22.646$

$405.6896 \quad 30.46705 \quad 24.388$

$390.478432 .53094 \quad 26.13$

$390.4784 \quad 34.57154 \quad 27.872$

$394.996836 .60739 \quad 29.614$

$101.081338 .64408 \quad 31.356$

$405.6896 \quad 40.68148 \quad 33.098$

$405.6896 \quad 12.71396 \quad 34.84$

$408.7618 \quad 44.74018 \quad 36.582$

$408.761846 .76017 \quad 38.324$

$413.370148 .77535 \quad 40.066$

$425.899350 .79644 \quad 41.808$

$413.370152 .80853 \quad 43.55$

$398.009154 .78766 \quad 45.292$

$390.478456 .73794 \quad 47.034$

$382.9476 \quad 58.66635 \quad 48.776$

$375.5678 \quad 60.57282 \quad 50.518$

$375.567862 .46418 \quad 52.26$

$382.9476 \quad 64.35456 \quad 54.002$

$390.478466 .25046 \quad 55.744$

$398.009168 .15147 \quad 57.486$

$402.617470 .05482 \quad 59.228$

$402.617471 .95386 \quad 60.97$

$405.6896 \quad 73.84734 \quad 62.712$

$405.689675 .73527 \quad 64.454$

$105.689677 .61514 \quad 66.196$

$394.996879 .47808 \quad 67.938$

$390.478481 .32043 \quad 69.68$

$\begin{array}{llll}382.9476 & 83.1449 & 71.422\end{array}$

$371.139984 .94488 \quad 73.164$

$365.298286 .72143 \quad 74.906$

$363.8533 \quad 88.4839 \quad 76.648$

$372.615990 .24594 \quad 78.39$ 


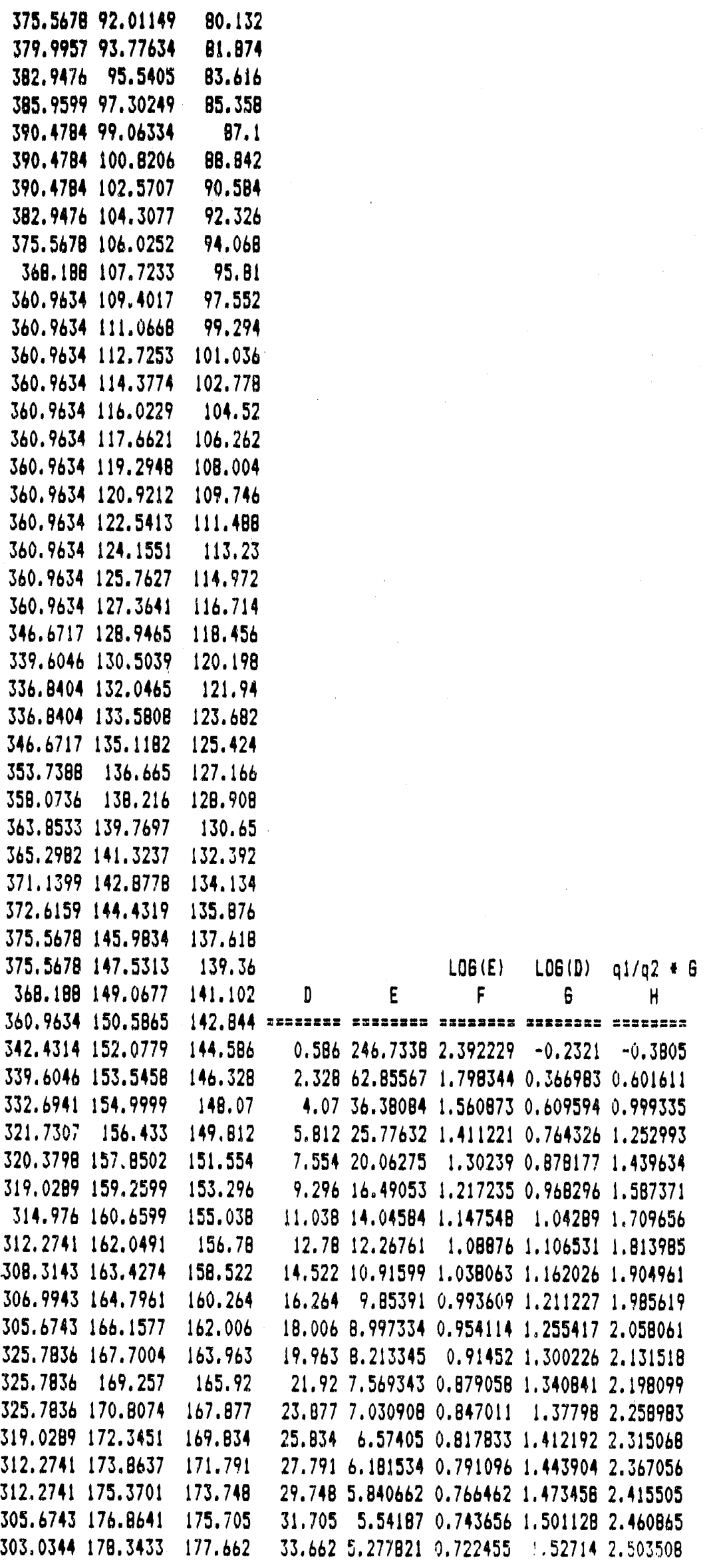


$299.0746 \quad 179.8104$

$299.0746 \quad 181.2683$

$295.2072 \quad 182.7167$

$299.0746 \quad 184.1597$

$299.0746 \quad 185.6013$

299.0746187 .0375

$299.0746 \quad 188.4683$

$299.0746 \quad 189.8938$

$299.0746 \quad 191.314$

$299.0746 \quad 192.7289$

$395.2072 \quad 194.1349$

$292.6289 \quad 195.5293$

292.6289196 .9162

286.1833198 .2919

286.1833199 .6564

286.1833201 .0161

282.4085202 .3671

$279.8919 \quad 203.707$

279.8919205 .0396

279.8919206 .3675

279.8919207 .6907

277.3753209 .0068

276.117210 .3146

276.117211 .6166

274.8587212 .9129

273.6004214 .2022

$273.6004 \quad 215.486$

273.6004216 .7652

273.6004218 .0401

273.6004219 .3106

273.6004220 .5767

273.6004221 .8385

273.6004223 .0959

$273.6004 \quad 224.349$

273.6004225 .5979

272.373226 .8413

$271.1456 \quad 228.078$

267.4635229 .3058

265.0088230 .5236

261.3267231 .7315

$261.3267 \quad 232.932$

$258.9335 \quad 234.126$

255.3438235 .3103

255.3438236 .4872

252.9507237 .6579

261.3267238 .8306

267.4635240 .0138

267.4635241 .1977

267.4635242 .3783

267.4635243 .5549

267.4635244 .7276

$261.3267 \quad 245.891$

261.3267247 .0449

249.361248 .1839

$255.3438 \quad 249.3136$

255.3438250 .4451
179.619

181.576

183.533

185.49

187.447

189.404

191.361

193.318

195.275

197.232

199.189

201.146

203.103

205.06

207.017

208.974

$210.93 !$

212.888

214.845

216.802

218.759

220.716

222.673

224.63

226.587

228.544

230.501

232.458

234.415

236.372

238.329

240.286

242.243

244.2

246.157

248.114

250.071

252.028

253.985

255.942

257.899

259.856

261.813

263.77

265.727

267.684

269.641

271.598

273.555

275.512

277.469

279.426

281.383

283.34

285.297

287.254
$35.6195 .042786 \quad 0.702671 \quad 1.551682 \quad 2.543741$

$37.5764 .832233 \quad 0.684148 \quad 1.574911 \quad 2.581821$

$\begin{array}{lllll}39.533 & 4.642526 & 0.666754 & 1.59696 & 2.617967\end{array}$

41.494 .4707160 .6503771 .6179132 .652366

$\begin{array}{llllll}43.447 & 4.314383 & 0.634919 & 1.63796 & 2.68518\end{array}$

$45.4044 .1715270 .620295 \quad 1.6570942 .716548$

$47.361 \quad 4.0404760 .606433 \quad 1.6754212 .746592$.

$49.3183 .9198260 .593267 \quad 1.6930052 .775419$

$51.2753 .8083860 .580741 \quad 1.709906 \quad 2.803124$

$53.232 \quad 3.705140 .5688051 .7261732 .829791$

$55.1893 .609216 \quad 0.5574131 .7418532 .855496$

$57.146 \quad 3.5198610 .546526 \quad 1.756986 \quad 2.880305$

$59.103 \quad 3.4364250 .536107 \quad 1.77161 \quad 2.904278$

$\begin{array}{llllll}61.06 & 3.358336 & 0.526124 & 1.785757 & 2.92747\end{array}$

$63.0173 .2850980 .516548 \quad 1.7994582 .949931$

$64.9743 .2162710 .507353 \quad 1.812742 .971704$

$66.9313 .1514690 .498513 \quad 1.825627 \quad 2.992832$

$\begin{array}{llllll}68.888 & 3.09035 & 0.490008 & 1.838144 & 3.01335\end{array}$

$70.8453 .032606 \quad 0.481816 \quad 1.8503093 .033294$

$\begin{array}{lllll}72.802 & 2.977968 & 0.47392 & 1.862143 & 3.052694\end{array}$

$74.7592 .9261890 .466302 \quad 1.8736633 .071579$

76.7162 .8770530 .4589481 .8848863 .089977

78.6732 .8303610 .4518421 .8958263 .107911

80.632 .7859360 .4449711 .9064973 .125404

82.5872 .7436160 .4383231 .9169123 .142478

$84.5442 .7032550 .431887 \quad 1.927083 \quad 3.159152$

86.5012 .6647210 .4256521 .9370213 .175444

$88.4582 .6279910 .419607 \quad 1.9467373 .191372$

$\begin{array}{lllll}90.415 & 2.592656 & 0.413745 & 1.95624 & 3.206952\end{array}$

$92.372 \quad 2.558914 \quad 0.408056 \quad 1.965543 .222197$

94.3292 .5265720 .4025321 .9746453 .237123

$96.286 \quad 2.495545 \quad 0.397165 \quad 1.983563 \quad 3.251743$

$98.2432 .465753 \quad 0.39195 \quad 1.992302 \quad 3.266068$

100.22 .4371260 .3868782 .0008683 .280111

$102.1572 .409595 \quad 0.3819442 .0092683 .293882$

$104.1142 .3830990 .377142 \quad 2.0175093 .307392$

$\begin{array}{lllllll}106.071 & 2.357581 & 0.372467 & 2.025597 & 3.32065\end{array}$

108.0282 .3329880 .3679122 .0335363 .333666

109.9852 .3092690 .3634752 .0413333 .346448

$\begin{array}{lllll}111.942 & 2.28638 & 0.359148 & 2.048993 & 3.359005\end{array}$

$\begin{array}{lllll}113.899 & 2.264278 & 0.35493 & 2.05652 & 3.371344\end{array}$

$\begin{array}{llllll}115.856 & 2.242922 & 0.350814 & 2.063919 & 3.383473\end{array}$

$\begin{array}{lllll}117.813 & 2.222276 & 0.346796 & 2.071193 & 3.395399\end{array}$

119.772 .2023040 .3428772 .0783483 .407128

$121.727 \quad 2.1829750 .3390492 .085387 \quad 3.418667$

123.6842 .1642570 .3353092 .0923143 .430022

125.6412 .1461230 .3316552 .0991313 .441199

127.5982 .1285440 .3280832 .1058443 .452203

$\begin{array}{lllll}129.555 & 2.111497 & 0.32459 & 2.112454 & 3.46304\end{array}$

$\begin{array}{lllll}131.512 & 2.094957 & 0.321175 & 2.118965 & 3.473714\end{array}$

$\begin{array}{lllll}133.469 & 2.078902 & 0.317834 & 2.12538 & 3.48423\end{array}$

135.4262 .0633110 .3145652 .1317023 .494594

137.3832 .0481650 .3113652 .1379333 .504808

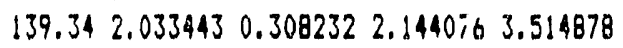

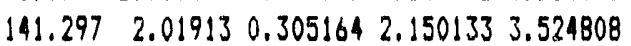

$143.2542 .005208 \quad 0.3021592 .2561073 .534601$ 
$\begin{array}{llllllll}252.9507 & 251.5709 & 289.211 & 145.211 & 1.99166 & 0.299215 & 2.162 & 3.544262\end{array}$ $\begin{array}{llllllll}251.7541 & 252.6897 & 291.168 & 147.168 & 1.978474 & 0.29633 & 2.167813 & 3.553792\end{array}$ $\begin{array}{llllllll}250.5576 & 253.8028 & 293.125 & 149.125 & 1.965633 & 0.293502 & 2.17355 & 3.563197\end{array}$ $\begin{array}{lllllllll}249.361 & 254.9102 & 295.082 & 151.082 & 1.953125 & 0.29073 & 2.179213 & 3.57248\end{array}$ $\begin{array}{llllllll}244.361 & 256.013 ! & 297.039 & 153.039 & 1.940937 & 0.288011 & 2.184802 & 3.581643\end{array}$ $\begin{array}{lllllllll}249.361 & 257.1125 & 298.996 & 154.996 & 1.929056 & 0.285345 & 2.19032 & 3.590689\end{array}$ $\begin{array}{lllllllll}249.361 & 258.2084 & 300.953 & 156.953 & 1.917472 & 0.282729 & 2.19577 & 3.599622\end{array}$ $\begin{array}{llllllll}249.361 & 259.3009 & 302.91 & 158.91 & 1.906173 & 0.280162 & 2.201151 & 3.608445\end{array}$ $\begin{array}{lllllllll}249.361 & 260.39 & 304.867 & 160.867 & 1.895149 & 0.277643 & 2.206467 & 3.617159\end{array}$ $\begin{array}{llllllll}249.361 & 261.4756 & 306.824 & 162.824 & 1.884391 & 0.275171 & 2.211718 & 3.625768\end{array}$ $\begin{array}{llllllllll}249.361 & 262.5579 & 308.781 & 164.781 & 1.873887 & 0.272743 & 2.216907 & 3.634274\end{array}$ $\begin{array}{llllllll}249.361 & 263.6369 & 310.738 & 166.738 & 1.86363 & 0.27036 & 2.222035 & 3.64268\end{array}$ $256.5404264 .7344312 .7233 \quad 168.72331 .853468 \quad 0.2679852 .2271753 .651107$ $\begin{array}{lllllllll}256.5404 & 265.835 & 314.7086 & 170.7086 & 1.843543 & 0.265653 & 2.232255 & 3.659435\end{array}$ $258.9335 \quad 266.9342 \quad 316.6939 \quad 172.6939 \quad 1.8338450 .263363 \quad 2.2372773 .667667$ $261.3267268 .0343 \quad 318.6792 \quad 174.6792 \quad 1.8243680 .2611132 .2422413 .675805$ $261.3267 \quad 269.133 \quad 320.6645 \quad 176.66451 .8151040 .2589022 .2471493 .683851$ $263.7814270 .2304322 .6498178 .64981 .806046 \quad 0.2567292 .2520033 .691807$ $266.2362 \quad 371.3284 \quad 324.6351 \quad 180.6351 \quad 1.7971870 .2545932 .256802 \quad 3.699676$ $268.6909272 .4272 \quad 326.6204 \quad 182.6204 \quad 1.788521 \quad 0.2524942 .2615493 .707458$ $271.1456 \quad 273.5267 \quad 328.6057 \quad 184.6057 \quad 1.780041 \quad 0.250432 .2662453 .715156$ $\begin{array}{llllllllll}273.6004 & 274.6268 & 330.591 & 186.59 ! & 1.77174 ! & 0.2484 & 2.270891 & 3.722772\end{array}$ $276.117 \quad 275.7276 \quad 332.5763 \quad 188.5763 \quad 1.763617 \quad 0.2464042 .275487 \quad 3.730307$ $279.8919 \quad 276.83 \quad 334.5616 \quad 190.5616 \quad 1.7556610 .2444412 .2800353 .737763$ $282.4085 \quad 277.9339 \quad 336.5469 \quad 192.5469 \quad 1.74787 \quad 0.2425092 .284537 \quad 3.745142$ $286.1833 \quad 279.0394 \quad 338.5322 \quad 194.5322 \quad 1.7402370 .240608 \quad 2.288991 \quad 3.752445$ $288.7616 \quad 280.1464340 .5175 \quad 196.51751 .7327590 .238738 \quad 2.2934013 .759674$ $295.2072 \quad 281.2567342 .5028 \quad 198.5028 \quad 1.7254310 .2368972 .297767 \quad 3.76683 !$ $\begin{array}{lllllllll}295.2072 & 282.3683 & 344.4881 & 200.4881 & 1.718247 & 0.235086 & 2.302089 & 3.773916\end{array}$ $296.4963283 .4772346 .4734202,47341.7112050 .2333022 .3063683 .780931$ $299.0746 \quad 284.5855 \quad 348.4587 \quad 204.4587 \quad 1.7042990 .231546 \quad 2.310606 \quad 3.787878$ $\begin{array}{lllllllll}299.0746 & 285.6922 & 350.444 & 206.444 & 1.697526 & 0.229816 & 2.314802 & 3.794758\end{array}$

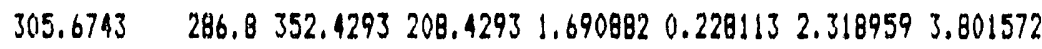
$312.2741287 .9138 \quad 354.4146210 .4146 \quad 1.684363 \quad 0.2264362 .323076 \quad 3.808321$ 316.327289 .0317356 .3999212 .39991 .9779660 .2247832 .3271543 .815007 296.4963290 .1342358 .3852214 .38521 .0716880 .2231552 .3311953 .821631 $286.1833 \quad 291.211 \quad 360.3705 \quad 216.3705 \quad 1.6655250 .2215512 .3351983 .828194$ $279.8919292 .2717 \quad 362.3558 \quad 218.355811 .659474 \quad 0.219972 .3391653 .834696$ $272.373293 .3181364 .3411220 .34111 .6535320 .2184132 .343096 \quad 3.84114$ $267.4635294 .3514 \quad 366.3264222 .32641 .6476960 .2168772 .34699 ! 3.847526$ $257.737295 .3696 \quad 368.3117224 .3117 \quad 1.6419640 .2553642 .3508523 .853856$ $\begin{array}{lllllllll}251.7541 & 296.3718 & 370.297 & 226.297 & 1.636332 & 0.213871 & 2.354679 & 3.860129\end{array}$ $249.361297 .3641372 .2823 \quad 228.2823 \quad 1.630798 \quad 0.21242 .3584723 .866348$ $243.5313 \quad 298.3465374 .2676 \quad 230.2676 \quad 1.6253590 .2109192 .362233 \quad 3.872513$ $240.0335 \quad 299.318 \quad 376.2529 \quad 232.2529 \quad 1.6200140 .2095192 .3659613 .878625$ $243.5313 \quad 300.2867378 .2382 \quad 334.2382 \quad 1.6147590 .208108 \quad 2.3696583 .884685$ $243.5313 \quad 301.2554380 .2235 \quad 236.2235 \quad 1.609592 \quad 0.2067162 .373323 \quad 3.890694$ $243.5313 \quad 302.2213382 .2088238 .20881 .6045120 .2053432 .3769583 .896652$ 243.5313303 .1843384 .1941240 .19411 .5995150 .2039882 .3805623 .902561 243.5313304 .1445386 .1794242 .17941 .5946010 .2026522 .3841373 .908422 $237.7016 \quad 305.097388 .1647 \quad 244.1647 \quad 1.589766 \quad 0.2013332 .3876833 .914234$ $\begin{array}{llllllll}237.7016 & 306.042 & 390.15 & 246.15 & 1.585009 & 0.200032 & 2.3912 & 3.92\end{array}$ 234.2951306 .9813392 .1353248 .13531 .5803290 .1987472 .3946893 .925719 $232.0241 \quad 307.913 \quad 394.1206 \quad 250.1206 \quad 1.575722 \quad 0.19748 \quad 2.3981493 .931393$ $228.6176 \quad 308.8372 \quad 396.1059252 .10591 .5711890 .196228 \quad 2.401583 \quad 3.937021$ $226.3465 \quad 309.754398 .0912 \quad 254.0912 \quad 1.566726 \quad 0.194993 \quad 3.40499 ? .942606$ 
$226.3465310 .6664 \quad 400.0765 \quad 256.0765 \quad 1.562332 \quad 0.193773 \quad 2.408373 .948147$ $226.3465311 .5762 \quad 402.0618258 .06181 .558006 \quad 0.1925692 .4117243 .953645$ $226.3465312 .4834404 .047 ! 260.047 ! 1.553746 \quad 0.19138 \quad 2.4150523 .959102$ $226.3465 \quad 313.380 \quad 406.0324 \quad 262.0324 \quad 1.54955 \quad 0.190206 \quad 2.4183553 .964516$ $226.3465314 .2901408 .0177264 .0177 \quad 1.5454180 .1890462 .421633 \quad 3.96989$ $226.3465315 .1897 \quad 410.003 \quad 266.003 \quad 1.541347 \quad 0.18792 .4248873 .975224$ 226.3965316 .0868411 .9883267 .98831 .5373370 .1867692 .4281163 .980518 $226.3465316 .9813413 .9736269 .97361 .533385 \quad 0.1856512 .4313213 .985773$ $226.3465317 .8734415 .9589271 .95891 .529492 \quad 0.1845472 .434503 \quad 3.990989$ $226.3465318 .7629417 .9442273 .9142 \quad 1.5256540 .1834562 .4376623 .996167$ $226.3465 \quad 319.65419 .9295275 .9295 \quad 1.5218720 .1823782 .440798 \quad 4.001308$ $226.3465320 .5346 \quad 421.9148277 .9148 \quad 1.5181440 .1813132 .4439124 .006413$ $226.3465 \quad 321.4168 \quad 423.9001279 .9001 \quad 1.514469 \quad 0.180262 .447003 \quad 4.01148$ $223.0308 \quad 322.2936 \quad 425.8854281 .8854 \quad 1.510846 \quad 0.17922 \quad 2.450073 \quad 4.016512$ $223.0308323 .1653 \quad 427.8707283 .8707 \quad 1.507273 \quad 0.178192 \quad 2.4531214 .021509$ $\begin{array}{llllllll}223.0308 & 324.0345 & 429.856 & 285.856 & 1.50375 & 0.177176 & 2.456147 & 4.026471\end{array}$ $220.8203 \quad 324.8995 \quad 431.8413287 .8113 \quad 1.500276 \quad 0.1761712 .459153 \quad 4.031399$ $223.0308325 .7621433 .8266289 .8266 \quad 1.4968490 .1751782 .4621384 .036292$ $224.136 \quad 326.6252435 .8119291 .8119 \quad 1.4934690 .1741962 .465103 \quad 4.041152$ $224.136 \quad 327.4868 \quad 437.7972 \quad 293.7972 \quad 1.490134 \quad 0.173225 \quad 2.468048 \quad 4.04598$ $\begin{array}{llllllll}224.136 & 328.346 & 439.7825 & 295.7825 & 1.486844 & 0.172265 & 2.470972 & 4.050775\end{array}$ $225.2413 \quad 329.2038 \quad 441.7678 \quad 297.7678 \quad 1.483598 \quad 0.171316 \quad 2.473878 \quad 4.055537$ $225.2413 \quad 330.0602 \quad 443.7531299 .75311 .480395 \quad 0.1703782 .4767644 .060268$ 223.0308330 .9124445 .7384301 .73841 .4772350 .1694492 .4796314 .064968 $220.8203 \quad 331.7587447 .7237303 .7237 \quad 1.4741150 .1685312 .4824794 .069637$ $217.5045 \quad 332.5982 \quad 449.709 \quad 305.709 \quad 1.471036 \quad 0.167623 \quad 2.4853084 .074276$ $215.294 \quad 333.431451 .6943307 .6943 \quad 1.467997 \quad 0.166725 \quad 2.4881194 .078884$ $215.294334 .2598453 .6796 \quad 309.6796 \quad 1.464997 \quad 0.1658372 .4909134 .083463$ $215.294335 .0864455 .8649311 .6649 \quad 1.4620350 .1649582 .4936884 .088013$ $215.294335 .9108 \quad 457.6502 \quad 313.6502 \quad 1.45911 \quad 0.1640882 .496446 \quad 4.092534$ $215.294 \quad 336.733 \quad 459.6355315 .6355 \quad 1.456222 \quad 0.1632282 .499186 \quad 4.097026$ $215.294 \quad 337.5531461 .6208317 .6208 \quad 1.453371 \quad 0.162376 \quad 2.501909 \quad 4.10149$ 212.0684338 .3682463 .6061319 .60611 .4505550 .1615342 .5046154 .105926 $209.918339 .1768 \quad 465.5914321 .5914 \quad 1.4477730 .1607012 .507304 \quad 4.110335$ $207.7676 \quad 339.9797 \quad 467.5767323 .5767 \quad 1.445026 \quad 0.159876 \quad 2.509977 \quad 4.114717$ $204.542 \quad 340.7761 \quad 469.562 \quad 325.562 \quad 1.4423120 .1590592 .5126344 .119072$ $204.542 \quad 341.5679471 .5473 \quad 327.5473 \quad 1.4396310 .1582512 .515274 \quad 4.1234$ $204,542 \quad 342.3577473,5526 \quad 329,9326 \quad 1.436983 \quad 0.1574312 .3178984,127702$ $204.542 \quad 343.1454475 .5179 \quad 331.5179 \quad 1.434366 \quad 0.15666 \quad 2.520507 \quad 4.131979$ $\begin{array}{llllllll}204.542 & 343.9311 & 477.5032 & 333.5032 & 1.43178 & 0.155876 & 2.5231 & 4.13623\end{array}$ $204.542 \quad 344.7148 \quad 479.4885335 .4885 \quad 1.429225 \quad 0.1551012 .525678 \quad 4.140455$ $204.542345 .4487481 .352 ! 337.3521 \quad 1.4268540 .1543792 .5280834 .144399$ $204.542 \quad 346.1807 \quad 483.2157 \quad 339.2157 \quad 1.424509 \quad 0.1536652 .5304764 .148321$

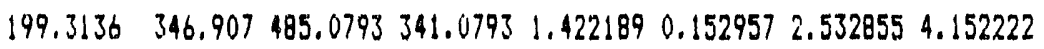
$201.405347 .6292486 .9429342 .94291 .4198950 .1522562 .535222 \quad 4.156101$

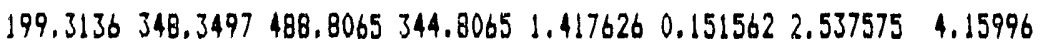
$197.2223349 .0653 \quad 490.6701346 .6701 \quad 1.4153810 .1508732 .539916 \quad 4.163797$ $197.2223 \quad 349.7777492 .5337348 .5337 \quad 1.4131590 .1501912 .5422454 .167614$ $197.2223350 .4885494 .3973350 .3973 \quad 1.4109620 .1495152 .5445614 .171411$ $199.3136 \quad 351.1991496 .2609352 .2609 \quad 1.408788 \quad 0.1488462 .546864 \quad 4.175188$ $199.3136 \quad 351.9096 \quad 498.1245354,1245 \quad 1.406637 \quad 0.148182 \quad 2.549156 \quad 4.178944$ $199.3136 \quad 352.6184 \quad 499,9881355.98811 .40450 B \quad 0.1475242 .5514354$ 4.182681

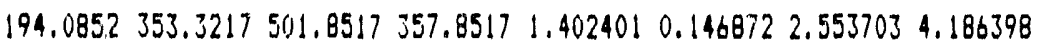
$199.3136 \quad 354.0234503 .7153359 .7153 \quad 1.4003170 .146226 \quad 2.5559594 .190097$

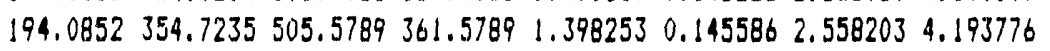

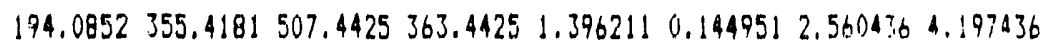




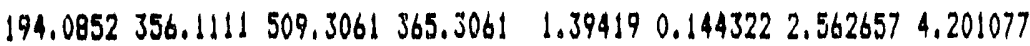
$194.0852356 .0026 \quad 511.1697367 .1694 \quad 1.3921890 .1436982 .564867 \quad 1.2047$ $189.0018 \quad 357.4885513 .0333 \quad 369.0333 \quad 1.390209 \quad 0.14308 \quad 2.567066 \quad 4.208304$ $186.9685358 .1675 \quad 514.8969370 .8969 \quad 1.388248 \quad 0.1424672 .569253 \quad 4.21189$ $183.9184358 .8412516 .7605372 .7605 \quad 1.386307 \quad 0.141859 \quad 2.57143 \quad 4.215459$ $183.9184359 .5111518 .6241374 .6241 \quad 1.3843850 .141257 \quad 2.573596 \quad 4.219009$ $183.9184 \quad 360.1795 \quad 520.4877376 .4877 \quad 1.382483 \quad 0.14066 \quad 2.5757514 .222542$ $185.9518360 .8479522 .3513 \quad 378.3513 \quad 1.3805990 .1400672 .5778954 .226058$ $183.9184361 .5147524 .2149380 .2149 \quad 1.378733 \quad 0.13948 \quad 2.5800294 .229556$ $186.9685362 .1809526 .0785382 .0785 \quad 1.3768860 .138898 \quad 2.582153 \quad 4.233037$ $180.955362 .8432527 .9421383 .94211 .375057 \quad 0.1383212 .584266 \quad 4.236501$ $183.9184363 .5019529 .8057385 .8057 \quad 1.3732450 .137748 \quad 2.5863694 .239949$ $183.9184364 .1613531 .6693387 .66931 .371451 \quad 0.137182 .5884614 .243379$ $183.9184364 .8193 \quad 533.5329389 .53291 .369674 \quad 0.1366172 .5905444 .246794$ $183.9184365 .4759535 .3965391 .39651 .367913 \quad 0.1360592 .5926174 .250192$ $\begin{array}{llllllll}183.9184 & 366.131 & 537.2601 & 393.2601 & 1.36617 & 0.135505 & 2.59468 & 4.253574\end{array}$ $183.9184366 .7846 \quad 539.1237395 .1237 \quad 1.3644430 .1349552 .5967334 .256939$ $183.9184 \quad 367.4368 \quad 540.9873 \quad 396.9873 \quad 1.362732 \quad 0.134412 .598777 \quad 4.26029$ $183.9184368 .0876 \quad 542.8509398 .8509 \quad 1.361037 \quad 0.13387 \quad 2.6008114 .263624$ $180.955 \quad 368.7346544 .7145 \quad 400.7145 \quad 1.359358 \quad 0.1333342 .6028354 .266943$ $183.9184369 .3802546 .5781402 .5781 \quad 1.357695 \quad 0.132802 \quad 2.604854 .270246$ $183.9184 \quad 370.0267548 .1417 \quad 404.4417 \quad 1.356046 \quad 0.1322752 .6068564 .273534$ $183.9184 \quad 370.6717 \quad 550.3053 \quad 406.3053 \quad 1.354413 \quad 0.1317512 .6088524 .276807$ $183.9184371 .3153 \quad 552.1689408 .1689 \quad 1.352795 \quad 0.131232 \quad 2.61084 \quad 4.280065$ $186.9685371 .9597554 .0325410 .03251 .351192 \quad 0.1307172 .6128184 .283309$ $184.935 ! 372.6033 \quad 555.8961411 .8961 \quad 1.349603 \quad 0.1302062 .6147884 .286537$ $183.9184373 .2434557 .7597413 .75971 .348028 \quad 0.1296992 .6167484 .289751$

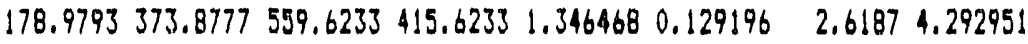
$177.0037374 .505456\} .4869417 .4869 \quad 1.3449210 .1286972 .6206434 .296136$ $174.0403 \quad 375.1282563 .3505 \quad 419.3505 \quad 1.3433890 .128202 \quad 2.6225774 .299307$ $174.0403 \quad 375.7475 \quad 565.214 ! 421.214 ! 1.341869 \quad 0.127712 .624503 \quad 4.302464$ $169.2448376 .3618 \quad 567.0777 \quad 423.0777 \quad 1.340363 \quad 0.127222 \quad 2.62642 \quad 4.305607$ $174.0403 \quad 376.9748 \quad 568.9413 \quad 424.9413 \quad 1.338870 .1267392 .6283294 .308736$

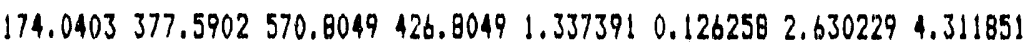

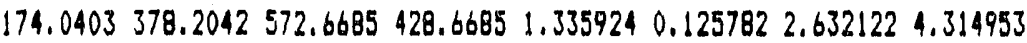

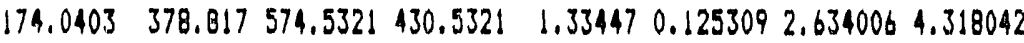
$174.0403 \quad 379.4284576 .3957432 .3957 \quad 1.3330280 .1248392 .6358814 .321117$

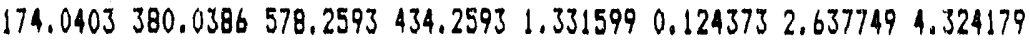

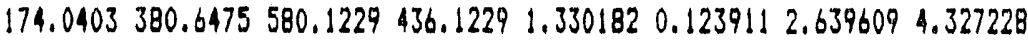

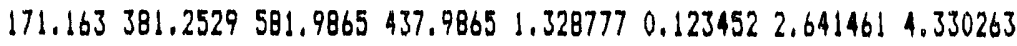

$171.163381 .8548 \quad 583.850 ! 439.8501 \quad 1.3273840 .1229972 .6433054 .333286$ $169.2448382 .4541585 .7137441 .7137 \quad 1.326003 \quad 0.122545 \quad 2.6451414 .336297$ $169.2448 \quad 383.0506 \quad 587.5773 \quad 143.5773 \quad 1.324633 \quad 0.1220962 .6469694 .339294$

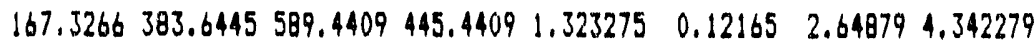
$167.3266 \quad 384.2357591 .3045 \quad 447.30451 .3219280 .1212082 .650603 \quad 4.345251$ $167.3266384 .8258593 .1681449 .1681 \quad 1.320593 \quad 0.1207692 .6524094 .348211$ $169.2448 \quad 385.416 \quad 595.0317451 .0317 \quad 1.319268 \quad 0.1203332 .654207 \quad 4.351159$

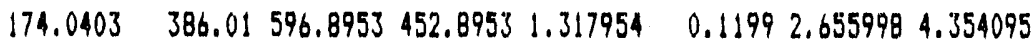
$174.0403386 .6063 \quad 598.7589454 .75891 .316651 \quad 0.1194712 .6577814 .357018$ $167.3266 \quad 387.1964600 .6225 \quad 456.6225 \quad 1.3153590 .1190442 .659557 \quad 4.35993$ $169.2448 \quad 387.7817 \quad 602.4861458 .48611 .314077 \quad 0.1186212 .661326 \quad 4.36283$ $168.2857388 .3665604 .3497 \quad 460.3497 \quad 1.312806 \quad 0.11822 .6630884 .365718$ $164.4492388 .9467606 .2133 \quad 462.2133 \quad 1.3115440 .1177832 .6648424 .368594$ $164.4492389 .5229608 .0769464 .0769 \quad 1.310293 \quad 0.117369 \quad 2.666594 .371459$ $164.4492 \quad 390.098609 .9405 \quad 465.9405 \quad 1.309052 \quad 0.116957 \quad 2.66833 \quad 4.374312$ $164.4192390 .6719611 .804 ! \quad 467.80411 .3078210 .116548 \quad 2.670064 \quad 4.377 ! 54$ 
$164.4492391 .2446613 .6677469 .6677 \quad 1.3066 \quad 0.1161432 .6717914 .379985$ $164.4492391 .8161615 .5313471 .53131 .305388 \quad 0.115742 .6735114 .382804$ $164.4492392 .3865617 .3949473 .39491 .3041860 .1153392 .675224 \quad 4.385612$

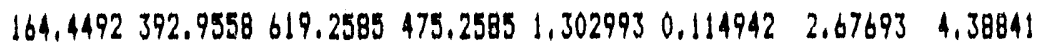

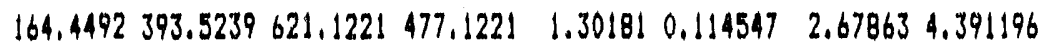
$164.4492394 .0909622 .9857478 .9857 \quad 1.3006350 .1141562 .680323 \quad 4.393971$ $164.4492394 .6567624,8493 \quad 480.8493 \quad 1.29947 \quad 0.1137662 .6820094 .396736$ $164.4492395 .2214626 .7129 \quad 482.7129 \quad 1.298314 \quad 0.11338 \quad 2.683689 \quad 4.39949$ $167.3266 \quad 395.7869628 .5765 \quad 484.5765 \quad 1.297167 \quad 0.1129962 .685362 \quad 4.402233$ 166.3674396 .3527630 .4401486 .44011 .2960280 .1126142 .6870294 .404966 $164.4492396 .9153 \quad 632.3037 \quad 488.3037 \quad 1.2948980 .112236 \quad 2.6886944 .407689$ $164.4492397 .4754634 .1673 \quad 490.1673 \quad 1.293777 \quad 0.11186 \quad 2.6903444 .410401$ $161.6577398 .0323636 .0309492 .03091 .2926650 .111486 \quad 2.691992 \quad 4.413102$ $161.6577398 .586 ! 637.8945 \quad 493.8945 \quad 1.29156 \quad 0.111115 \quad 2.693634 \quad 4.415794$ $162.5882399 .1394 \quad 639.7581495 .75811 .290464 \quad 0.110746 \quad 2.695274 .418475$ $164.4492399 .6937641 .6217 \quad 497.62171 .289376 \quad 0.11038 \quad 2.696899 \quad 4.421146$ $169.2448 \quad 400.2754 \quad 643.565 \quad 499.565 \quad 1.288251 \quad 0.112 .698592 \quad 4.423921$ $169.2448400 .8594645 .5083501 .5083 \quad 1.2871340 .1096242 .7002784 .426685$ $169.2448 \quad 401.4421 \quad 647.4516 \quad 503.4516 \quad 1.286026 \quad 0.10925 \quad 2.7019584 .429439$ $169.2448 \quad 402.0237649 .3949505 .3949 \quad 1.284926 \quad 0.1088782 .7036314 .432182$ $169.2448 \quad 402.604651 .3382 \quad 507.3382 \quad 1.2838340 .1085092 .7052984 .434914$ $167.3266 \quad 403.1817653 .2815509 .2815 \quad 1.282751 \quad 0.108142 \quad 2.7069584 .437636$ $167.3266 \quad 403.7568655 .2248511 .2248 \quad 1.281676 \quad 0.107778 \quad 2.708612 \quad 4.440347$

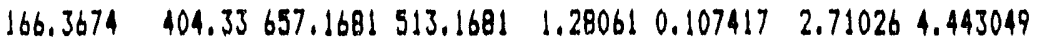
$164.4492 \quad 404.9659 .1114515 .11141 .2795510 .107058 \quad 2.711901 \quad 4.44574$ $164.4492 \quad 405.4675661 .0547517 .05471 .278501 \quad 0.1067012 .713536 \quad 4.44842$

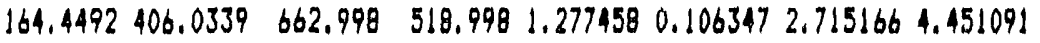
$164.4492 \quad 406.599664 .9413 \quad 520.9413 \quad 1.276423 \quad 0.1059952 .7167894 .453752$ $164,4492 \quad 407.163 \quad 666.8846522 .8846 \quad 1.275395 \quad 0.105645 \quad 2.7184064 .456403$

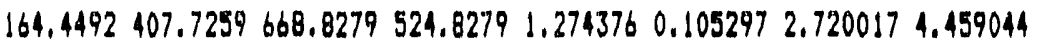

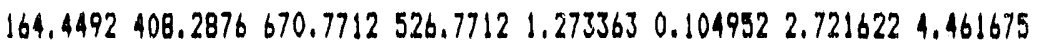
$164.4492 \quad 408.8481672 .7145528 .71451 .272359 \quad 0.104612 .7232214 .464297$ 164.4492409 .4075674 .6578530 .65781 .2713610 .1042692 .7248154 .466909 $166.3674 \$ 09.9671676 .6011532 .60111 .2703710 .1039312 .726402 \quad 4.469512$ $166.3674 \quad 110.5269 \quad 678.5444534 .5144 \quad 1.2693880 .1035942 .7279844 .472105$ $164.4492 \quad 111.084 ! 680.4877536 .4877 \quad 1.2684 ! 2 \quad 0.10326 ! 2.729564 .474688$ $\begin{array}{llllllll}164.4492 & 411.639 & 682.431 & 538.431 & 1.267444 & 0.102929 & 2.73113 & 4.477262\end{array}$ $164.4492 \quad 112.1927684 .3743 \quad 540.3743 \quad 1.266482 \quad 0.102599 \quad 2.732695 \quad 1.479827$ $164.4492 \quad 412.7452666 .3176 \quad 542.3176 \quad 1.265527 \quad 0.10227 ! 2.7342544 .462383$ $164.4492 \quad 413.2967 \quad 688.2609544 .2604 \quad 1.2645790 .101946 \quad 2.735807 \quad 4.48493$ $164.4492 \quad 413.847690 .2042546 .2012 \quad 1.2636380 .101623 \quad 2.7373554 .487467$ $164.4492414 .3962 \quad 692.1475 \quad 548.14751 .2627030 .1013012 .7388974 .489996$ $164.4492 \quad 114.9444694 .0908550 .0908 \quad 1.2617750 .100982 \quad 2.7404344 .192515$ 164.4492415 .4913696 .0341552 .03411 .2608530 .1006652 .7419664 .495026 164.4492416 .0372697 .9774553 .97741 .2599380 .1003492 .7434924 .497528

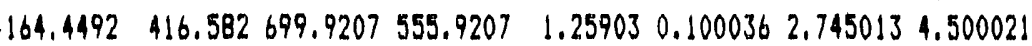
$164.4492 \quad 417.1257 \quad 701.864 \quad 557,864 \quad 1.250127 \quad 0.099725 \quad 2.7465284 .502505$ $164,4492417.6683703 .8073559 .8073 \quad 1.2572310 .0994152 .7480394 .504981$ $164.4492 \quad 418.2098 \quad 705.7506 \quad 561.7506$
$164.256342 \quad 0.099108 \quad 2.749544 \quad 4.507448$ $164.4492418 .7502707 .6939563 .69391 .2554580 .098802 \quad 2.7510434 .509907$ $164.4492 \quad 419.2895 \quad 709.6372565 .6372 \quad 1.25458 \quad 0.098498 \quad 2.7525384 .512357$ 164.4492419 .8278711 .5805567 .58051 .2537090 .0981972 .7540274 .514799 $164.4492 \quad 420.3649713 .5238569 .5238 \quad 1.252843 \quad 0.0978972 .7555124 .517233$ $164.4492 \quad 420.901715 .4671571 .46711 .2519830 .0975982 .7569914 .519658$ $164.4492 \quad 421.436717 .4104 \quad 573.41041 .2511290 .097302 \quad 2.758466 \quad 4.522075$

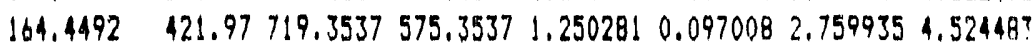


$164.4492 \quad 122.5028 \quad 721.297 \quad 577.297 \quad 1.249438 \quad 0.096715 \quad 2.761399 \quad 4.526884$ $164.4492423 .0347723 .2403 \$ 979.24031,2486010.0964242 .7628544 .529277$ $164.4492 \quad 423.5654725,1836581.1836 \quad 1.247770 .096135 \quad 2.7643134 .531661$ 164.1492424 .0951727 .1269583 .12691 .2469450 .0958472 .7657634 .534038 $164.4492424 .6237 \quad 729.0702585 .07021 .2461240 .0955612 .7672084 .536407$ $164.4492 \quad 425.1513731 .0135587 .0135 \quad 1.245310 .095277 \quad 2.7686484 .538767$ $164.4492 \quad 425.6779 \quad 732.9568 \quad 589.9568 \quad 1.24450 .094995 \quad 2.770083 \quad 4.54112$ $164.4492 \quad 126.2034734,9001590.90011 .2436960 .0947142 .7715144 .543466$ $164.4492 \quad 426.7278 \quad 736.8434592 .8434 \quad 1.242897 \quad 0.094435 \quad 2.772944 .545803$ $164.4492427 .2513 \quad 738.7867 \quad 594.7867 \quad 1.2421040 .094158 \quad 2.7743614 .548133$

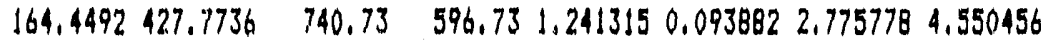
$\begin{array}{llllllll}164.4492 & 428.295 & 712.6733 & 598.6733 & 1.240532 & 0.093608 & 2.77719 & 4.55277\end{array}$ $164.4492428 .8153 \quad 741.6166 \quad 600.6166 \quad 1.2397540 .0933352 .778597 \quad 4.555078$

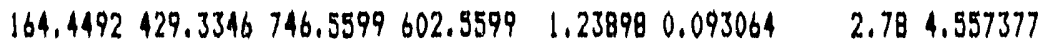
$164.4492429 .8529748 .5032604 .5032 \quad 1.238212 \quad 0.092795 \quad 2.781399 \quad 4.55967$ $164.4492430 .3701750 .1465606 .44651 .2374490 .092527 \quad 2.782792 \quad 4.561955$

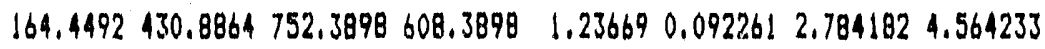
$164.4492431 .4016 \quad 734,3331610.33311 .2359370 .091996 \quad 2.7855674 .566503$ $164.4492431 .9158 \quad 756.2764612 .27641 .2351880 .0917332 .7869484 .568766$ $164.4492 \quad 132.429758 .2197 \quad 614.2197 \quad 1.2344440 .091471 \quad 2.798324 \quad 4.571023$ $\begin{array}{lllllllll}162.5882 & 432.9399 & 7601.163 & 616.163 & 1.233704 & 0.091211 & 2.789696 & 4.573272\end{array}$ $162,5882 \quad 433.4486 \quad 762.1063618 .1063 \quad 1.23297 \quad 0.090952 \quad 2.791063 \quad 4.575313$ $159.7966 \quad 433.9544 \quad 764.0496 \quad 620.0496 \quad 1.2322390 .090695 \quad 2.7924264 .577748$ $162.5882 \quad 434.4592 \quad 765.9929621 .9929 \quad 1.231514 \quad 0.0904392 .7937854 .579976$

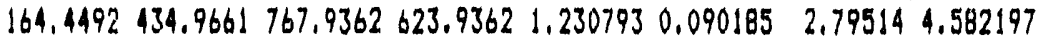
$164.4492435 .4734769 .8795625 .87951 .2300760 .089932 \quad 2.7964914 .584411$ $164.4492 \quad 435.9796 \quad 771.8228627 .8228 \quad 1.229364 \quad 0.0896812 .7978374 .586618$ $164.4492 \quad 436.4849 \quad 773.7661629 .766 ! 1.228656 \quad 0.08943 \quad 2.7991794 .588818$ $164.4492436 .9892775 .7094631 .7094 \quad 1.2279530 .089182 \quad 2.8005174 .591012$ $159.7966 \quad 137.4894 \quad 771.6527633 .6527 \quad 1.2272540 .0869342 .8018514 .593199$

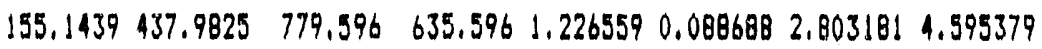
$195.1439438 .4717 \quad 781.5393 \quad 637.5393 \quad 1.225868 \quad 0.0884442 .804507 \quad 4.597552$ $155.1439438 .9599783 .4826 \quad 639.4826 \quad 1.225182 \quad 0.088201 \quad 2.805829 \quad 4.599719$ $155.1439439 .4472785 .4259641 .4259 \quad 1.22150 .0879592 .807146 \quad 4.601879$

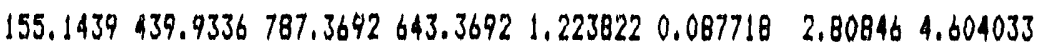
$155.1439440 .4191789 .3125649 .3125 \quad 1.223148 \quad 0.087479 \quad 2.80977 \quad 4.60618$ $159.7966 \quad 440.9066 \quad 791.2558 \quad 647.25581 .222478 \quad 0.0872412 .811076 \quad 4.608321$ $159.7966 \quad 141.3962793 .1991649 .1991 \quad 1.221812 \quad 0.0870042 .812378 \quad 1.610456$ $159.7966 \quad 441.8849795 .1424 \quad 651.1424 \quad 1.221150 .086769 \quad 2.813676 \quad 1.612584$ $\begin{array}{lllllll}159.7966 & 142.3727 & 797.0857 \quad 653.0857 & 1.220492 & 0.086535 & 2.81497 & 4.614705\end{array}$ $155.1439 \quad 442.8565 \quad 799.029 \quad 655.029 \quad 1.2198380 .086302 \quad 2.816261 \quad 4.616821$ $\begin{array}{llllllll}155.1439 & 443.3365 & 800.9723 & 656.9723 & 1.219187 & 0.08607 & 2.817547 & 4.61893\end{array}$ $\begin{array}{lllllllll}155.1439 & 443.8156 & 802.9156 & 658.9156 & 1.218541 & 0.08584 & 2.81883 & 4.621032\end{array}$ $155.1439444 .2938 \quad 804.8589660 .8589 \quad 1.217898 \quad 0.085611 \quad 2.8201094 .623129$

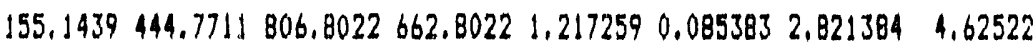
$155.1439 \quad 445.2475 \quad 808.7455664 .74551 .2166240 .085156 \quad 2.8226554 .627304$ $155.1439 \quad 445.723 \quad 810.6888 \quad 666.6888 \quad 1.2 .15993 \quad 0.0849312 .823923 \quad 4.629382$ $157.9355 \quad 146.1994 \quad 812.6321668 .6321 \quad 1.215365 \quad 0.0847072 .8251874 .631454$ $157.9355 \quad 446.6766 \quad 814.5754 \quad 670.5754 \quad 1.2147410 .0844842 .8264484 .633521$

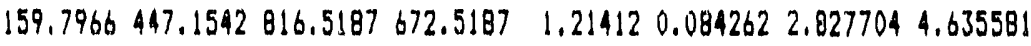

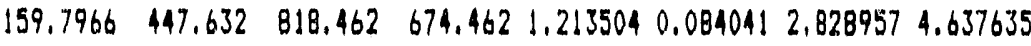

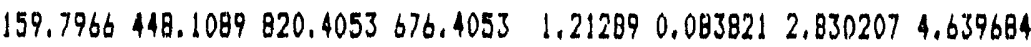

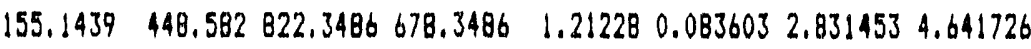
$155.1439449 .0513 \quad 824.2919680 .2919 \quad 1.2116740 .083386 \quad 2.8326954 .643763$ $155.1439449 .5198 \quad 826.2352 \quad 682.2352 \quad 1.211071 \quad 0.083172 .833934 \quad 4.645794$ $155.1439449 .9874828 .1785684 .1785 \quad 1.2104710 .082955 \quad 2.835169 \quad 4.547819$ 
$195.1439 \quad 450.4123 \quad 829,9479689.94751 .209929 \quad 0,082762.8362914 .649657$ 155.1439450 .8365831 .7165687 .71651 .2093890 .0825662 .8374094 .651491 $150,633545 ! .2572 \quad 833,4855689.4855 \quad 1,20885 ! 0.0823732,838525 \quad 4,65332$ $150.6335 \quad 451.6746 \quad 835.2545691 .2545 \quad 1.2003170 .0821812 .8396384 .655144$ $155.1439 \quad 152.094 \quad 837.0235 \quad 693.02351 .207785 \quad 0.081992 .8407484 .656964$ $155.1439452 .5154 \quad 838.7925694 .79251 .2072560 .0817992 .8418554 .658779$ $155.1439 \quad 152.936 \quad 840.5615696 .5615 \quad 1.20673 \quad 0.081612 .842959 \quad 4.660589$ $155,1439 \quad 453.356 \quad 842,3305 \quad 698,33051.2062060 .0814222 .84406 ! 4.662395$ $150,6335 \quad 453.7726 \quad 844,0995 \quad 700.0495 \quad 1.2056850 .081234 \quad 2.845164 .664196$ $150.6335454,1858845,8685701.86851 .2051670 .0810472 .8462564 .665993$ $146.123 \quad 454.5958 \quad 847,6375 \quad 703.6375 \quad 1.2046510 .0808612 .8473494 .667785$ $150.6335 \quad 455.005849 .4065705 .4065 \quad 1.204138 \quad 0.080676 \quad 2.8484394 .669573$ $150.6335455 .4162 \quad 851.1755 \quad 707.17551 .203627 \quad 0.080492 \quad 2.849527 \quad 4.671356$ $150,6335 \quad 455.8268 \quad 852,9445708,94451,2031190.0803092 .850612 \quad 4.673135$ $155.1439456 .2393 \quad 854.7135 \quad 710.71351 .202613 \quad 0.080126 \quad 2.851695 \quad 1.674909$ $155.1439456 .6537856 .4825712 .4825 \quad 1.202110 .0799442 .852774 \quad 4.676679$ $155.1439457 .0675858 .2515714 .2515 \quad 1,301610.079763 \quad 2.8538514 .678445$ 155.1439457 .4806860 .0205716 .02051 .2011120 .0795832 .8519254 .680206 $150.6335457 .8904861 .7895 \quad 717.78951 .2006160 .0794042 .8559974 .681962$ $150.6335458 .2968 \quad 863.5585719 .5585 \quad 1.200123 \quad 0.079226 \quad 2.857066 \quad 4.683715$ $146.123458 .7001865 .3275721 .3275 \quad 1.1996320 .0790482 .8581324 .685463$ 146.123459 .1002867 .0965723 .09651 .1991440 .0788712 .8591964 .687207

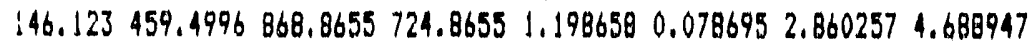

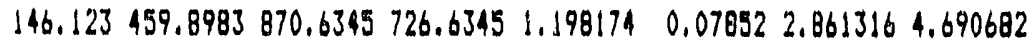
$146.123 \quad 160.3965872 .4035728 .40351 .1976930 .0783452 .8623724 .692413$ $146.123 \quad 460.6939874 .1725730 .1729 \quad 1.1972140 .078172 \quad 2.863425 \quad 4.69414$ $150.6335461 .0933875 .9415731 .94151 .1967370 .0779992 .864476 \quad 4.695863$ 150.6335461 .4946877 .7105733 .71051 .1962630 .0778272 .8655254 .697582 $150.6335 \quad 461.8952879,4795735.47951 .1957910 .0776552 .8665714 .699296$ $150.6335462 .2951881 .2485737 .24851 .19532 ! 0.0774842 .8676144 .701006$ $146.123 \quad 462.6919883 .0175739 .0175 \quad 1.1948530 .0773152 .8686554 .702713$ $146.123463 .08568864 .7865 \quad 740.7865 \quad 1.1943860 .0771452 .8696934 .704415$

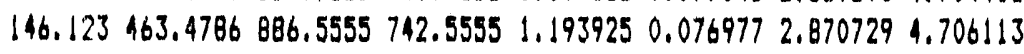
$146.123 \quad 463.871888 .3245744 .3245 \quad 1.1934640 .0768092 .8717624 .707807$ $146.123 \quad 464.2628 \quad 890.0935 \quad 746.0935 \quad 1.193005 \quad 0.076642 \quad 2.872793 \quad 4.709497$ $146.123 \quad 464.6539891 .8625 \quad 747.8625 \quad 1.1925490 .0764762 .873822 \quad 4.711183$ $146.123 \quad 465.0445893 .6315 \quad 749.6315 \quad 1.192094 \quad 0.0763112 .8749464 .712865$ $146.123 \quad 465.4344895 .4005751 .4005 \quad[.1916420 .0761462 .8758714 .714543$ $146.123 \quad 465.8237897 .1695 \quad 753.1695 \quad 1.1911920 .075982 \quad 2.876893 \quad 4.716218$ $150.6335466 .2148898 .9385754 .9385 \quad 1.1907440 .075818 \quad 2.877912 \quad 4.717898$ $150.6335 \quad 466.6078900 .7075 \quad 756.7075 \quad 1.190298 \quad 0.075656 \quad 2.878928 \quad 4.719554$ $150.6335467 .0001902 .4765 \quad 758.47651 .1898540 .0754942 .8799424 .721217$ $150.6335 \quad 467.3919904 .2455760 .24551 .189412 \quad 0.075332 \quad 2.8809544 .722875$

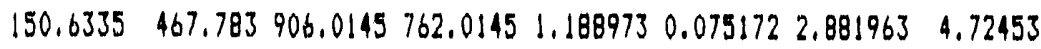

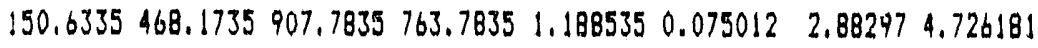
$150.6335 \quad 468.5633909 .5525765 .5525 \quad 1.1880990 .0748532 .883975 \quad 4.727828$ 146.123468 .9501911 .3215767 .32151 .1876660 .0746942 .8849774 .729471 146.123469 .3338913 .0905769 .09051 .1872340 .0745362 .8859774 .731111 $146.123 \quad 469.7169914 .8595 \quad 770.8595 \quad 1,18680400.0743792 .886975 \quad 4.732746$ $146.123 \quad 470.0995916 .6285772 .6285 \quad 1.1863770 .074223 \quad 2.8879714 .734378$ $146.123 \quad 470.4814918 .3975774 .3975 \quad 1.1859510 .0740672 .8889644 .736006$

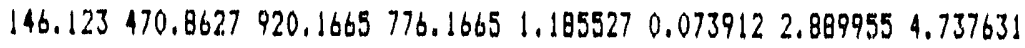
$146.123 \quad 471.2434921 .9355 \quad 777.9355 \quad 1.1851050 .0737572 .890944 \quad 4.739252$ $146.123471 .6235923 .7045779 .70451 .1846850 .073603 \quad 2.891934 .740869$ $150.6335472 .0054 \quad 925.4735781 .4735 \quad 1.184267 \quad 0.07345 \quad 2.892914 \quad 1.742482$ $150.6335 \quad 472.3892927 .2425783 .2425 \quad 1.1838510 .0732972 .893896 \quad 4.744192$ 
146.123472 .7699929 .0119789 .01151 .1834370 .0731492 .8948764 .749698 146.123473 .1476930 .7809786 .78091 .1830240 .0729942 .8998541 .747301 $146.123 \quad 473.9248932 .5499788 .5499 \quad 1.182614 \quad 0.0728432 .896829 \quad 4.7489$ 146.123473 .9013934 .3189790 .318941 .1822090 .0726932 .8978024 .730499 $146.123474 .2773936 .0879792 .0873 \quad 1.1817980 .0729432 .8987734 .792087$ 146.123474 .6926937 .8969793 .856951 .1813930 .0723942 .8997424 .793679

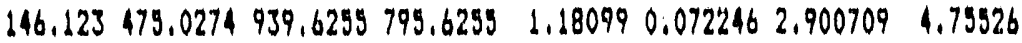
$146.123 \$ 75.4016941 .3945797 .39451 .1809800 .072098 \quad 2.9016734 .796841$ 146.123479 .7792943 .1639799 .163951 .1801880 .0719912 .9026364 .798419 $146.123 \quad 476.1483944 .9329 \quad 800.9325 \quad 1.179790 .0718052 .9039964 .799993$ 146.123476 .9207946 .7019802 .70191 .1793940 .0716992 .9049544 .761964

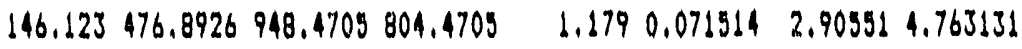
146.123477 .2639990 .2399806 .23991 .1786070 .0713692 .9064644 .764699 $146.123477 .6346952 .0089808 .0085 \quad 1.1782160 .0712292 .907416 \quad 4.766296$

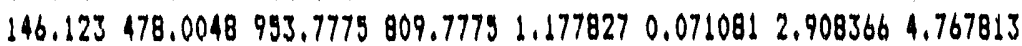
146.123478 .3744995 .9465811 .94691 .1774390 .0709382 .9093134 .769366 146.123478 .7434997 .3159813 .31991 .1770530 .0707962 .9102594 .770916 $\$ 46.123479 .1118999 .0849819 .0849 \$ 1.1766690 .0706542 .9112034 .772463$ $146.123479 .4797960 .8939816 .8935 \quad 1.1762860 .0705132 .9121444 .774007$

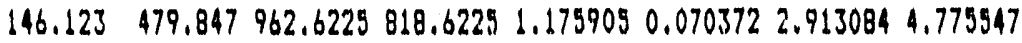
$146.123 \quad 480.2137964 .3919820 .3919 \quad 1.179526 \quad 0.070232 \quad 2.9140214 .777084$ $146.123480 .5799966 .1605822 .1609 \quad 1.1751480 .0700932 .9149974 .778617$ $146.123 \quad 480.9495967 .9295823 .9299 \quad 1.1747720 .069954 \quad 2.919894 .780148$ $146.123481 .3105969 .6985829 .6985 \quad 1.1743980 .0698192 .9168214 .781679$ $146.123 \quad 481.679971 .4679827 .4675 \quad 1.1740250 .069677 \quad 2.9177914 .783198$

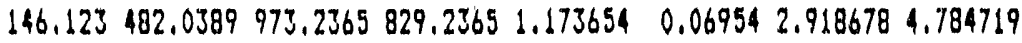
$146.123 \quad 482.4023975 .0055831 .0055 \quad 1.1732840 .069403 \quad 2.9196044 .786236$

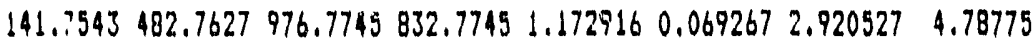
$141.7943 \quad 483.1201978 .5439834 .54351 .1725490 .0691312 .9214494 .789261$

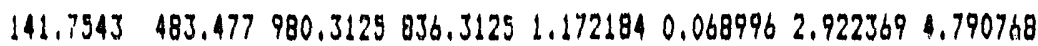
$141.7543 \quad 483.8334982 .0815838 .0819 \quad 1.1718210 .0688612 .923286 \quad 1.792273$ $141.7543484 .1892983 .8505839 .89051 .1714590 .0687272 .924202 \quad 4.793774$ $137.3855 \quad 184.9422985 .6195841 .61951 .171099 \quad 0.0685932 .929116 \quad 4.795272$ 137.3855 484.8923 $987.3889843 .3885 \quad 4.17074 \quad 0.068462 .9260284 .796767$ $137.3859485 .2419989 .1979845 .1575 \quad 1.1703820 .060328 \quad 2.926938 \quad 4.798258$ 

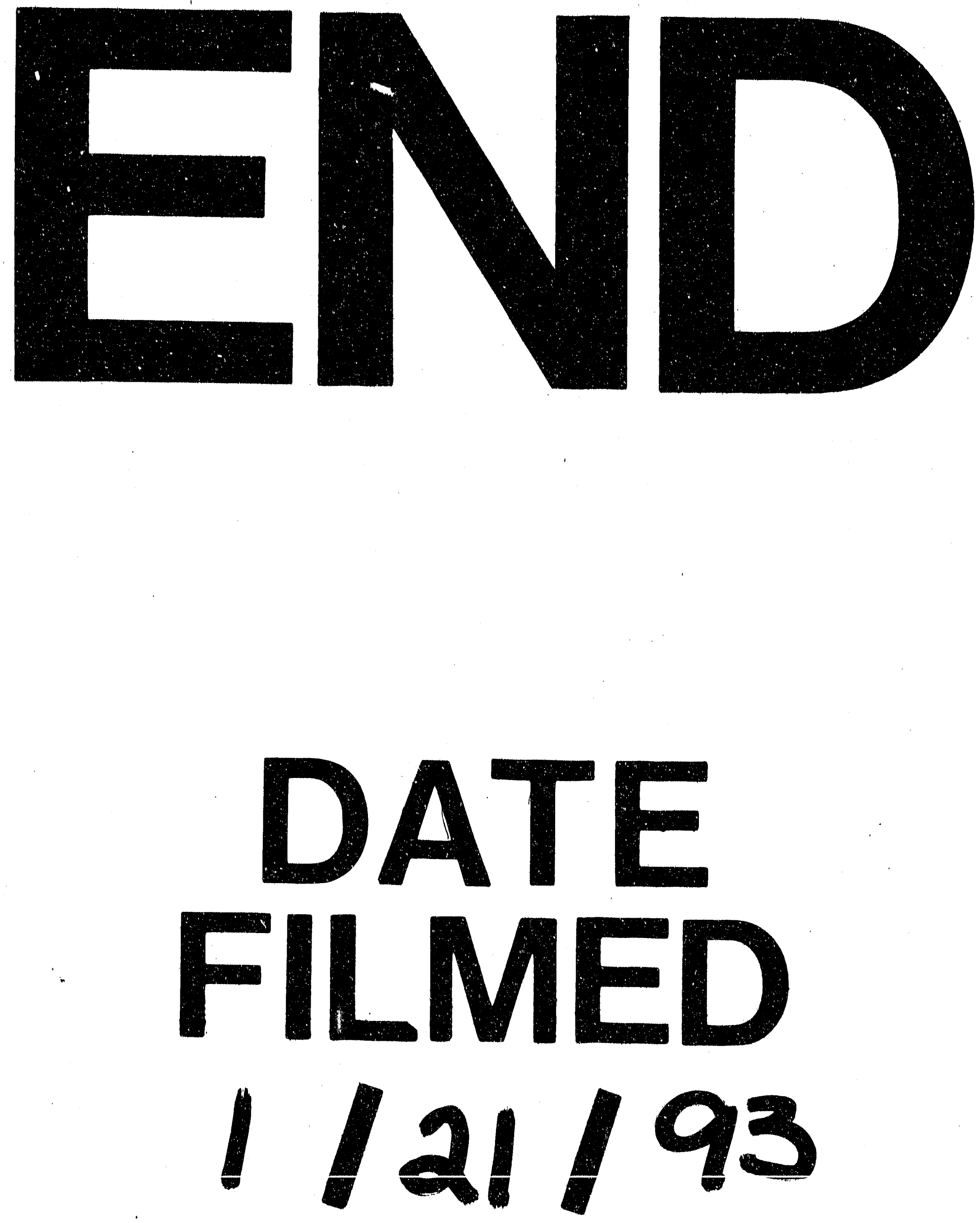
